UNIVERSIDADE DE SÃO PAULO INSTITUTO DE ASTRONOMIA, GEOFÍSICA E CIÊNCIAS ATMOSFÉRICAS DEPARTAMENTO DE CIÊNCIAS ATMOSFÉRICAS

\title{
Variabilidade da Posição da Zona de Convergência Intertropical no Atlântico Oeste e a Oscilação de Madden-Julian
}

Ana Helena Corrêa Maciel

São Paulo 

Ana Helena Corrêa Maciel

Variabilidade da Posição da Zona de Convergência Intertropical no Atlântico Oeste e a Oscilação de Madden-Julian

Dissertação

apresentada

ao

Departamento de Ciências Atmosféricas do Instituto de Astronomia, Geofísica e Ciências Atmosféricas da Universidade de São Paulo como requisito parcial para obtenção do título de Mestre em Ciências.

Área de Concentração: Meteorologia Orientador: Prof. Dr. Tércio Ambrizzi Coorientadora: Dra. Ana Carolina Nóbile Tomaziello

Versão corrigida. O original encontra-se disponível na Unidade.

São Paulo 

À família que me ajudou a chegar até aqui e à que estou construindo... 



\section{AGRADECIMENTOS}

Agradeço primeiramente a Deus, pela dádiva da vida e por me proporcionar segurança, conforto e força para que eu não desistisse nos momentos difíceis.

Ao meu marido, Daniel Felizi, meu companheiro de vida, que sempre esteve ao meu lado, aconselhando e compreendendo os momentos difíceis com muita paciência. Obrigada por fazer parte dessa trajetória e por sempre me incentivar a realizar os meus sonhos.

Aos meus queridos pais, Ana Lúcia e Silvio Ricardo, que serão sempre minha inspiração de coragem, determinação e gratidão.

Ao meu irmão, André Ricardo, minha cunhada Sara e aos meus amigos de Jaú e Bauru por sempre acreditarem em mim e pela compreensão nos momentos de ausência.

Agradeço ao meu orientador, Profo. Drō. Tercio Ambrizzi, pelos ensinamentos, colaboração, apoio e paciência.

À minha co-orientadora, $\operatorname{Dr}^{\underline{a}}$ Ana Carolina Nóbile Tomaziello, pela colaboração nas correções e escrita da Dissertação e pelos ensinamentos.

Aos colegas de sala Andressa, Marie, Yusveliz, Marcos e Franciele pela motivação, cumplicidade e parceria no decorrer dessa jornada. A todos os meus colegas de turma, que passaram pelos mesmos momentos de dificuldade ao longo desses anos.

À Coordenação de Aperfeiçoamento de Pessoal de Nível Superior (CAPES) pela concessão da bolsa de estudos.

A essas pessoas, que estarão sempre eternizadas em meu coração, palavras nunca serão suficientes para expressar meu eterno agradecimento. 

"Só se pode alcançar um grande êxito quando nos mantemos fiéis a nós mesmos."

Friedrich Nietzsche 



\section{RESUMO}

MACIEL, A. H. C. Variabilidade da Posição da Zona de Convergência Intertropical no Atlântico Oeste e a Oscilação de Madden-Julian. 2020. 97 f. Dissertação (Mestrado em Meteorologia) - Instituto de Astronomia, Geofísica e Ciências Atmosféricas, Universidade de São Paulo, São Paulo, 2020.

A Zona de Convergência Intertropical (ZCIT) é um dos sistemas meteorológicos mais importantes e evidentes nos trópicos. Esse sistema tem fundamental importância na determinação dos regimes de precipitação nesta região. Uma das principais características da ZCIT é seu deslocamento latitudinal, que representa seu ciclo anual. A ZCIT no Atlântico (ZCIT-A) pode chegar a $2^{\circ} \mathrm{S}$ em março e abril e $14^{\circ} \mathrm{N}$ entre agosto e setembro, período em que a ZCIT se encontra em seus extremos austrais e boreais, respectivamente. Além do deslocamento sazonal, a ZCIT também pode ser modulada na escala intrassazonal. A principal fonte de variabilidade intrassazonal na atmosfera é a Oscilação de Madden-Julian (OMJ), que pode modular sistemas em regiões remotas do globo. Além disso, a OMJ é o principal mecanismo atmosférico que modula a precipitação na Região Nordeste e no leste da Amazônia na escala intrassazonal. O monitoramento da posição média da ZCIT-A e sua associação com outros sistemas meteorológicos possui grande importância para a determinação da estação chuvosa das Regiões Norte e Nordeste, principalmente sobre a região costeira dessas áreas. $O$ presente trabalho teve como principal objetivo investigar as flutuações intrassazonais de posições latitudinais da ZCIT do Atlântico Oeste (ZCIT-AO) e sua relação com a OMJ. Para isso, foi desenvolvido um índice para localizar a ZCIT-AO latitudinalmente. Através desse índice foram feitas análises estatísticas e os resultados puderam ser associados à atividade da OMJ. As análises mostraram que o índice elaborado é eficiente pois conseguiu descrever bem o ciclo anual da ZCITAO. Após a filtragem do índice na banda intrassazonal, a comparação de eventos extremos com as fases da OMJ permitiu identificar um padrão na ocorrência de eventos, principalmente no outono no qual foi identificada uma maior ocorrência de eventos extremos austrais durante as fases 3 a 6 , enquanto os extremos boreais foram mais frequentes nas fases 7 a 2 da OMJ. Essa relação pode influenciar diretamente em regimes de precipitação das regiões adjacentes ao Atlântico tropical, bem como a Região Nordeste do Brasil. Além disso, composições de radiação de onda longa emergente (ROLE), vento próximo à superfície, precipitação, função de corrente e vento meridional em altos níveis, permitiram analisar os padrões intrassazonais dessas variáveis em cada uma das fases, para cada estação. As análises de composições e de padrões de teleconexão permitiram concluir que as perturbações 
atmosféricas geradas pela OMJ na região dos Oceanos Índico e Pacífico podem modular indiretamente o posicionamento da ZCIT-AO através de trens de ondas de Rossby. O fortalecimento, enfraquecimento ou deslocamento da Alta Subtropical do Atlântico Sul (ASAS) e da Alta Subtropical do Atlântico Norte (ASAN) foram alguns dos mecanismos observados nesse trabalho associados ao deslocamento latitudinal da ZCIT-AO. Na maioria dos casos, um trem de ondas se desloca sobre o Pacífico Norte e/ou Sul e chega à região do Atlântico Norte e/ou Sul favorecendo anomalias ciclônicas ou anticiclônicas, contribuindo diretamente para o enfraquecimento ou fortalecimento dos alísios, o que favorece o deslocamento da ZCIT-AO para norte ou sul. Por fim, um breve estudo de casos extremos permitiu verificar que outros mecanismos podem atuar e modular a variabilidade intrassazonal da posição da ZCIT$\mathrm{AO}$, pois os eventos extremos austrais selecionados atuaram durante a inatividade da OMJ. Os eventos extremos boreais apresentaram a ZCIT-AO bem melhor definida quando comparado aos extremos austrais. Dessa forma, o presente trabalho sugere que as fases da OMJ podem contribuir para o deslocamento da ZCIT-AO e para o favorecimento ou não de precipitação sobre o Brasil, principalmente Regiões Norte e Nordeste, colaborando para o avanço do conhecimento desta importante interação.

Palavras-chave: ZCIT, Atlântico tropical, OMJ, variabilidade intrassazonal. 


\begin{abstract}
MACIEL, AHC. Variability of the West Atlantic Intertropical Convergence Zone Position and the Madden-Julian Oscillation. São Paulo: Institute of Astronomy, Geophysics and Atmospheric Sciences, University of São Paulo, 2020. 97 p. Dissertation. Master in Meteorology.
\end{abstract}

The Intertropical Convergence Zone (ITCZ) is one of the most important and evident weather systems in the tropics. This system has a fundamental importance in determining precipitation regimes in this region. One of the main features of ITCZ is its latitudinal displacement, which represents its annual cycle. ITCZ in the Atlantic can reach $2^{\circ} \mathrm{S}$ in March and April and $14^{\circ} \mathrm{N}$ between August and September, during which time ITCZ is at its austral and boreal extremes, respectively. In addition to seasonal displacement, ITCZ can also be modulated on the intraseasonal scale. The main source of intraseasonal variability in the atmosphere is the Madden-Julian Oscillation (MJO), which can modulate systems in remote regions of the globe. In addition, MJO is the main atmospheric mechanism that modulates precipitation in the Northeast and eastern Amazonia on the intraseasonal scale. Monitoring the mean position of ITCZ-A and its association with other meteorological systems is very important in determining the rainy season of the North and Northeast Regions, especially in the coastal region of these areas. The main goal of the present work was to investigate the intraseasonal fluctuations of latitudinal positions of the West Atlantic ITCZ (ITCZ-WA) and its relationship with the MJO. For this, an index was developed latitudinally locate the ITCZ-WA. Through this index statistical analysis were made and the results could be associated with the activity of the MJO. The analysis showed that the elaborated index is efficient because it is able to well describe the annual cycle of ITCZ-WA. After filtering the index in the intraseasonal band, the comparison of extreme events with the MJO phases allowed to identify a pattern in the occurrence of events, especially in the fall when a greater occurrence of austral extreme events was identified during phases 3 to 6 , while boreal extremes were more frequent in phases 7 to 2 of the MJO. This relationship can directly influence precipitation regimes of tropical Atlantic adjacent regions, as well as the Northeast Region of Brazil. In addition, outgoing long-wave radiation (OLR), surface wind, precipitation, stream function and meridional wind at high levels compositions allowed to analyze the intraseasonal patterns of these variables in each phase for each season. The composites and teleconnection patterns analysis allowed to conclude that the atmospheric disturbances generated by MJO in the Indian and Pacific Oceans can indirectly modulate the positioning of the ITCZ-WA through Rossby wave trains. The strengthening, weakening or displacement of South 
Atlantic Subtropical High (SASH) and North Atlantic Subtropical High (NASH) were some of the mechanisms observed in this work associated with the latitudinal displacement of the ITCZ-WA. In most cases, a wave train displaces over the North and/or South Pacific and reaches the North and/or South Atlantic region favoring cyclonic or anticyclonic anomalies, directly contributing to the weakening or strengthening of trade winds, which favors the northward or southward displacement of the ITCZ-WA. Finally, a brief study of extreme cases showed that other mechanisms can act and modulate intraseasonal variability of the position of ITCZ-WA, as austral extreme events selected acted during inactive MJO. The ITCZ-WA was much better defined during extreme boreal events when compared to the austral ones. Thus, the present work suggests that the MJO phases may contribute to the displacement of the ITCZ-WA and to the favoring or not the precipitation over Brazil, mainly in North and Northeast Regions, cooperating on advance the knowledge on this important interaction.

Keywords: ITCZ, tropical Atlantic, MJO, intraseasonal variability. 


\section{LISTA DE FIGURAS}

Figura 1 - (a) Modelo de circulação meridional da atmosfera em termos globais, mostrando os ventos em superfície e as áreas de alta $(A)$ e baixa $(B)$ pressão, (b) esquematização da célula de Hadley na região tropical e formação da banda de nebulosidade convectiva associada à ZCIT. Fonte: Varejão-Silva (2006) 29

Figura 2 - Representação esquemática das variações no tempo e espaço (plano zonal) do distúrbio relacionado à oscilação de 40-50 dias. Fonte: Madden e Julian (1972) 33

Figura 3 - (a) Composições de anomalias de vento zonal (u) em 850 hPa (U850) para as fases da OMJ. O sombreado escuro (claro) corresponde a regiões com anomalias negativas (positivas), (b) O mesmo de (a), mas para anomalias de radiação de onda longa (ROLE). Fonte: Jones (2009)

Figura 4 - Composição de anomalias de função de corrente em 200 hPa calculada em média para dias com (a) PSA 1 positivo, (b) PSA 2 positivo, (c) PSA 2 negativo e (d) PSA 1 negativo. Os intervalos de contorno são $3 \times 10^{6} \mathrm{~m}^{2} \mathrm{~s}^{-1}$. Os contornos de zero foram omitidos. Fonte: Mo e Higgins (1998).

Figura 5 - Região de estudo para a elaboração do índice de posições latitudinais da ZCIT-AO (IZCIT-AO).

Figura 6 - Espectro de ondeletas do IZCIT-AO antes da filtragem do mesmo. As linhas brancas representam a significância estatística ao nível de $90 \%$ de confiança

Figura 7 - Série temporal de posições latitudinais diárias da ZCIT-AO para o ano de 1995. Posições latitudinais determinadas a partir de ROLE (curva laranja), vento meridional (curva verde) e média dessas posições (curva cinza). O IZCIT-AO é representado pela curva em preto 48

Figura 8 - Composições de anomalias intrassazonais de ROLE (W/m²) e escoamento em $925 \mathrm{hPa}(\mathrm{m} / \mathrm{s})$ para os extremos austrais (acima) e boreais (abaixo) nas estações 
Outono (esquerda) e Primavera (direita). Os vetores em negrito e as áreas contornadas representam significância estatística ao nível de 5\%. A caixa preta representa a Região de Estudo e a linha vermelha representa o percentil (limiar) do IZCIT-AO para cada caso

Figura 9 - Número de eventos extremos austrais (laranja) e boreais (verde) para nas estações Outono (a) e Primavera (b) em cada ano (1995-2010).

Figura 10 - Porcentagem de eventos extremos boreais e austrais de acordo com a atividade da OMJ (inativa - verde ou ativa - laranja) para as estações de Outono (a) e Primavera (b) .52

Figura 11 - Histogramas da duração dos eventos extremos austrais no Outono (a) e Primavera (b) .53

Figura 12 - Histogramas da duração dos eventos extremos boreais no Outono (a) e Primavera (b). .53

Figura 13 - Porcentagem de eventos extremos austrais e boreais que ocorreram em cada fase da OMJ para as estações Outono (a) e Primavera (b). .55

Figura 14 - Composições para os eventos extremos boreais para a Primavera (SON) e fase 0 da OMJ das anomalias de (a) vento em $850 \mathrm{hPa}\left({ }^{*} 100 \mathrm{~m} / \mathrm{s}\right)$ e ROLE (W/m²), (b) vento meridional em $200 \mathrm{hPa}(\mathrm{m} / \mathrm{s})$, (c) precipitação (mm/dia) e (d) função de corrente em $200 \mathrm{hPa}\left(\mathrm{x} 10^{\wedge} 6 \mathrm{~m}^{2} / \mathrm{s}\right)$. A caixa preta representa a Região de Estudo e a linha vermelha representa o percentil (limiar) do IZCIT-AO para esse caso. Os vetores em negrito e as áreas contornadas representam significância estatística ao nível de $5 \%$. .59

Figura 16 - Idem à Figura 14, porém para fase 2 da OMJ. 61

Figura 17 - Idem à Figura 14, porém para fase 3 da OMJ 62

Figura 18 - Idem à Figura 14, porém para fase 4 da OMJ 63

Figura 19 - Idem à Figura 14, porém para fase 5 da OMJ 64 
Figura 20 - Idem à Figura 14, porém para fase 6 da OMJ. .65

Figura 21 - Idem à Figura 14, porém para fase 7 da OMJ .66

Figura 22 - Idem à Figura 14, porém para fase 8 da OMJ .67

Figura 23 - Composições para os eventos extremos austrais para a Primavera (SON) e fase 0 da OMJ das anomalias de (a) vento em $850 \mathrm{hPa}\left({ }^{*} 100 \mathrm{~m} / \mathrm{s}\right)$ e ROLE $\left(\mathrm{W} / \mathrm{m}^{2}\right)$, (b) vento meridional em $200 \mathrm{hPa}(\mathrm{m} / \mathrm{s})$, (c) precipitação $(\mathrm{mm} / \mathrm{dia})$ e (d) função de corrente em $200 \mathrm{hPa}\left(\times 10^{\wedge} 6 \mathrm{~m}^{2} / \mathrm{s}\right)$. A caixa preta representa a Região de Estudo e a linha vermelha representa o percentil (limiar) do IZCIT-AO para esse caso. Os vetores em negrito e as áreas contornadas representam significância estatística ao nível de $5 \%$ 71

Figura 24 - Idem à Figura 23, porém para fase 1 da OMJ .72

Figura 25 - Idem à Figura 23, porém para fase 2 da OMJ 73

Figura 26 - Idem à Figura 23, porém para fase 3 da OMJ 74

Figura 27 - Idem à Figura 23, porém para fase 4 da OMJ 75

Figura 28 - Idem à Figura 23, porém para fase 5 da OMJ 76

Figura 29 - Idem à Figura 23, porém para fase 6 da OMJ .77

Figura 30 - Idem à Figura 23, porém para fase 7 da OMJ 78

Figura 31 - Idem à Figura 23, porém para fase 8 da OMJ 79

Figura 32 - Composições para os eventos extremos boreais para o Outono (MAM) e fase 0 da OMJ das anomalias de (a) vento em $850 \mathrm{hPa}\left({ }^{*} 100 \mathrm{~m} / \mathrm{s}\right)$ e ROLE $\left(\mathrm{W} / \mathrm{m}^{2}\right)$, (b) vento meridional em $200 \mathrm{hPa}(\mathrm{m} / \mathrm{s})$, (c) precipitação $(\mathrm{mm} / \mathrm{dia})$ e (d) função de corrente em $200 \mathrm{hPa}\left(\times 10^{\wedge} 6 \mathrm{~m}^{2} / \mathrm{s}\right)$. A caixa preta representa a Região de Estudo e a linha vermelha representa o percentil (limiar) do IZCIT-AO para esse caso. Os vetores em negrito e as áreas contornadas representam significância estatística ao nível de $5 \%$. 
Figura 33 - Idem à Figura 32, porém para fase 1 da OMJ.

Figura 34 - Idem à Figura 32, porém para fase 2 da OMJ..................................... 86

Figura 35 - Idem à Figura 32, porém para fase 3 da OMJ.................................... 87

Figura 36 - Idem à Figura 32, porém para fase 4 da OMJ...................................8

Figura 37 - Idem à Figura 32, porém para fase 5 da OMJ....................................89

Figura 38 - Idem à Figura 32, porém para fase 6 da OMJ....................................90

Figura 39 - Idem à Figura 32, porém para fase 7 da OMJ.....................................91

Figura 40 - Idem à Figura 32, porém para fase 8 da OMJ...................................92

Figura 41 - Composições para os eventos extremos austrais para o Outono (MAM) e fase 0 da OMJ das anomalias de (a) vento em $850 \mathrm{hPa}\left({ }^{*} 100 \mathrm{~m} / \mathrm{s}\right.$ ) e ROLE $\left(\mathrm{W} / \mathrm{m}^{2}\right)$, (b) vento meridional em $200 \mathrm{hPa}$ (m/s), (c) precipitação (mm/dia) e (d) função de corrente em $200 \mathrm{hPa}\left(\times 10^{\wedge} 6 \mathrm{~m}^{2} / \mathrm{s}\right)$. A caixa preta representa a Região de Estudo e a linha vermelha representa o percentil (limiar) do IZCIT-AO para esse caso. Os vetores em negrito e as áreas contornadas representam significância estatística ao nível de $5 \%$. .96

Figura 42 - Idem à Figura 41, porém para fase 1 da OMJ. 97

Figura 43 - Idem à Figura 41, porém para fase 2 da OMJ. .98

Figura 44 - Idem à Figura 41, porém para fase 3 da OMJ. .99

Figura 45 - Idem à Figura 41, porém para fase 4 da OMJ. 100

Figura 46 - Idem à Figura 41, porém para fase 5 da OMJ. 101

Figura 47 - Idem à Figura 41, porém para fase 6 da OMJ 102

Figura 48 - Idem à Figura 41, porém para fase 7 da OMJ 103 
Figura 49 - Idem à Figura 41, porém para fase 8 da OMJ.

Figura 50 - Composições de médias diárias de anomalias intrassazonais de ROLE $\left(\mathrm{Wm}^{2}\right)$ e vento $(850 \mathrm{hPa})\left(\mathrm{ms}^{-1}\right)$ para o Caso 1. Regiões estatisticamente significativas estão contornadas ou em negrito (vetores).

Figura 51 - Imagem de satélite global para o dia 04/05/2004 às $12 Z$ (Fonte: NCDCNOAA)

Figura 52 - Composições de médias diárias de anomalias intrassazonais de ROLE $\left(\mathrm{Wm}^{2}\right)$ e vento $(850 \mathrm{hPa})\left(\mathrm{ms}^{-1}\right)$ para o Caso 2. Regiões estatisticamente significativas estão contornadas ou em negrito (vetores). 108

Figura 53 - Imagem de satélite global para o dia 17/10/1997 às $12 Z$ (Fonte: NCDCNOAA). 109

Figura 54 - Composições de médias diárias de anomalias intrassazonais de ROLE $\left(\mathrm{Wm}^{2}\right)$ e vento $(850 \mathrm{hPa})\left(\mathrm{ms}^{-1}\right)$ para o Caso 3. Regiões estatisticamente significativas estão contornadas ou em negrito (vetores). 110

Figura 55 - Imagem de satélite global para o dia 14/04/2004 às $12 Z$ (Fonte: NCDCNOAA)

Figura 56 - Composições de médias diárias de anomalias intrassazonais de ROLE $\left(\mathrm{Wm}^{2}\right)$ e vento $(850 \mathrm{hPa})\left(\mathrm{ms}^{-1}\right)$ para o Caso 4 . Regiões estatisticamente significativas estão contornadas ou em negrito (vetores).

Figura 57 - Imagem de satélite global para o dia 24/11/2000 às $12 Z$ (Fonte: NCDCNOAA). 



\section{LISTA DE TABELAS}

Tabela 1 - Dados estatísticos para cada caso selecionado 106 



\section{LISTA DE ABREVIATURAS E SIGLAS}

ASAN Alta Subtropical do Atlântico Norte

ASAS Alta Subtropical do Atlântico Sul

AS América do Sul

CEOFs Funções Ortogonais Empíricas Combinadas

CFSR Climate Forecast System Reanalysis

ENOS El Niño Oscilação Sul

EOF $\quad$ Função Ortogonal Empírica

FFT Transformada Rápida de Fourier (Fast Fourier Transform)

HN Hemisfério Norte

HS Hemisfério Sul

IZCIT-AO Índice de posicionamento da Zona de Convergência Intertropical do Atlântico Oeste

MAM Março-abril-maio

NE Região Nordeste do Brasil

NOAA National Atmospheric and Oceanic Administration

OLR Outgoing longwave radiation

OMJ Oscilação de Madden-Julian

PNA Pacífico-América do Norte (Pacific-North American)

PSA Pacífico-América do Sul (Pacific-South American) 
PSA1 Primeiro modo do Pacífico-América do Sul

PSA2 Segundo modo do Pacífico-América do Norte

ROLE Radiação de onda longa emergente

SE Região Sudeste do Brasil

SON Setembro-outubro-novembro

TSM Temperatura da superfície do mar

ZCIT Zona de Convergência Intertropical

ZCIT-A Zona de Convergência Intertropical do Atlântico

ZCIT-AO Zona de Convergência Intertropical do Atlântico Oeste 


\section{SUMÁRIO}

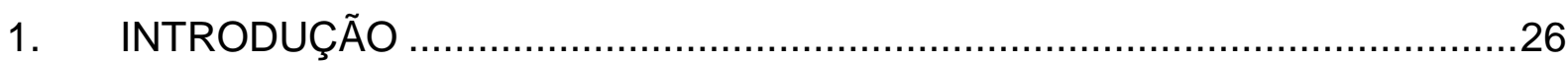

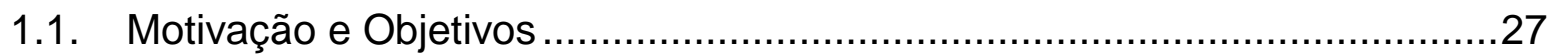

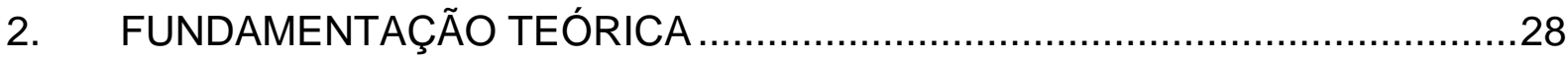

2.1. A Zona de Convergência Intertropical (ZCIT) ......................................28

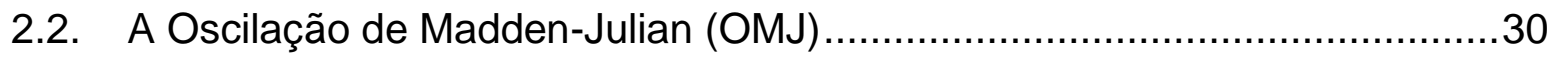

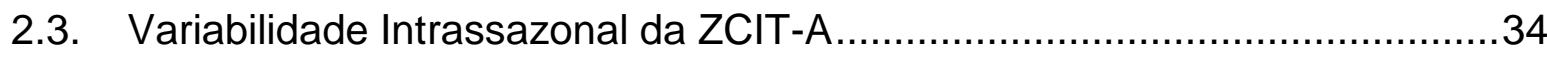

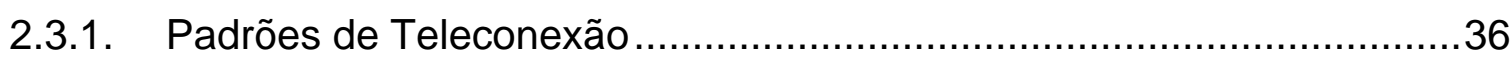

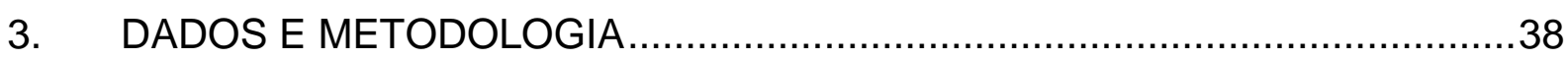

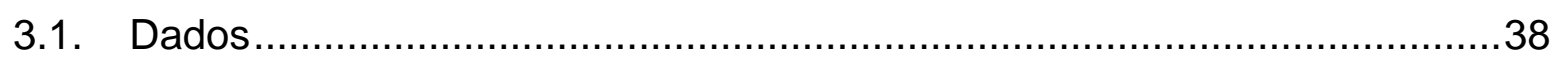

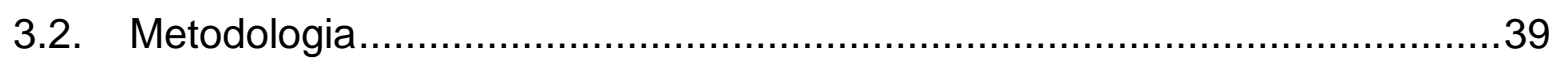

3.2.1. Critério para a Localização da ZCIT no Atlântico Oeste .........................39

3.2.2. Análise Estatística do Índice da ZCIT-AO (IZCIT-AO) ..........................43

3.2.3. Critério para Seleção de Eventos Extremos .........................................43

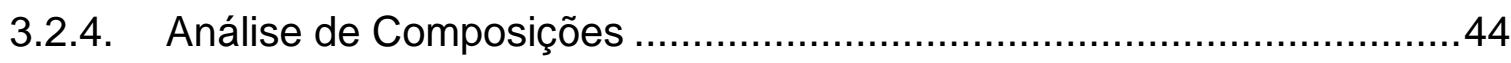

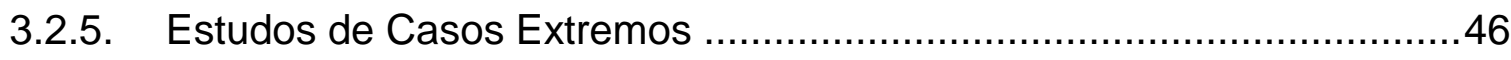

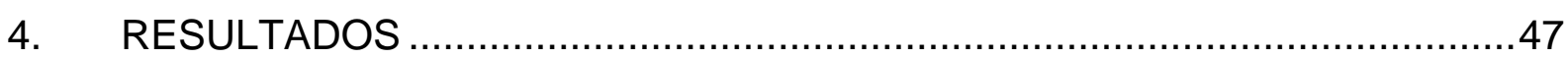

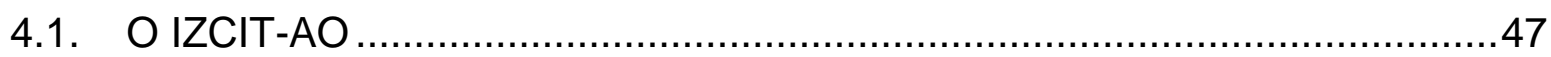

4.1.1. Relação entre as Fases da OMJ e o Posicionamento da ZCIT no Atlântico Oeste 54

4.2. Análise de Composições e de Padrões de Teleconexão .55 


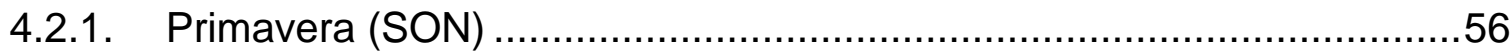

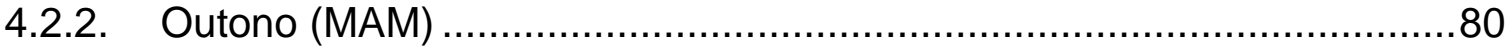

4.3. Estudo de Casos Extremos ............................................................. 105

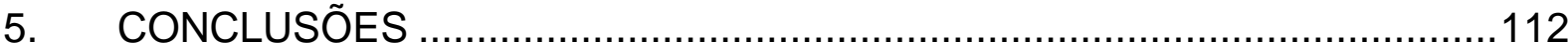

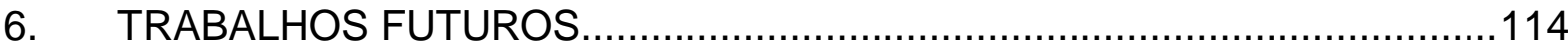

7. REFERÊNCIAS BIBLIOGRÁFICAS ............................................... 116 


\section{INTRODUÇÃO}

A Zona de Convergência Intertropical (ZCIT) é um dos sistemas meteorológicos mais importantes e evidentes nos trópicos (WALISER; SOMERVILLE, 1994). Esse sistema tem fundamental importância na determinação dos regimes de precipitação nesta região. Ele é caracterizado por uma banda alongada de nebulosidade convectiva organizada aproximadamente na direção zonal ao redor do globo em baixas latitudes, onde os ventos alísios de sudeste e de nordeste convergem (HASTENRATH, 1996; BAIN et al., 2011; HAFEZ, 2012).

Uma das principais características da ZCIT é seu deslocamento latitudinal, que representa seu ciclo anual. Devido ao aquecimento terrestre diferencial ao longo do ano, que está associado ao movimento de translação da Terra e à sua inclinação, a ZCIT se desloca para norte ou para sul, atingindo suas posições mais boreais entre agosto e setembro e mais austrais entre março e abril (HASTENRATH; HELLER, 1977).

Com relação especificamente à "ZCIT do Atlântico" (ZCIT-A), que será o principal foco deste trabalho, o comportamento do deslocamento latitudinal sazonal é o mesmo. Melo, Cavalcanti e Souza (2009) mostraram que, nessa região, a ZCIT-A pode chegar a $2^{\circ} \mathrm{S}$ em março e abril e $14^{\circ} \mathrm{N}$ entre agosto e setembro, período em que a mesma se encontra em seus extremos austrais e boreais, respectivamente.

Além de seu deslocamento sazonal, a ZCIT também pode ser modulada na escala intrassazonal. A variabilidade da posição latitudinal da ZCIT-A nessa escala já foi investigada no final da década de 80 , quando Uvo e Nobre (1989) mostraram suas flutuações na escala de 10 a 20 dias. A principal fonte de variabilidade intrassazonal na atmosfera é a Oscilação de Madden-Julian (OMJ) (MADDEN; JULIAN, 1971, 1972), que pode modular sistemas em regiões remotas do globo. Entretanto, essa modulação não está restrita à sua banda (30-60 dias) devido aos padrões de teleconexão trópicos-extratrópicos excitados pela forçante convectiva no Indo- 
Pacífico (TOMAZIELLO, 2014), que podem influenciar padrões atmosféricos em outras bandas dentro da escala intrassazonal.

De Souza e Ambrizzi (2006) ressaltaram que a modulação da OMJ na precipitação da América do Sul tropical, região oeste da ZCIT-A, na escala intrassazonal, bem como a relação dos impactos de trens de onda de Rossby sobre a mesma região, carecem de melhor entendimento. Diante disso, justifica-se a necessidade de aprofundar estudos sobre a variabilidade da ZCIT-A oeste na escala intrassazonal.

\subsection{Motivação e Objetivos}

De acordo com Melo, Cavalcanti e Souza (2009), o monitoramento da posição média da ZCIT-A e sua associação com outros sistemas meteorológicos possui grande importância para a determinação da estação chuvosa das Regiões Norte e Nordeste, principalmente sobre a região costeira dessas áreas. Além disso, De Souza e Ambrizzi (2006) mostraram que a OMJ é o principal mecanismo atmosférico que modula a precipitação na Região Nordeste e no leste da Amazônia na escala intrassazonal.

Diante do exposto, este trabalho teve como principal objetivo investigar as flutuações intrassazonais das posições latitudinais da ZCIT-A observadas por Uvo e Nobre (1989). Em particular, foi avaliada a relação entre a variabilidade do posicionamento latitudinal da "ZCIT sobre o Atlântico-Oeste" (ZCIT-AO) na escala intrassazonal e a atividade da OMJ, tendo como objetivos específicos:

- Estabelecer um critério de localização latitudinal da ZCIT no Atlântico Oeste, que retenha sua variabilidade na escala intrassazonal;

- Analisar a relação da atividade da OMJ (ativa e inativa) e suas fases com os extremos austrais e boreais da posição latitudinal da ZCIT-AO; 
- Avaliar possíveis mecanismos atmosféricos locais e padrões de teleconexão atmosférica associados a essa variabilidade.

\section{FUNDAMENTAÇÃO TEÓRICA}

\subsection{A Zona de Convergência Intertropical (ZCIT)}

A Zona de Convergência Intertropical (ZCIT) é caracterizada por uma banda zonal de atividade convectiva que atua na região tropical do globo, causando instabilidade sobre a mesma. Ela pode ser definida por uma faixa de nebulosidade descontínua que circunda o globo e oscila latitudinalmente durante o ano. É um dos mais importantes sistemas meteorológicos que atua nos trópicos, pois influencia diretamente a caracterização do regime de precipitação das áreas tropicais, modulando o clima dessas regiões (FERREIRA, 1996), uma vez que é um fenômeno associado à circulação global de grande escala.

Esse sistema se localiza no ramo ascendente da célula de Hadley (WALISER; SOMERVILLE, 1994) sendo formado pela confluência dos ventos alísios na região equatorial (UVO, 1989) (Figura 1a), que, ao convergirem em baixos níveis, geram movimentos ascendentes e, consequentemente, nuvens convectivas com grande desenvolvimento vertical (Figura 1b) (VAREJÃO-SILVA, 2006). Além disso, a localização da ZCIT também está relacionada à região em que se encontra o cavado equatorial, à zona de máxima temperatura da superfície do mar (TSM), zona de máxima convergência de massa e zona da banda de máxima cobertura de nuvens convectivas (FERREIRA, 1996). Entretanto, como Hastenrath e Lamb (1977) mostraram, nem sempre essas zonas se localizam sobre a mesma latitude ao mesmo tempo. 
Devido à sua estrutura termodinâmica, a ZCIT se desloca latitudinalmente em decorrência do aquecimento terrestre diferencial durante o ano (DE SOUZA, 2005), causado pelo movimento de translação da Terra e a inclinação de seu eixo. Segundo Ferreira (1996), a ZCIT se desloca sazonalmente durante o ano, atingindo suas posições mais a norte durante o verão do Hemisfério Norte $(H N)$ e mais a sul em abril. Além disso, Hastenrath (1996) mostrou que esse sistema também costuma se posicionar sobre áreas com anomalias positivas de TSM e anomalias negativas de pressão ao nível médio do mar.

a)

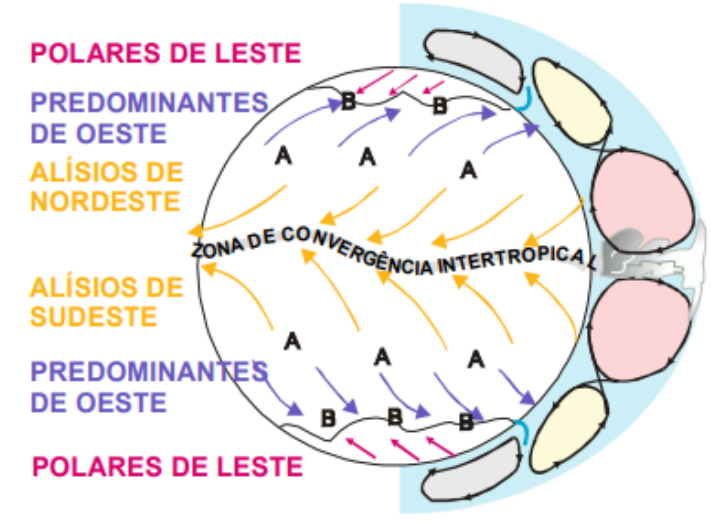

b)

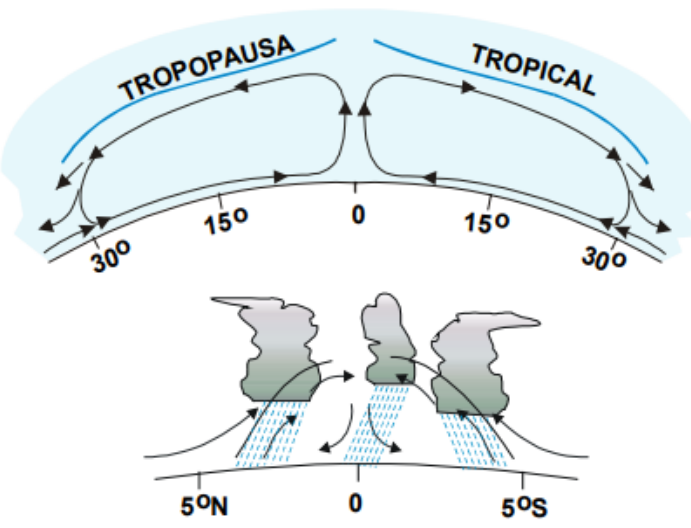

Figura 1 - (a) Modelo de circulação meridional da atmosfera em termos globais, mostrando os ventos em superfície e as áreas de alta (A) e baixa (B) pressão, (b) esquematização da célula de Hadley na região tropical e formação da banda de nebulosidade convectiva associada à ZCIT. Fonte: Varejão-Silva (2006)

O deslocamento sazonal ZCIT-A durante o ano caracteriza seu ciclo anual bem definido (ASNANI, 1993). Suas posições médias mais austrais (boreais) são atingidas entre março e abril (agosto e setembro), chegando a aproximadamente $2^{\circ} \mathrm{S}$ (14ํN) (MELO; CAVALCANTI; SOUZA, 2009). Essa migração sazonal tem papel fundamental na determinação da estação chuvosa no norte da Região Nordeste (MELO; CAVALCANTI; SOUZA, 2009). De acordo com Philander et al. (1996), o posicionamento da ZCIT-A predominantemente no hemisfério boreal está associado principalmente à geometria continental, pois ventos que cruzam o equador de sul para 
norte em direção à faixa oeste da África provocam ressurgência na costa sudoeste do continente. Com águas mais quentes a norte e mais frias a sul, a ZCIT-A tende a posicionar-se majoritariamente no hemisfério boreal (PHILANDER et al., 1996). Waliser e Gautier (1993) observaram que no outono austral, época do ano que a ZCITA se encontra na sua posição mais a sul, embora a banda principal de nebulosidade da ZCIT-A ainda se encontre sobre o Hemisfério Norte, uma banda secundária surge no Hemisfério Sul (HS) em alguns dias (MELO; CAVALCANTI; SOUZA, 2009). Segundo Uvo e Nobre (1989), a formação de bandas duplas de nebulosidade está relacionada com anos chuvosos no Nordeste do Brasil.

Além dessas marcantes variações na banda anual, Uvo e Nobre (1989) mostraram, como mencionado na Introdução, que a posição latitudinal da ZCIT-A também apresenta flutuações na escala de 10 a 20 dias. Como a variabilidade da ZCIT-A nessa escala de tempo será o principal foco deste trabalho, ela será discutida com mais detalhes na Subseção 2.3.

\subsection{A Oscilação de Madden-Julian (OMJ)}

As oscilações intrassazonais são fenômenos de baixa frequência que ocorrem em escalas de tempo menores do que uma estação, com período de $10 \mathrm{a}$ 100 dias aproximadamente (GHIL; MO, 1991).

$\mathrm{Na}$ década de 70 , os pesquisadores Madden e Julian, descobriram a existência de uma oscilação que ocorre na escala de tempo de 40 a 50 dias. Em seus trabalhos foram documentadas características fundamentais dessa oscilação, concluindo que consiste em uma circulação zonal de grande escala na região tropical que se origina próxima ao Oceano Índico, se desloca para leste e contorna o globo num período de 30 a 60 dias (MADDEN; JULIAN, 1994), causando variações na convecção tropical. Desde então muitos estudos foram realizados a fim de melhorar a 
compreensão dessa oscilação (p. ex. MALONEY; HARTMANN, 1998; WHEELER; HENDON, 2004; JONES, 2009).

No estudo em que essa oscilação foi detectada, Madden e Julian (1971) calcularam os espectros de variáveis meteorológicas de Canton, uma ilha localizada no Pacífico Tropical Oeste ( $3^{\circ}$ S e $171^{\circ}$ O), onde séries temporais de pressão e dados diários de radiossondagem possibilitaram aferir não só a pressão atmosférica nessa região, como também outras variáveis em superfície e em altitude. Através dessas análises os autores notaram grande coerência entre a pressão em superfície, vento zonal e temperatura em vários níveis, com um pico espectral variando entre 41 e 53 dias (MADDEN; JULIAN, 1994). Analisando os espectros de outras estações, os pesquisadores chegaram à conclusão de que os picos espectrais ocorrem, de uma maneira geral, no período de 40 a 50 dias.

$\mathrm{Na}$ Figura 2, podemos observar um esquema ilustrativo (MADDEN; JULIAN, 1972) de como a OMJ e seu desenvolvimento e deslocamento podem alterar a circulação zonal da região equatorial. Na parte inferior, podemos observar a perturbação média do campo de pressão, sendo que as anomalias negativas são representadas pelas áreas sombreadas. As células de circulação são baseadas na média dos distúrbios do vento zonal. As nuvens representam o aumento da convecção em grande escala. A altura da tropopausa também é ilustrada. As letras indicadas em cada esquema representam as datas associadas à oscilação nas estações de pressão em Canton. A figura indicada pela letra A mostra que Canton apresenta uma baixa pressão, enquanto a figura sinalizada pela letra $E$ indica alta pressão na mesma localidade. As outras letras representam tempos intermediários.

Alguns autores estudaram o ciclo de vida da OMJ e decompuseram sua atividade em oito fases de acordo com sua localização (MALONEY; HARTMANN, 1998; MATTHEWS, 2000; WHEELER; HENDON, 2004; JONES, 2009). A fase 0 corresponde ao período inativo da $\mathrm{OMJ}$, enquanto as fases de 1 a 4 representam 0 início da oscilação e as fases 5 a 8 o término. A Figura 3 mostra os padrões de anomalia de vento zonal em $850 \mathrm{hPa}$ (Figura 3a) e radiação de onda longa emergente (ROLE) (Figura 3b) para cada fase da OMJ (JONES, 2009). A fase 1 corresponde a 
supressão sobre a Indonésia e Pacífico e convecção sobre a África e Índico. A fase 2 caracteriza-se por supressão sobre o Pacífico Oeste e leste da Indonésia e convecção na África e Índico. Na fase 3 da OMJ é observada convecção sobre o Índico e oeste da Indonésia e supressão sobre o oeste da África, Atlântico e América do Sul tropical. A fase 4 é caracterizada por convecção sobre a Indonésia e supressão sobre a África Ocidental e América do Sul (AS) e Atlântico tropicais. As fases de 5 a 8 apresentam os padrões inversos das fases 1 a 4 mencionadas acima (JONES, 2009), respectivamente. De acordo com Wheeler e Hendon (2004), o tempo de transição entre uma fase e outra é de aproximadamente 6 dias.

A OMJ pode modular sistemas em regiões remotas do globo. Essa modulação não está restrita à sua escala devido aos padrões de teleconexão trópicosextratrópicos excitados pela forçante convectiva (HOSKINS; KAROLY, 1981) no IndoPacífico (TOMAZIELLO, 2014). Além disso, flutuações com períodos menores do que o da OMJ, ainda que intrassazonais, não estão necessariamente associadas à oscilação, como mencionado por Mo e Higgins (1998) e Jones e Schemm (2000). 


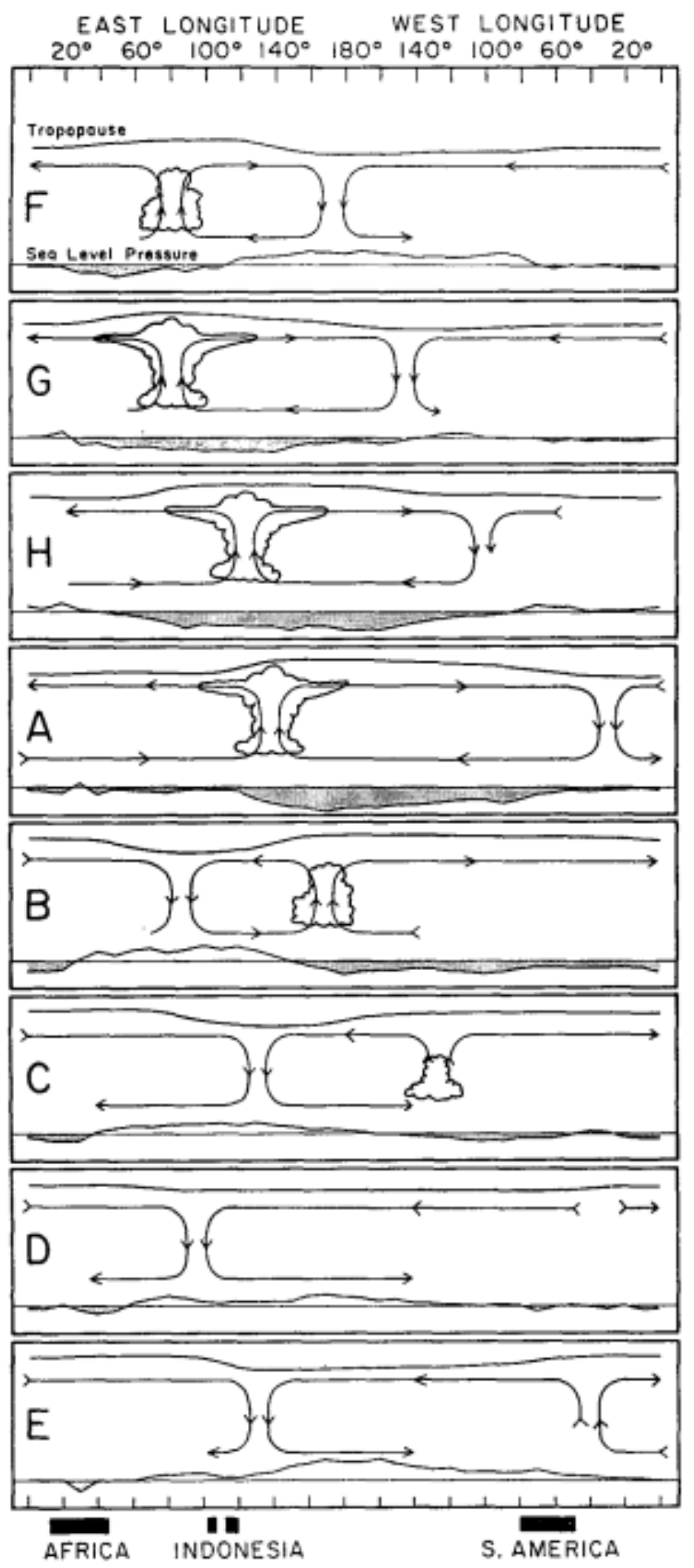

Figura 2 - Representação esquemática das variações no tempo e espaço (plano zonal) do distúrbio relacionado à oscilação de 40-50 dias. Fonte: Madden e Julian (1972) 
a)

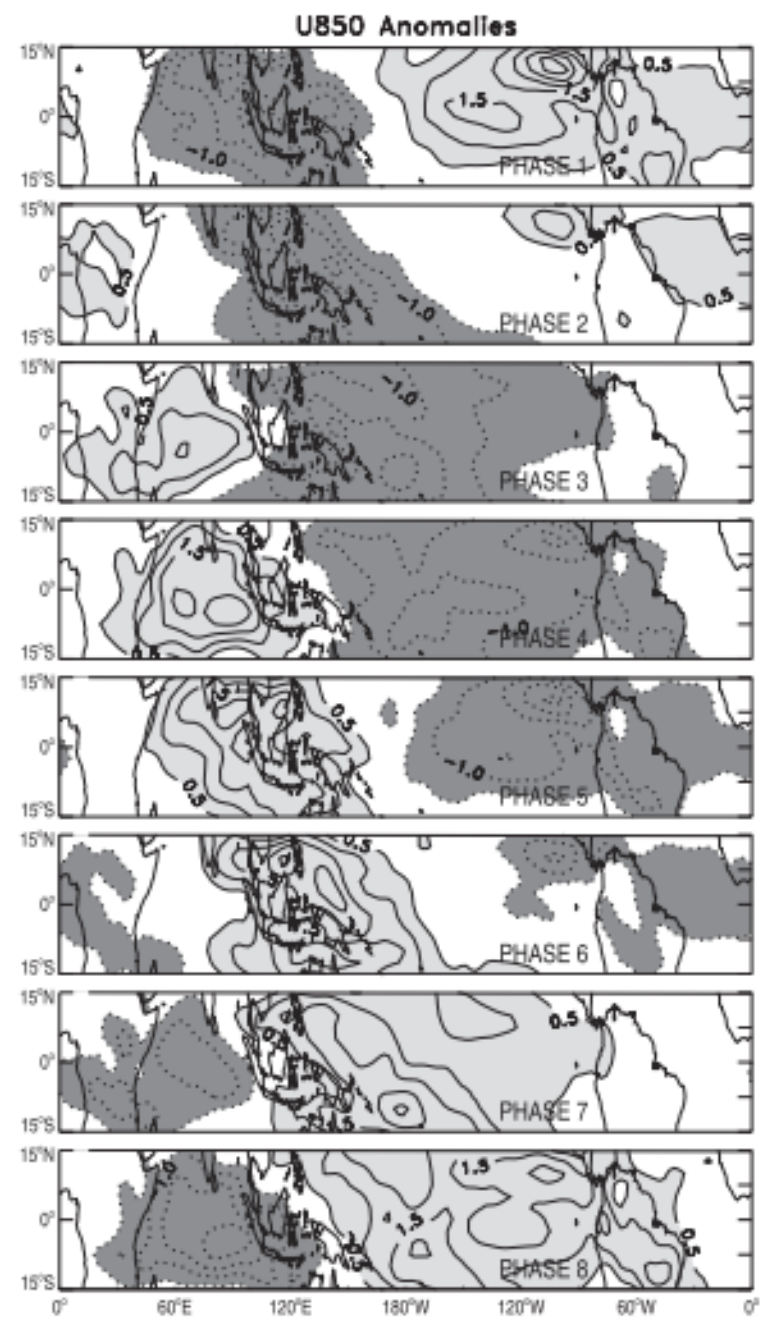

b)
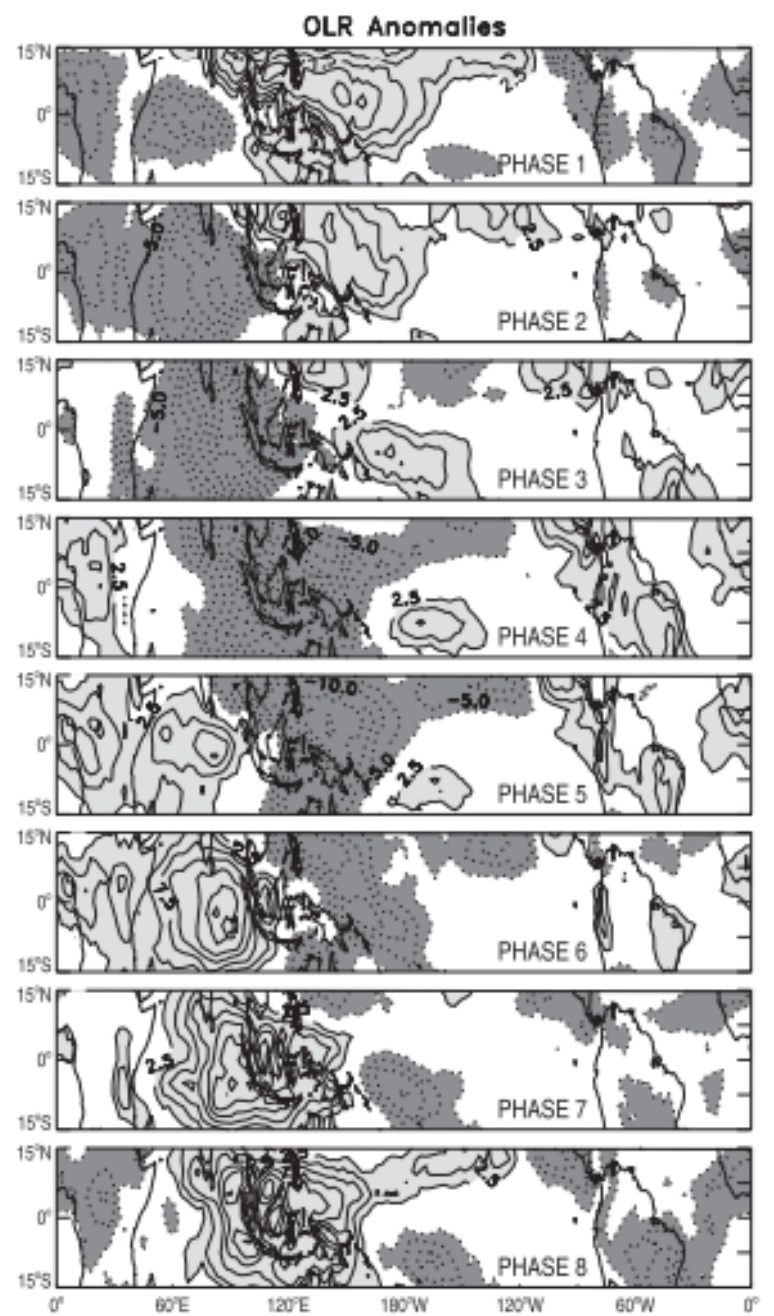

Figura 3 - (a) Composições de anomalias de vento zonal (u) em $850 \mathrm{hPa}$ (U850) para as fases da OMJ. O sombreado escuro (claro) corresponde a regiões com anomalias negativas (positivas), (b) O mesmo de (a), mas para anomalias de radiação de onda longa (ROLE).

Fonte: Jones (2009)

\subsection{Variabilidade Intrassazonal da ZCIT-A}

O posicionamento latitudinal da ZCIT-A também apresenta variabilidade na escala intrassazonal. Como já mencionado na Seção 2.1, no final da década de 80 , Uvo e Nobre (1989), através de análises espectrais, haviam mostrado que a posição latitudinal da ZCIT-A apresenta flutuações na escala de 10 a 20 dias. Esses autores 
determinaram o posicionamento da ZCIT-A com base na posição média da banda convectiva em imagens de satélite e também na zona de confluência dos alísios (UVO; NOBRE, 1989).

Tomaziello, Carvalho e Gandu (2016) investigaram a variabilidade da intensidade da ZCIT-A na escala intrassazonal durante o verão (novembro a março) e inverno (maio a setembro) austrais através de um índice multivariado baseado no primeiro modo das Funções Ortogonais Empíricas Combinadas (CEOFs) de precipitação e vento em $850 \mathrm{hPa}$. Os autores mostraram que a variabilidade intrassazonal da intensidade da ZCIT-A durante o verão (inverno) austral tem associação com a modulação das características do Anticiclone do Atlântico Norte (Sul) e, consequentemente, da intensidade dos ventos alísios, por um trem de onda de Rossby que se propaga no Hemisfério Norte (Sul) (TOMAZIELLO; CARVALHO; GANDU, 2016). Esse padrão ondulatório também induz divergência em altos níveis na região da ZCIT-A, o que leva à intensificação da convecção na zona de convergência na escala intrassazonal. Kiladis e Weickmann (1992) e De Souza, Kayano e Ambrizzi (2005) já haviam mencionado que a atividade da ZCIT-A na escala intrassazonal pode ser modulada por distúrbios ondulatórios de latitudes médias.

Com relação às fases da OMJ, Tomaziello, Carvalho e Gandu (2016) concluíram que a maior parte dos eventos intrassazonais na região da ZCIT-A, que foram selecionados através dos percentis superiores e inferiores $(75 \%$ e $25 \%$ respectivamente) de um índice desenvolvido no trabalho, ocorrem quando a OMJ está ativa durante o verão austral, já no inverno metade dos eventos está relacionada à OMJ ativa. Essa análise mostra que outros mecanismos também são responsáveis por modular a ZCIT-A na escala intrassazonal que não a OMJ. Além disso, os autores observaram que a intensificação (desintensificação) da convecção na ZCIT-A ocorre com maior frequência durante as fases em que há convecção (supressão) sobre o Pacífico Oeste e supressão (convecção) sobre o Índico e África (TOMAZIELLO; CARVALHO; GANGU, 2016). 


\subsubsection{Padrões de Teleconexão}

As teleconexões são definidas, de forma geral, como uma resposta atmosférica a uma forçante em algum lugar remoto do globo. Em outras palavras, uma anomalia na atmosfera ou no oceano em determinada região pode gerar alterações ou reações atmosféricas em locais distantes, muitas vezes a milhares de quilômetros de distância. O estudo e a identificação de padrões de teleconexão são de grande relevância, pois, com uma melhor compreensão da atuação desses fenômenos, podemos identificar e inclusive prever comportamentos anômalos da atmosfera em locais remotos do globo.

Um dos principais estudos de teleconexões utilizando dados observacionais foi realizado por Wallace e Gutzler (1981), no qual os autores encontraram cinco padrões de teleconexão para o HN. Desses, o padrão Pacífico América do Norte, conhecido pela sigla PNA, se apresenta em forma de trem de onda a partir do Pacífico Equatorial e influencia a temperatura e o regime de precipitação na América do Norte principalmente no inverno.

Baseados em metodologias similares às utilizadas para o $\mathrm{HN}$, alguns padrões também foram estabelecidos para o HS. Mo e Ghil (1987) encontraram sobre o HS um padrão semelhante ao PNA do HN, que forma uma conexão entre o Pacífico Sul e o Atlântico Sul, o qual foi denominado de Pacífico-América do Sul (PSA). O padrão do PSA é composto por um trem de onda que se estende do Pacífico Sul, próximo à Austrália, até o sul da América do Sul e Atlântico adjacente e pode ser identificado tanto no inverno quanto no verão. Esse padrão apresenta variabilidade em diversas escalas de tempo, como interanual (KAROLY, 1989; MO; HIGGINS, 1998) e interdecenal (MO, 2000), mas a principal abordagem do presente trabalho esteve relacionada à variabilidade intrassazonal.

O trabalho de Mo e Higgins (1998), que foi baseado em análise de EOF (função ortogonal empírica) de função de corrente em $200 \mathrm{hPa}$, identificou dois modos referentes ao padrão PSA durante o inverno austral. Esses padrões, denominados 
PSA1 e PSA2, apresentam períodos de 16 a 40 dias e, segundo os autores, se assemelham à oscilação intrassazonal tropical. O modo PSA1 positivo associa-se a convecção no Pacífico Central-Oeste e supressão sobre o Índico, enquanto o modo PSA2 positivo está associado a convecção no Pacífico Central ao sul do equador e supressão no Pacífico Oeste (MO; HIGGINS, 1998). Os modos negativos de ambos os padrões apresentam características inversas. O tempo médio de transição descrito pelos autores entre uma categoria e outra é de 4,9 dias. A Figura 4 mostra os padrões espaciais dos modos referentes ao PSA e sua evolução.

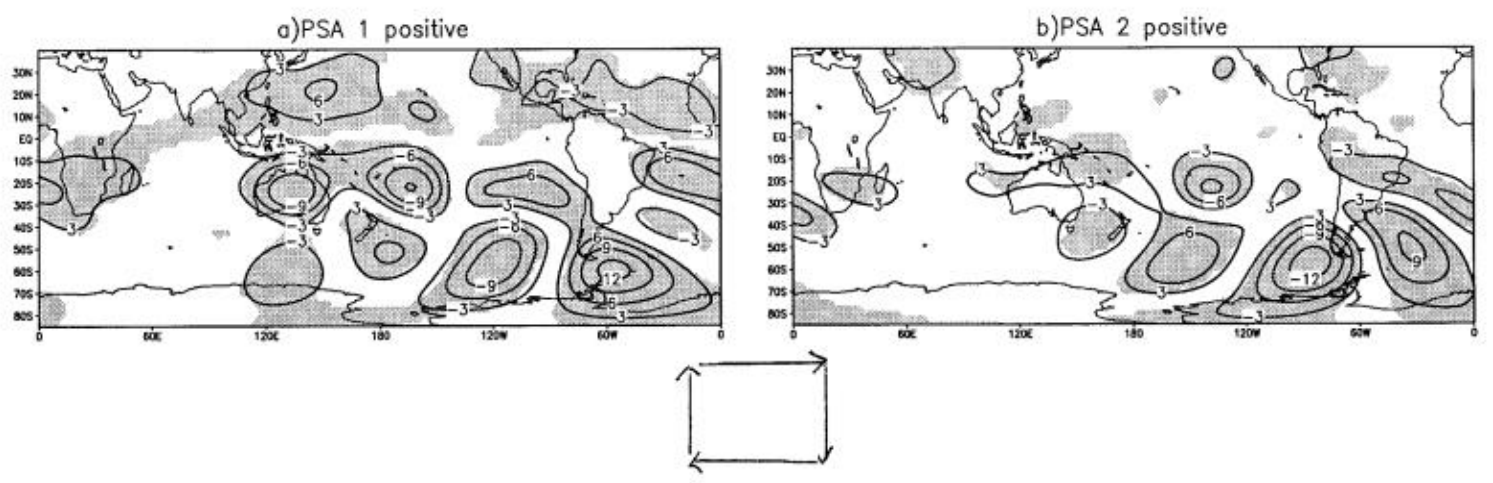

c) PSA 2 negative

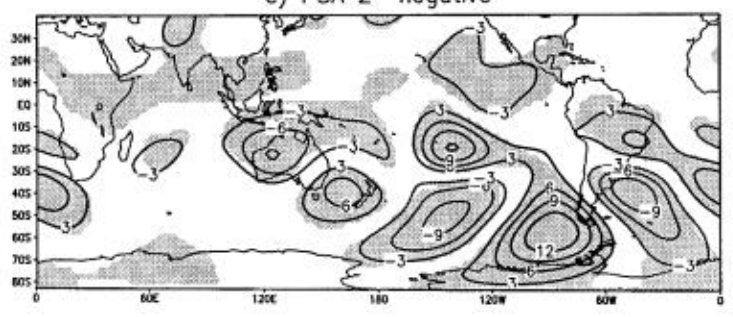

d) PSA 1 negative

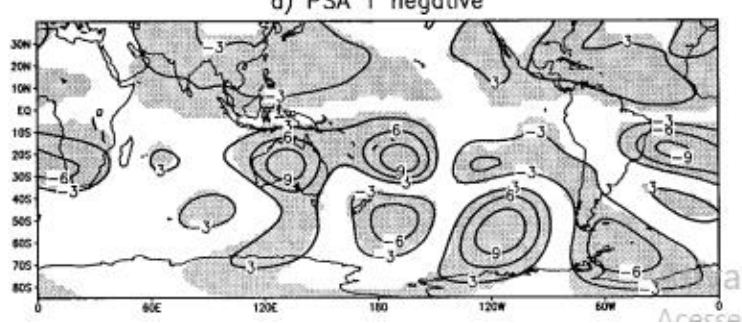

Figura 4 - Composição de anomalias de função de corrente em 200 hPa calculada em média para dias com (a) PSA 1 positivo, (b) PSA 2 positivo, (c) PSA 2 negativo e (d) PSA 1 negativo. Os intervalos de contorno são $3 \times 10^{6} \mathrm{~m}^{2} \mathrm{~s}^{-1}$. Os contornos de zero foram omitidos. Fonte: Mo e Higgins (1998). 


\section{DADOS E METODOLOGIA}

Nas Seções a seguir serão descritos os dados utilizados em cada uma das análises desenvolvidas no presente estudo e a metodologia aplicada às mesmas.

\subsection{Dados}

Os dados de vento zonal e meridional (escoamento) em 200, 850 e 925 $\mathrm{hPa}$, utilizados neste estudo, bem como os dados de função de corrente (psi) em 200 hPa e os de precipitação acumulada, são referentes às Climate Forecast System Reanalysis (CFSR) (SAHA et al., 2010) em pontos de grade espaçados em 0,5 x 0,5 grau de latitude-longitude. Os dados foram utilizados tanto para a elaboração do índice desenvolvido neste trabalho - que será descrito na próxima Subseção (3.2) - como também para a elaboração de composições. Estes dados estão disponíveis para o período de 1979 a 2010 em resolução diária (a cada 6 horas), cobrindo o globo todo. Para o presente estudo foram obtidas médias diárias dessas variáveis ou, no caso da precipitação, foram calculados os acumulados diários.

Para os dados de ROLE foram utilizados os interpolados globais diários da NOAA (National Oceanic and Atmospheric Administration) Climate Data Record (OLR-Daily CDR) (LEE, 2014). Estes dados estão disponíveis para o período de 1979 a 2012, cobrindo o globo todo com espaçamento horizontal de 1 x 1 grau de latitudelongitude em médias diárias (LEE, 2014; LEE; SCHRECK; KNAPP, 2014).

O período de estudo proposto inicialmente era de 32 anos, de 1 de janeiro de 1979 a 31 de dezembro de 2010. Entretanto, após a análise exploratória dos dados, verificou-se que existiam dados faltantes na série temporal de ROLE, principalmente no ano de 1985. Por isso, foi escolhido um período em que essa série está completa 
para a realização do estudo. O novo período contém 16 anos de dados e se inicia em 1 de janeiro de 1995 e termina em 31 de dezembro de 2010.

A série temporal do índice multivariado da OMJ utilizada para investigar as relações entre a posição da ZCIT na região de estudo e a atividade da OMJ (ativa ou inativa), bem como suas fases, foi cortesia do Dr. Charles Jones (Earth Research Institute - University of California, Santa Barbara). Esse índice, que tem resolução diária, identifica oito fases do ciclo de vida da oscilação à medida que a mesma se propaga para leste, como discutido na Subseção 2.2. É importante ressaltar que existem vários métodos para identificar a fase de um evento da OMJ. Esses métodos podem diferir tanto em dados utilizados como em metodologia. Logo, as fases e amplitude dos eventos podem variar de um índice para outro. Os detalhes do cálculo do índice utilizado no presente trabalho podem ser vistos em Jones (2009).

As imagens de satélite no canal do infravermelho $(11 \mu \mathrm{m})$ utilizadas nos

estudos de casos deste trabalho estão disponíveis em https://www.ncdc.noaa.gov/gibbs/. As imagens obtidas (GridSat-B1) foram elaboradas através dos satélites GOES 9, GOES 10, GOES 12, METEOSAT 5 e METEOSAT 7, todos em órbita geoestacionária, através de uma mesclagem dos dados obtidos em cada um dos satélites individualmente.

\subsection{Metodologia}

\subsubsection{Critério para a Localização da ZCIT no Atlântico Oeste}

Foi elaborado um critério de localização latitudinal da ZCIT-AO no período de interesse. O critério proposto no presente trabalho baseia-se na máxima cobertura de nuvens convectivas e na zona de confluência dos ventos alísios de nordeste e de sudeste. Este método fundamenta-se em dois aspectos da ZCIT simultaneamente ao 
invés de apenas um, diferindo de muitos estudos da literatura que utilizaram uma única variável para este propósito (p. ex., ENFIELD, 1996; GU; ADLER, 2009; CARVALHO; OYAMA, 2013). Como mencionado na Seção 2.1, a ZCIT apresenta aspectos que não necessariamente se encontram sobre a mesma latitude. Logo, a utilização de duas variáveis para a determinação da posição da ZCIT-AO faz com que o método proposto possa ser mais eficaz e assertivo.

O domínio de estudo para a elaboração do índice proposto de posições latitudinais da ZCIT-AO abrange o Atlântico equatorial oeste, compreendendo a região de $44^{\circ} \mathrm{O}$ a $30^{\circ} \mathrm{O}$ e de $2^{\circ} \mathrm{S}$ a $10^{\circ} \mathrm{N}$ (Figura 5), determinado de modo a evitar influências da convecção continental (CHIANG; KUSHNIR; GIANNINI, 2002), além de conter a banda de nebulosidade profunda média associada à ZCIT (FERREIRA et al., 2005).

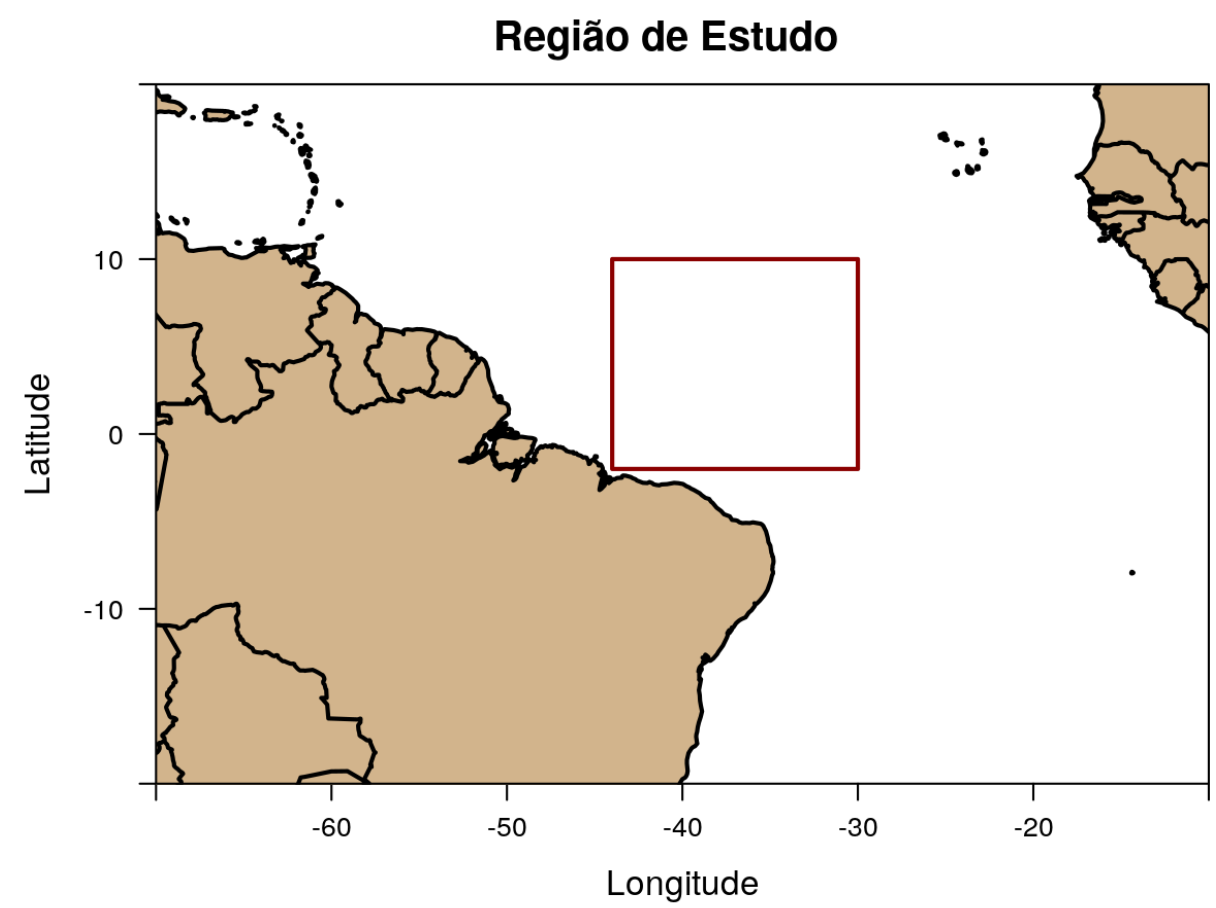

Figura 5 - Região de estudo para a elaboração do índice de posições latitudinais da ZCITAO (IZCIT-AO). 
Inicialmente foram determinadas as posições latitudinais para cada grau de longitude da ZCIT na região de estudo a partir de valores mínimos de ROLE. Para cada longitude dentro do domínio (15 graus) foi feita uma varredura em todas as latitudes, procurando o valor mínimo de ROLE. Esse valor mínimo indica a região de máxima cobertura de nuvens. Diferentemente de Souza e Cavalcanti (2009), esse valor deve satisfazer um limiar específico, similarmente à metodologia utilizada por Ferreira et al. (2005). Esses autores destacam que não há um consenso na literatura sobre qual é o limiar exato adequado para identificar a convecção. Tendo em vista que Ferreira et al. (2005) utilizaram o limiar de $230 \mathrm{Wm}^{-2}$ para localizar a ZCIT-A de forma eficaz, este foi o valor utilizado no presente trabalho. O método de Ferreira et al. (2005), bem como este limiar, é o utilizado no Monitoramento Global da posição da ZCIT-A na página do CPTEC/INPE. Quando esse limiar não foi atingido em determinada longitude, a posição latitudinal foi obtida através da média entre as posições nas longitudes imediatamente a leste e a oeste. Caso um ponto da borda do domínio não tenha atingido o limiar assumiu-se que a posição latitudinal da ZCIT-AO naquele ponto seja igual à posição no ponto imediatamente a leste ou a oeste dentro da região de estudo.

A partir da mesma metodologia descrita acima, foram obtidas posições latitudinais também com base no vento meridional $(v)$ em baixos níveis. A varredura foi feita procurando valores mínimos em módulo de $v$, ou seja, quando o vento meridional muda de sinal. Esses valores representam a região de confluência do vento meridional. Esta técnica foi utilizada por Enfield (1996), Uvo e Nobre (1989) e Xavier et al. (2000) para localizar latitudinalmente a ZCIT sobre o Atlântico. Para que esta análise e metodologia mantivessem o mesmo padrão do índice elaborado através dos dados de ROLE, os dados de $v$ foram interpolados para que os mesmos apresentassem resolução correspondente à de ROLE. Ou seja, os dados de vento meridional foram degradados de 0,5 × 0,5 grau de latitude-longitude para $1 \times 1 \mathrm{grau}$ dentro da região de estudo. Essa metodologia foi aplicada para o vento meridional em 850 e $925 \mathrm{hPa}$, sendo que as posições latitudinais obtidas através do vento no nível de $925 \mathrm{hPa}$ mostraram maior correspondência com as posições obtidas através dos dados de ROLE e foram as utilizadas neste trabalho. 
Para gerar um índice da variabilidade da posição da ZCIT-AO através de cada uma das variáveis, foi feita uma média das posições em cada longitude, obtendo uma única posição latitudinal dentro da região de estudo em cada dia para cada uma das variáveis, resultando em duas séries temporais de posições latitudinais da ZCITAO, uma baseada em ROLE e outra em vento meridional.

Coelho (2002) mostrou que o procedimento adotado para encontrar as posições latitudinais da ZCIT-A através de valores mínimos de ROLE não foi eficiente para a determinação do posicionamento diário da ZCIT-A. Entretanto, neste trabalho foi utilizada uma região que contém, em sua maior parte, a banda de nebulosidade profunda média associada à ZCIT-AO (FERREIRA et al., 2005), evitando assim que as convecções que surgissem dentro da região de estudo não estivessem relacionadas à ZCIT-AO. Além disso, o índice final foi composto por posições latitudinais baseadas em dois aspectos simultâneos da ZCIT: ROLE e vento meridional.

Embora as duas séries apresentassem uma boa correlação $(0,7)$, as posições latitudinais encontradas muitas vezes divergiam. Como citado na Subseção 2.1, Hastenrath e Lamb (1977) mostraram que os aspectos meteorológicos que identificam a localização da ZCIT apresentam-se próximos em superfície, mas não necessariamente ao longo da mesma latitude. Tendo isso em vista, já era previsto que poderia haver duas posições latitudinais diferentes que representassem a localização da ZCIT-AO, uma baseada em ROLE e outra no vento meridional. Então, a localização da mesma foi determinada pelo ponto médio entre as séries de posições determinadas com ROLE e com $v$, gerando uma única série temporal, que foi chamada de Índice da ZCIT-AO (IZCIT-AO) neste trabalho. Em caso de haver ZCIT dupla, o critério proposto localizou a banda principal, uma vez que esse índice se baseia em máxima convecção e máxima confluência dos alísios. 


\subsubsection{Análise Estatística do Índice da ZCIT-AO (IZCIT-AO)}

Os meses utilizados nas análises propostas foram Março, Abril e Maio representando o outono austral e Setembro, Outubro e Novembro representando a primavera austral. Essas estações foram selecionadas com o objetivo de reter os períodos nos quais a ZCIT-AO se encontra mais a sul (outono) ou mais ao norte (primavera), desprezando os períodos de transição para norte ou para sul, pois a variabilidade de outras escalas temporais, como o ciclo anual, poderia influenciar a intrassazonal.

Foi feita então uma análise de ondeletas do IZCIT-AO, a fim de verificar os períodos de maior densidade espectral. Como o foco deste trabalho é a variabilidade intrassazonal esta escala foi analisada mais detalhadamente, com o objetivo de determinar em que banda de frequência a variabilidade do índice é mais significativa dentro dessa escala.

Para investigar a variabilidade da ZCIT-AO na escala intrassazonal realizou-se uma filtragem do IZCIT-AO com uma Transformada Rápida de Fourier (Fast Fourier Transform - FFT, em inglês) (CHATFIELD, 1996) na banda de 10 a 70 dias, após remover a tendência e o ciclo anual da série temporal do índice. Os dias 29 de fevereiro de anos bissextos foram ignorados, mantendo o padrão de 365 dias para cada ano.

\subsubsection{Critério para Seleção de Eventos Extremos}

A partir da série temporal do IZCIT-AO filtrado, os "eventos extremos" foram determinados através das posições mais austrais (percentil de $25 \%$ ) e das posições mais boreais (percentil de 75\%) da ZCIT-AO na banda intrassazonal, para cada estação. Através da série temporal do índice multivariado da OMJ, que tem resolução 
diária e identifica oito fases do ciclo de vida da oscilação à medida que a mesma se propaga para leste, foram investigadas as relações entre a posição da ZCIT na região de estudo e a atividade da OMJ (ativa ou inativa) e suas fases. Esta análise foi feita a partir de estatísticas simples nos períodos de interesse.

Foram calculadas as proporções dos eventos ocorridos em cada fase da OMJ ativa. Nesse caso, o teste de significância estatística (SPIEGEL, 1972) utilizado determina se a diferença entre duas proporções é estatisticamente significativa ao nível de $5 \%$ de significância.

Para fins de análise, um "evento extremo" foi definido quando o IZCIT-AO se manteve acima ou abaixo dos percentis de $75 \%$ e $25 \%$, respectivamente, independente de quantos dias consecutivos. Em outras palavras, um evento pode durar de um a "n" dias, desde que o IZCIT-AO filtrado mantenha-se acima ou abaixo dos percentis que definem os "eventos extremos", sendo aplicada uma tolerância de um dia fora de tais percentis, ou seja, se em um dia o IZCIT-AO não atingiu os percentis mas no dia seguinte voltou a atender o critério anterior, foi considerado apenas um evento.

\subsubsection{Análise de Composições}

Para analisar os campos espaciais, foram produzidas composições para as variáveis meteorológicas em estudo, as quais serão detalhadas a seguir. Esses campos foram gerados através da média de vários eventos com as mesmas características determinados anteriormente. $O$ primeiro passo para o cálculo das composições foi a filtragem das variáveis utilizadas na banda intrassazonal. O método de filtragem empregado foi o mesmo utilizado para filtrar o IZCIT-AO, a Transformada Rápida de Fourier (FFT, sigla em inglês) (CHATFIELD, 1996). Também foram calculados os testes de significância estatística ao nível de 5\% para as composições. 
Primeiramente, foram geradas composições de anomalias de ROLE e escoamento em $925 \mathrm{hPa}$ para os eventos extremos selecionados, a fim de verificar os padrões espaciais desses eventos e, possivelmente, corroborar o método utilizado na elaboração do IZCIT-AO.

Em seguida, foram calculadas composições para os mesmos eventos extremos, porém durante cada uma das fases da OMJ separadamente, com alta resolução sobre todo o globo. As composições foram feitas para as variáveis a seguir e seguem o mesmo período de análise descrito anteriormente (1995 a 2010):

- Função de corrente em 200 hPa;

- Vento meridional em $200 \mathrm{hPa}$;

- Radiação de onda longa emergente (ROLE);

- Vento em 850 hPa (o escoamento em 925 hPa apresentou, visualmente, um padrão confuso dos vetores por ter influência da superfície e por isso não foi utilizado);

- Precipitação acumulada em 24 horas.

Os dados cobrem o globo todo longitudinalmente e variam de -75 a $75^{\circ}$ de latitude. Devido à alta resolução, a filtragem exigiu alta performance computacional, fazendo com que o tempo necessário para o procedimento se estendesse além do esperado.

Essas variáveis foram escolhidas considerando que através do vento em $850 \mathrm{hPa}$, ROLE e precipitação pode-se verificar o posicionamento da ZCIT e, utilizando as variáveis função de corrente e vento meridional em altitude, é possível determinar padrões de teleconexão na banda intrassazonal.

As composições das variáveis descritas foram calculadas para cada fase da OMJ (fase neutra e de 1 a 8), conforme já mencionado, em cada uma das estações definidas para o estudo, ou seja, outono e primavera:

- Eventos extremos austrais - primavera (SON) - fases 0 a 8;

- Eventos extremos boreais - primavera (SON) - fases 0 a 8; 
- Eventos extremos austrais - outono (MAM) - fases 0 a 8;

- Eventos extremos boreais - outono (MAM) - fases 0 a 8.

\subsubsection{Estudos de Casos Extremos}

A fim de realizar uma avaliação mais detalhada de alguns casos específicos, foram determinados os eventos mais extremos do período em análise, ou seja, os eventos austrais e boreais mais intensos para cada uma das estações, totalizando quatro casos.

Após a determinação de cada um desses eventos foram calculadas composições para cada caso, utilizando as mesmas variáveis descritas na Subseção 3.2.4. Além do cálculo das composições, também foram obtidas imagens de satélite, a fim de facilitar a visualização do posicionamento da ZCIT-AO. O objetivo dessas análises foi identificar padrões de teleconexão ou outros mecanismos atmosféricos que pudessem interferir e contribuir para o deslocamento extremo da ZCIT-AO durante os eventos.

Para facilitar a nomenclatura, os casos selecionados foram nomeados da seguinte forma:

- Caso 1: Extremo austral outono: 30/04 a 08/05/2004;

- Caso 2: Extremo austral primavera: 13 a 21/10/1997;

- Caso 3: Extremo boreal outono: 11 a 18/04/2004;

- Caso 4: Extremo boreal primavera: 18 a 28/11/2000. 


\section{RESULTADOS}

\subsection{O IZCIT-AO}

Foi calculado o espectro de ondeletas do IZCIT-AO (Figura 6) para verificar os modos de variabilidade dominantes na série temporal do índice e como eles variam no tempo. Na Figura podemos observar que o espectro é mais intenso (cor vermelha) próximo ao período de 365 dias, o que está de acordo com o esperado, pois a ZCIT tem alta variabilidade na escala anual. Outros picos aparecem no período de aproximadamente 180 dias, o que deve estar relacionado ao ciclo semianual da ZCITAO. As linhas brancas contornam as regiões onde há significância estatística ao nível de $90 \%$ de confiança. Outros picos estatisticamente significativos aparecem na escala de 2 a 6 anos aproximadamente, possivelmente associados ao El Niño Oscilação Sul (ENOS). Na escala intrassazonal aparecem picos mais estatisticamente significativos a partir de 10 até 100 dias aproximadamente. Com base na literatura e a fim de englobar esses picos, a banda escolhida para a filtragem do IZCIT-AO na escala intrassazonal foi de 10-70 dias.

Para sintetizar e exemplificar o índice elaborado (IZCIT-AO), a Figura 7 mostra a série temporal de posições latitudinais determinadas a partir de ROLE (laranja), vento meridional (verde), média das posições (cinza) e o índice filtrado (preto) para o ano de 1995. Podemos observar através da curva do IZCIT-AO (Figura 7) o ciclo anual do posicionamento da ZCIT-AO. No outono austral, ela se mantém mais a sul, enquanto na primavera austral ela se mantém mais a norte. Esse deslocamento sazonal da ZCIT-AO está relacionado ao aquecimento diferencial dos hemisférios norte e sul ao longo do ano e está de acordo com a literatura (MELO; CAVALCANTI; SOUZA, 2009). As oscilações diárias que vemos na Figura 7 também foram suavizadas após a aplicação do filtro passa-banda 10-70 dias. 


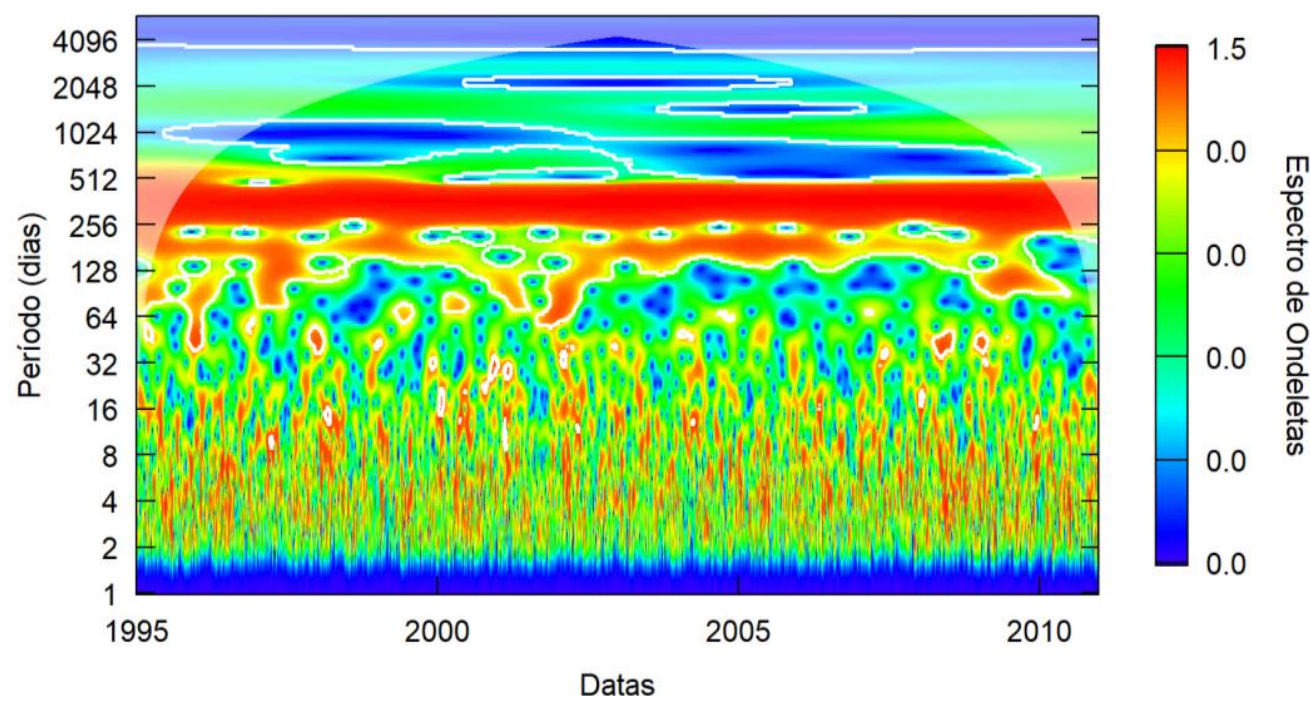

Figura 6 - Espectro de ondeletas do IZCIT-AO antes da filtragem do mesmo. As linhas brancas representam a significância estatística ao nível de $90 \%$ de confiança.

Posição latidunial diária da ZCIT - 1995

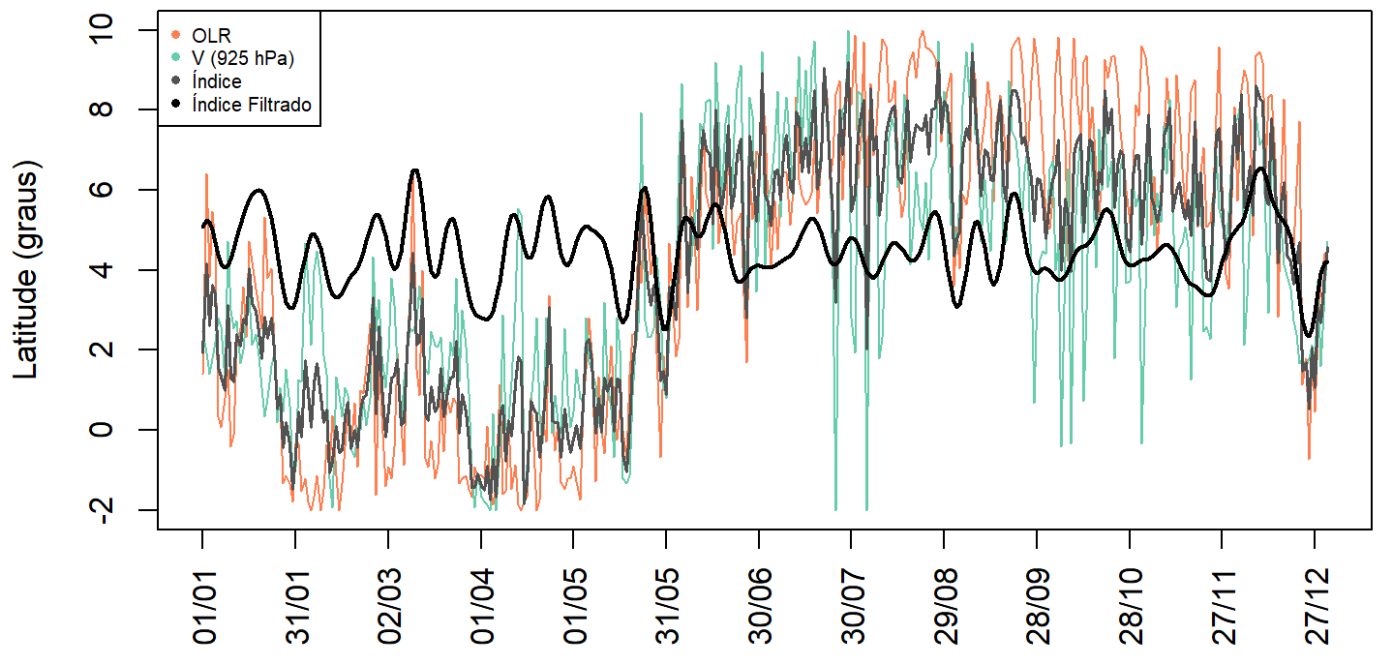

Figura 7 - Série temporal de posições latitudinais diárias da ZCIT-AO para o ano de 1995. Posições latitudinais determinadas a partir de ROLE (curva laranja), vento meridional (curva verde) e média dessas posições (curva cinza). O IZCIT-AO é representado pela curva em preto. 
Podemos identificar aspectos da ZCIT-AO nas composições (Figura 8) geradas a partir da média dos eventos extremos, através da máxima cobertura de nuvens (mínimo de ROLE) e confluência dos alísios (MELO; CAVALCANTI; SOUZA, 2009), como discutido anteriormente. Os valores negativos de ROLE (azul) indicam a região onde há maior cobertura de nuvens e os valores positivos (marrom) onde há um déficit de cobertura de nuvens. O retângulo preto indica a região de estudo e a linha vermelha representa o valor do quartil (limiar) do IZCIT-AO para cada extremo. Nas composições que representam os eventos extremos austrais (Figuras 9a e 9b), os valores negativos de ROLE localizam-se a sul do limiar estabelecido pelo IZCITAO (linha vermelha), ou seja, abaixo do percentil de $25 \%$ do índice, indicando que a ZCIT pode estar localizada, em média, sobre essa região nos eventos selecionados. Já nas composições que representam os eventos extremos boreais (Figuras 9c e 9d), os valores negativos de ROLE encontram-se a norte do limiar, ou seja, acima do percentil de $75 \%$ do IZCIT-AO. A confluência dos ventos em $925 \mathrm{hPa}$ é melhor observada na Figuras 9a e 9d. Essa análise nos mostra os padrões esperados para as duas estações austrais, outono e primavera, sendo a ZCIT-AO localizada mais a norte nos extremos boreais e mais a sul nos extremos austrais, corroborando o índice proposto para a localização latitudinal da ZCIT-AO e o método para definição dos eventos extremos. O valor do limiar para os extremos austrais é de $3,96^{\circ} \mathrm{N}$ e $3,83^{\circ} \mathrm{N}$ para a primavera e outono, respectivamente, e para os extremos boreais os valores são $5,00^{\circ} \mathrm{N}$ e $5,04^{\circ} \mathrm{N}$ também para a primavera e outono, respectivamente. 
a)

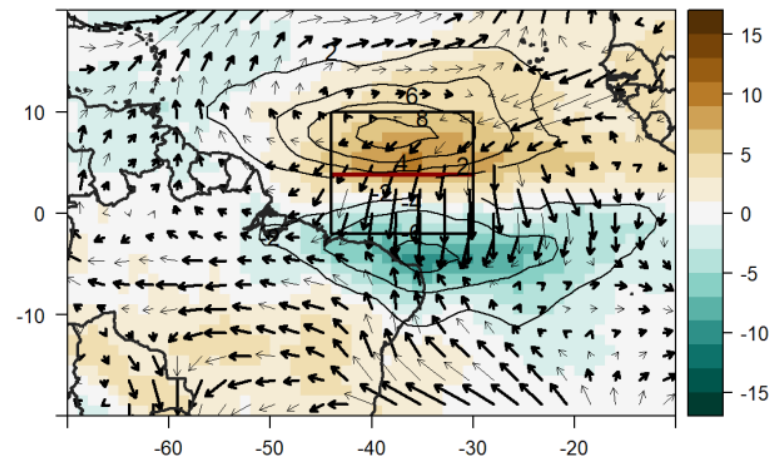

c)

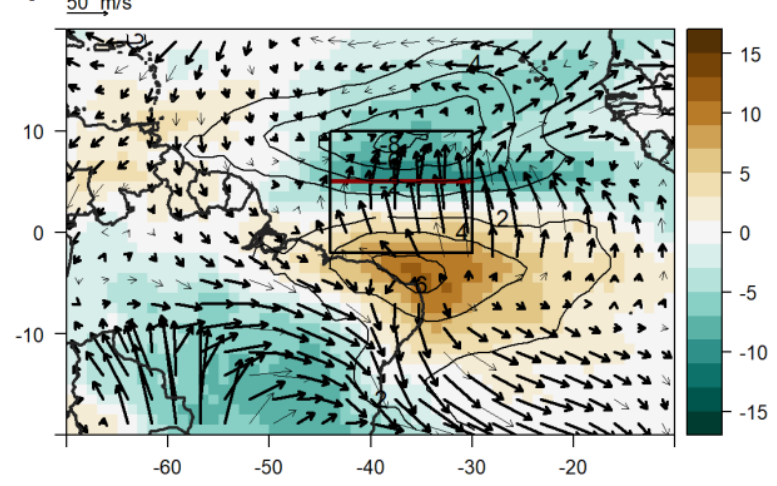

b) $50 \mathrm{~m} / \mathrm{s}$

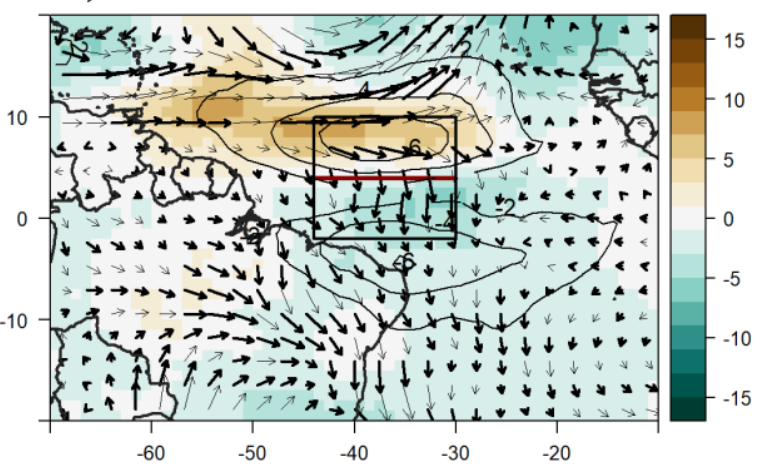

d) $50 \mathrm{~m} / \mathrm{s}$ tremos Boreais - Primavera (SON)

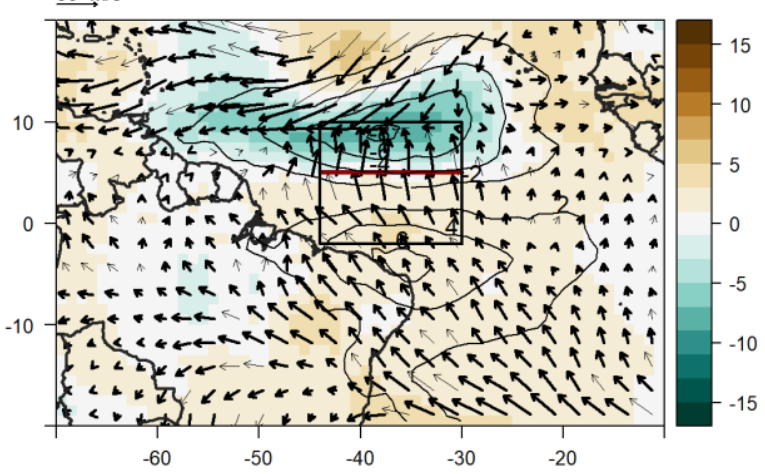

Figura 8 - Composições de anomalias intrassazonais de ROLE $\left(\mathrm{W} / \mathrm{m}^{2}\right)$ e escoamento em $925 \mathrm{hPa}(\mathrm{m} / \mathrm{s})$ para os extremos austrais (acima) e boreais (abaixo) nas estações Outono (esquerda) e Primavera (direita). Os vetores em negrito e as áreas contornadas representam significância estatística ao nível de $5 \%$. A caixa preta representa a Região de Estudo e a linha vermelha representa o percentil (limiar) do IZCIT-AO para cada caso.

A Figura 9 mostra o número de eventos extremos boreais, ou seja, os eventos em que a ZCIT-AO encontra-se mais a norte, e austrais, eventos em que a ZCIT-AO encontra-se mais a sul, para cada ano (1995-2010) nas duas estações, outono (Figura 9a) e primavera (Figura 9b) austrais obtidos a partir dos quartis da série do IZCIT-AO filtrado, como descrito na Subseção 3.2. Para ambas as estações, a média é de aproximadamente 23 eventos extremos austrais e boreais por ano. Através do teste das diferenças das proporções (SPIEGEL, 1972) realizado ao nível de 5\% de significância, pode-se verificar que há diferenças estatisticamente significativas nos anos de 2007 e 2010 para o outono e 1995, 2001 e 2002 na primavera. Para o outono, os anos citados mostraram maior ocorrência de eventos extremos boreais, enquanto 
na primavera, os anos de 1995 e 2001 mostraram maior ocorrência de eventos extremos austrais e o ano de 2002 mostrou maior ocorrência de eventos extremos boreais. Isso significa que, durante esses anos e nos períodos analisados, influências intrassazonais podem ter contribuído para a localização da ZCIT-AO mais a norte ou mais a sul, caracterizando os eventos extremos boreais e austrais, respectivamente.

a)

\section{Outono (MAM)}

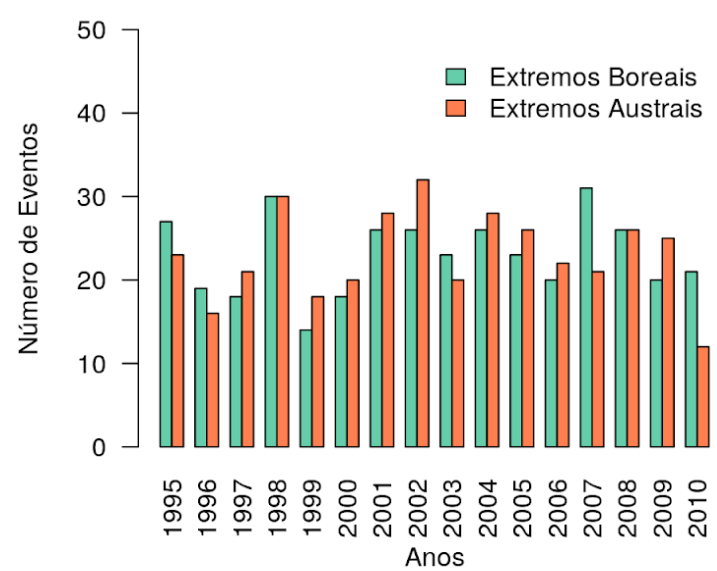

b)

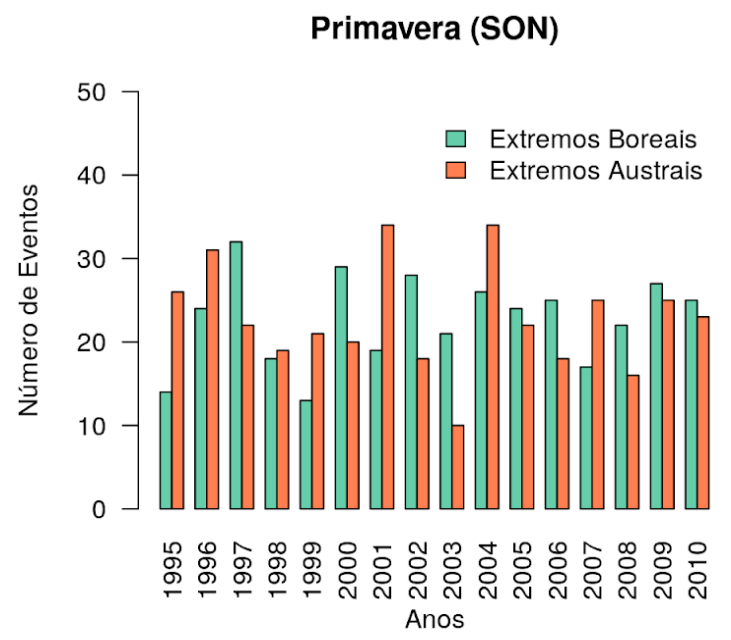

Figura 9 - Número de eventos extremos austrais (laranja) e boreais (verde) para nas estações Outono (a) e Primavera (b) em cada ano (1995-2010).

A Figura 10 mostra a relação dos extremos austrais e boreais da ZCIT-AO com a atividade da OMJ (ativa e inativa). Podemos observar que os eventos extremos ocorrem principalmente enquanto a OMJ estava ativa para as duas estações, especificamente $71 \%$ dos extremos boreais e $60 \%$ dos extremos austrais no outono (Figura 10a) e 68\% dos extremos boreais e 60\% dos extremos austrais na primavera (Figura 10b). As diferenças entre as proporções dos extremos durante OMJ ativa e inativa são estatisticamente significativas ao nível de 5\%. Embora os extremos ocorram, em sua maioria, durante a OMJ ativa, ainda há uma porcentagem de eventos que ocorre enquanto a OMJ se encontra inativa, indicando que outros mecanismos podem modular a variabilidade intrassazonal da posição da ZCIT além da OMJ, 
mecanismos esses que ainda não são definidos, como mencionado por Jones e Schemm (2000).

a)

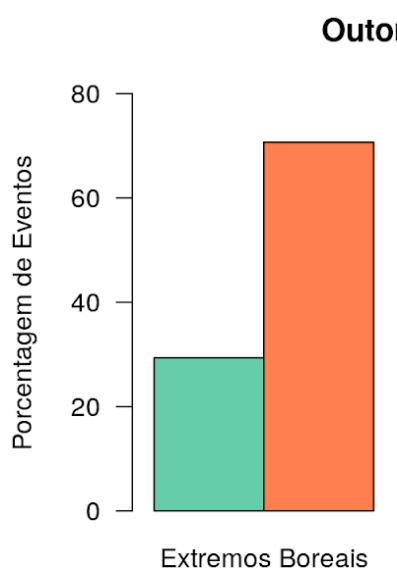

Outono (MAM)

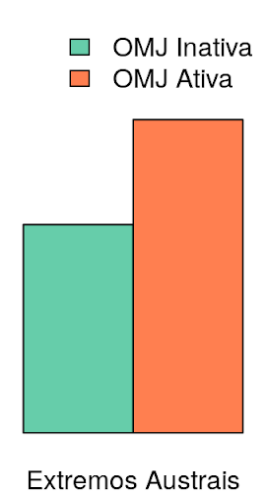

b)

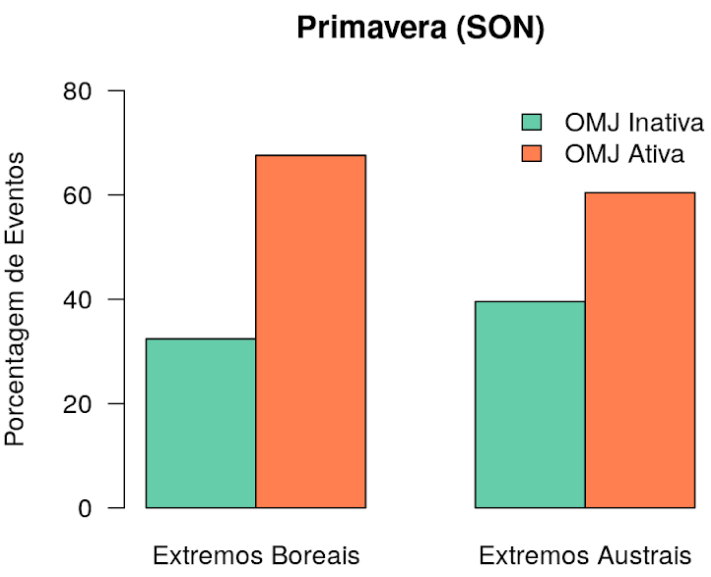

Figura 10 - Porcentagem de eventos extremos boreais e austrais de acordo com a atividade da OMJ (inativa - verde ou ativa - laranja) para as estações de Outono (a) e Primavera (b).

Foram calculados histogramas para investigar a frequência de duração dos eventos extremos (Figuras 11 e 12). Através desses gráficos podemos identificar que a duração média dos eventos foi bem próxima, sendo elas:

- 4,7 dias para extremos austrais no outono;

- 5,1 dias para extremos austrais na primavera;

- 5,0 dias para extremos boreais no outono;

- 5,1 dias para extremos boreais na primavera.

Os padrões dos histogramas se mantiveram semelhantes nos quatro casos, com maior número de eventos com menores durações diminuindo conforme a duração aumenta. Em adição, o número de eventos extremos austrais com duração menor (até 5 dias) é superior ao de extremos boreais com a mesma duração. 
a)

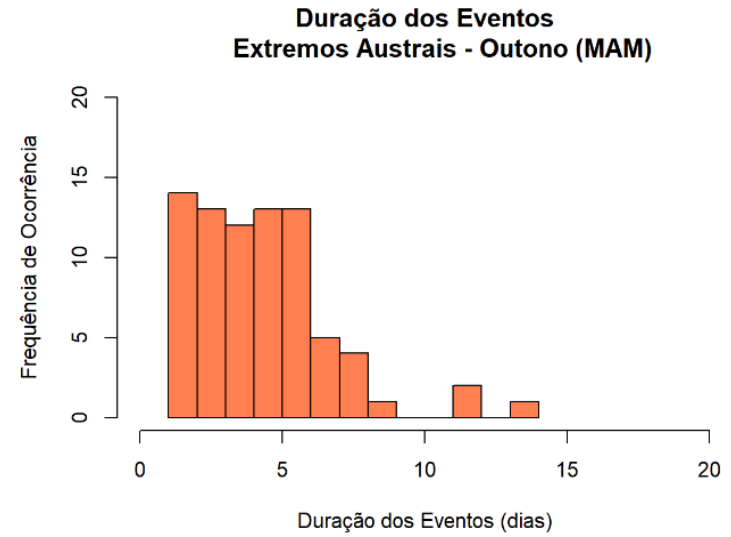

b)

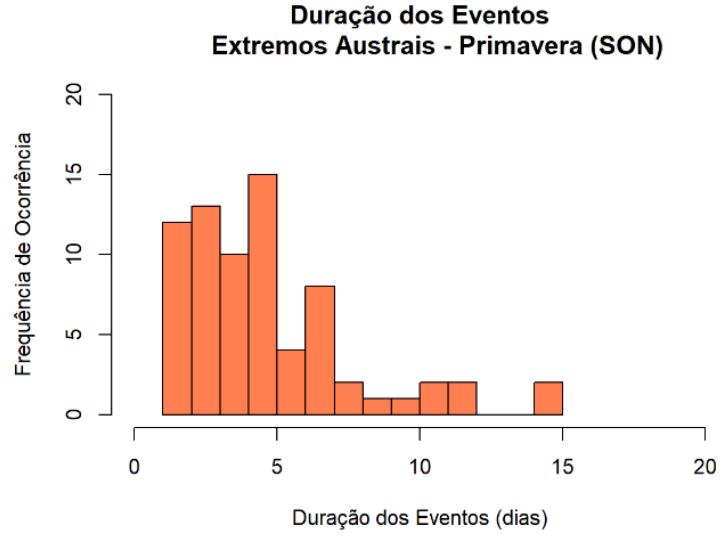

Figura 11 - Histogramas da duração dos eventos extremos austrais no Outono (a) e Primavera (b).

a)

Duração dos Eventos,

Extremos Boreais - Outono (MAM)

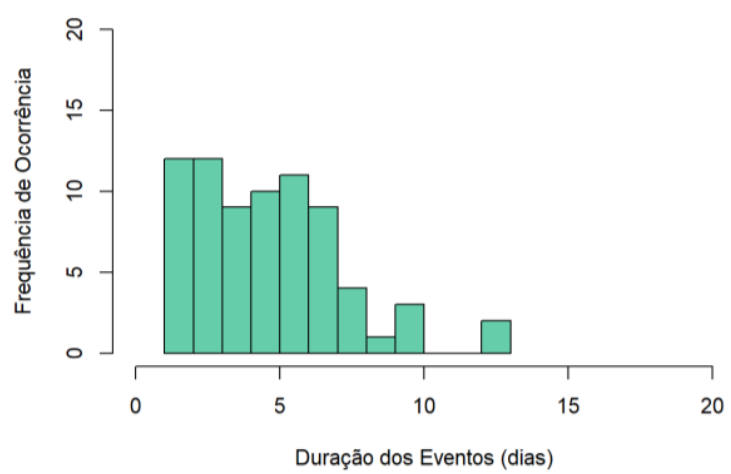

b)

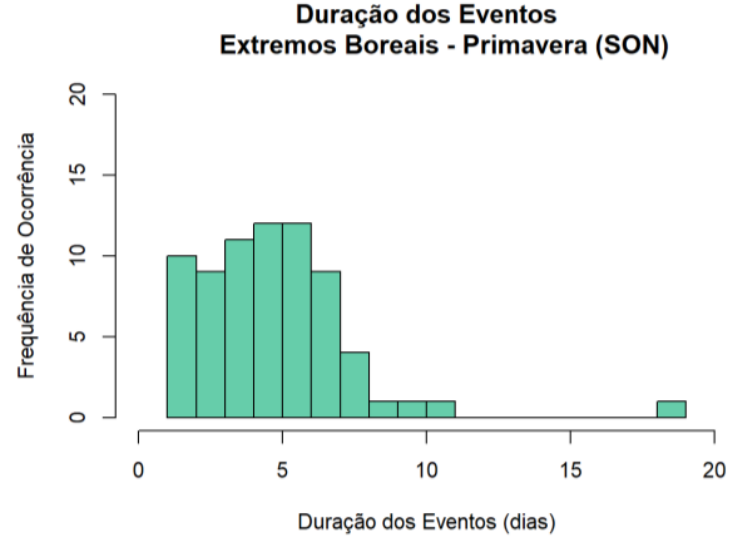

Figura 12 - Histogramas da duração dos eventos extremos boreais no Outono (a) e Primavera (b). 


\subsubsection{Relação entre as Fases da OMJ e o Posicionamento da ZCIT no Atlântico Oeste}

A Figura 13 mostra as proporções dos eventos extremos da ZCIT-AO ocorridos em cada fase da OMJ. Os valores em porcentagem são com relação a todos os eventos ocorridos durante OMJ ativa. Podemos notar claramente uma predominância de eventos em algumas fases específicas. No outono (Figura 13a), os eventos extremos boreais ocorrem com maior frequência do que os austrais nas fases 1, 2, 7 e 8, enquanto os austrais ocorrem com maior frequência do que os boreais nas fases 3, 4, 5 e 6 . As fases que apresentam diferenças de proporções estatisticamente significativas ao nível de 5\% são 2, 4, 5, 7 e 8. As fases que apresentam maior porcentagem de eventos extremos boreais são as que apresentam anomalia negativa de ROLE na região do Atlântico tropical. Já as fases que tem maior porcentagem de eventos extremos austrais são as associadas com anomalia negativa de ROLE que avança do oeste da Indonésia e leste do oceano Índico na fase 3 até a parte leste da Indonésia e oceano Pacífico oeste na fase 6 e anomalias positivas de ROLE sobre 0 Atlântico tropical e AS (Figura 3).

$\mathrm{Na}$ primavera (Figura 13b), os extremos boreais ocorrem com maior frequência do que os austrais nas fases 1, 4, 5 e 6, enquanto o contrário ocorre nas fases 2, 3, 7 e 8 . Nesse caso, apenas a fase 8 apresenta diferença de proporção estatisticamente significativa ao nível de $5 \%$. Ainda que no outono a evolução da atividade da OMJ (deslocamento para leste) com relação aos extremos seja mais nítida, na primavera ocorre o inverso, com exceção das fases 1 e 3 . Ou seja, temos maior porcentagem de eventos extremos boreais enquanto a oscilação apresenta anomalias negativas de ROLE na região do Índico Oeste, África e Atlântico tropical (fase 1) e sobre as regiões adjacentes à Indonésia (fases 4, 5 e 6), e maior porcentagem de eventos extremos austrais no período em que a oscilação apresenta anomalias positivas de ROLE sobre a Indonésia e regiões adjacentes (fases 7 e 8) e anomalias negativas sobre o Índico (fases 2 e 3) (Figura 3). 
a)

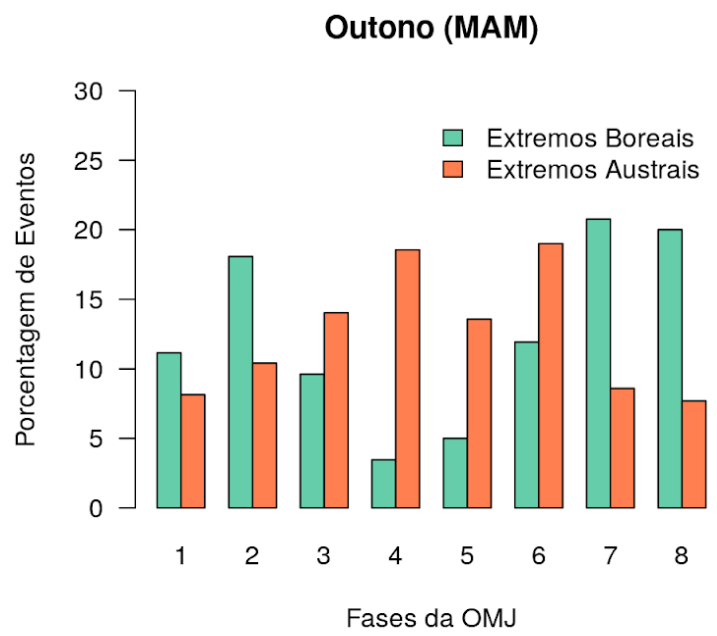

b)

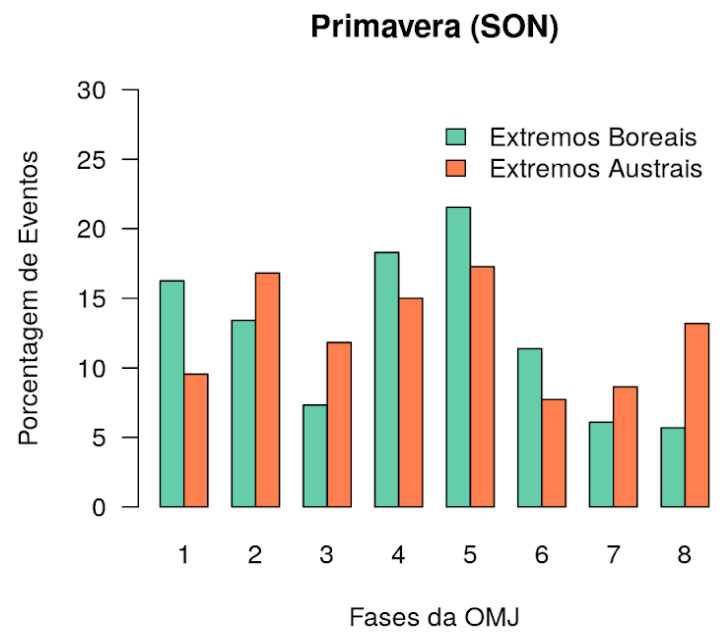

Figura 13 - Porcentagem de eventos extremos austrais e boreais que ocorreram em cada fase da OMJ para as estações Outono (a) e Primavera (b).

\subsection{Análise de Composições e de Padrões de Teleconexão}

Nessa Subseção serão apresentadas as Figuras das composições de vento em $850 \mathrm{hPa}(\mathrm{m} / \mathrm{s})$, ROLE $\left(\mathrm{W} / \mathrm{m}^{2}\right)$, vento meridional em $200 \mathrm{hPa}(\mathrm{m} / \mathrm{s})$, precipitação acumulada (mm/dia) e função de corrente em $200 \mathrm{hPa}\left(\mathrm{m}^{2} / \mathrm{s}\right)$ que mostram, para cada fase, a média dos eventos extremos austrais e boreais na Primavera (SON) e no Outono (MAM). É importante ressaltar que as variáveis foram filtradas na banda intrassazonal e os campos representam, portanto, anomalias. 


\subsubsection{Primavera (SON)}

\subsubsection{Extremos boreais}

As discussões a seguir são referentes às Figuras de 14 a 22 e representam os casos extremos boreais para a primavera austral (SON). O limiar do IZCIT-AO que delimitou a seleção desses casos foi a norte de aproximadamente $5 \stackrel{N}{ } \mathrm{~N}$.

A fase 0 (Figura 14) apresenta favorecimento de convecção a norte do limiar através do campo de ROLE (Figura 14a) e anomalia positiva de precipitação (Figura 14c) sobre a mesma região. Os campos em altos níveis (Figuras 14b e 14d) apresentam ainda um favorecimento da Alta Subtropical do Atlântico Sul (ASAS) e enfraquecimento da Alta Subtropical do Atlântico Norte (ASAN).

Através dos campos de anomalia de função de corrente e vento meridional em $200 \mathrm{hPa}$ observa-se nas fases 1, 2, 3 e 4 (Figuras 15, 16, 17 e 18) um padrão de anomalias anticiclônicas sobre o Atlântico Sul, o que pode favorecer a intensificação da ASAS. Em função deste padrão, a ZCIT-AO pode ter se deslocado para norte do limiar estabelecido para esses eventos, pois a intensificação da ASAS fortalece os ventos alísios de sudeste e favorece a confluência dos alísios mais a norte, já que os alísios de nordeste ficariam mais fracos comparados aos de sudeste. Na fase 1 (Figura 15), os campos de ROLE (Figura 15a) e precipitação (Figura 15c) mostram, respectivamente, favorecimento de convecção e anomalia positiva de precipitação sobre a faixa oeste da Região Norte do Brasil e sobre a região a norte do limiar (ainda dentro da região de estudo definida para a elaboração do índice), além de supressão de convecção sobre a Região Centro-Oeste. Para a fase 2 (Figura 16), o campo de ROLE (Figura 16a) mostra favorecimento de convecção sobre a Região Sul do Brasil, além de desfavorecimento sobre o Brasil Central e Região Sudeste (SE), e o campo de precipitação (Figura 16c) mostra anomalia positiva de precipitação a norte do limiar, como era esperado para os casos extremos boreais. Nas fases 3 e 4 (Figuras 17 e 
18), os campos de ROLE (Figuras 17a e 18a) mostram desfavorecimento de convecção sobre parte das Regiões SE e Nordeste (NE) e os campos de precipitação (Figura 17c e 18c) mostram precipitação acima da média a norte do limiar.

A fase 5 (Figura 19) é caracterizada pela propagação de um trem de onda barotrópico sobre o $\mathrm{HN}$ que pode ser observado nos campos de vento em $850 \mathrm{hPa}$ (Figura 19a), vento meridional em 200 hPa (Figura 19b) e função de corrente em 200 hPa (Figura 19c). Devido ao posicionamento de um sistema anticiclônico, centrado em aproximadamente $50^{\circ} \mathrm{N}$ sobre o continente e Atlântico Norte, associado à propagação de um trem de onda, a ASAN, que tem sua posição média um pouco mais a sul, pode ter sido desfavorecida. Consequentemente, a ZCIT-AO pode ter se posicionado mais a norte de sua posição habitual, ficando a norte do limiar. Os campos de ROLE (Figura 19a) e precipitação (Figura 19c) mostram, respectivamente, favorecimento de convecção e anomalias positivas de precipitação a norte do limiar, além de representarem claramente o padrão de precipitação esperado para essa fase, com favorecimento de convecção sobre a região da Indonésia e Pacífico Oeste e desfavorecimento sobre parte das Regiões NE e SE do Brasil.

A propagação de um trem de ondas barotrópico sobre o HS (em aproximadamente $50^{\circ} \mathrm{S}$ ) pode ser observada nas composições de vento meridional em $200 \mathrm{hPa}$ (Figura 20b), função de corrente em $200 \mathrm{hPa}$ (Figura 20d) e vento em $850 \mathrm{hPa}$ (Figura 20a) da fase 6 (Figura 20). Um outro padrão de propagação de ondas também pode ser observado um pouco mais a norte, entre o equador e $30^{\circ} \mathrm{S}$, em altos níveis da atmosfera (200 hPa) (Figuras 20b e 20d). Esse padrão favoreceu circulação ciclônica sobre as Regiões SE e NE do Brasil, o que pode ter favorecido a configuração da ZCIT-AO para norte do limiar.

Nas fases 7 e 8 (Figuras 21 e 22) a propagação de um trem de ondas barotrópico em aproximadamente $50^{\circ} \mathrm{N}$ a partir do Pacífico Norte causou desfavorecimento da ASAN, devido ao favorecimento de anomalias ciclônicas sobre - Atlântico Norte, localizadas entre 30 e $40^{\circ}$ N. Por consequência, a ZCIT-AO deslocou-se para norte do limiar definido para esse caso, pois o desfavorecimento da ASAN pode ter contribuído para a desintensificação dos alísios de nordeste. Os 
campos de ROLE (Figuras 21a e 22a) e de precipitação (Figuras 21c e 22c) de ambas as fases mostram, respectivamente, favorecimento de convecção e anomalia positiva de precipitação a norte do limiar, corroborando o deslocamento do sistema para norte. Além disso, os campos de ROLE (Figura 22a) e precipitação (Figura 22c) da fase 8 (Figura 22) mostram supressão de convecção e anomalia negativa de precipitação sobre grande parte das Regiões Norte (N) e NE e sobre parte do SE. 

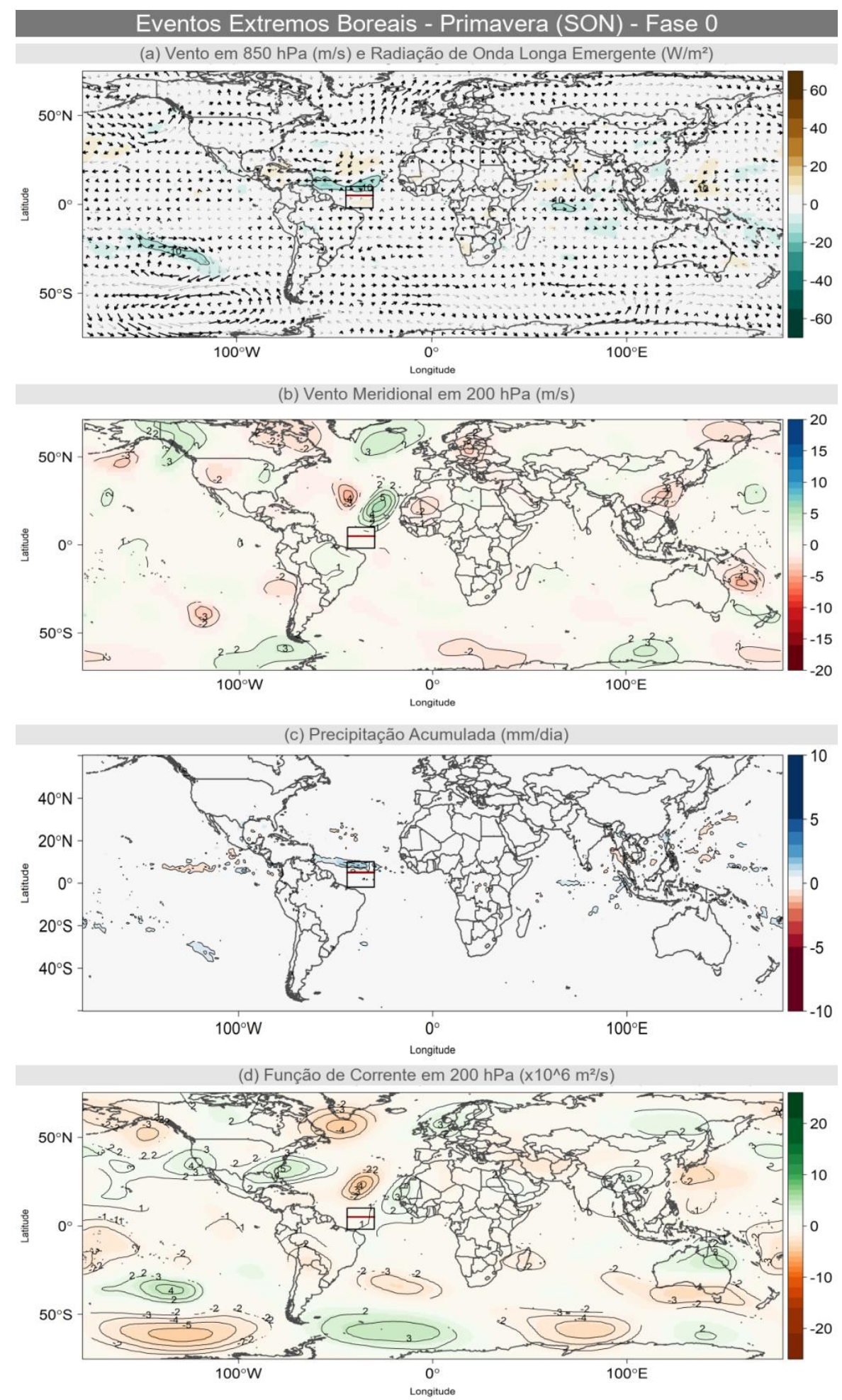

Figura 14 - Composições para os eventos extremos boreais para a Primavera (SON) e fase 0 da OMJ das anomalias de (a) vento em $850 \mathrm{hPa}\left({ }^{*} 100 \mathrm{~m} / \mathrm{s}\right.$ ) e ROLE (W/m²), (b) vento meridional em $200 \mathrm{hPa}$ (m/s), (c) precipitação (mm/dia) e (d) função de corrente em $200 \mathrm{hPa}$ $\left(x 10^{\wedge} 6 \mathrm{~m}^{2} / \mathrm{s}\right)$. A caixa preta representa a Região de Estudo e a linha vermelha representa 0 percentil (limiar) do IZCIT-AO para esse caso. Os vetores em negrito e as áreas contornadas representam significância estatística ao nível de 5\%. 


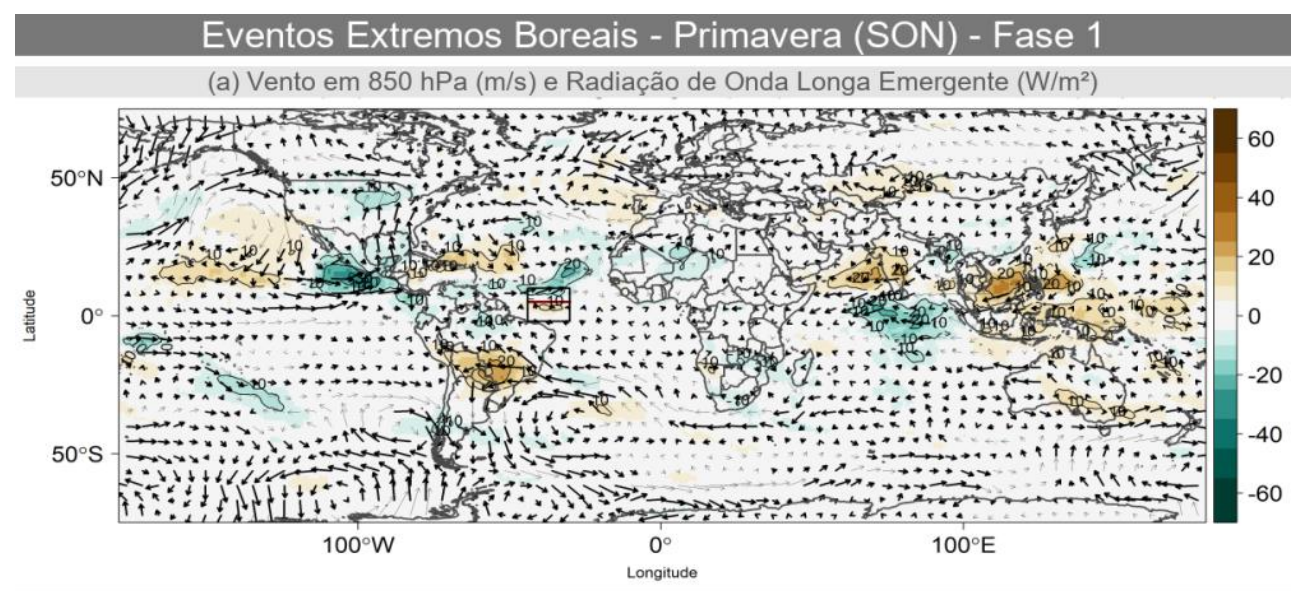

(b) Vento Meridional em $200 \mathrm{hPa}(\mathrm{m} / \mathrm{s})$

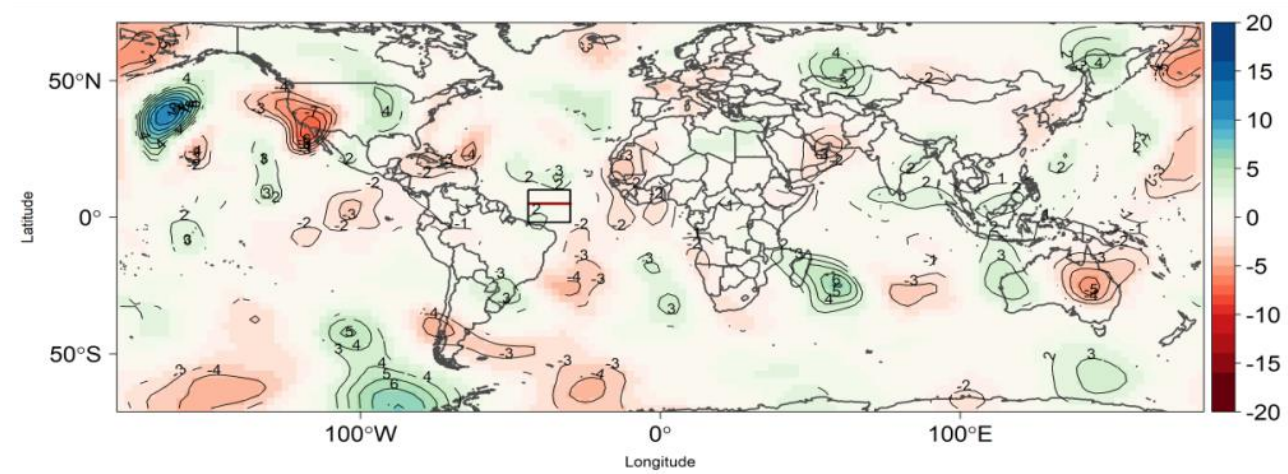

(c) Precipitação Acumulada ( $\mathrm{mm} / \mathrm{dia}$ )

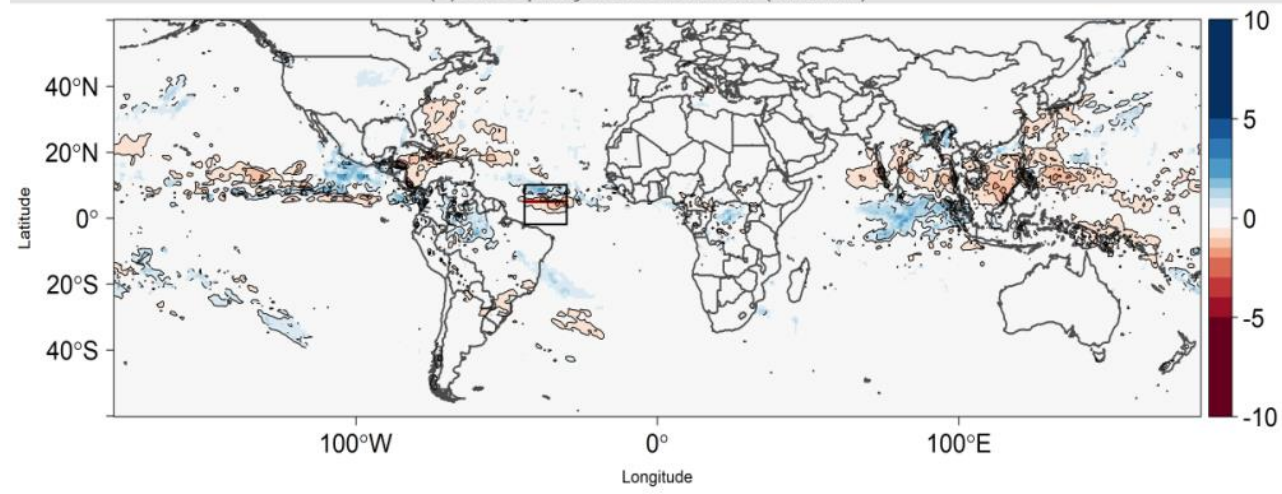

(d) Função de Corrente em $200 \mathrm{hPa}\left(\times 10^{\wedge} 6 \mathrm{~m}^{2} / \mathrm{s}\right)$

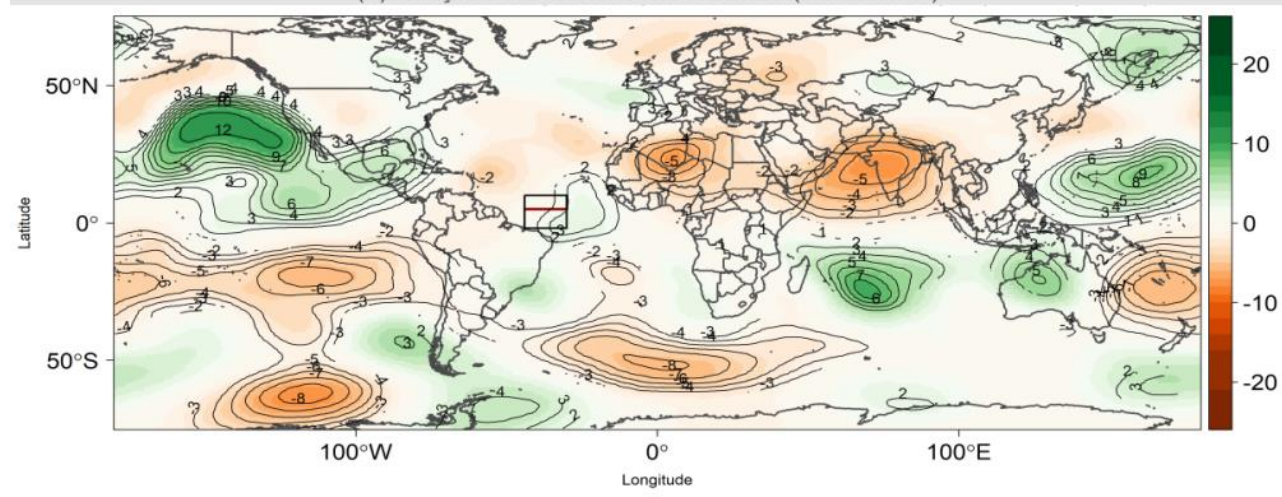

Figura 15 - Idem à Figura 14, porém para fase 1 da OMJ. 


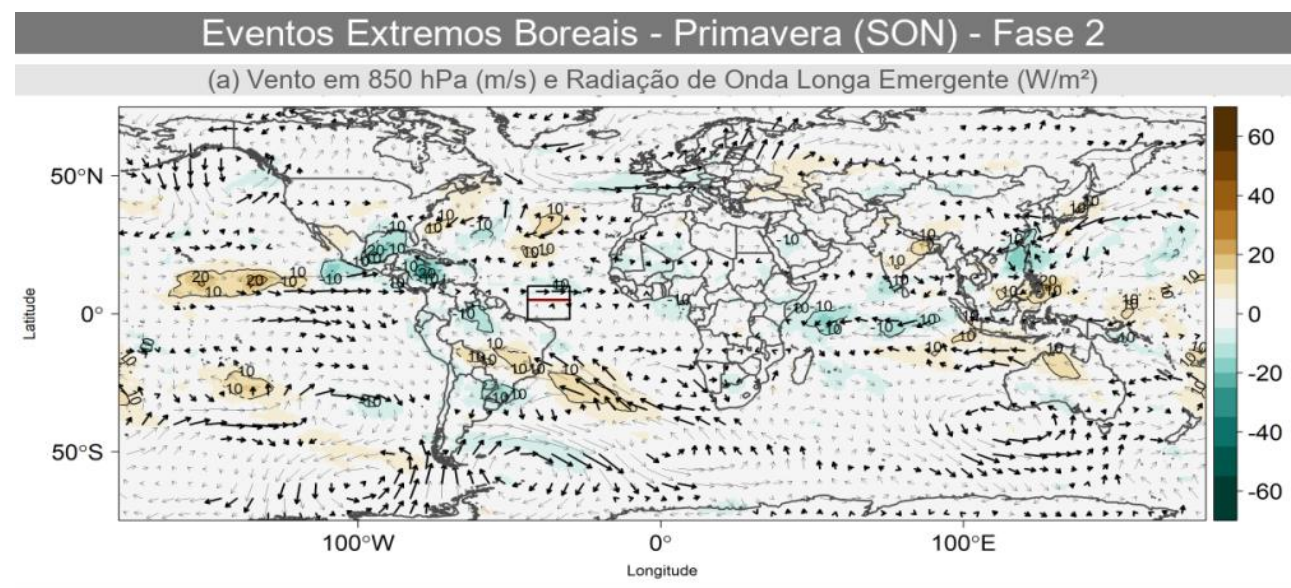

(b) Vento Meridional em $200 \mathrm{hPa}(\mathrm{m} / \mathrm{s})$

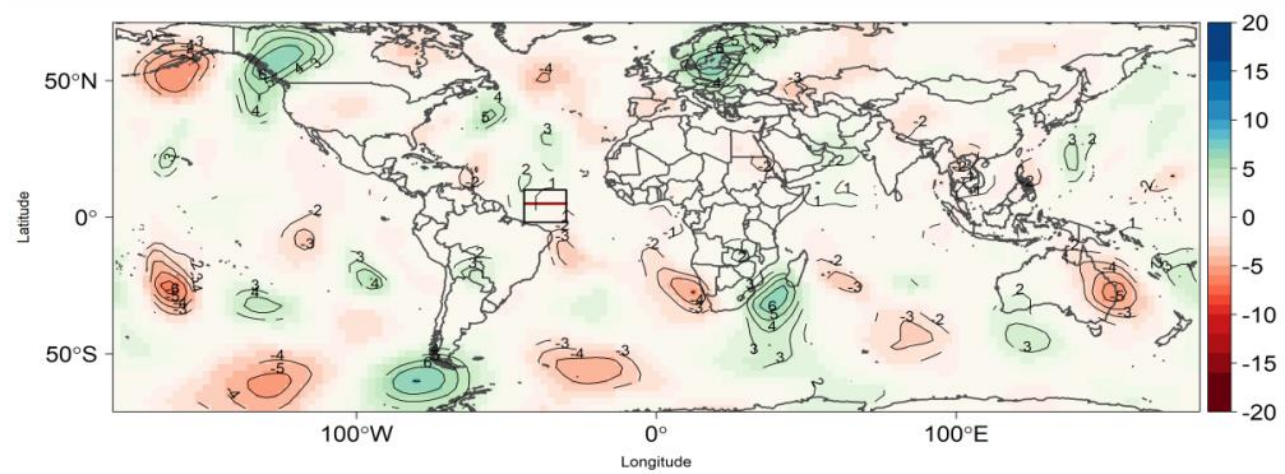

(c) Precipitação Acumulada ( $\mathrm{mm} / \mathrm{dia}$ )

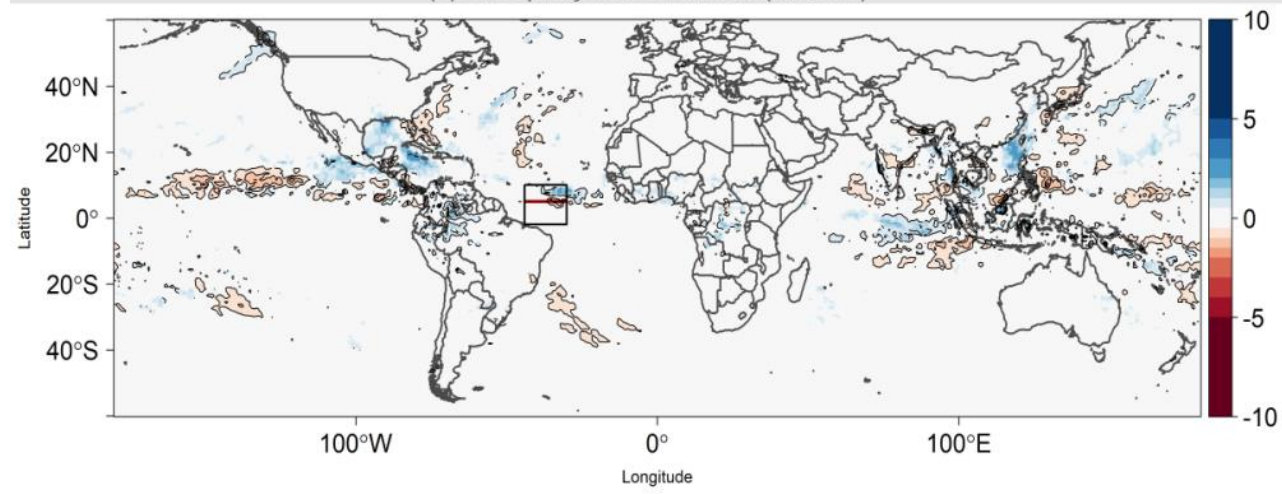

(d) Função de Corrente em $200 \mathrm{hPa}\left(\times 10^{\wedge} 6 \mathrm{~m}^{2} / \mathrm{s}\right)$

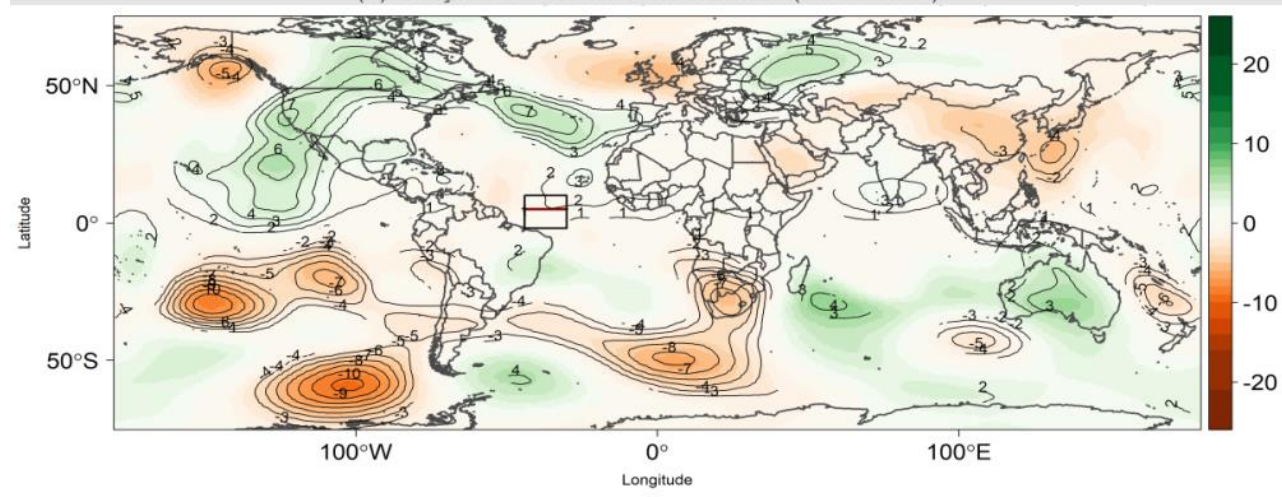

Figura 15 - Idem à Figura 14, porém para fase 2 da OMJ. 


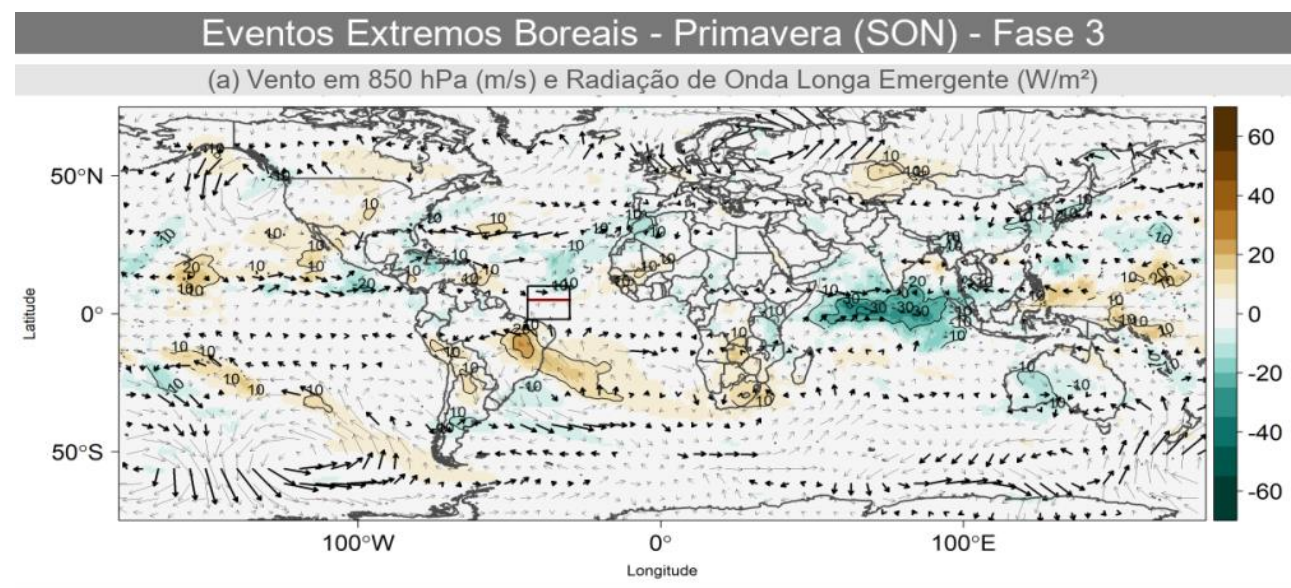

(b) Vento Meridional em $200 \mathrm{hPa}(\mathrm{m} / \mathrm{s})$

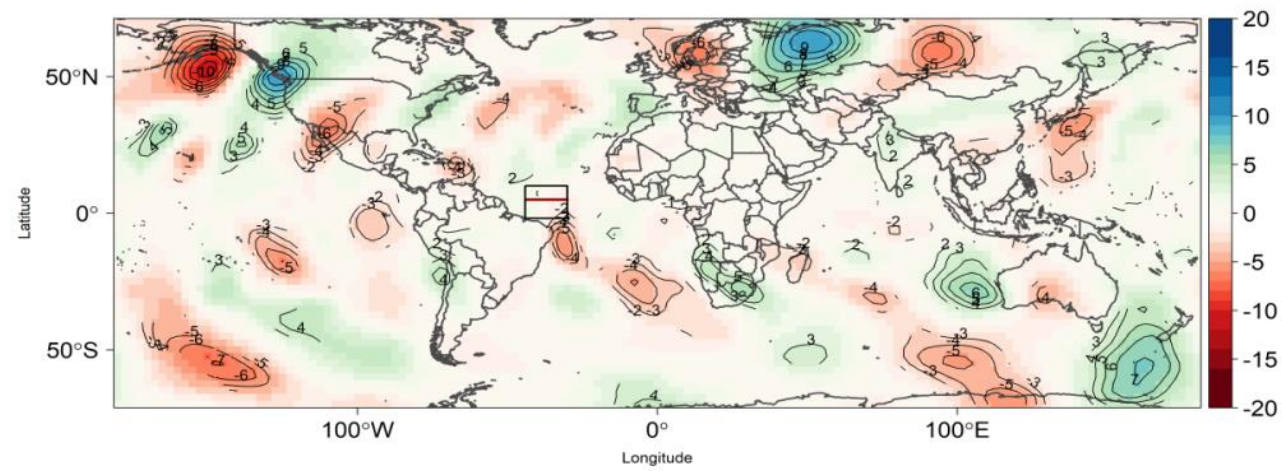

(c) Precipitação Acumulada ( $\mathrm{mm} / \mathrm{dia})$

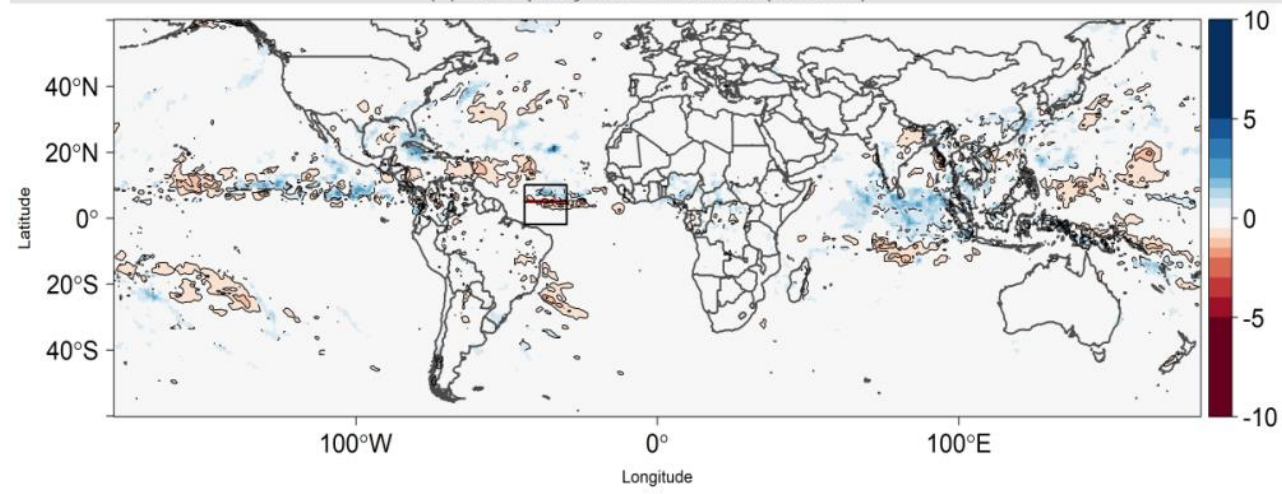

(d) Função de Corrente em $200 \mathrm{hPa}\left(\times 10^{\wedge} 6 \mathrm{~m}^{2} / \mathrm{s}\right)$

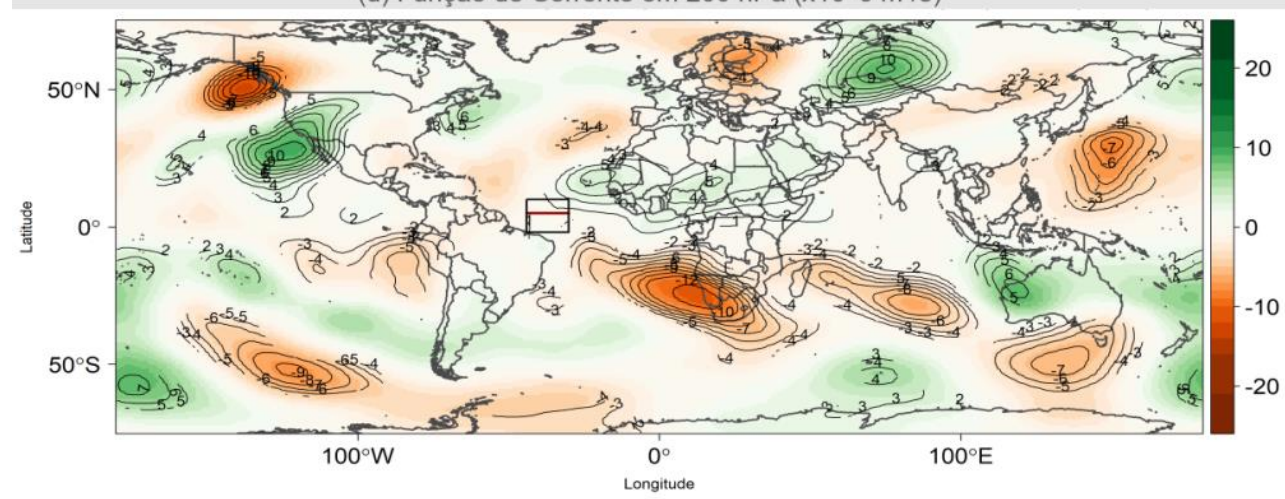

Figura 16 - Idem à Figura 14, porém para fase 3 da OMJ. 


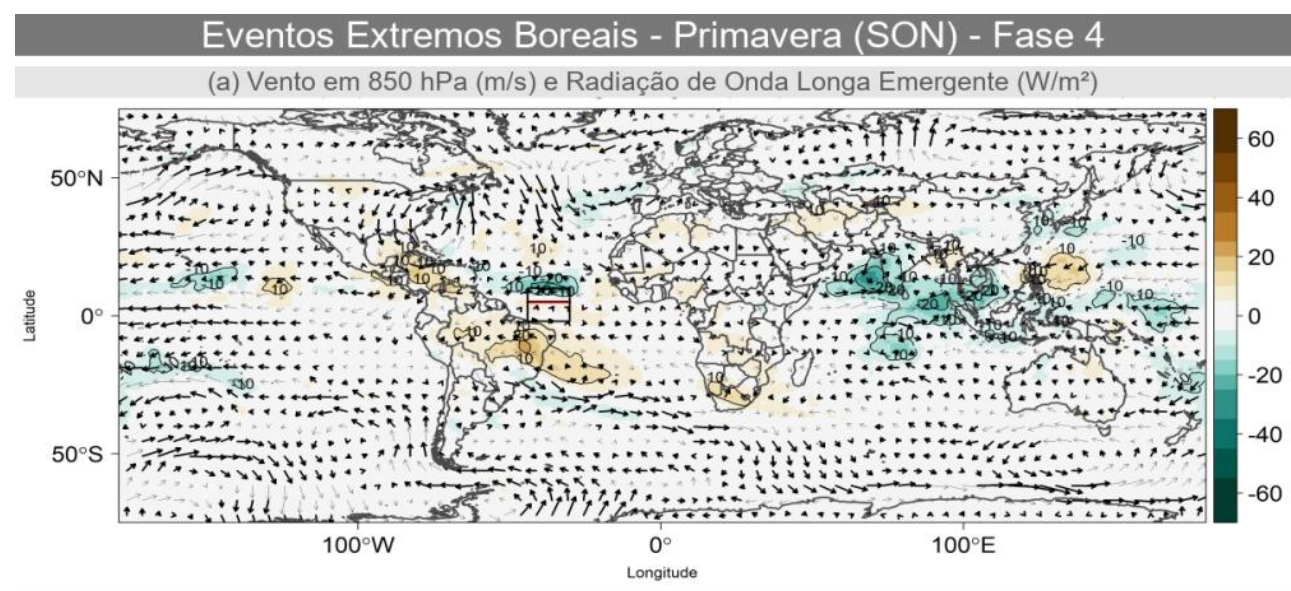

(b) Vento Meridional em $200 \mathrm{hPa}(\mathrm{m} / \mathrm{s})$

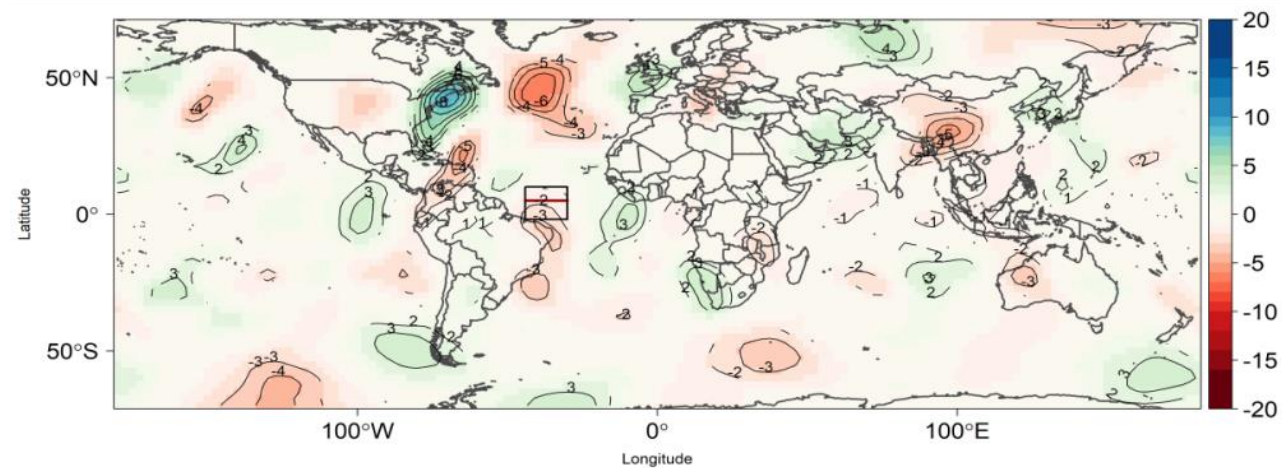

(c) Precipitação Acumulada ( $\mathrm{mm} / \mathrm{dia}$ )

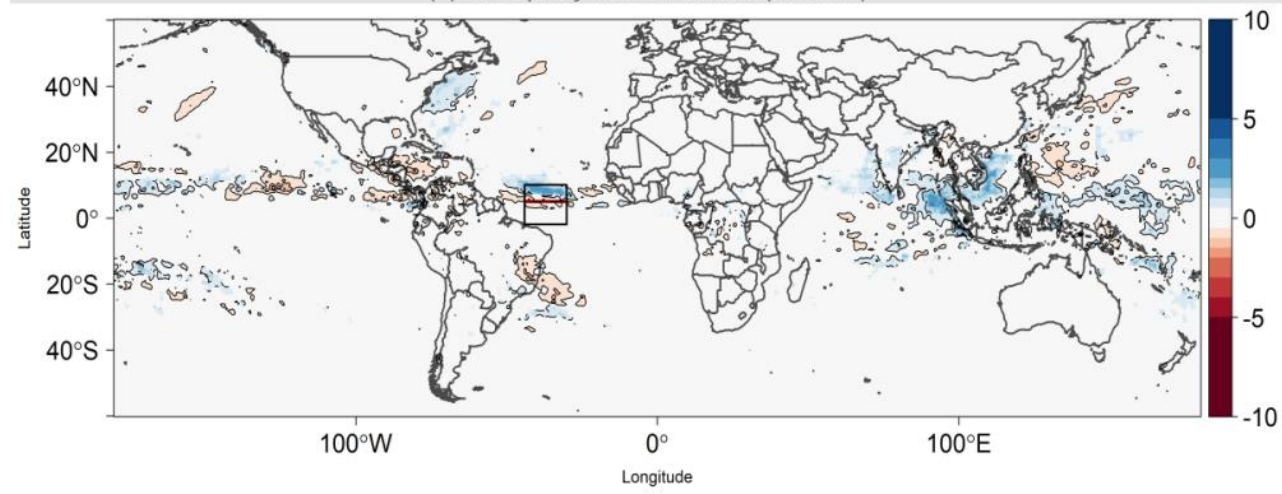

(d) Função de Corrente em $200 \mathrm{hPa}\left(\times 10^{\wedge} 6 \mathrm{~m}^{2} / \mathrm{s}\right)$

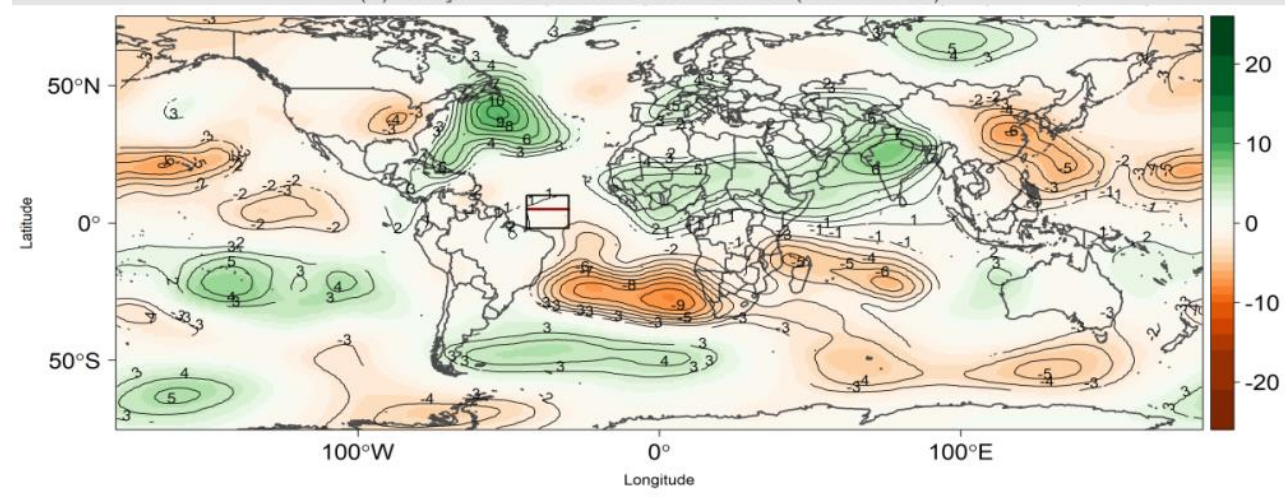

Figura 17 - Idem à Figura 14, porém para fase 4 da OMJ. 


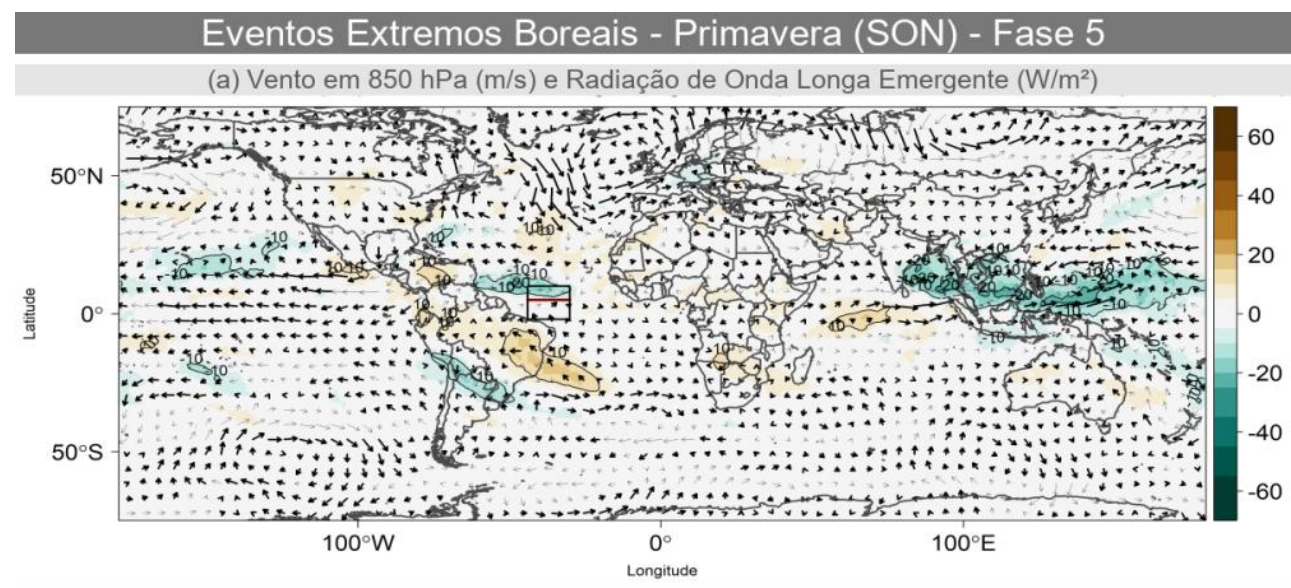

(b) Vento Meridional em $200 \mathrm{hPa}(\mathrm{m} / \mathrm{s})$

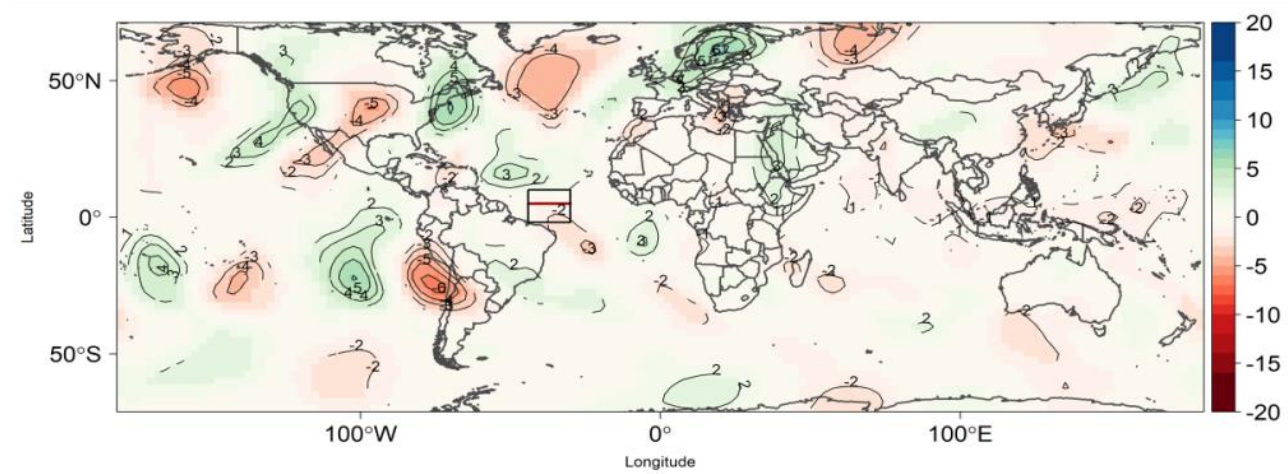

(c) Precipitação Acumulada ( $\mathrm{mm} / \mathrm{dia}$ )

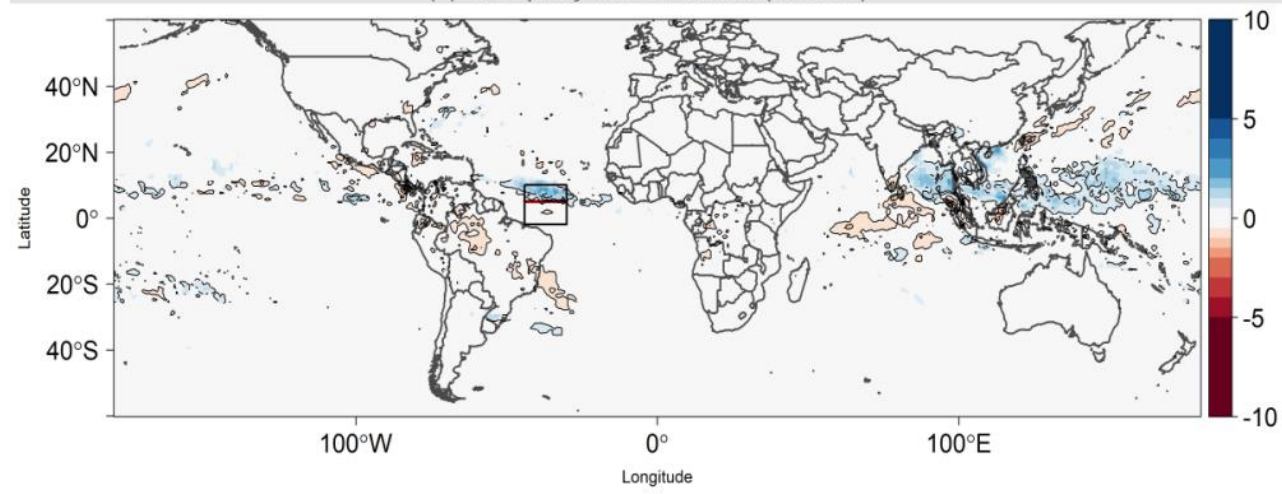

(d) Função de Corrente em $200 \mathrm{hPa}\left(\times 10^{\wedge} 6 \mathrm{~m}^{2} / \mathrm{s}\right)$

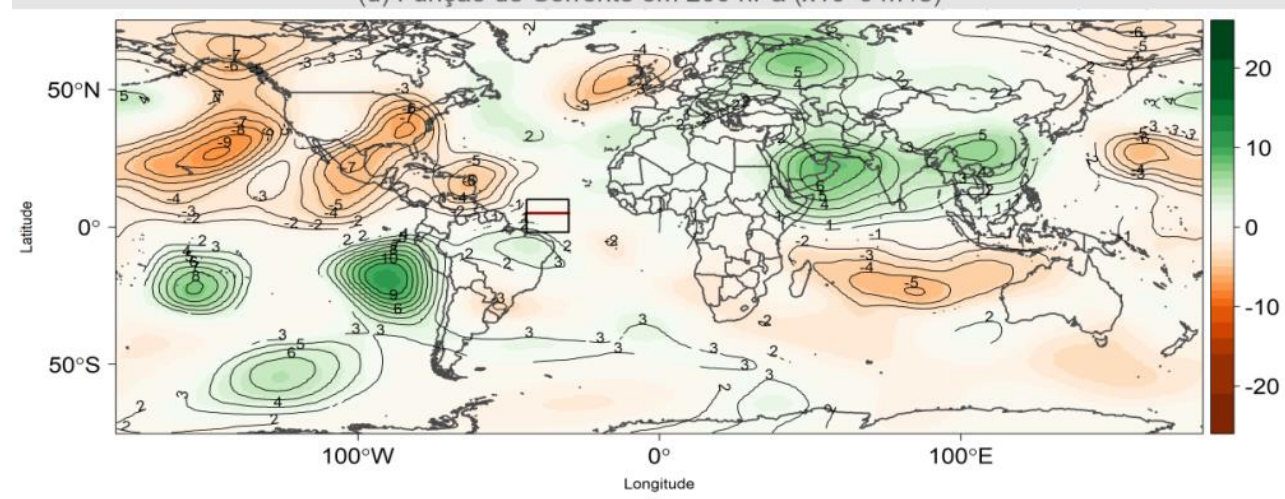

Figura 18 - Idem à Figura 14, porém para fase 5 da OMJ. 


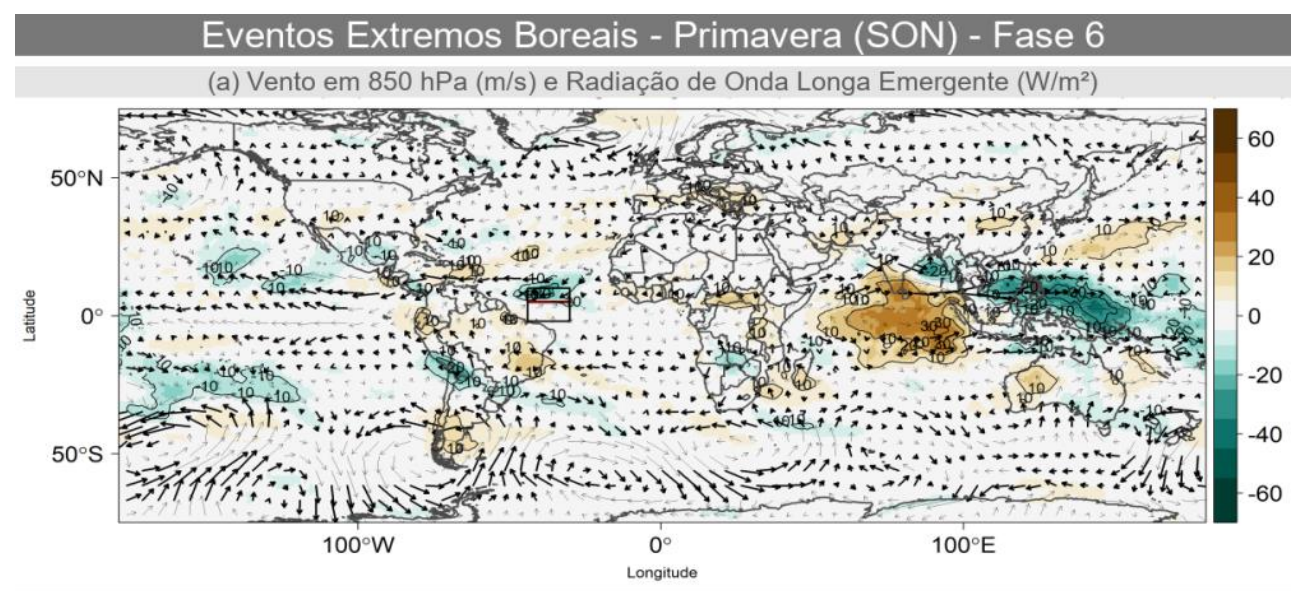

(b) Vento Meridional em $200 \mathrm{hPa}(\mathrm{m} / \mathrm{s})$

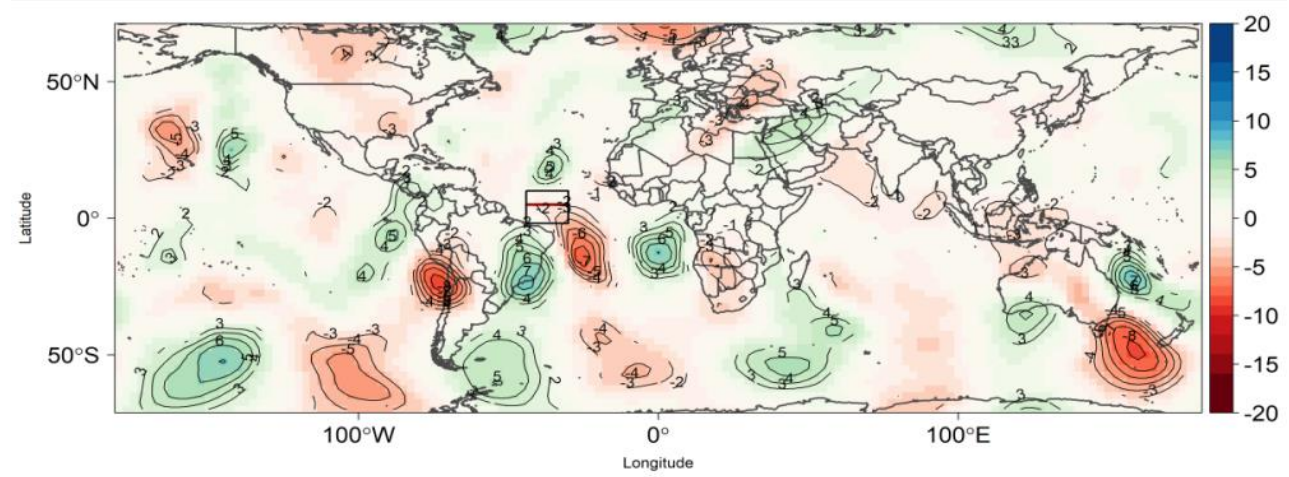

(c) Precipitação Acumulada ( $\mathrm{mm} / \mathrm{dia}$ )

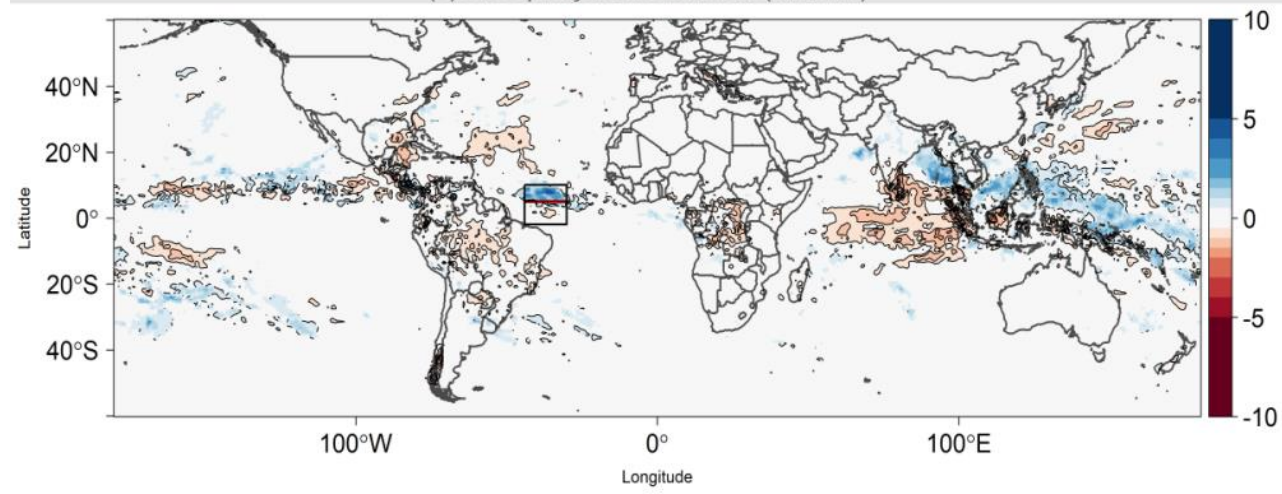

(d) Função de Corrente em $200 \mathrm{hPa}\left(\times 10^{\wedge} 6 \mathrm{~m}^{2} / \mathrm{s}\right)$

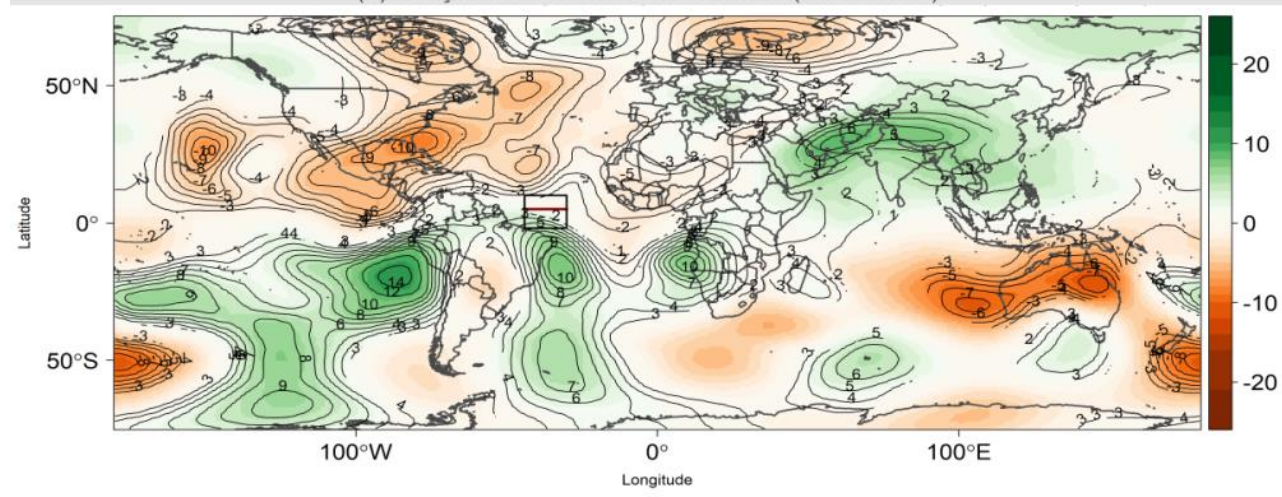

Figura 19 - Idem à Figura 14, porém para fase 6 da OMJ. 

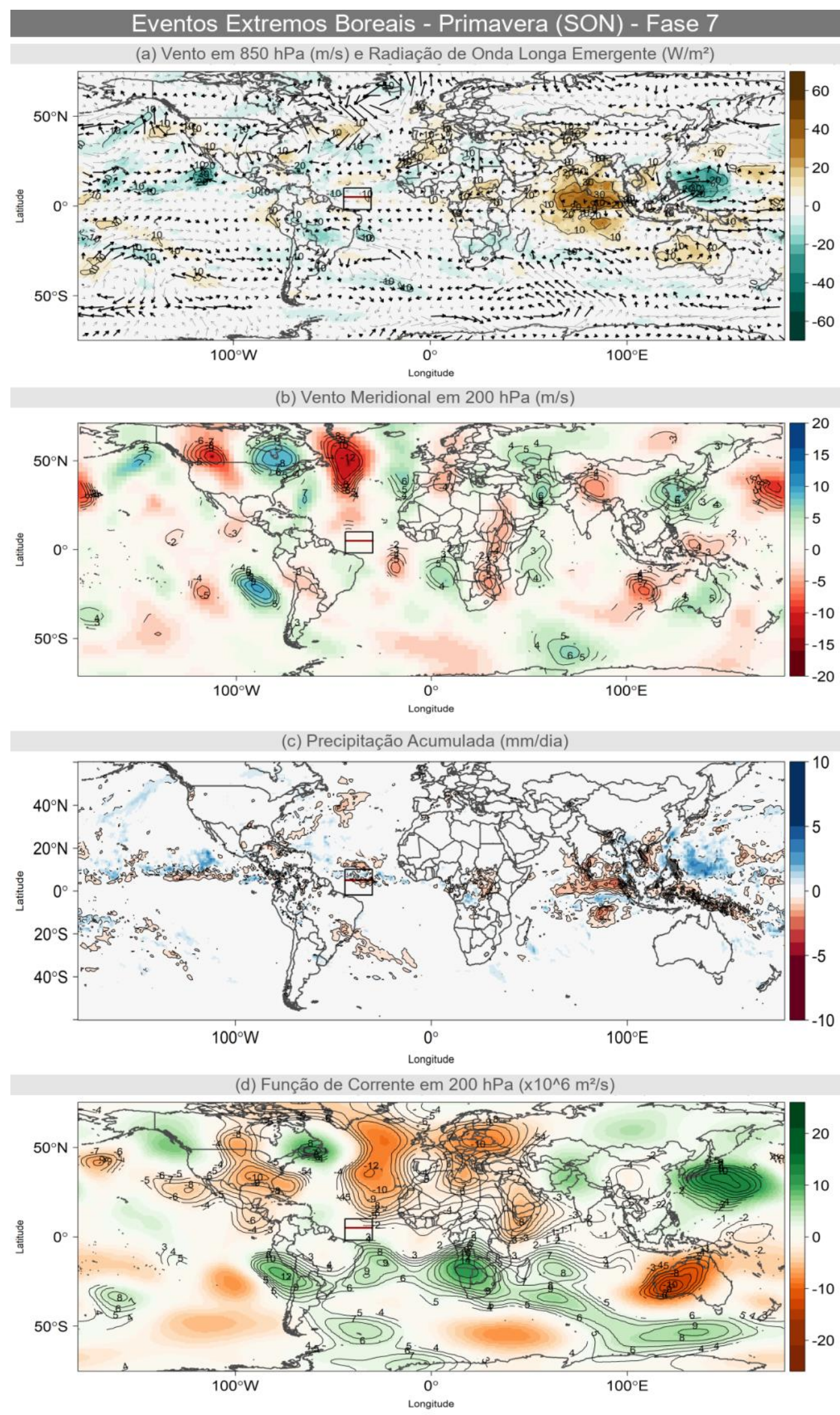

Figura 20 - Idem à Figura 14, porém para fase 7 da OMJ. 


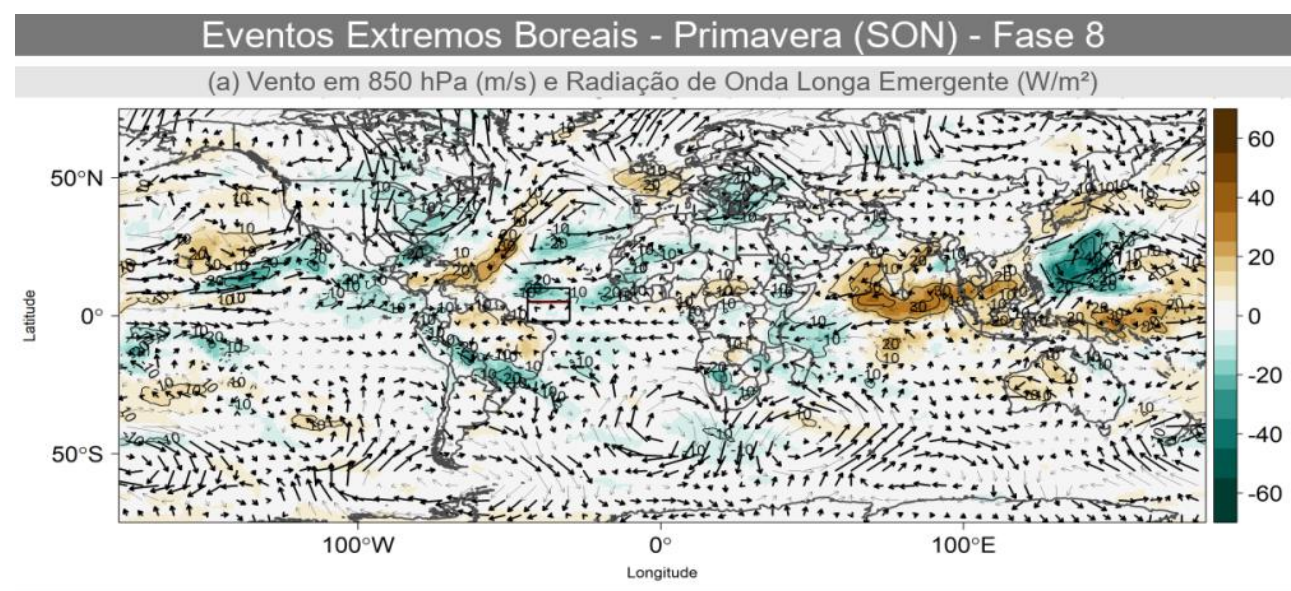

(b) Vento Meridional em $200 \mathrm{hPa}(\mathrm{m} / \mathrm{s})$
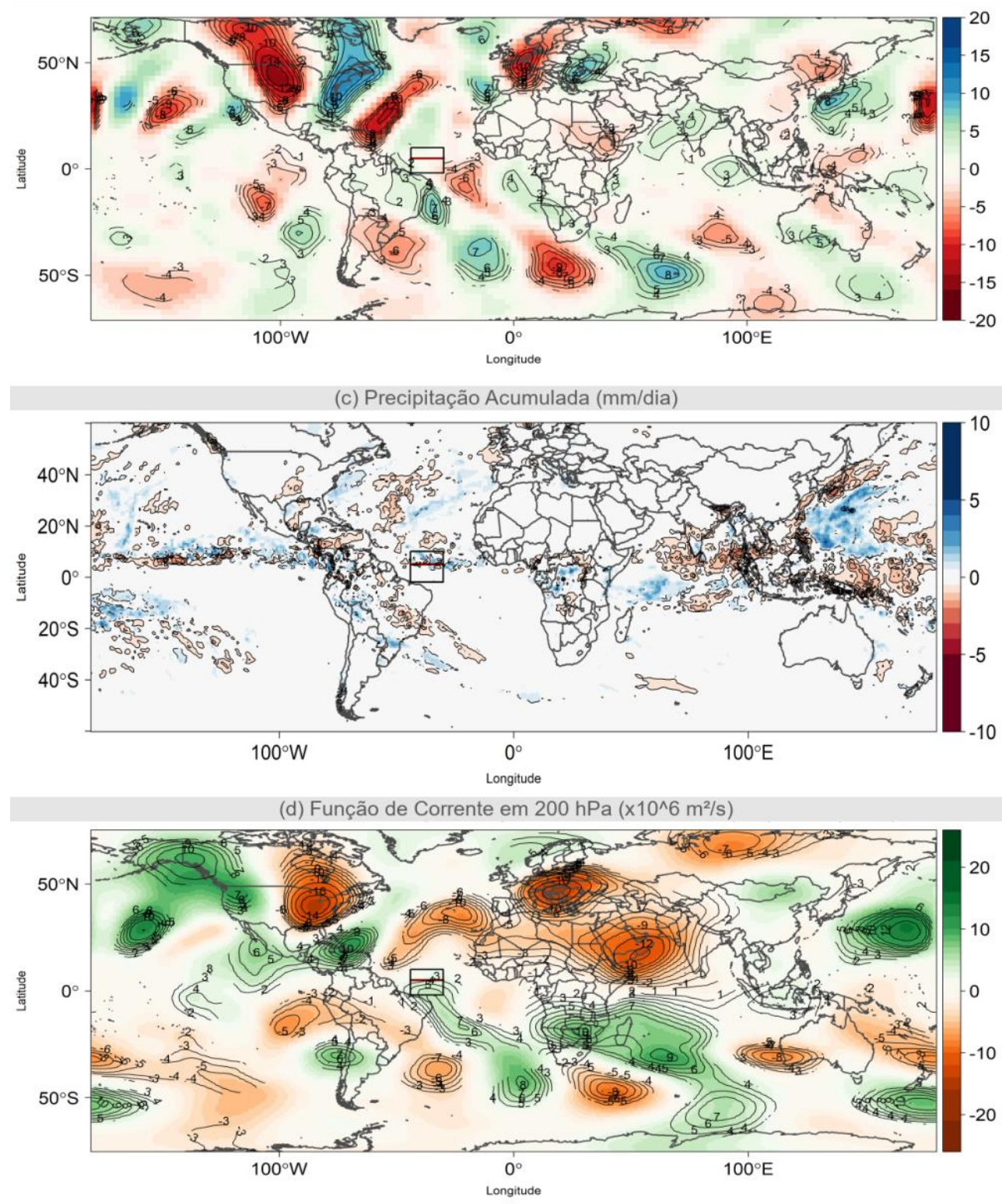

Figura 21 - Idem à Figura 14, porém para fase 8 da OMJ. 


\subsubsection{Extremos austrais}

As discussões e análises acerca das composições calculadas para os eventos extremos austrais na primavera (Figuras 23 a 31) serão mostradas a seguir. O valor do limiar baseado no IZCIT-AO que delimitou a seleção desses casos foi a sul de aproximadamente $4^{\circ} \mathrm{N}$.

A fase 0 (Figura 23) apresenta supressão de convecção a norte do limiar do IZCIT-AO (linha vermelha) através do campo de ROLE (Figura 23a). Os campos em altos níveis (Figuras 23b e 23d) apresentam ainda um desfavorecimento da ASAS (que pode ser constatado no campo de vento da Figura 23a) devido a um padrão ciclônico observado sobre o Atlântico Sul.

Na fase 1 (Figura 24) os campos de vento meridional e função de corrente em altos níveis (Figuras 24b e 24d) mostram um padrão ciclônico sobre o Atlântico Sul, em aproximadamente $20^{\circ} \mathrm{S}$ causado pela propagação de um trem de ondas vindo do Pacífico Sul. Entretanto, em $850 \mathrm{hPa}$ (Figura 24a), pode ser observada uma circulação anticiclônica centrada em aproximadamente $20^{\circ} \mathrm{S}$, o que indica que a estrutura do trem de onda se torna baroclínica à medida que se aproxima do equador. Isso pode ter fortalecido a ASAS e favorecido a convergência de umidade sobre o NE do Brasil. O campo de ROLE (Figura 24a) mostra favorecimento de convecção sobre o NE e litoral norte do Brasil, se estendendo até parte do SE e o Atlântico. Entretanto, não é possível observar claramente um deslocamento da ZCIT-AO para sul do limiar através dos campos de ROLE (Figura 24a) e precipitação (Figura 24c) nessa fase. $O$ padrão de favorecimento e supressão de convecção observado é bem próximo ao esperado para essa fase da OMJ, pois apresenta favorecimento de convecção sobre o Índico tropical e desfavorecimento sobre parte da Indonésia e Pacífico Oeste, além de favorecimento sobre o NE, e parte das Regiões SE e N do Brasil.

A Figura 25 mostra as composições geradas para a fase 2. Nos campos em altos níveis (Figuras 25b e 25d), podemos notar a propagação de um trem de ondas barotópico a partir do Pacífico Sul que segue até o Atlântico Sul. Embebido nesse trem de onda, está o favorecimento de uma circulação anticiclônica sobre parte 
da Região NE do Brasil. Entretanto, os campos de ROLE e precipitação (Figuras 25a e 25 c respectivamente) não mostram favorecimento de convecção ou anomalia positiva de precipitação a sul do limiar. Ainda no campo de ROLE (Figura 25a), observamos favorecimento de convecção sobre a Região SE do Brasil e supressão sobre a faixa oeste da Região Central e extremo sul do país.

As composições para as fases 3 e 4 (Figuras 26 e 27) mostram um favorecimento de circulação anticiclônica em altos (Figuras 26b, 26c, 27b e 27c) e baixos níveis (Figuras 26a e 27a) sobre o Atlântico Norte embebido na propagação de um trem de onda a partir do Pacífico equatorial, o que intensifica a ASAN. Com isso, há um deslocamento da ZCIT-AO para sul, pois os alísios de nordeste se intensificam, como já mencionado anteriormente. Em todas as fases, os campos de ROLE (Figuras 26a e 27a) mostram supressão da convecção a norte do limiar. Na fase 4 (Figura 27), há favorecimento de convecção (Figura 27a) sobre a faixa leste da Região SE do Brasil, o que não é esperado quando a OMJ se encontra nessa fase pois, segundo Jones (2009), as Regiões N, NE e SE do Brasil apresentam supressão de convecção na fase 4.

A propagação de um trem de ondas na fase 5 (Figura 28) pode ser observada nos campos de baixos e altos níveis (Figuras 28a, 28b e 28d). Esse padrão encontra-se a partir do Pacífico equatorial Oeste e segue até o Atlântico Sul (Figura 28d), onde favorece a ASAS localizada sobre o Atlântico em aproximadamente $20^{\circ} \mathrm{S}$. Os campos de ROLE (Figura 28a) e precipitação (Figura 28c) apresentam, respectivamente, supressão de convecção e anomalias negativas de precipitação a norte do limiar, mas não apresentam valores claros positivos ou negativos a sul do mesmo, o que impede a definição clara do posicionamento da ZCIT-AO.

As Figuras 29, 30 e 31 mostram os campos gerados para as fases 6, 7 e 8 da OMJ. Nesses casos há favorecimento de circulação ciclônica sobre o Atlântico Sul, o que desfavorece a ASAS e pode ter contribuído para o deslocamento da ZCIT-AO para sul, ficando a sul do limiar estabelecido. Além disso, os campos de ROLE (Figuras 29a, 30a e 31a) mostram favorecimento de convecção a sul do limiar do índice em todas as fases. Na fase 6 (Figura 29) o campo de ROLE (Figura 29a) mostra 
favorecimento de convecção sobre parte das Regiões SE e CO, na fase 7 (Figura 30) há favorecimento sobre a região SE e na fase 8 (Figura 31) há favorecimento sobre parte das Regiões NE e SE. O favorecimento de convecção sobre o Brasil nessas fases está de acordo com os padrões definidos pela literatura (JONES, 2009), com desfavorecimento de convecção sobre NE na fase 6 e favorecimento de convecção sobre SE e parte do NE nas fases 7 e 8. 

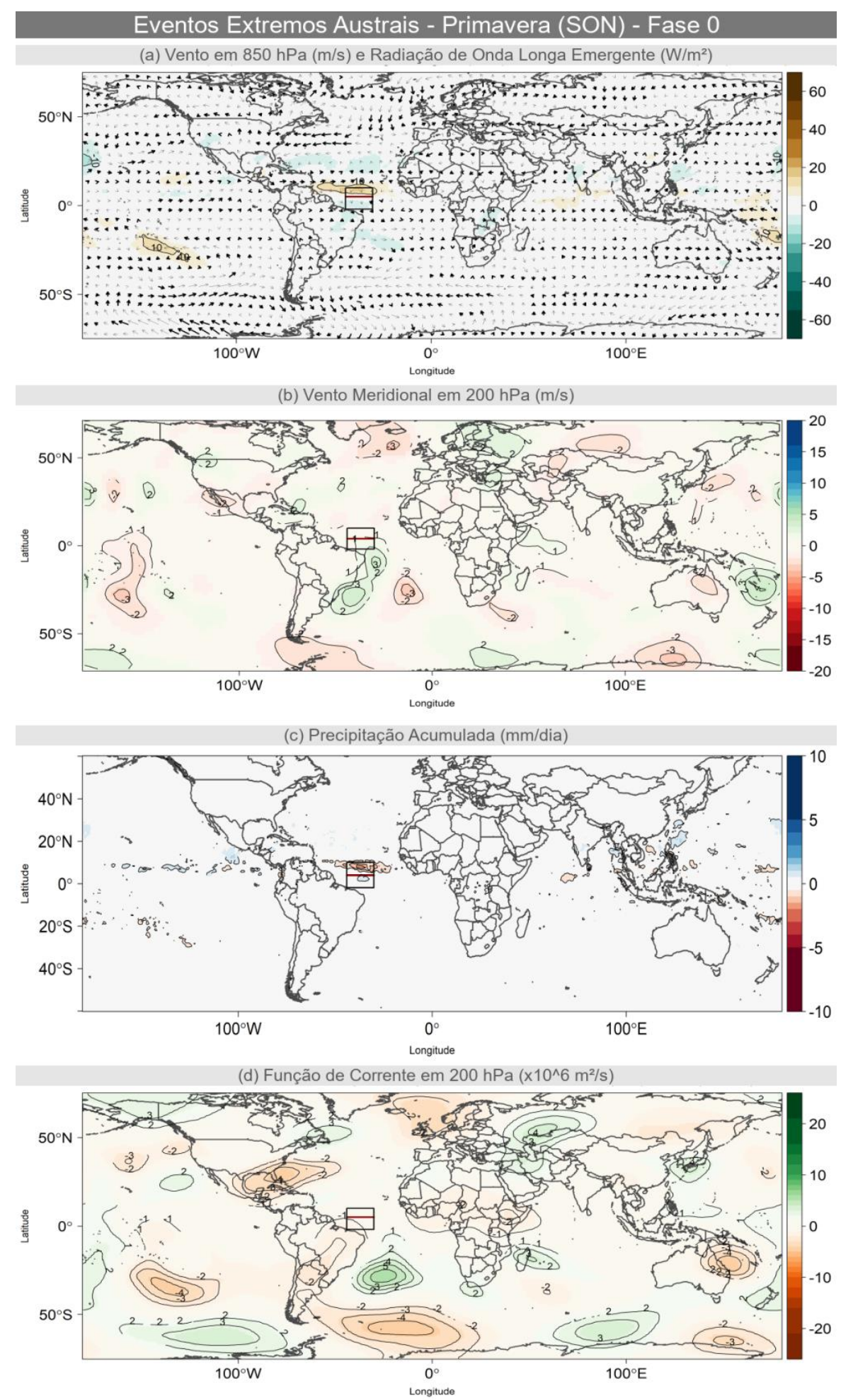

Figura 22 - Composições para os eventos extremos austrais para a Primavera (SON) e fase 0 da OMJ das anomalias de (a) vento em $850 \mathrm{hPa}\left({ }^{*} 100 \mathrm{~m} / \mathrm{s}\right.$ ) e ROLE $\left(\mathrm{W} / \mathrm{m}^{2}\right)$, (b) vento meridional em $200 \mathrm{hPa}$ (m/s), (c) precipitação (mm/dia) e (d) função de corrente em $200 \mathrm{hPa}$ $\left(\mathrm{x} 10^{\wedge} 6 \mathrm{~m}^{2} / \mathrm{s}\right)$. A caixa preta representa a Região de Estudo e a linha vermelha representa 0 percentil (limiar) do IZCIT-AO para esse caso. Os vetores em negrito e as áreas contornadas representam significância estatística ao nível de 5\%. 


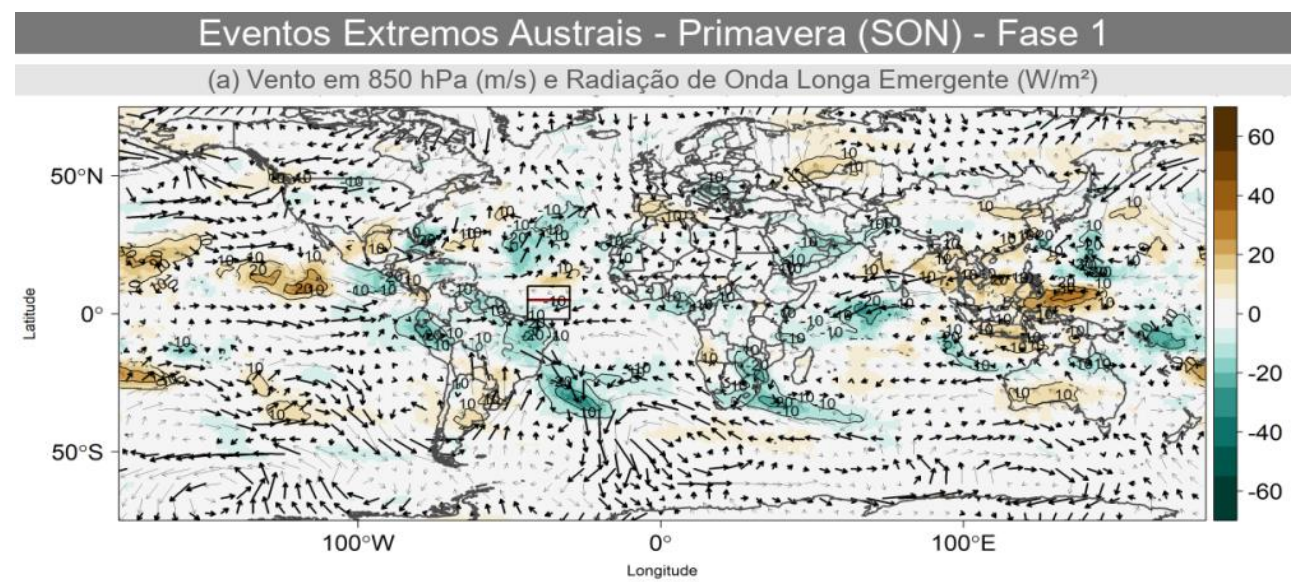

(b) Vento Meridional em $200 \mathrm{hPa}(\mathrm{m} / \mathrm{s})$

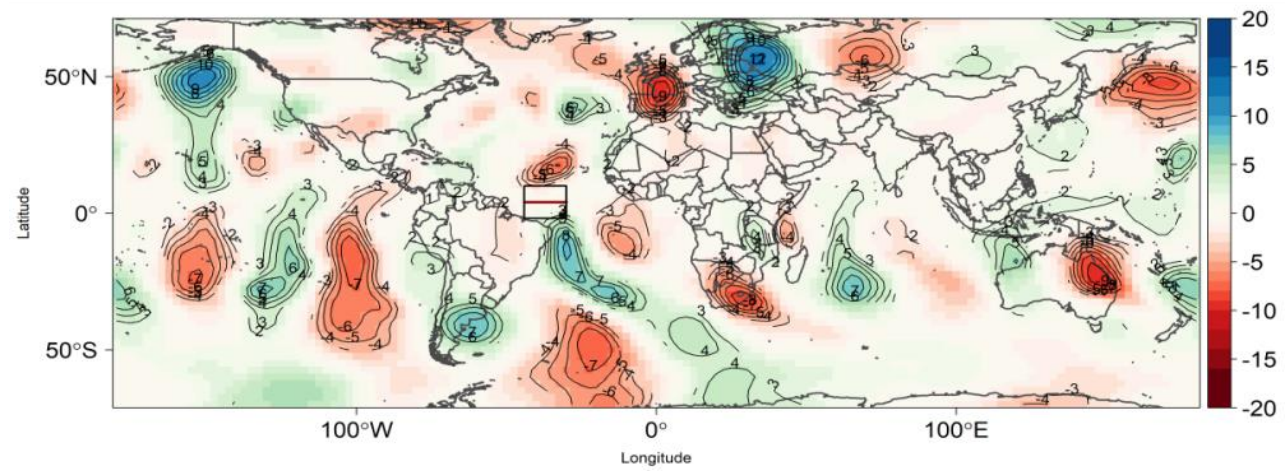

(c) Precipitação Acumulada ( $\mathrm{mm} / \mathrm{dia}$ )

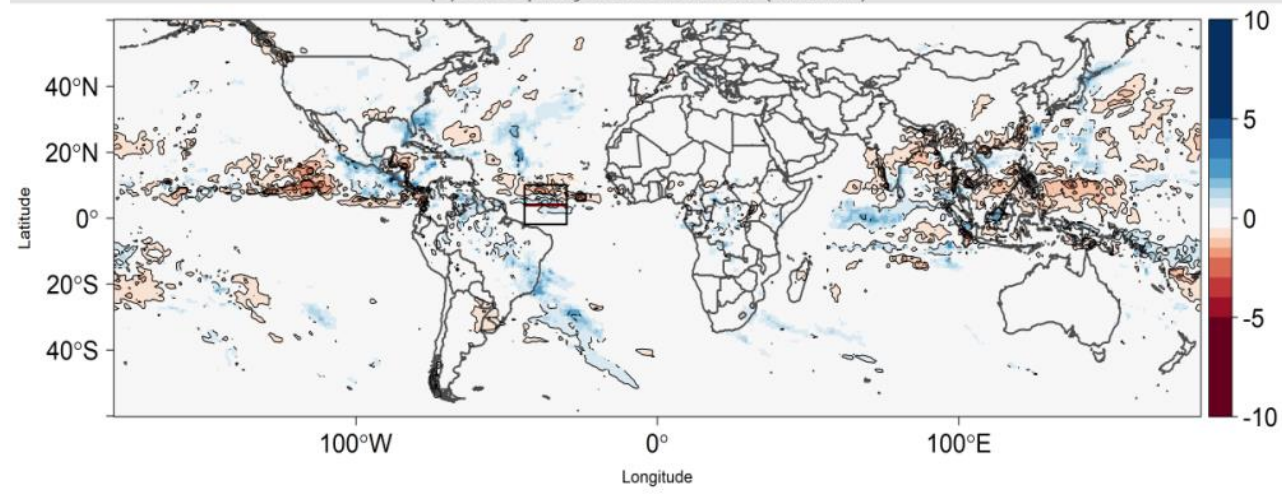

(d) Função de Corrente em $200 \mathrm{hPa}\left(\times 10^{\wedge} 6 \mathrm{~m}^{2} / \mathrm{s}\right)$

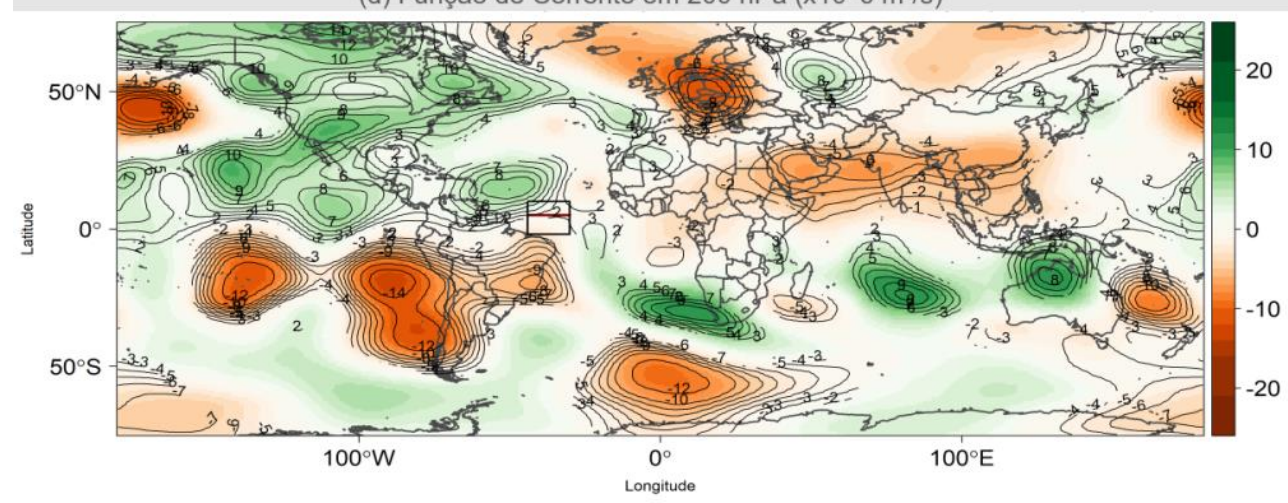

Figura 23 - Idem à Figura 23, porém para fase 1 da OMJ. 


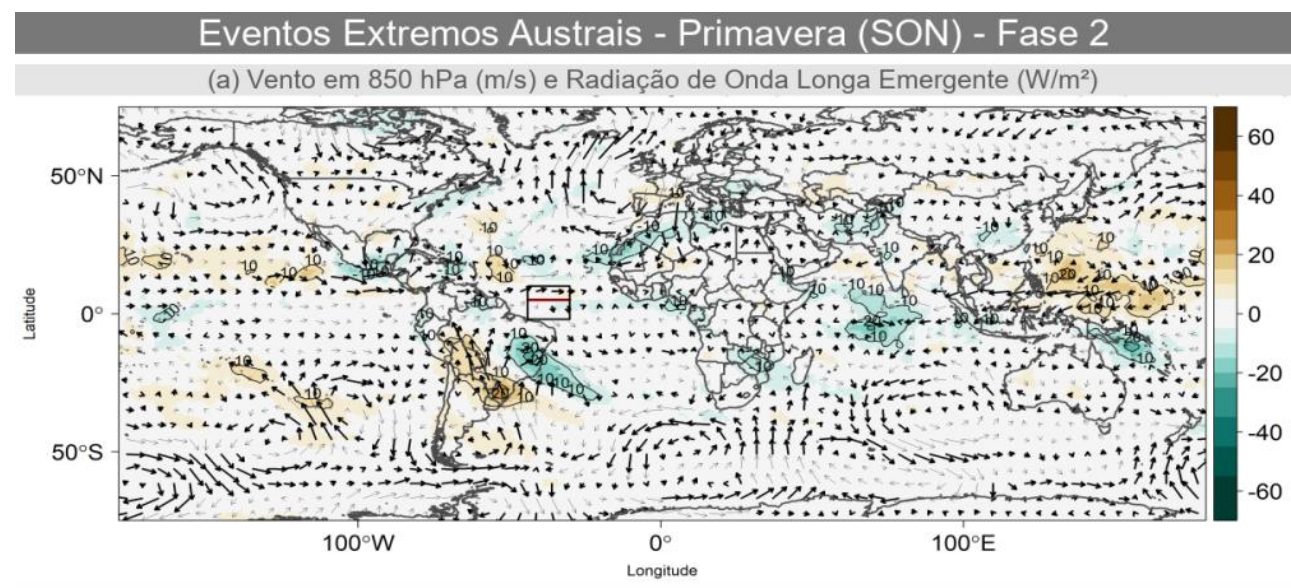

(b) Vento Meridional em $200 \mathrm{hPa}(\mathrm{m} / \mathrm{s})$

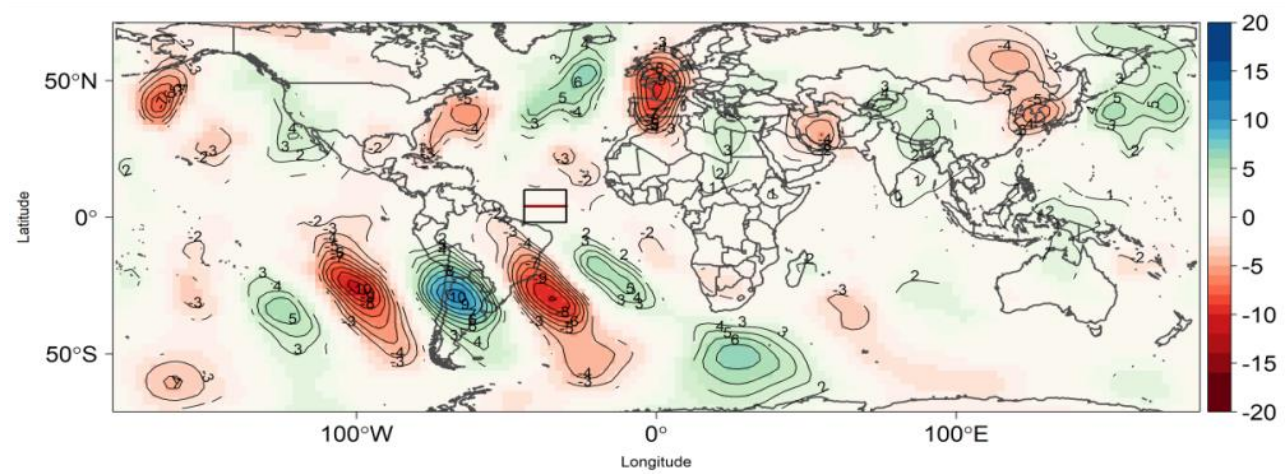

(c) Precipitação Acumulada ( $\mathrm{mm} / \mathrm{dia}$ )

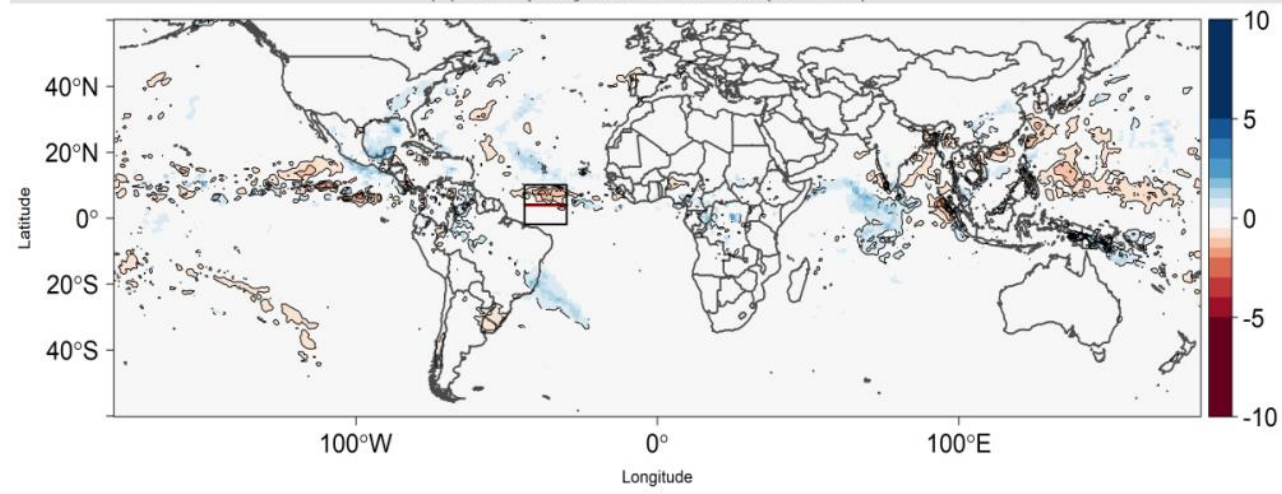

(d) Função de Corrente em $200 \mathrm{hPa}\left(\times 10^{\wedge} 6 \mathrm{~m}^{2} / \mathrm{s}\right)$

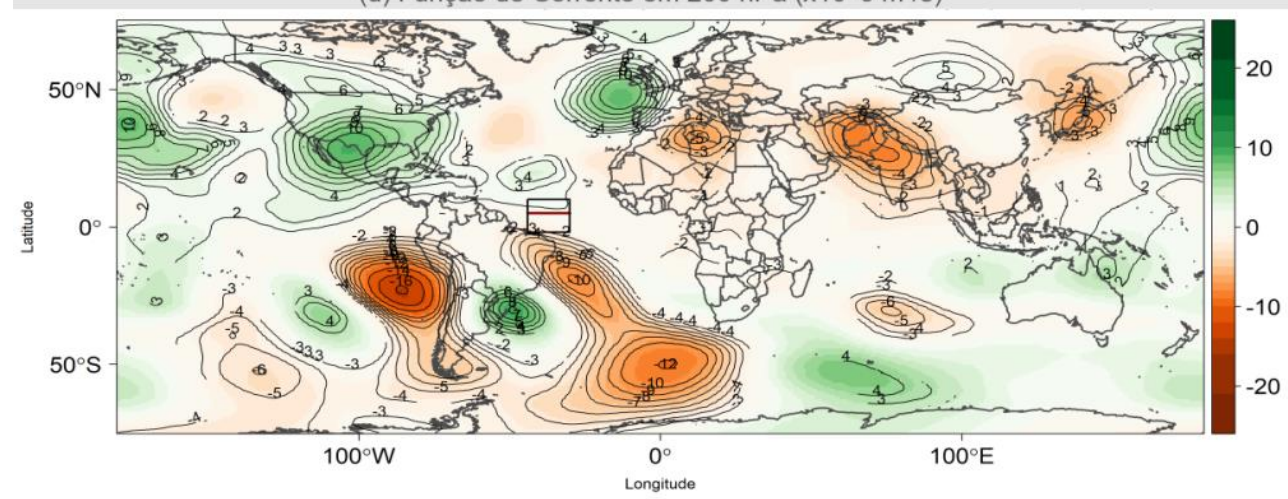

Figura 24 - Idem à Figura 23, porém para fase 2 da OMJ. 


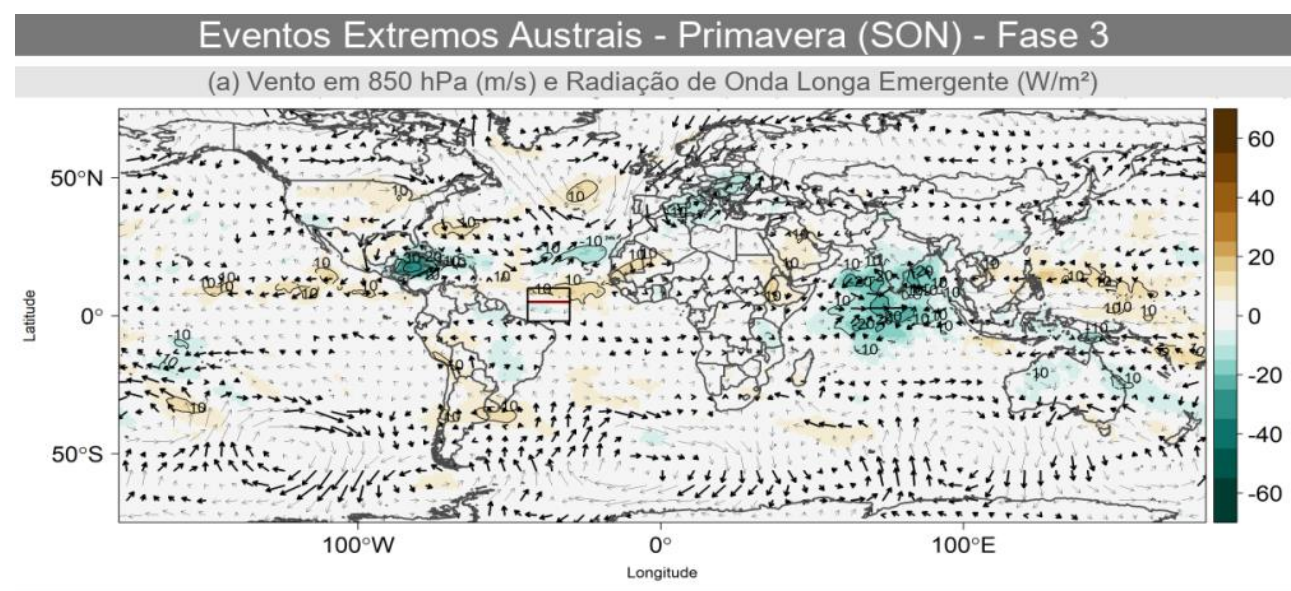

(b) Vento Meridional em $200 \mathrm{hPa}(\mathrm{m} / \mathrm{s})$

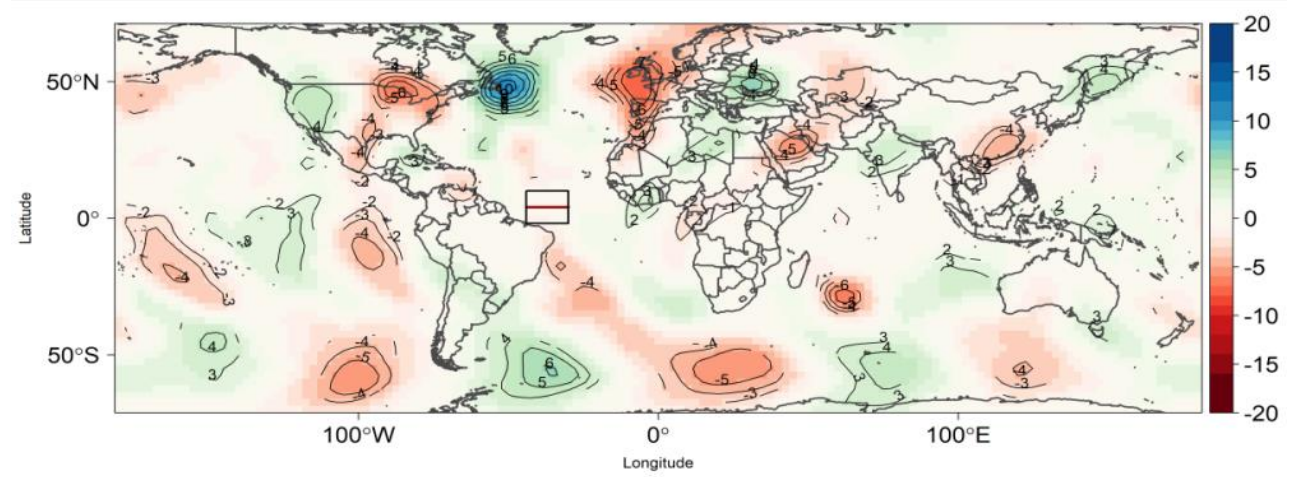

(c) Precipitação Acumulada ( $\mathrm{mm} / \mathrm{dia}$ )

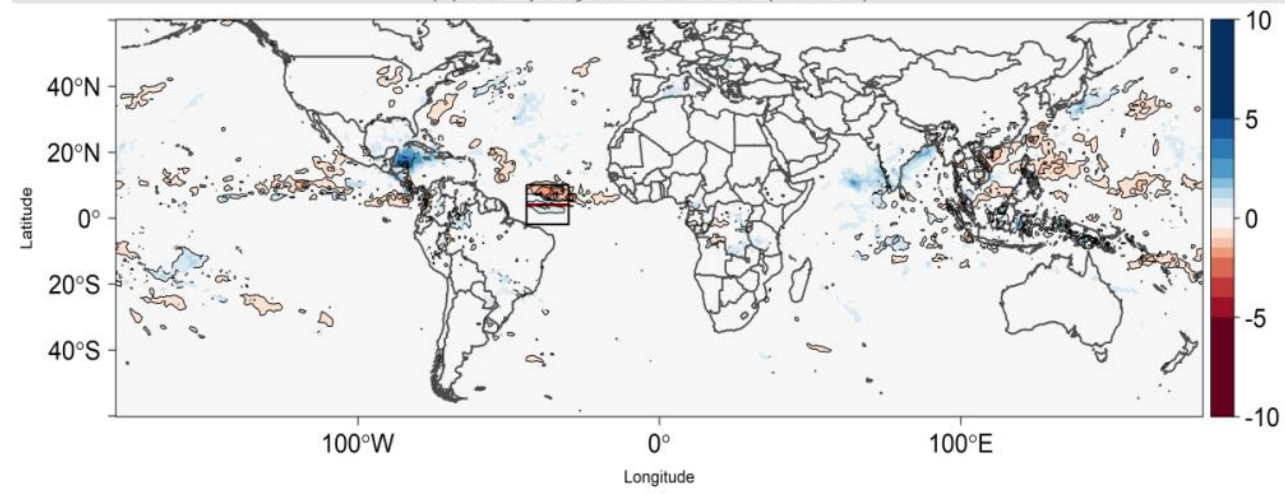

(d) Função de Corrente em $200 \mathrm{hPa}\left(\times 10^{\wedge} 6 \mathrm{~m}^{2} / \mathrm{s}\right)$

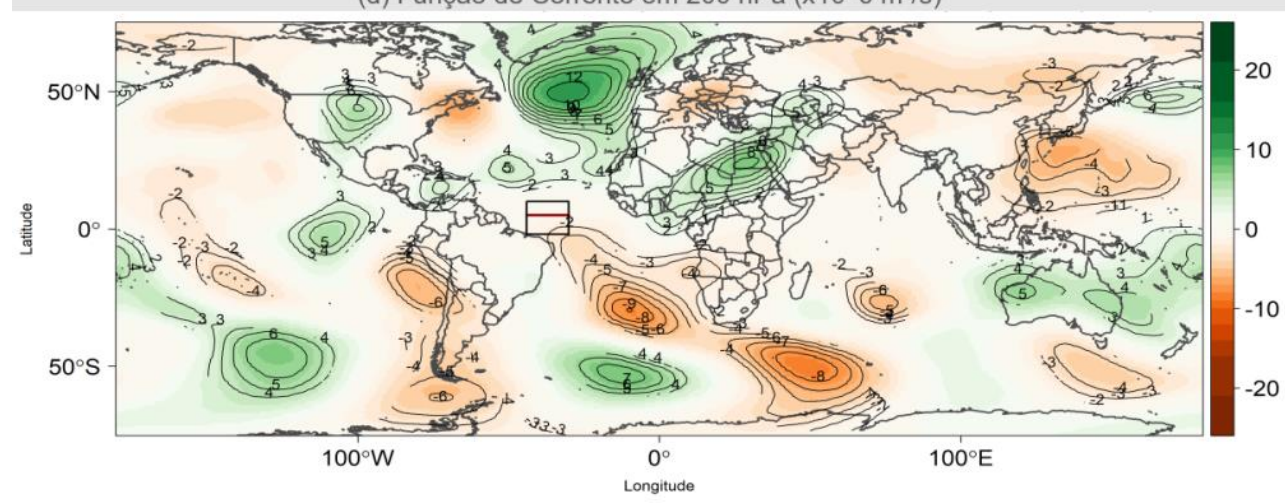

Figura 25 - Idem à Figura 23, porém para fase 3 da OMJ. 


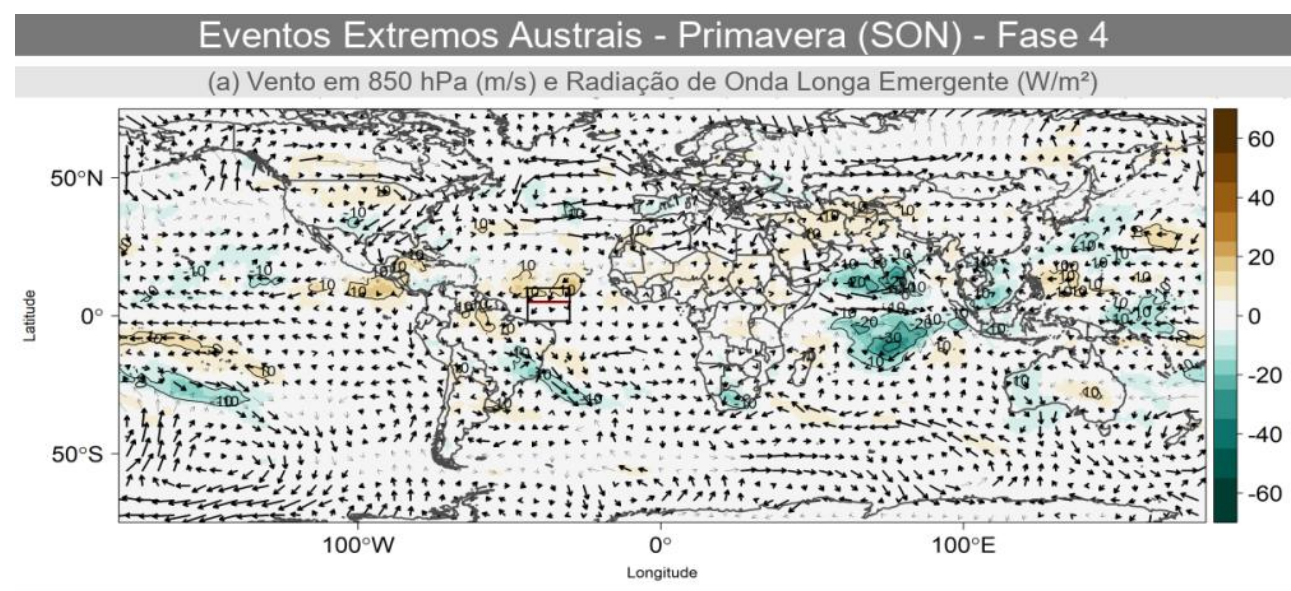

(b) Vento Meridional em $200 \mathrm{hPa}(\mathrm{m} / \mathrm{s})$

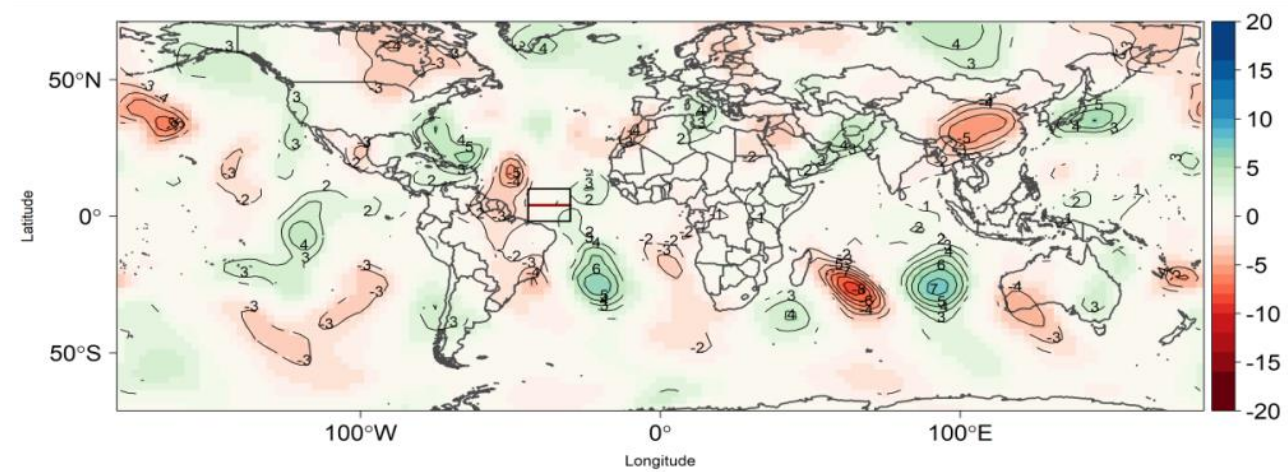

(c) Precipitação Acumulada ( $\mathrm{mm} / \mathrm{dia}$ )

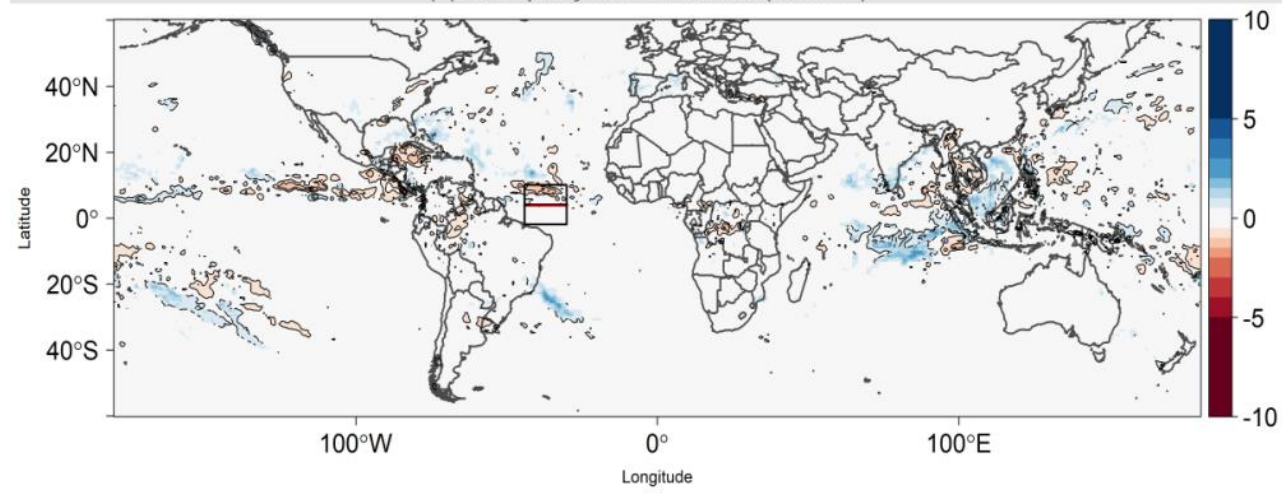

(d) Função de Corrente em $200 \mathrm{hPa}\left(\times 10^{\wedge} 6 \mathrm{~m}^{2} / \mathrm{s}\right)$

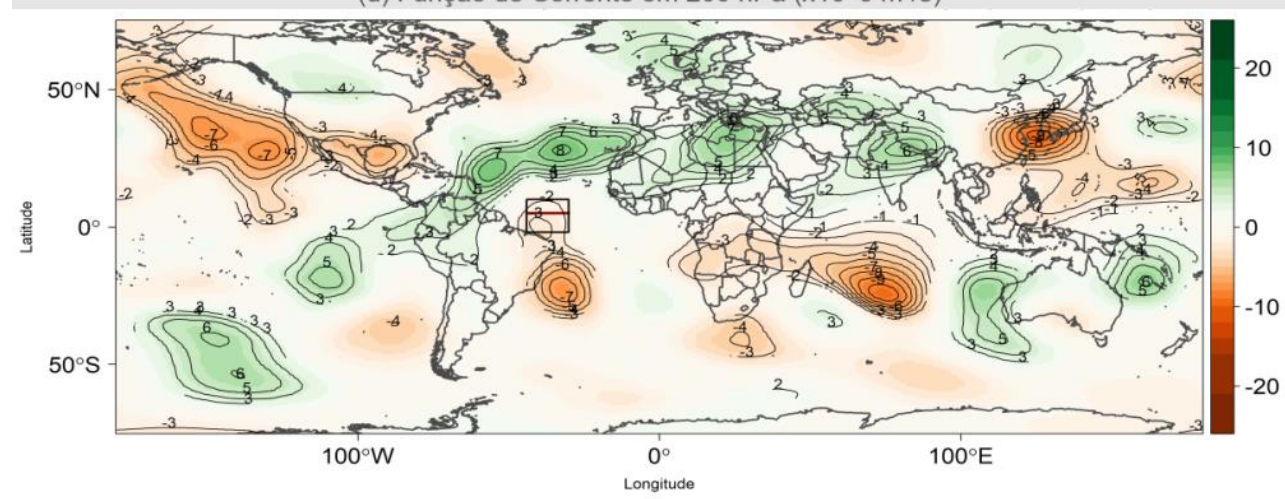

Figura 26 - Idem à Figura 23, porém para fase 4 da OMJ. 


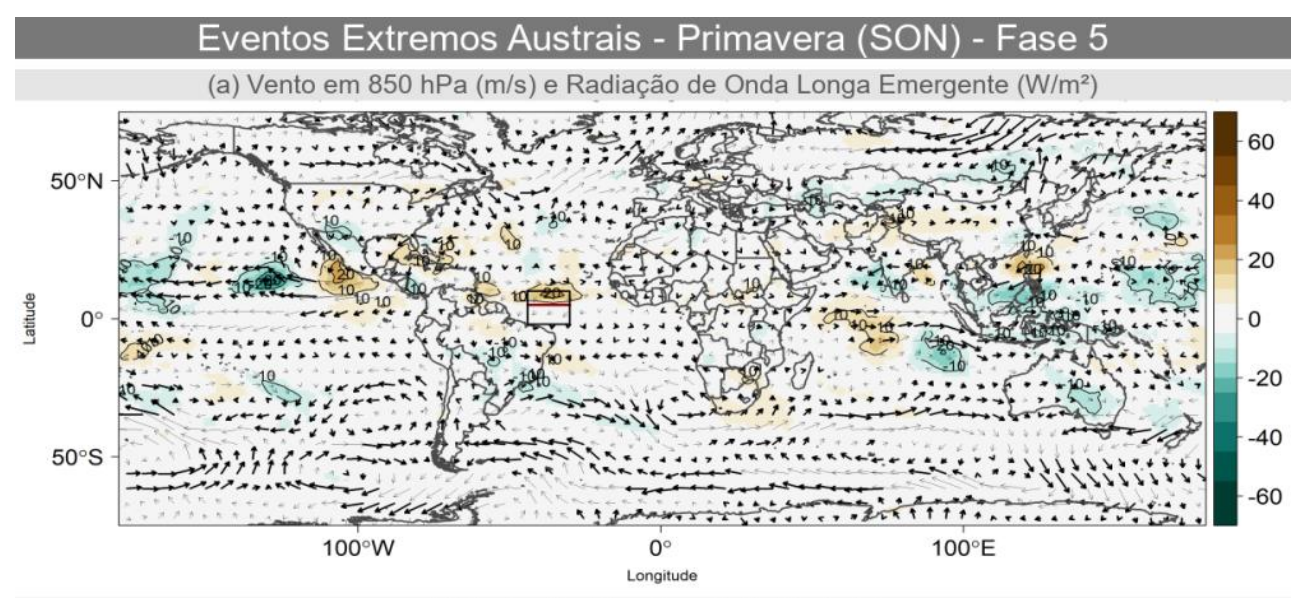

(b) Vento Meridional em $200 \mathrm{hPa}(\mathrm{m} / \mathrm{s})$

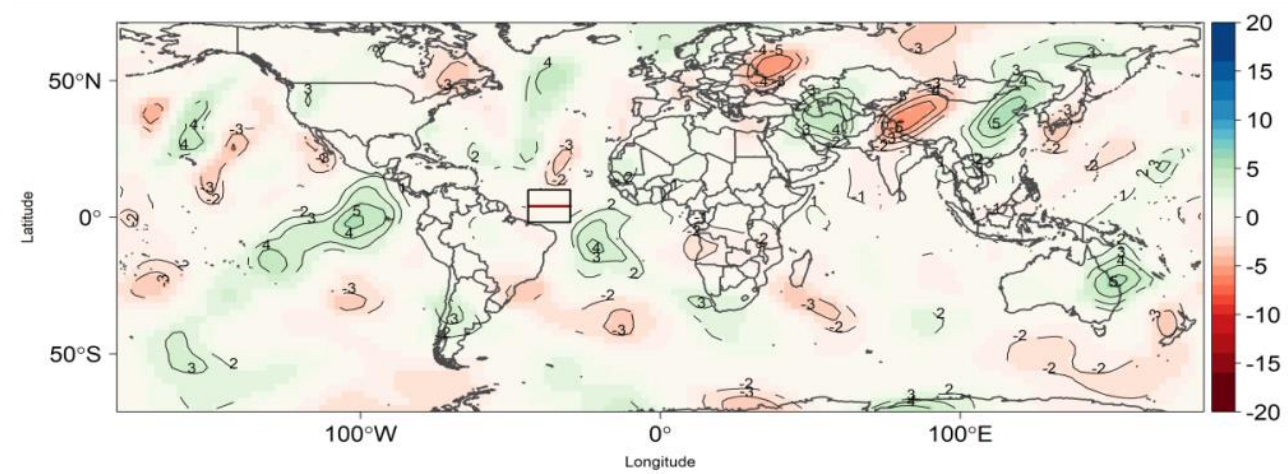

(c) Precipitação Acumulada ( $\mathrm{mm} / \mathrm{dia}$ )

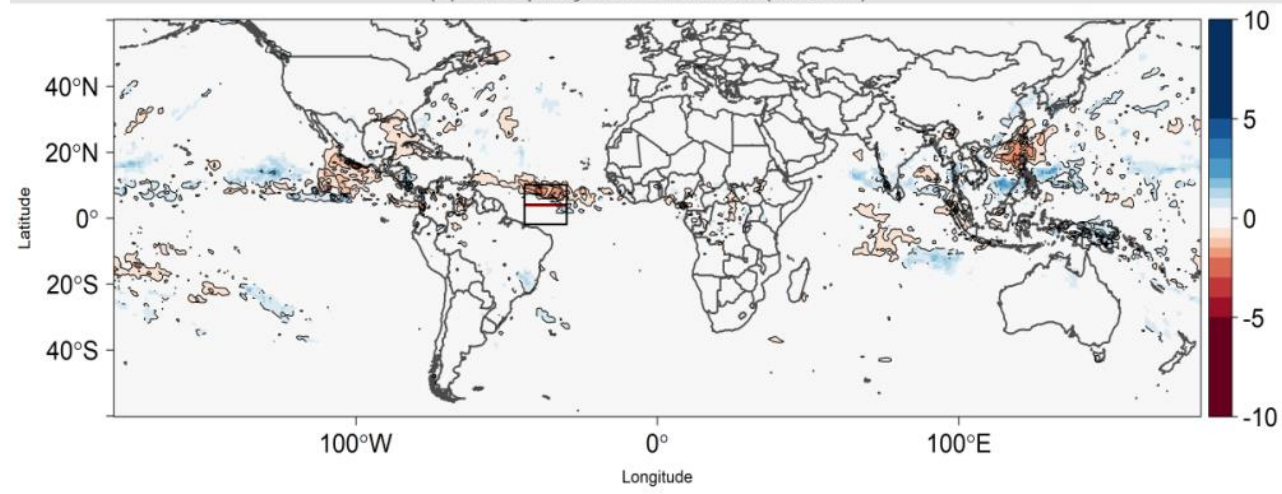

(d) Função de Corrente em $200 \mathrm{hPa}\left(\times 10^{\wedge} 6 \mathrm{~m}^{2} / \mathrm{s}\right)$

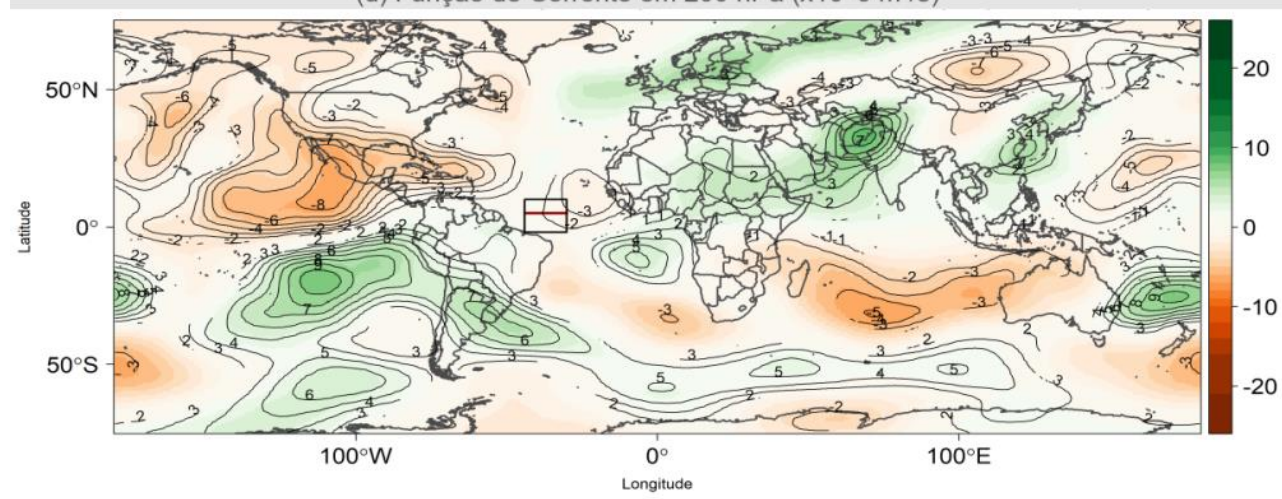

Figura 27 - Idem à Figura 23, porém para fase 5 da OMJ. 


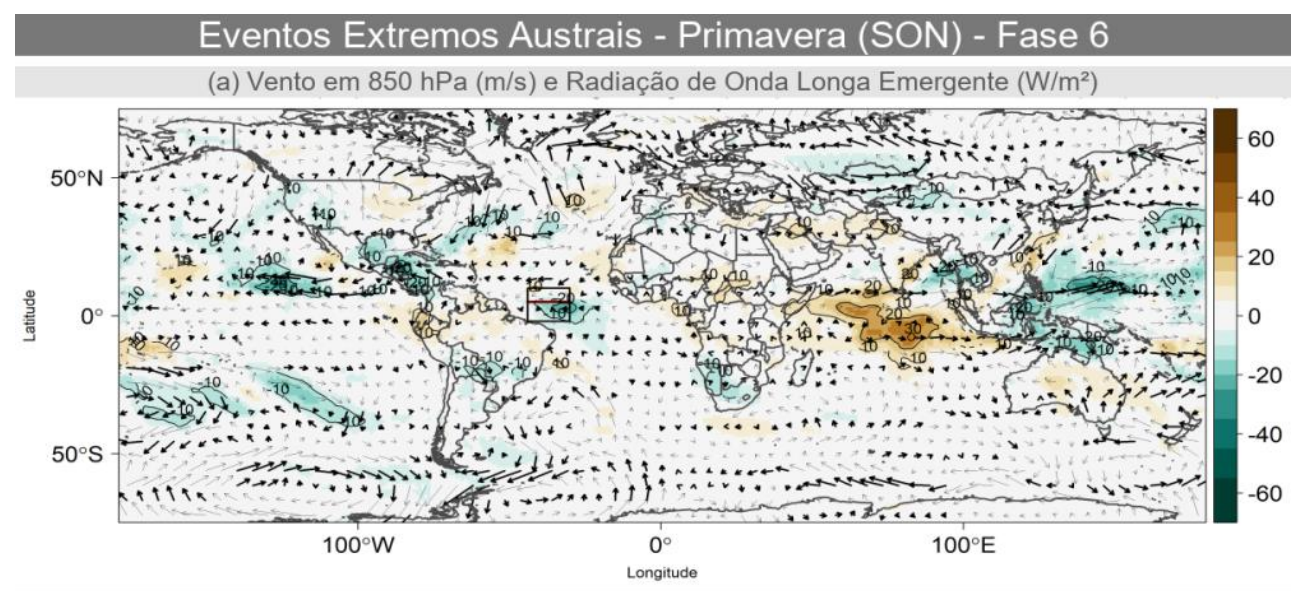

(b) Vento Meridional em $200 \mathrm{hPa}(\mathrm{m} / \mathrm{s})$

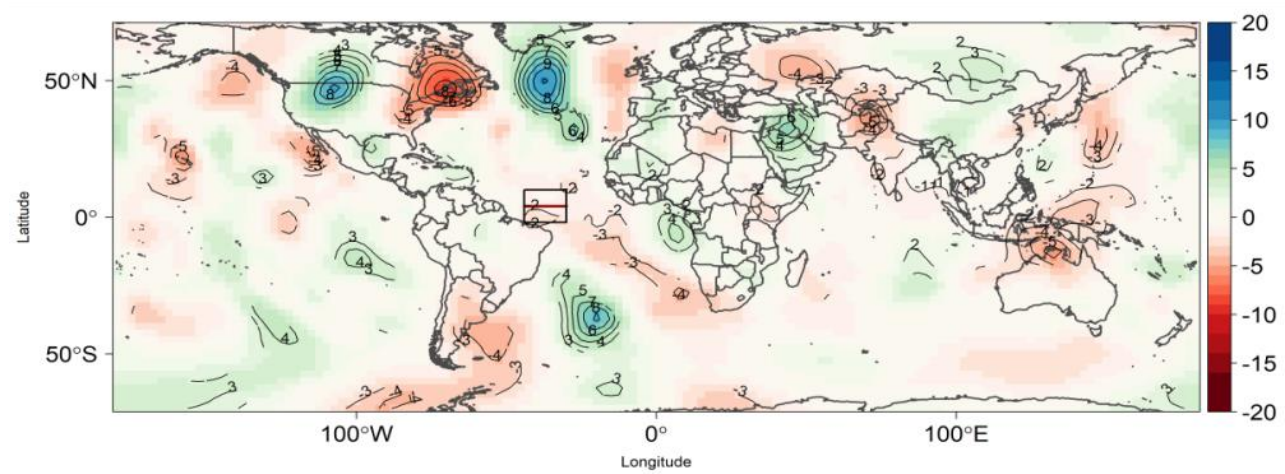

(c) Precipitação Acumulada ( $\mathrm{mm} / \mathrm{dia}$ )

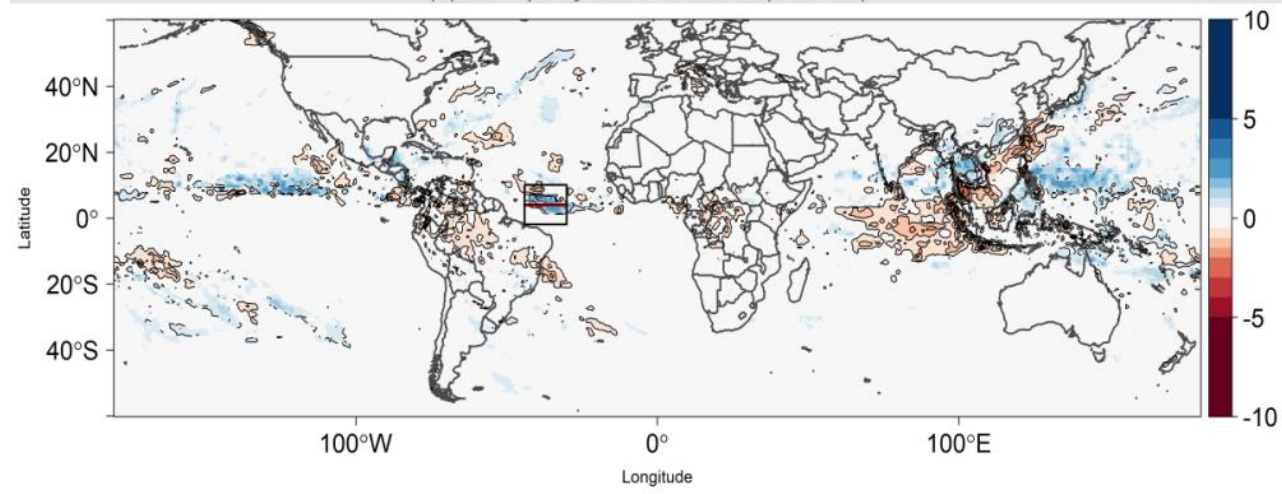

(d) Função de Corrente em $200 \mathrm{hPa}\left(\times 10^{\wedge} 6 \mathrm{~m}^{2} / \mathrm{s}\right)$

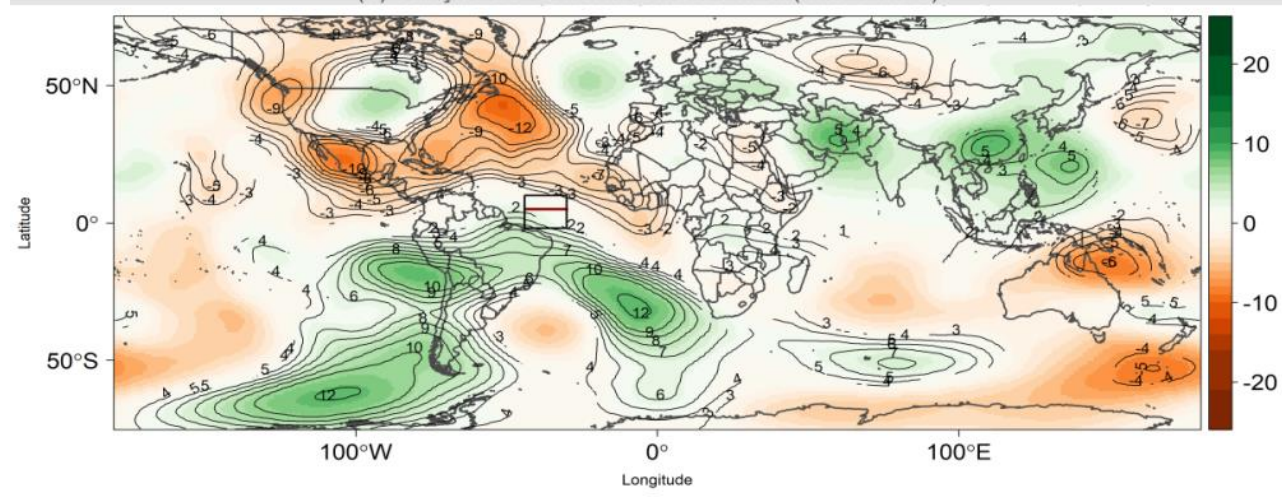

Figura 28 - Idem à Figura 23, porém para fase 6 da OMJ. 


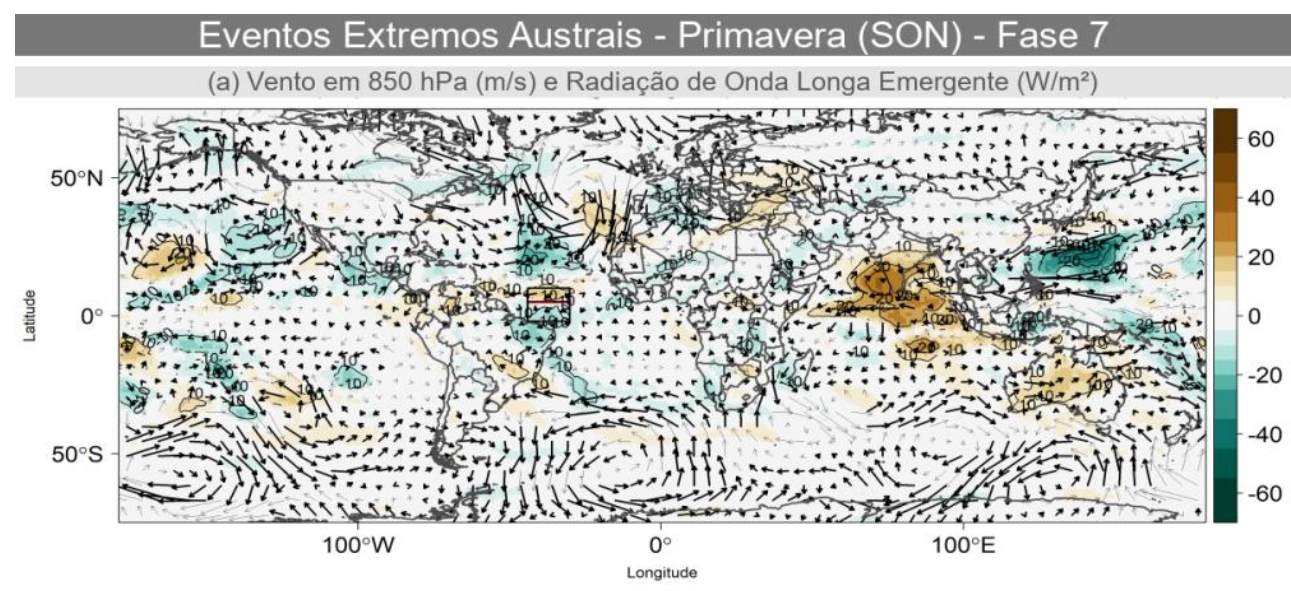

(b) Vento Meridional em $200 \mathrm{hPa}(\mathrm{m} / \mathrm{s})$
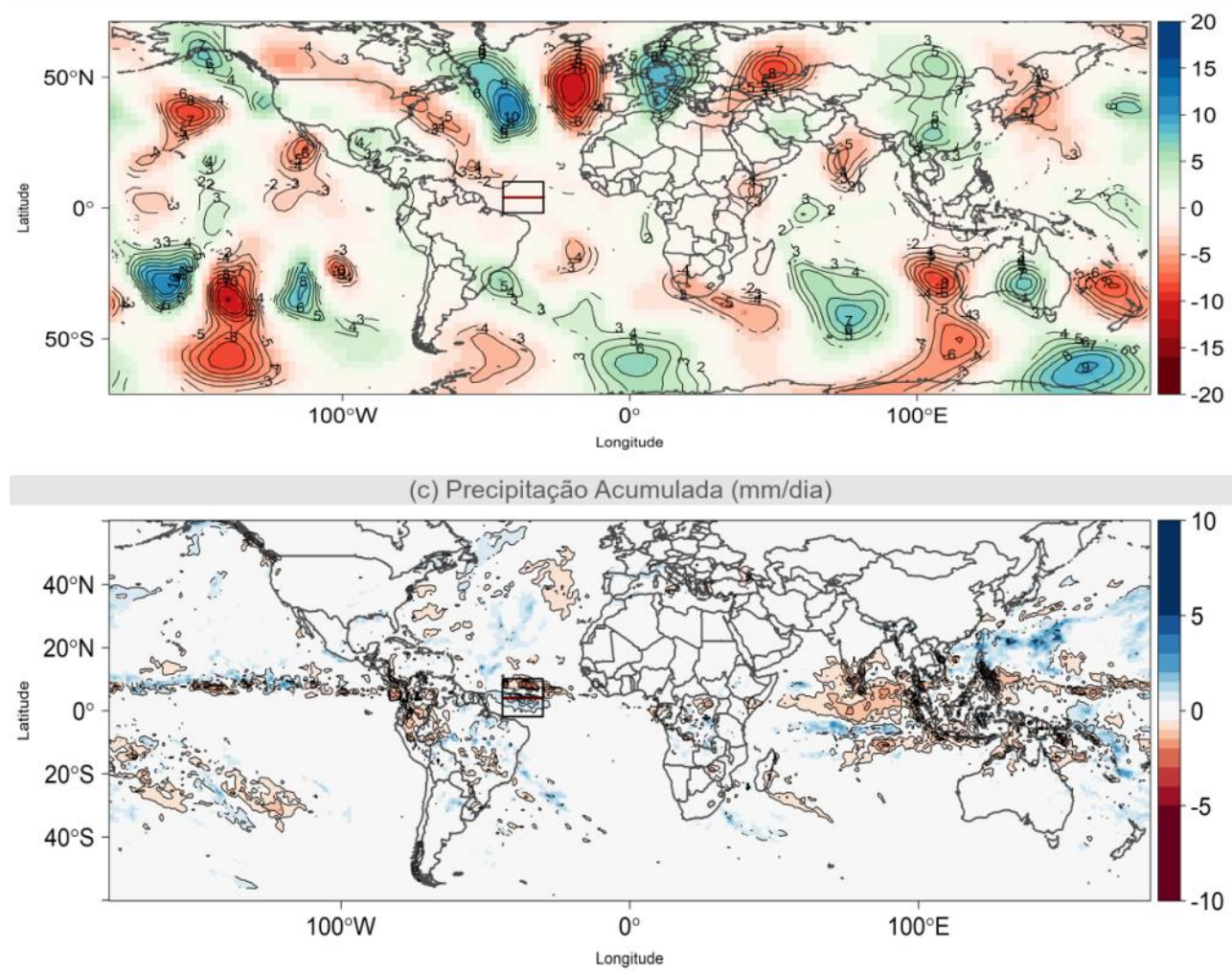

(d) Função de Corrente em $200 \mathrm{hPa}\left(\times 10^{\wedge} 6 \mathrm{~m}^{2} / \mathrm{s}\right)$

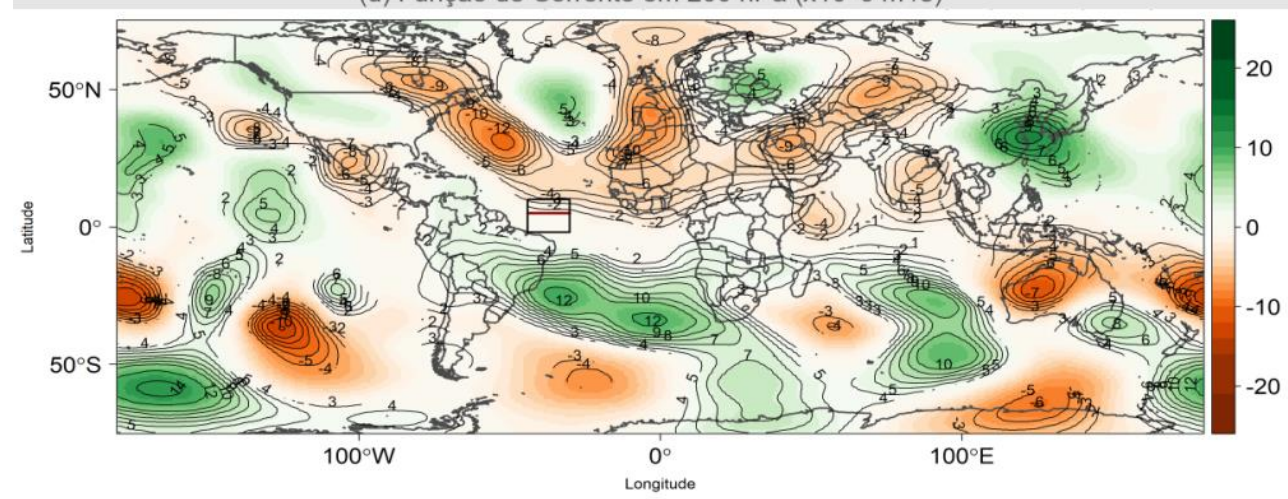

Figura 29 - Idem à Figura 23, porém para fase 7 da OMJ. 


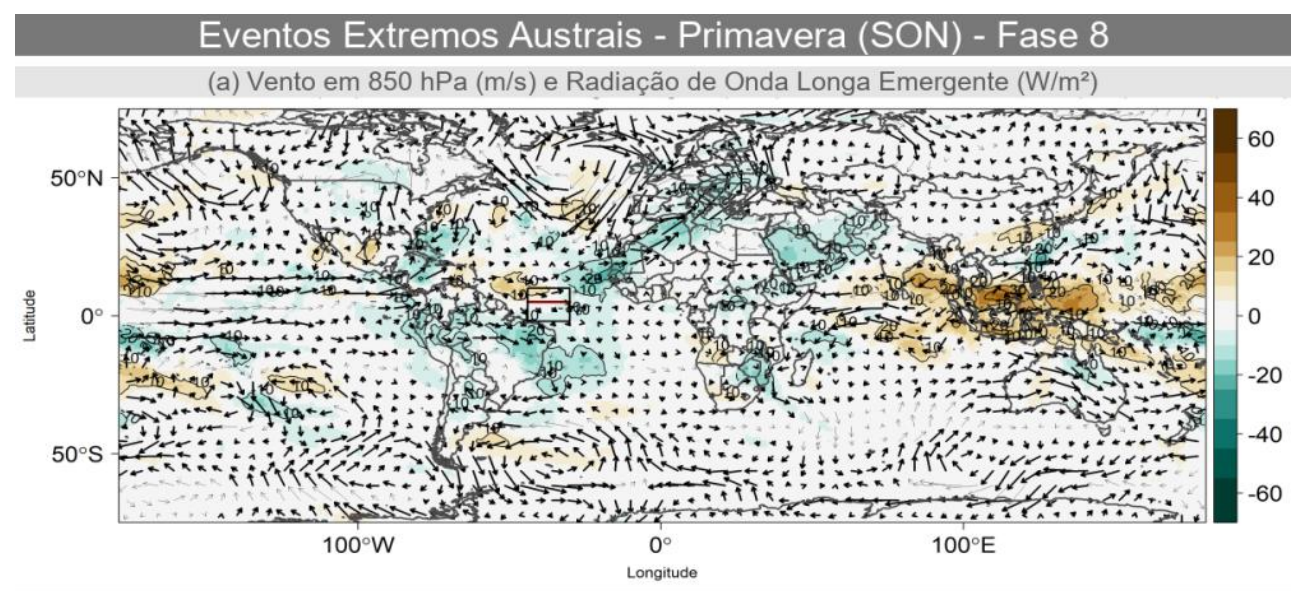

(b) Vento Meridional em $200 \mathrm{hPa}(\mathrm{m} / \mathrm{s})$

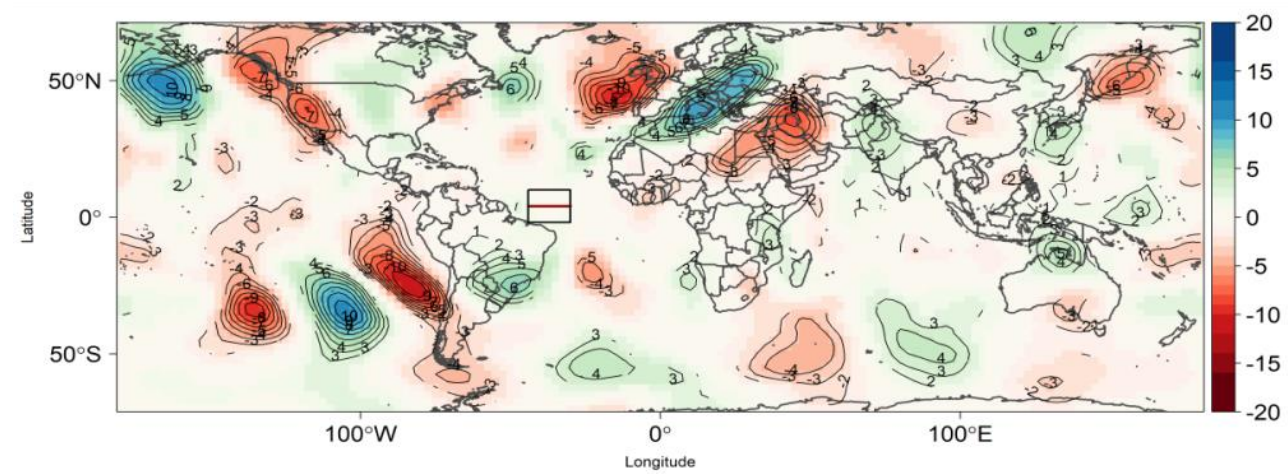

(c) Precipitação Acumulada ( $\mathrm{mm} / \mathrm{dia}$ )

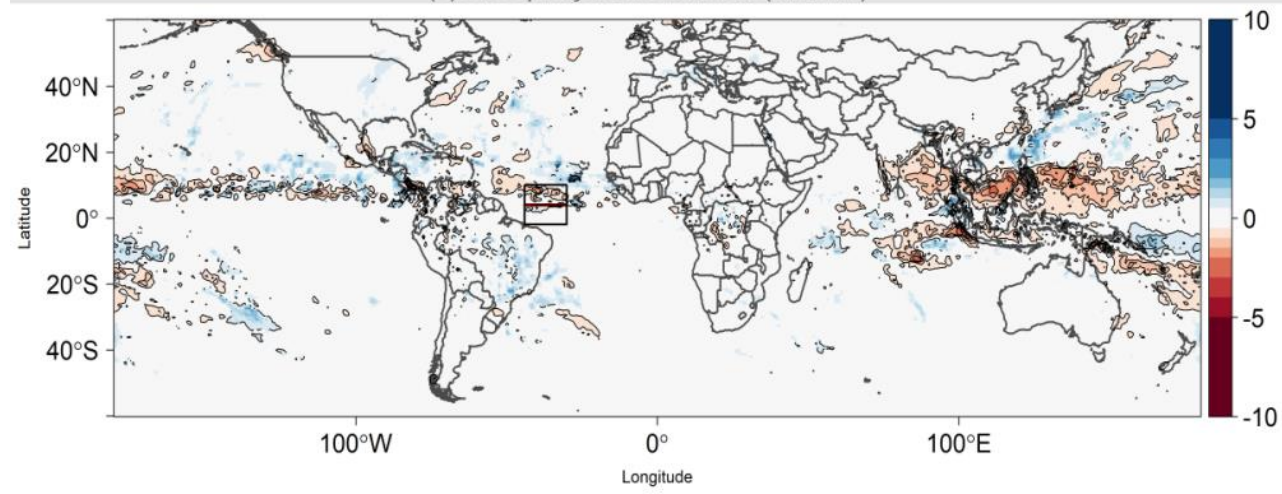

(d) Função de Corrente em $200 \mathrm{hPa}\left(\times 10^{\wedge} 6 \mathrm{~m}^{2} / \mathrm{s}\right)$

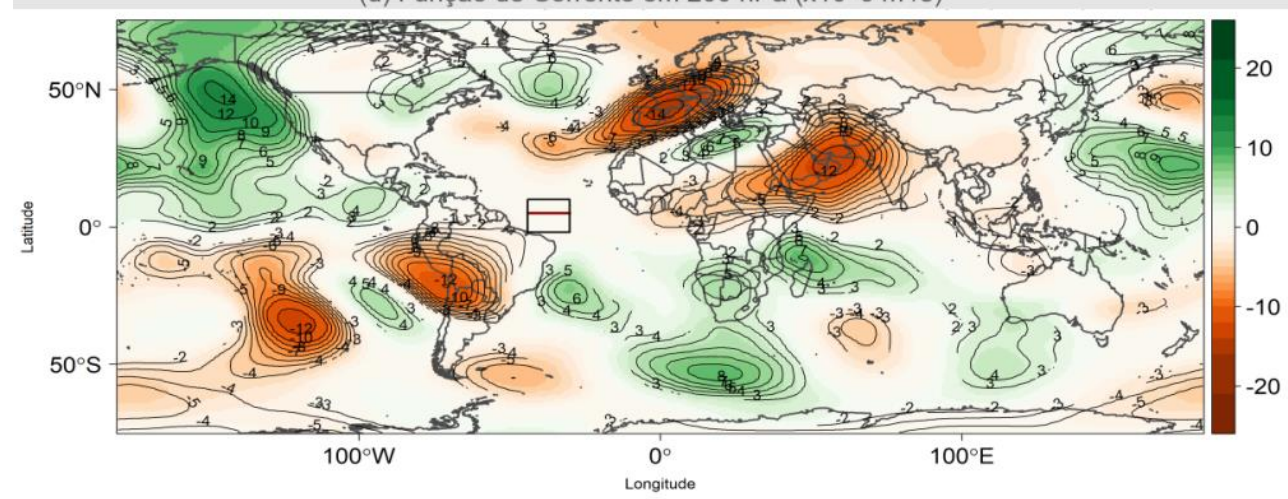

Figura 30 - Idem à Figura 23, porém para fase 8 da OMJ. 


\subsubsection{Outono (MAM)}

\subsubsection{Extremos boreais}

As discussões a seguir se baseiam nas análises das Figuras 32 a 40 que representam os eventos extremos boreais no outono. O limiar que delimitou a seleção desses casos foi a norte de aproximadamente $5^{\circ} \mathrm{N}$.

A fase 0 da OMJ (Figura 32) apresenta desfavorecimento de convecção a sul do IZCIT-AO através do campo de ROLE (Figura 32a) e anomalias negativas de precipitação (Figura 32c) sobre a mesma região. Os campos em altos níveis (Figuras 32b e 32d) apresentam ainda um padrão de anomalia ciclônica sobre a Região Sul do Brasil.

Na fase 1 (Figura 33), observa-se nos campos de vento meridional (Figura 33b) e função de corrente (Figura 33d) uma anomalia anticiclônica em $200 \mathrm{hPa}$ a sudoeste da AS na mesma localidade onde também é encontrada uma anomalia anticiclônica em baixos níveis (850 hPa) (Figura 33a), indicando que essa estrutura apresenta uma organização barotrópica, que pode estar associada a um trem de ondas de Rossby. Os campos em altos níveis (Figuras 33b e 33d) mostram um padrão de circulação ciclônica e anticiclônica que se intercalam entre o Pacífico, AS e Atlântico, indicando a propagação do trem de ondas. Devido a essa propagação, também se observa uma anomalia anticiclônica em altos níveis (Figuras 33b e 33d) sobre a faixa leste do Brasil (entre SE e NE) e anomalia ciclônica em baixos níveis (Figura 33a) sobre a mesma região, indicando que o trem de onda se torna baroclínico à medida que se aproxima do equador. Esse padrão pode ter contribuído para o deslocamento da ZCIT-AO para norte, ficando ao norte do limiar estabelecido, devido à desintensificação dos ventos alísios de sudeste e intensificação dos ventos de sudoeste sobre o Atlântico tropical, concentrando a ZCIT-A principalmente sobre o Atlântico tropical leste. O campo de ROLE (Figura 33a) apresenta favorecimento de 
convecção a norte do limiar e desfavorecimento a sul, enquanto o campo de precipitação (Figura 33c) mostra anomalias positivas a norte do índice e negativas a sul, indicando o posicionamento mais a norte da ZCIT-AO no período. A circulação anticiclônica sobre a faixa leste do país pode ter favorecido a convergência de umidade em baixos níveis, explicando assim o favorecimento de convecção observado sobre parte do SE no campo de ROLE.

$\mathrm{Na}$ fase 2 (Figura 34) podemos observar através dos campos de vento meridional em 200 hPa (Figura 34b), função de corrente em 200 hPa (Figura 34d) e vento em $850 \mathrm{hPa}$ (Figura 34a) sobre o $\mathrm{HN}$ um padrão de propagação de trem de ondas de Rossby (barotrópico). Sobre o Atlântico Norte há favorecimento de circulação ciclônica sobre a região que habitualmente se encontra a ASAN, o que pode ter causado um enfraquecimento do sistema e contribuído para o deslocamento da ZCIT-AO para norte, desfavorecendo a convecção a sul do limiar estabelecido para o IZCIT-AO neste caso, o que é confirmado através do campo de precipitação (Figura 34c).

A propagação do trem de ondas de Rossby observado sobre o HS na fase 3 (Figura 35) favorece circulação anticiclônica sobre a região onde a ASAS se encontra em média localizada (Figuras 35b e 35d). O favorecimento desse sistema de alta pressão sobre o Atlântico Sul contribui para o deslocamento da ZCIT-AO para norte devido ao fortalecimento dos alísios de sudeste, justificando o favorecimento de convecção observado no campo de ROLE a norte do limiar e a anomalia negativa de precipitação a sul do mesmo.

A Figura 36 apresenta as composições geradas para a fase 4. As anomalias apresentam padrões e valores mais elevados comparados aos outros eventos pois o número de casos selecionados para essa fase foi baixo (9 eventos). É possível observar, ao longo de um trem de onda, um padrão de circulação anticiclônica em altos níveis da atmosfera (Figuras 36b e 36d) sobre o Atlântico Sul, em aproximadamente $15^{\circ} \mathrm{S}$. Entretanto, a circulação passa a ser baroclínica à medida que se aproxima do Sul da AS, favorecendo circulação ciclônica em níveis baixos (Figura 36a) sobre a mesma região. Esse padrão favoreceu a convergência de 
umidade entre $\mathrm{N}$ e SE do Brasil e desfavoreceu convecção sobre o norte do $\mathrm{NE}$ (Figura 36a). Não fica claro como a ZCIT-AO deslocou-se para norte do limiar, mas a supressão de convecção a sul do limiar favoreceu convecção a norte do mesmo. Os campos de precipitação (Figura 36c) e ROLE (Figura 36a) mostram, respectivamente, anomalia negativa de precipitação e desfavorecimento de convecção a sul do índice, chegando à costa da Região NE, indicando o posicionamento da ZCIT-AO mais a norte.

A fase 5 (Figura 37) apresenta, a partir da América do Norte, um padrão de propagação de trem de ondas que se propaga ao longo do Atlântico Norte, próximo à região de estudo. Os campos de precipitação (Figura 37c) e ROLE (Figura 37a) mostram anomalias negativas de precipitação a sul do limiar e positivas a norte e supressão de convecção a sul do mesmo e favorecimento a norte, indicando o deslocamento da ZCIT-AO a norte do limiar. Nesse caso, trens de onda podem ser observados desde o Pacífico equatorial Oeste em ambos os hemisférios, alternando entre circulações ciclônicas e anticiclônicas com configuração barotrópica até se aproximarem do equador em aproximadamente $60^{\circ} \mathrm{L}$.

Na fase 6 (Figura 38), um padrão de propagação de ondas que se desloca a partir do Pacífico equatorial Oeste até o Atlântico Norte (Figuras 38b e 38d) parece favorecer a ASAN, como pode ser observado através do padrão anticiclônico dos ventos em baixos níveis (Figura 38a). No HS, também pode ser observada a propagação de um trem de onda a partir do Pacífico equatorial Oeste que se desintensifica quando chega próximo à AS. Em 850 hPa (Figura 38a), é observado um padrão anticlônico sobre o Atlântico Sul que se associa com a ASAS intensificada, o que deve ter contribuído para o deslocamento da ZCIT-AO para norte. Essas anomalias anticiclônicas estão embebidas em um trem de ondas de Rossby que se propaga ao longo do Pacífico Sul em direção ao Atlântico Sul (Figuras 38a e 38d). Os campos de ROLE (Figura 38a) e precipitação (Figura 38c) mostram que há favorecimento de convecção e anomalia positiva de precipitação logo a norte do limiar.

A fase 7 (Figura 39) é caracterizada por apresentar um desfavorecimento da ASAN que está embebido na propagação de um trem de ondas de Rossby a partir 
do Pacífico Norte. Devido ao enfraquecimento desse sistema, a ZCIT-AO pode ter se deslocado a norte do limiar estabelecido pelo IZCIT-AO, o que pode ser corroborado pelos campos de ROLE (Figura 39a) e precipitação (Figura 39c), que mostram favorecimento de convecção e anomalia positiva de precipitação a norte do limiar.

$\mathrm{Na}$ Figura 40, são apresentadas as composições de eventos extremos boreais da ZCIT-AO durante a fase 8 da OMJ. Nesse caso, também há enfraquecimento da ASAN observado através dos campos em baixos e altos níveis: vento em $850 \mathrm{hPa}$ (Figura 40a), vento meridional (Figura 40b) e função de corrente (Figura 40d). Esse padrão parece estar associado a um trem de onda que se deslocou a partir do Pacífico equatorial Oeste até o Atlântico Norte. Como mencionado em outros casos, a ZCIT-AO pode ter se posicionado a norte do limiar devido ao enfraquecimento dos alísios de nordeste em decorrência da ASAN enfraquecida. 

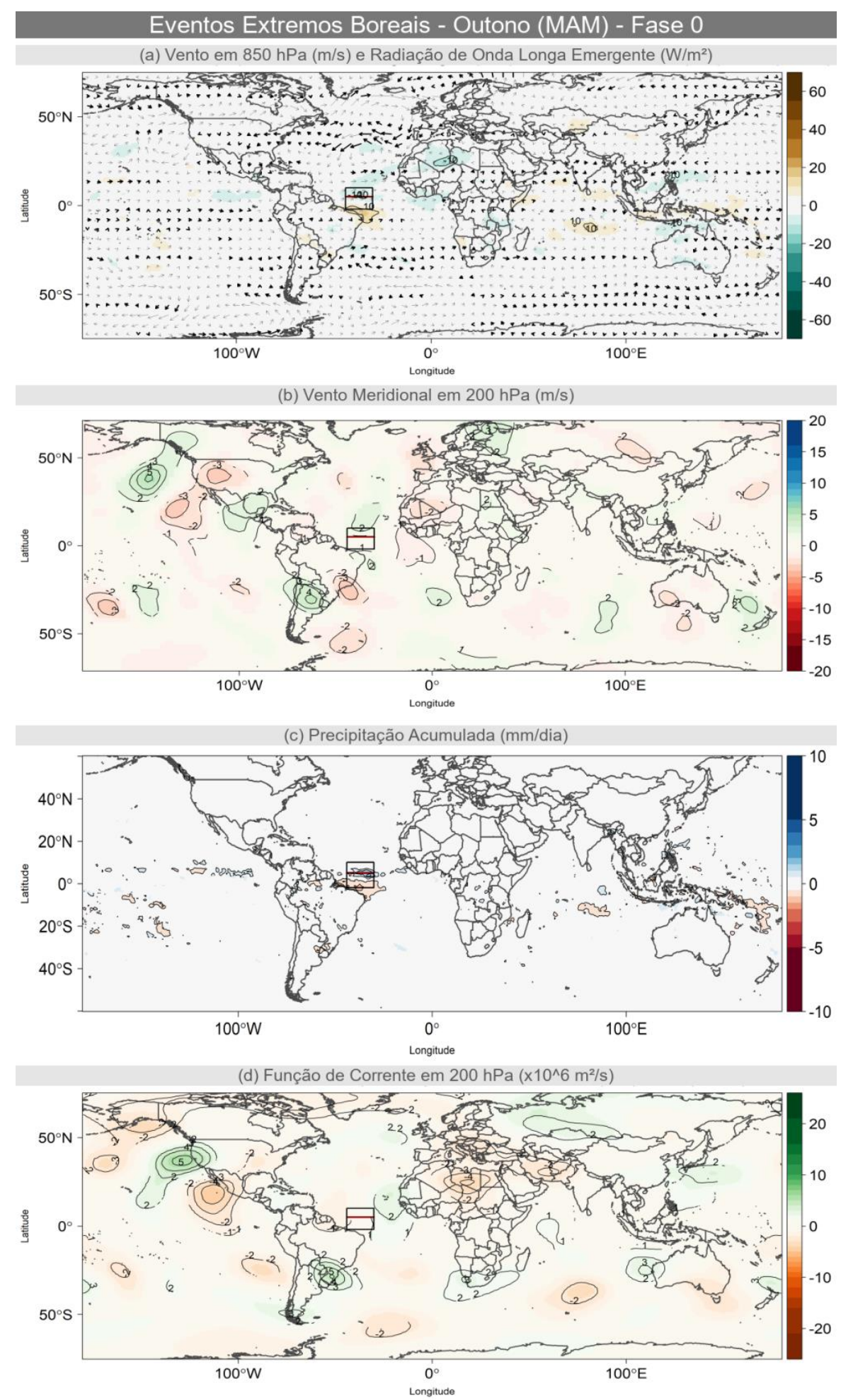

Figura 31 - Composições para os eventos extremos boreais para o Outono (MAM) e fase 0 da OMJ das anomalias de (a) vento em $850 \mathrm{hPa}\left({ }^{*} 100 \mathrm{~m} / \mathrm{s}\right)$ e ROLE $\left(\mathrm{W} / \mathrm{m}^{2}\right)$, (b) vento meridional em $200 \mathrm{hPa}$ (m/s), (c) precipitação (mm/dia) e (d) função de corrente em $200 \mathrm{hPa}$ $\left(x 10^{\wedge} 6 \mathrm{~m}^{2} / \mathrm{s}\right)$. A caixa preta representa a Região de Estudo e a linha vermelha representa 0 percentil (limiar) do IZCIT-AO para esse caso. Os vetores em negrito e as áreas contornadas representam significância estatística ao nível de 5\%. 


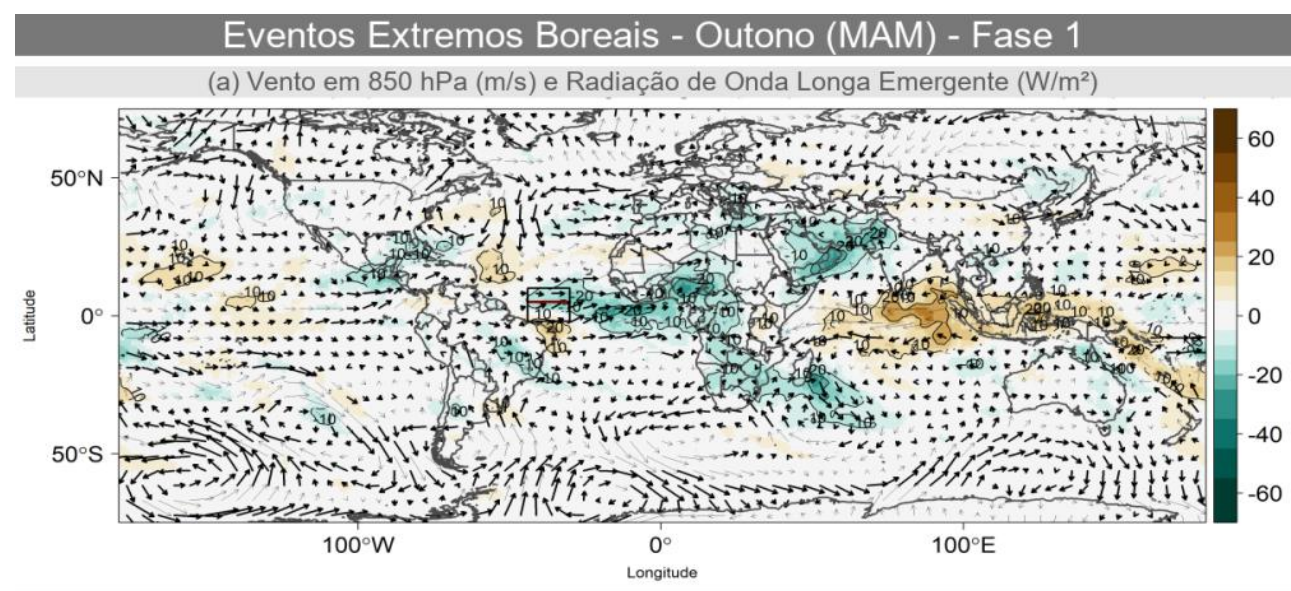

(b) Vento Meridional em $200 \mathrm{hPa}(\mathrm{m} / \mathrm{s})$

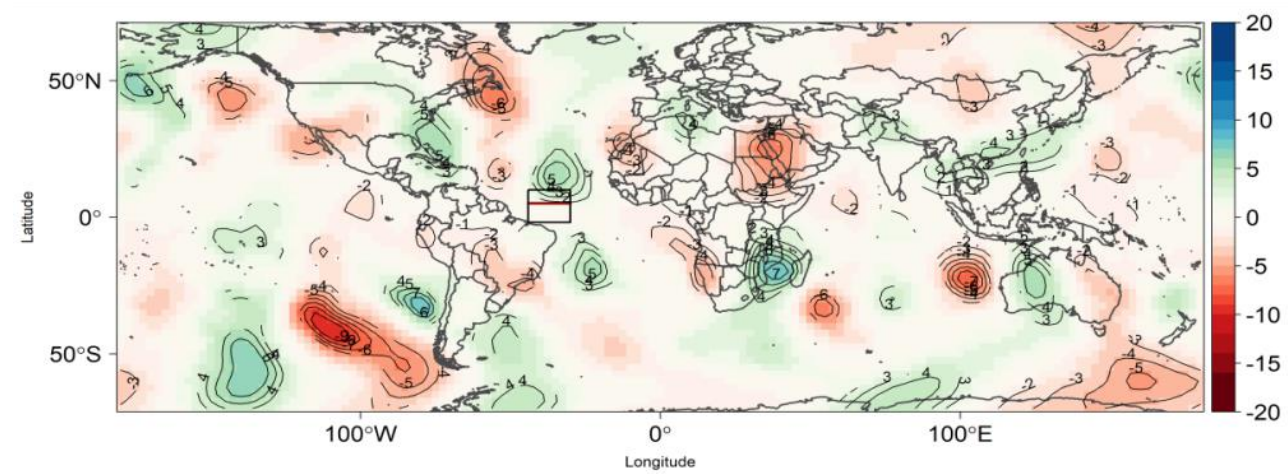

(c) Precipitação Acumulada ( $\mathrm{mm} / \mathrm{dia}$ )

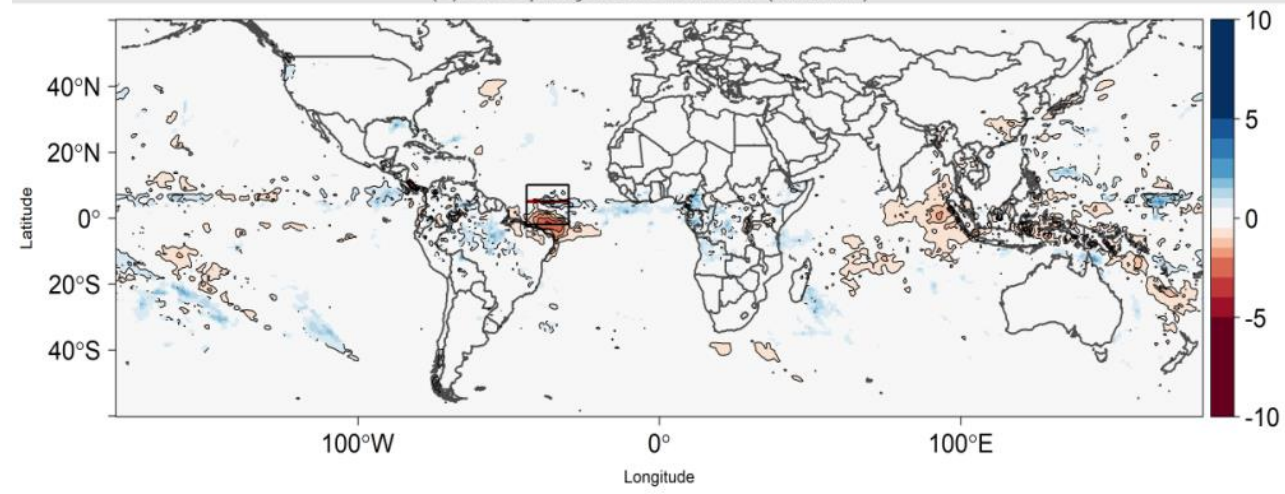

(d) Função de Corrente em $200 \mathrm{hPa}\left(\times 10^{\wedge} 6 \mathrm{~m}^{2} / \mathrm{s}\right)$

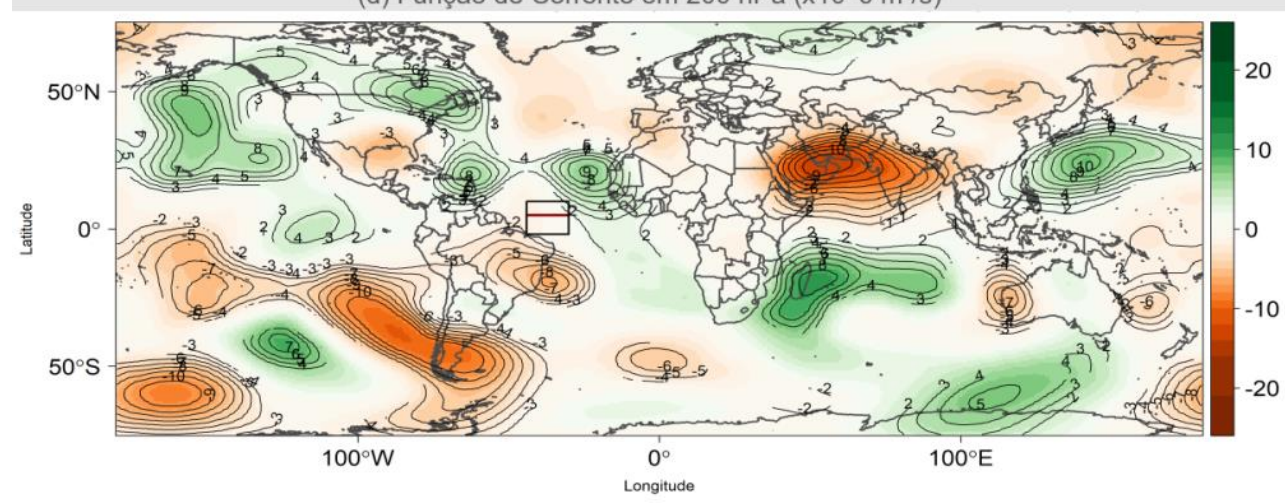

Figura 32 - Idem à Figura 32, porém para fase 1 da OMJ. 


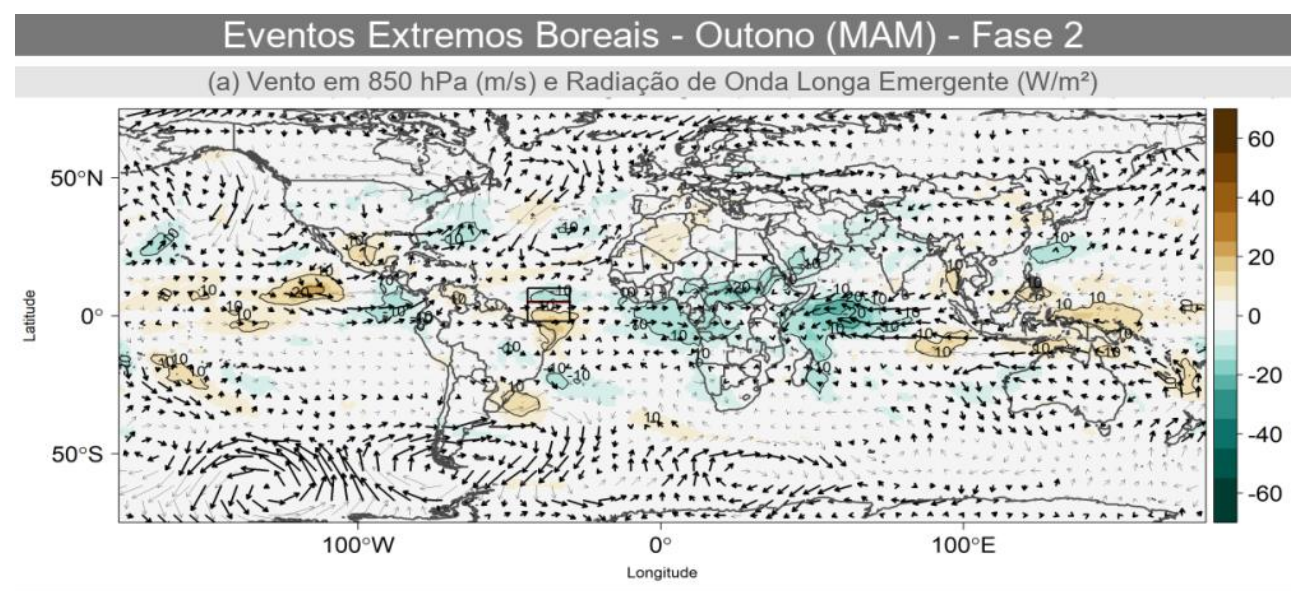

(b) Vento Meridional em $200 \mathrm{hPa}(\mathrm{m} / \mathrm{s})$

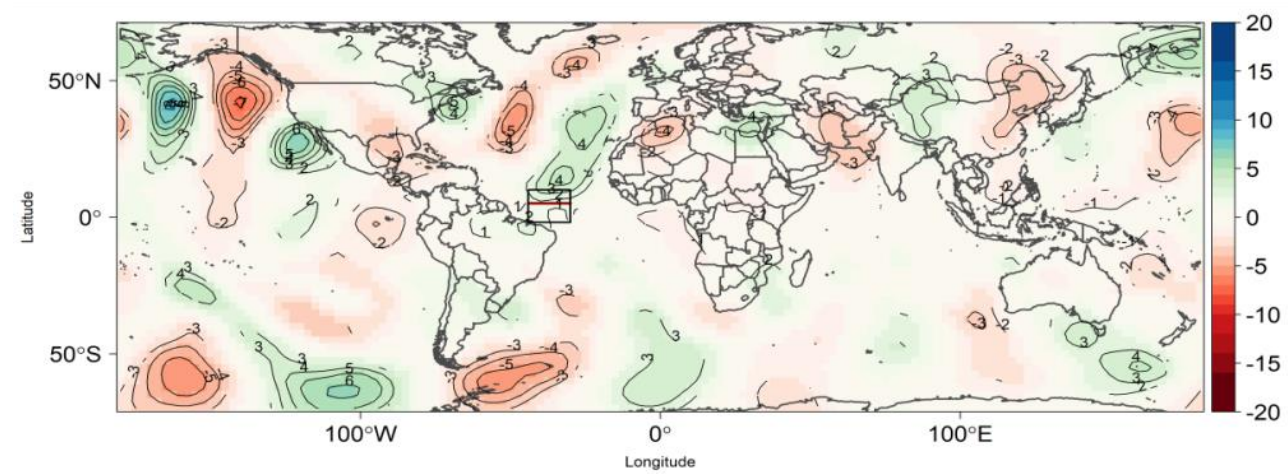

(c) Precipitação Acumulada ( $\mathrm{mm} / \mathrm{dia}$ )

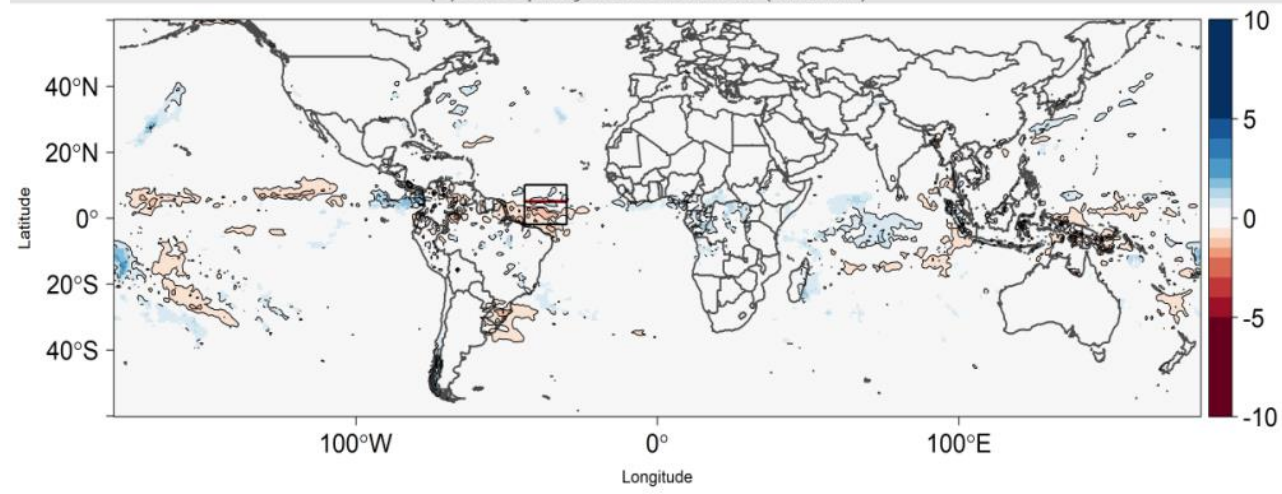

(d) Função de Corrente em $200 \mathrm{hPa}\left(\times 10^{\wedge} 6 \mathrm{~m}^{2} / \mathrm{s}\right)$

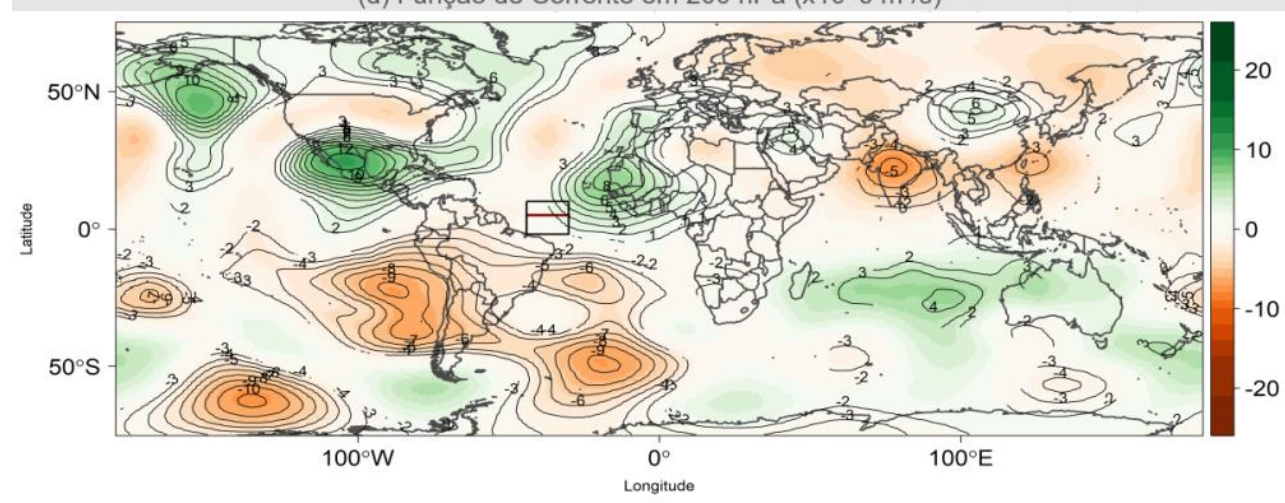

Figura 33 - Idem à Figura 32, porém para fase 2 da OMJ. 


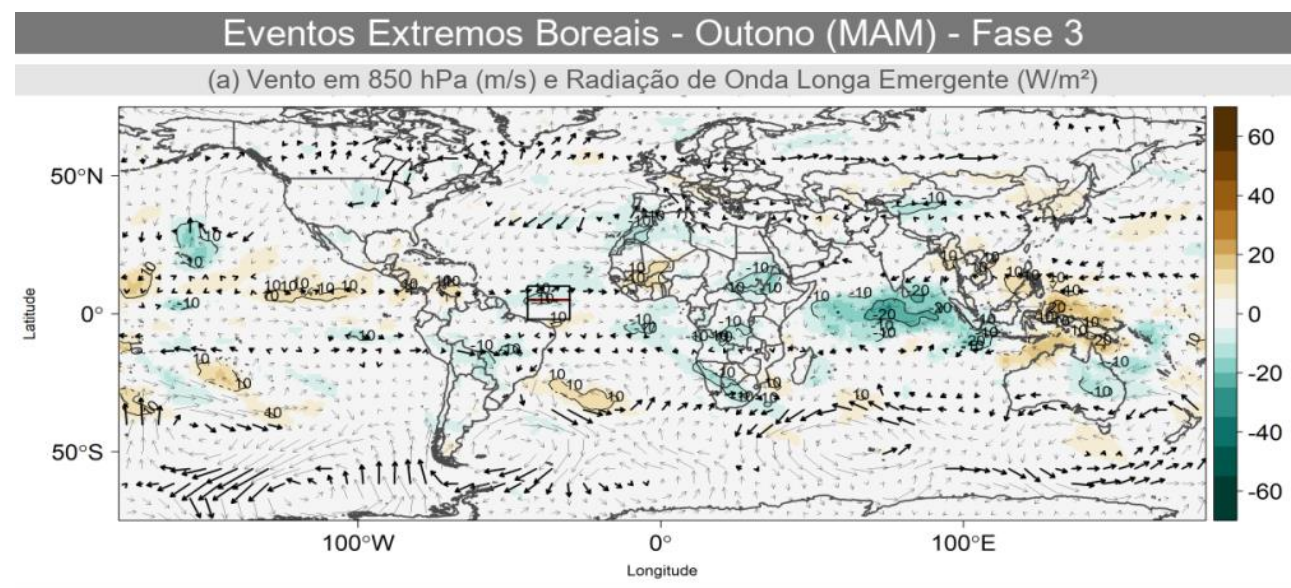

(b) Vento Meridional em $200 \mathrm{hPa}(\mathrm{m} / \mathrm{s})$

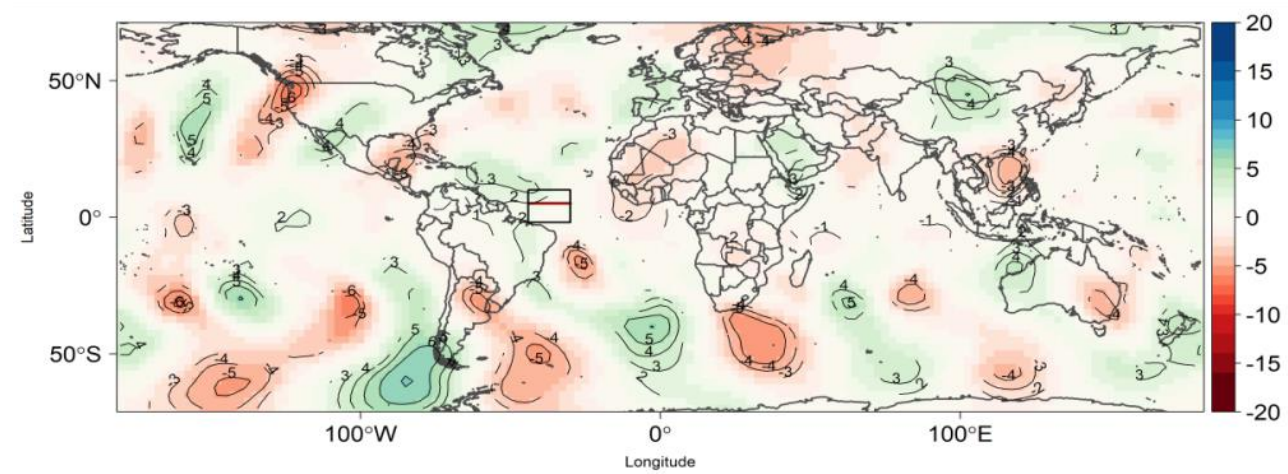

(c) Precipitação Acumulada ( $\mathrm{mm} / \mathrm{dia}$ )

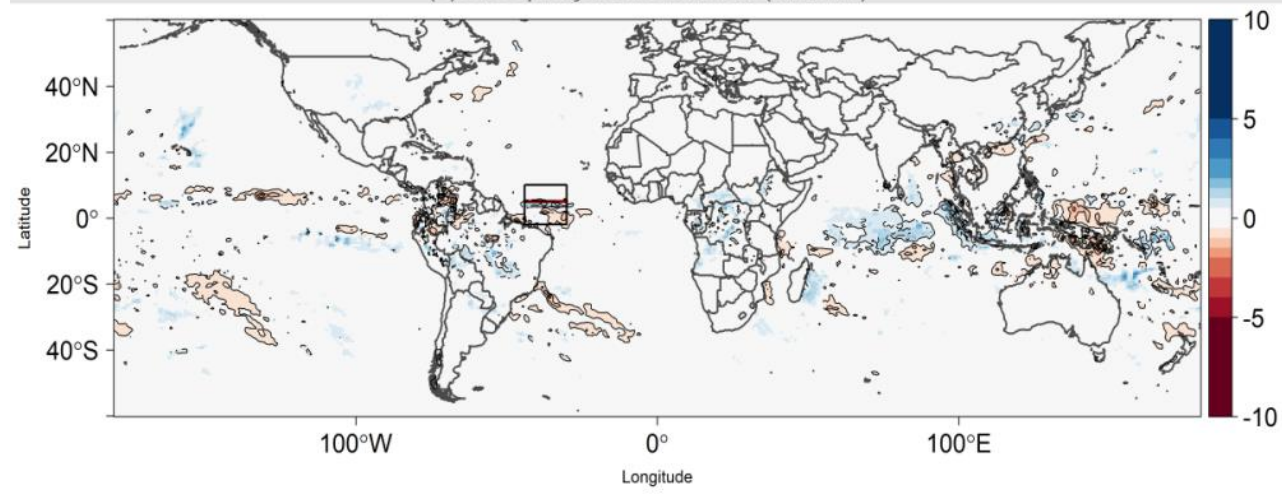

(d) Função de Corrente em $200 \mathrm{hPa}\left(\times 10^{\wedge} 6 \mathrm{~m}^{2} / \mathrm{s}\right)$

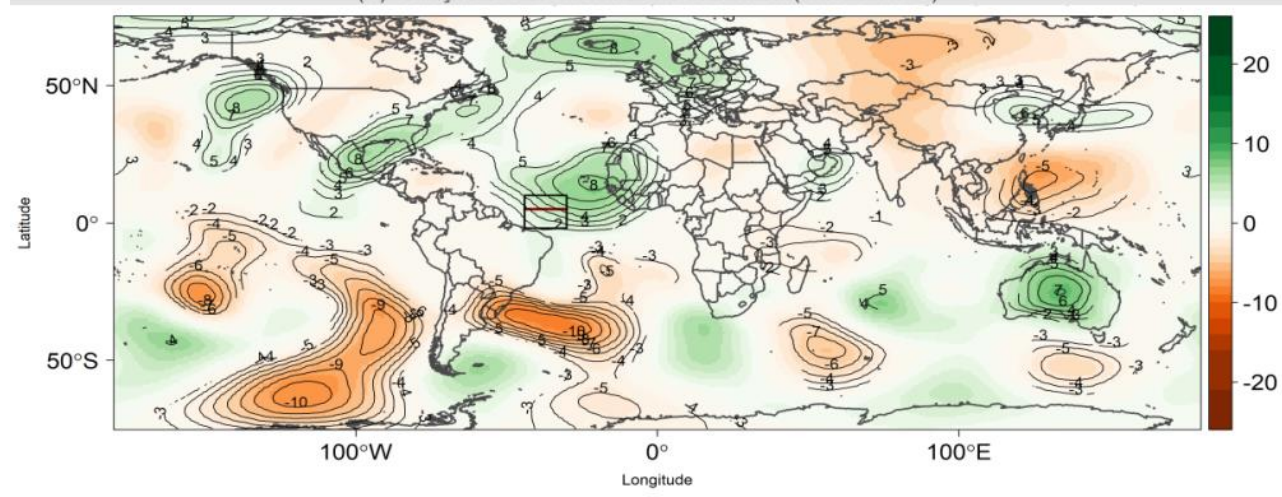

Figura 34 - Idem à Figura 32, porém para fase 3 da OMJ. 

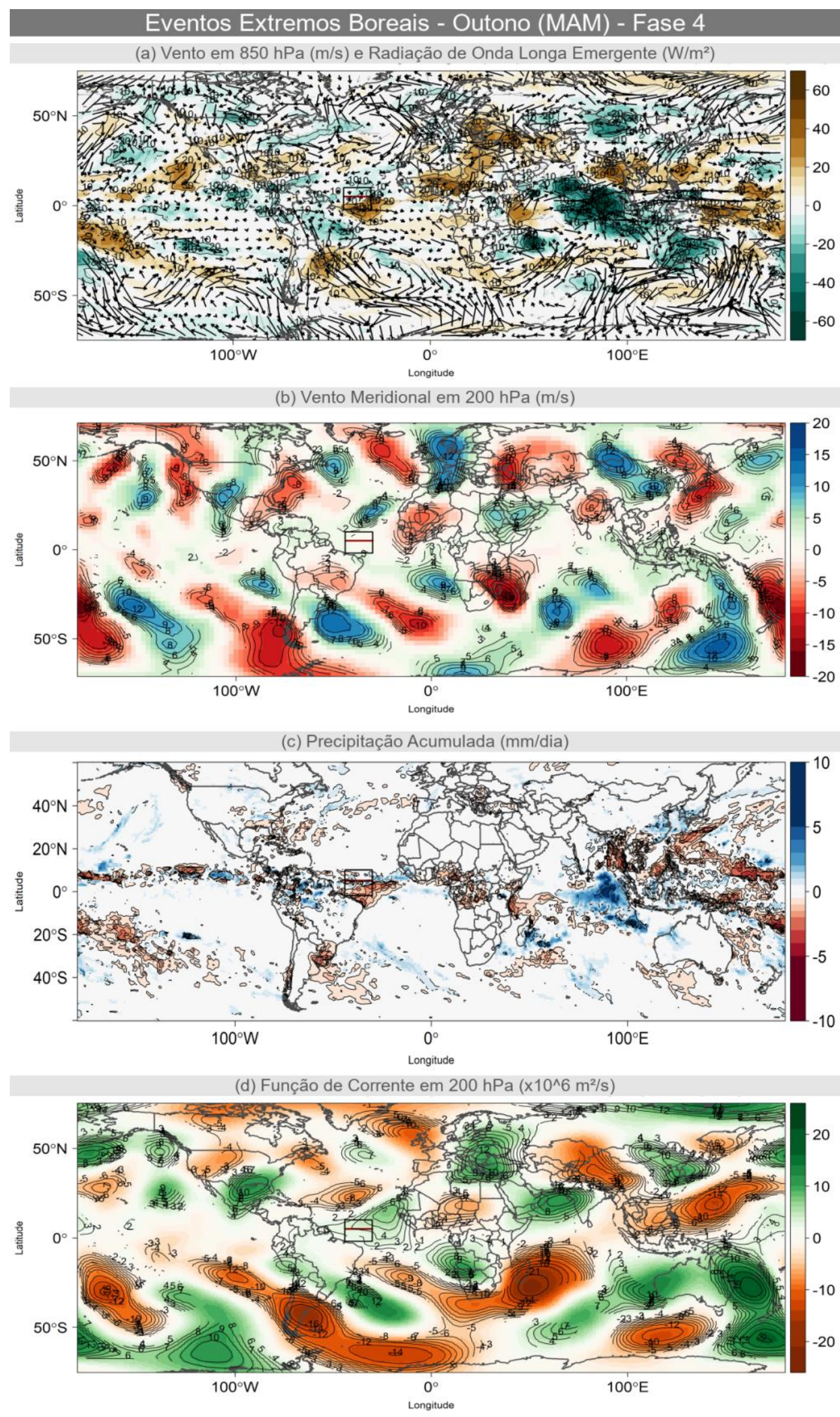

Figura 35 - Idem à Figura 32, porém para fase 4 da OMJ. 

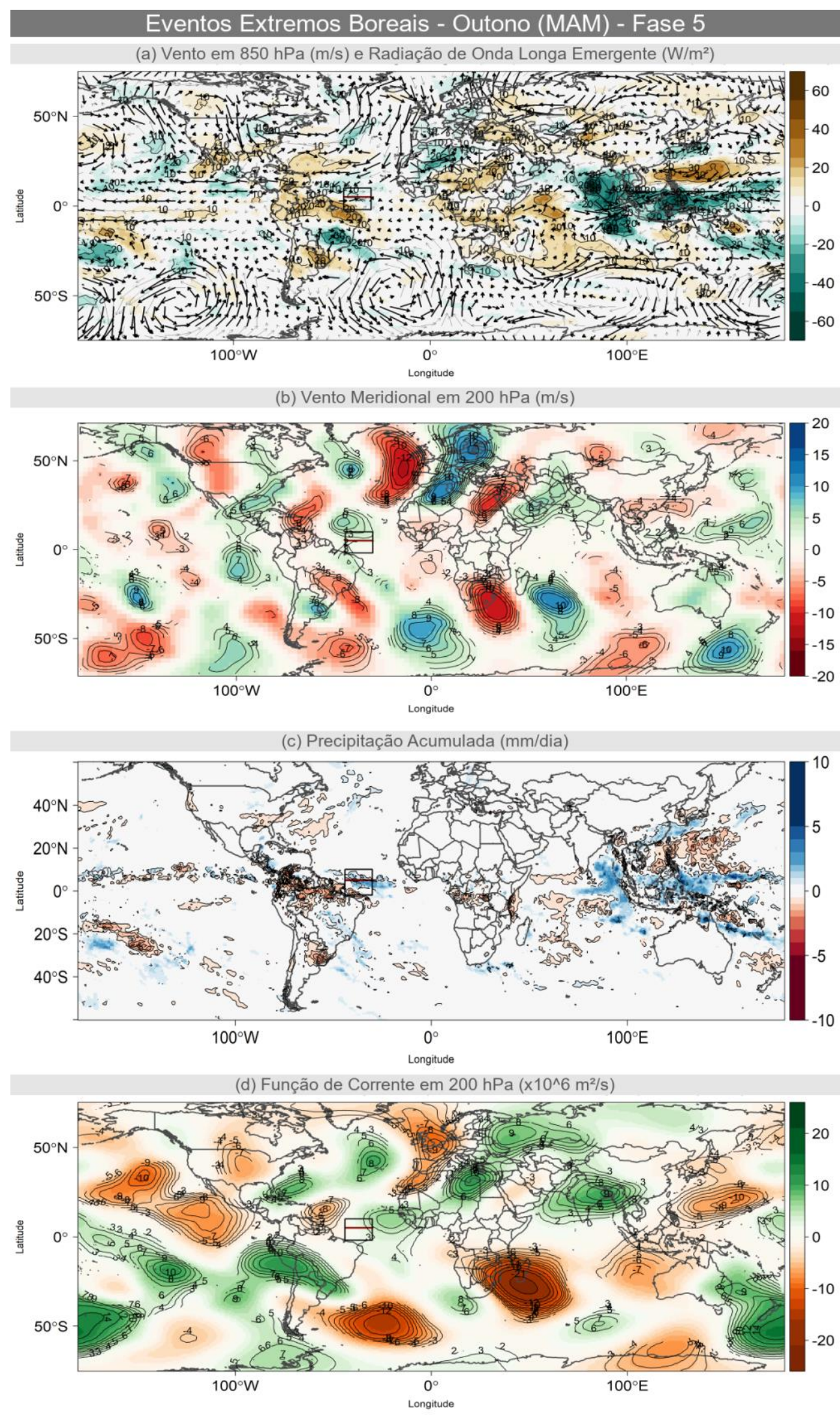

Figura 36 - Idem à Figura 32, porém para fase 5 da OMJ. 


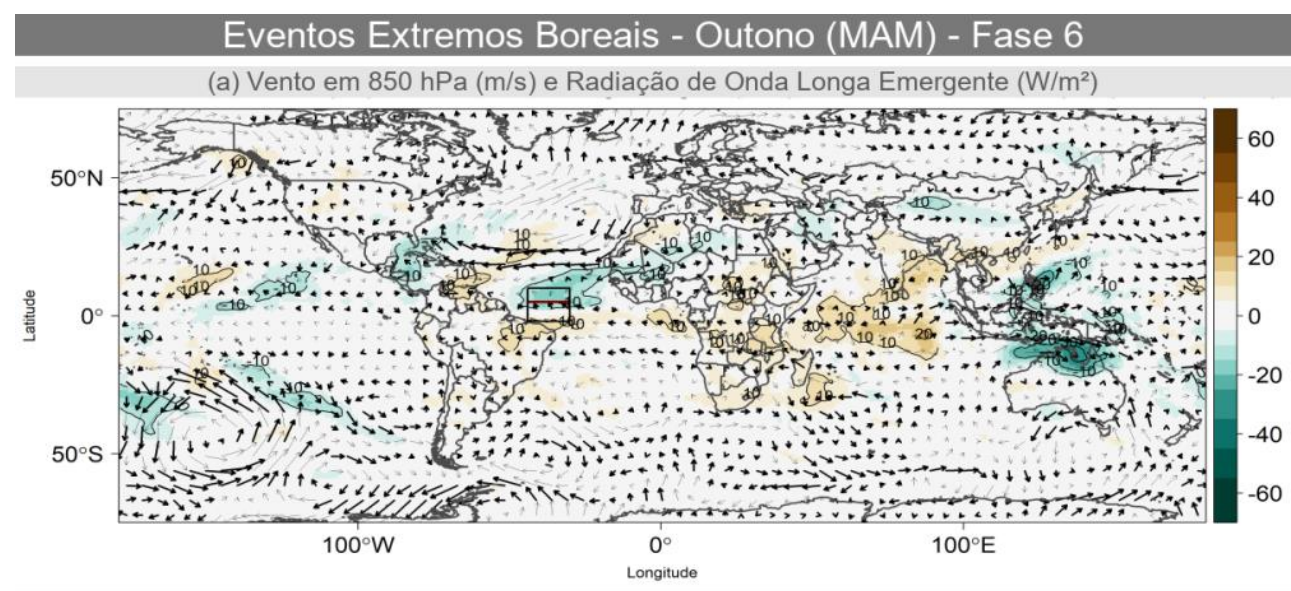

(b) Vento Meridional em $200 \mathrm{hPa}(\mathrm{m} / \mathrm{s})$

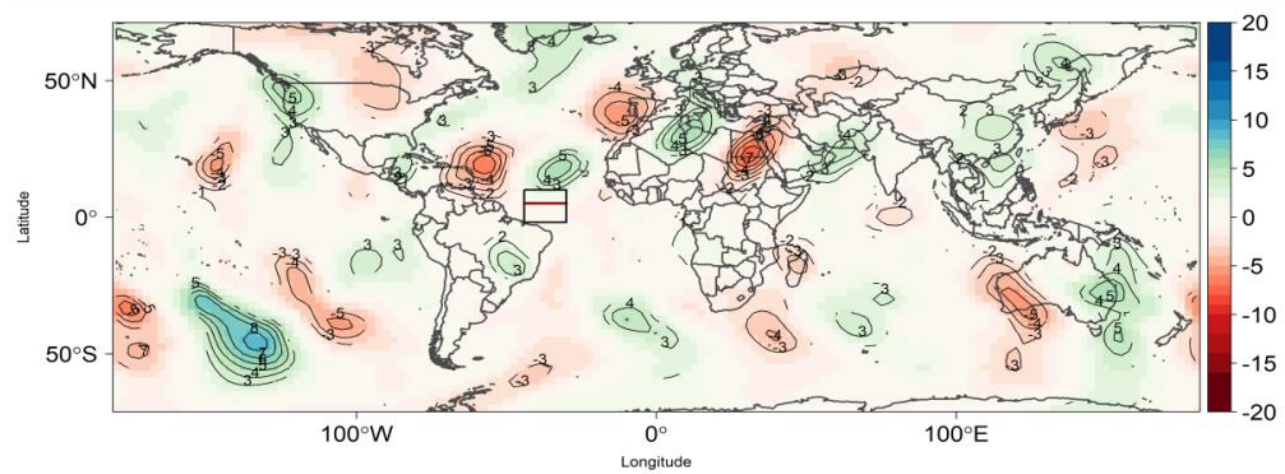

(c) Precipitação Acumulada ( $\mathrm{mm} / \mathrm{dia}$ )

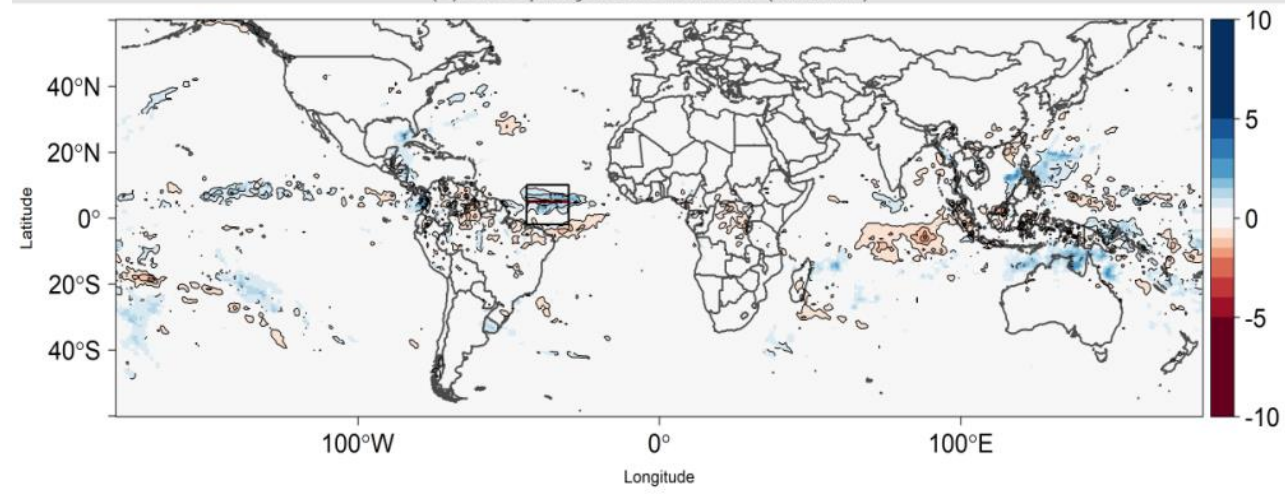

(d) Função de Corrente em $200 \mathrm{hPa}\left(\times 10^{\wedge} 6 \mathrm{~m}^{2} / \mathrm{s}\right)$

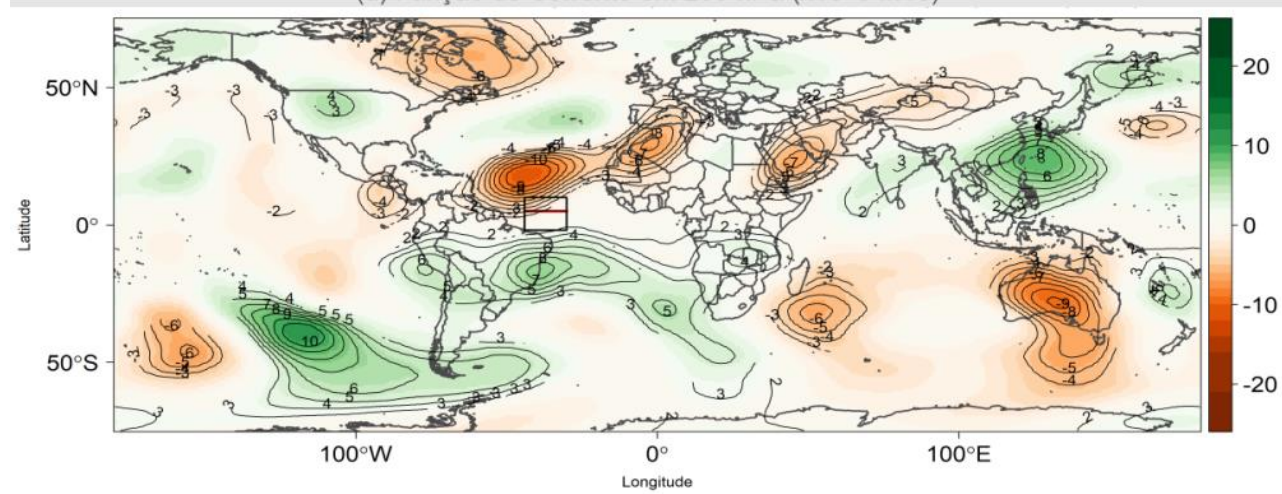

Figura 37 - Idem à Figura 32, porém para fase 6 da OMJ. 


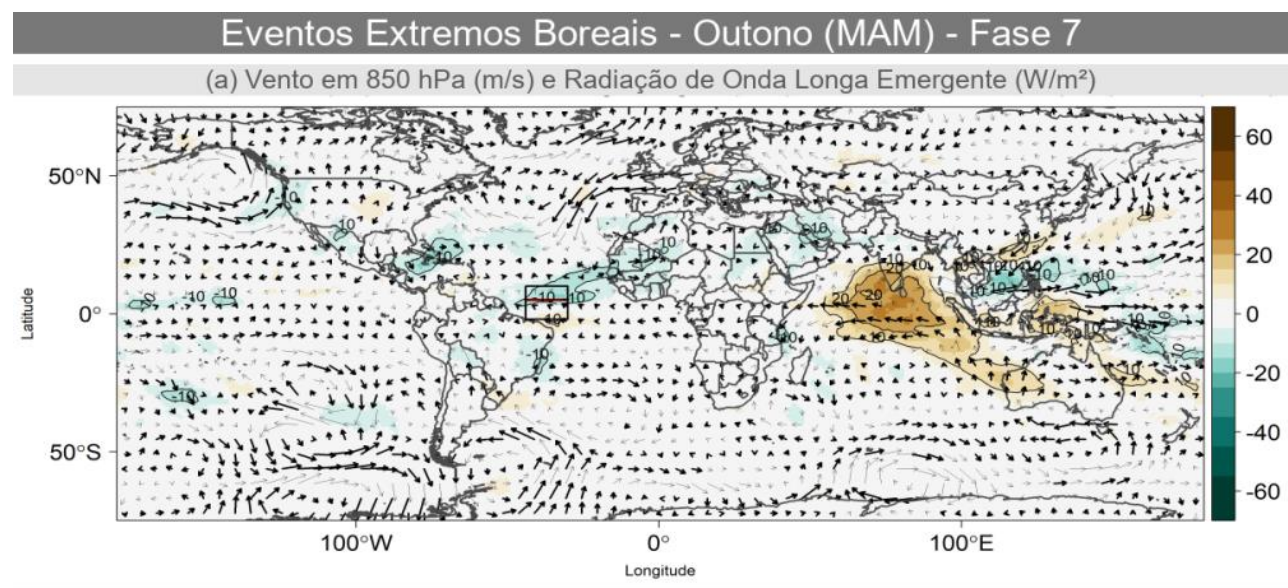

(b) Vento Meridional em $200 \mathrm{hPa}(\mathrm{m} / \mathrm{s})$

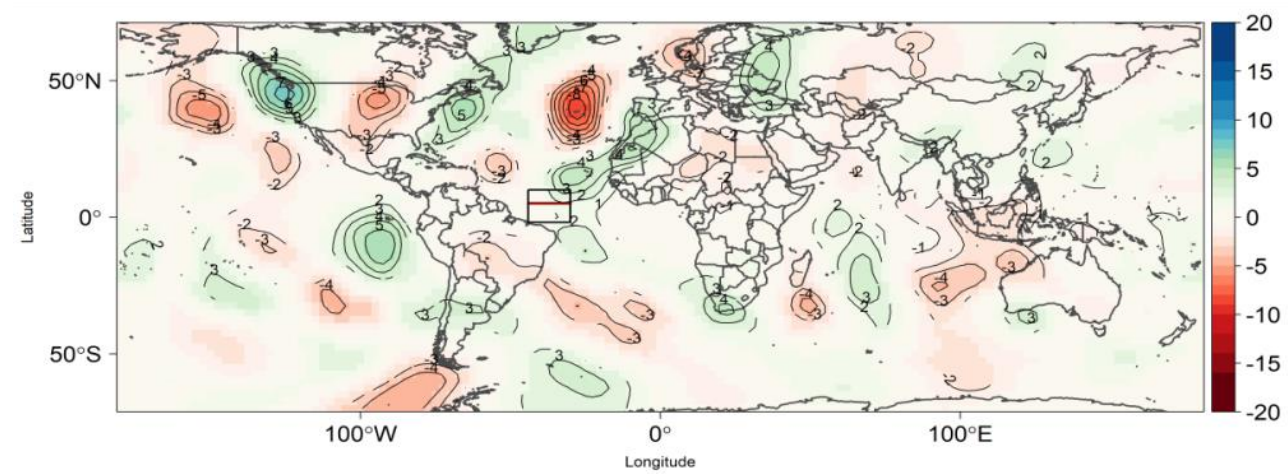

(c) Precipitação Acumulada ( $\mathrm{mm} / \mathrm{dia}$ )

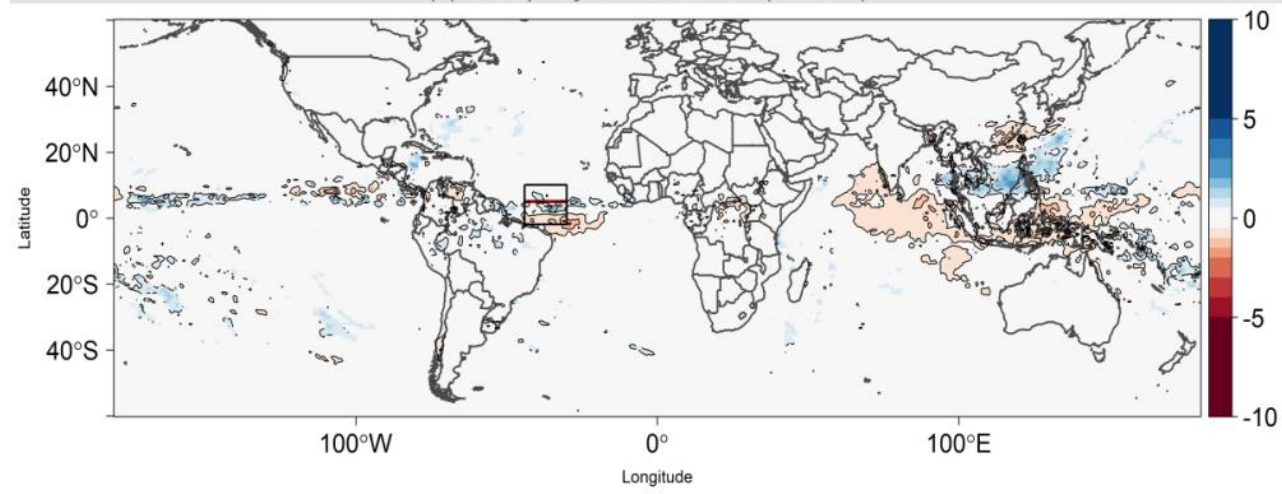

(d) Função de Corrente em $200 \mathrm{hPa}\left(\times 10^{\wedge} 6 \mathrm{~m}^{2} / \mathrm{s}\right)$

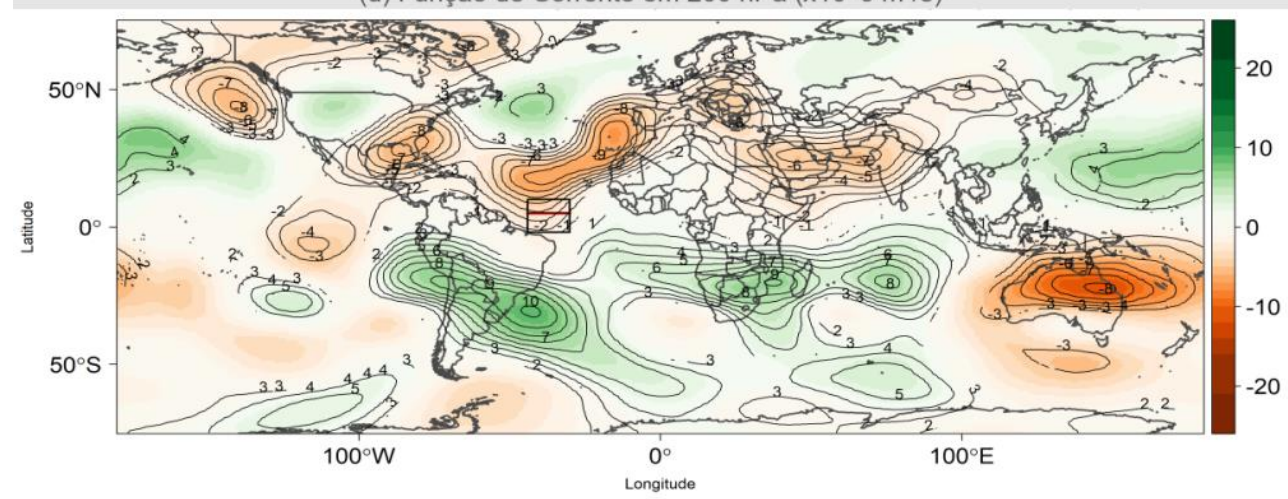

Figura 38 - Idem à Figura 32, porém para fase 7 da OMJ. 


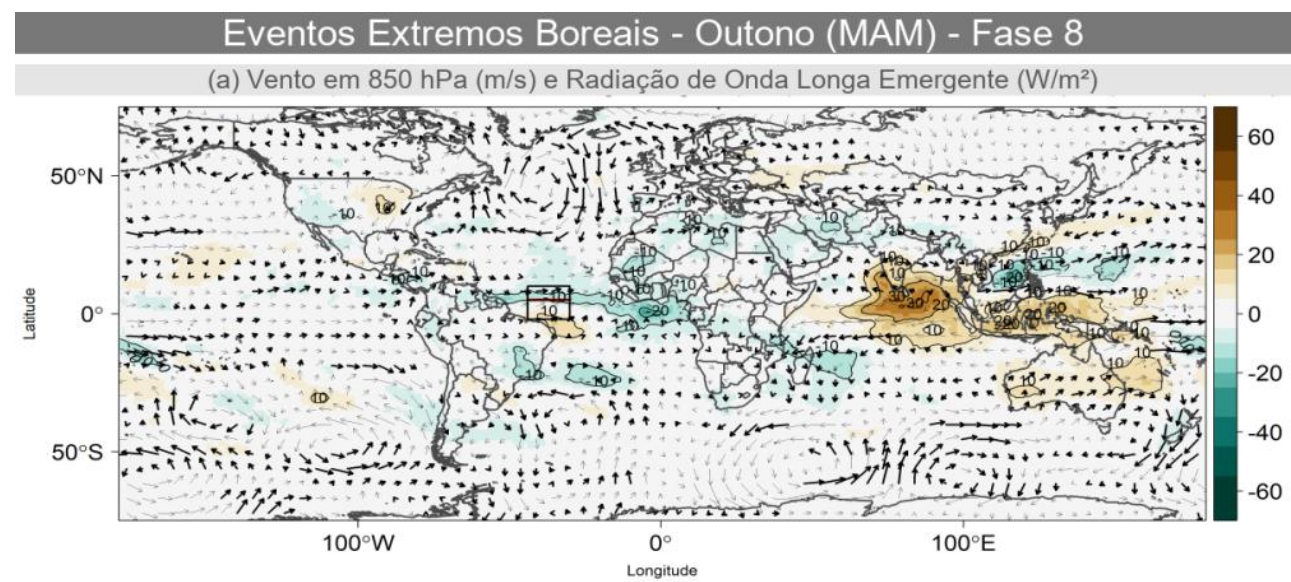

(b) Vento Meridional em $200 \mathrm{hPa}(\mathrm{m} / \mathrm{s})$

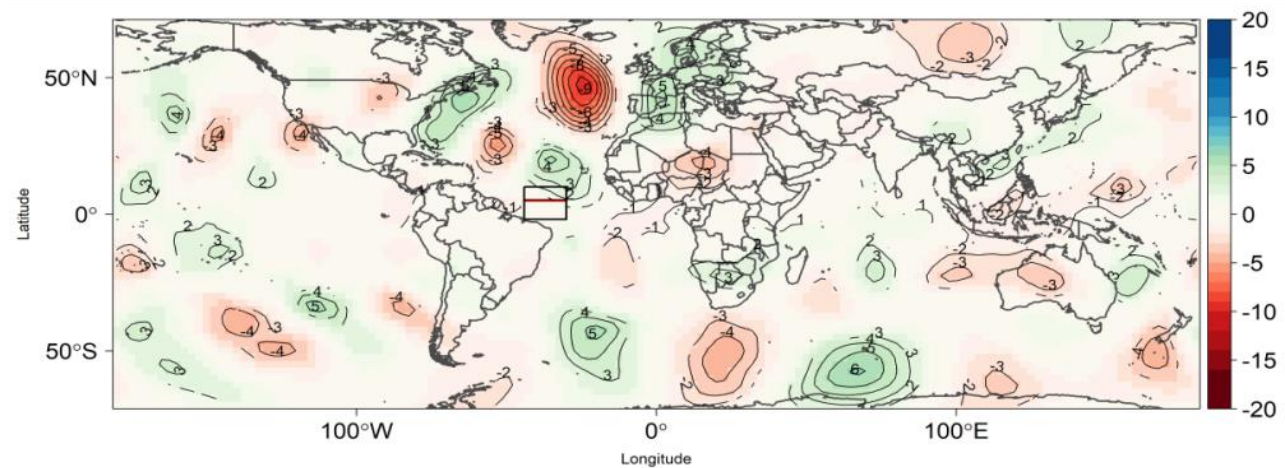

(c) Precipitação Acumulada ( $\mathrm{mm} / \mathrm{dia}$ )

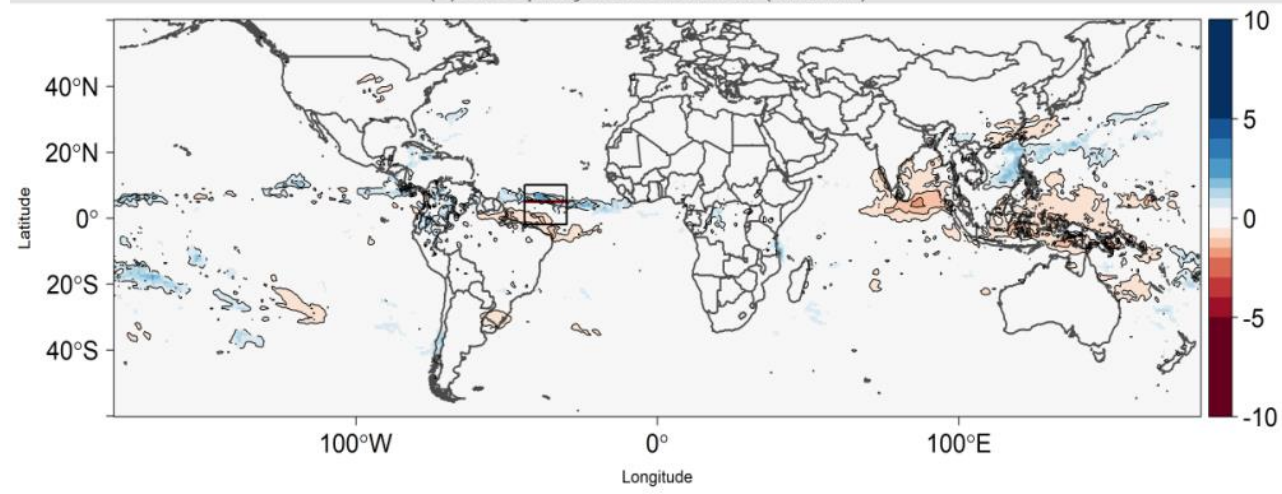

(d) Função de Corrente em $200 \mathrm{hPa}\left(\times 10^{\wedge} 6 \mathrm{~m}^{2} / \mathrm{s}\right)$

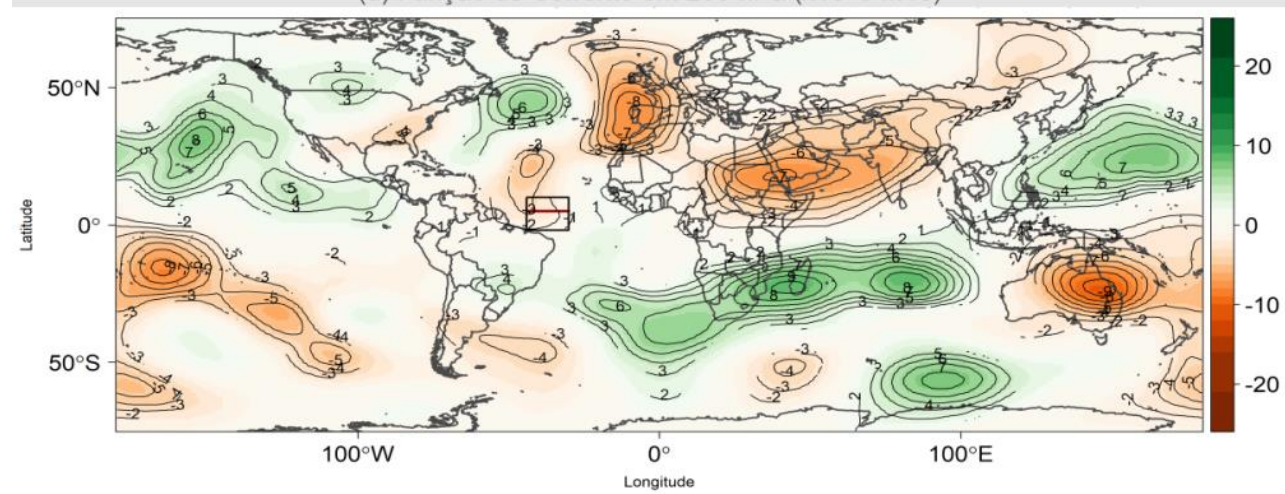

Figura 39 - Idem à Figura 32, porém para fase 8 da OMJ. 


\subsubsection{Extremos austrais}

As discussões e análises das composições calculadas para os eventos extremos austrais no outono (Figuras 41 a 49) serão mostradas a seguir. $O$ limiar que delimitou a seleção desses casos foi a sul de aproximadamente $3,8^{\circ} \mathrm{N}$.

A fase 0 (Figura 41) apresenta desfavorecimento de convecção (Figura 41a) e anomalia negativa de precipitação (Figura 41c) a norte do limiar através dos campos de ROLE e precipitação, e padrão oposto a sul do mesmo.

Nos campos de função de corrente (Figura 42d) e vento meridional em 200 $\mathrm{hPa}$ (Figura 42b) da fase 1 (Figura 42) podemos observar um padrão de desfavorecimento da ASAS embebido em um trem de onda que se desloca para leste a partir da faixa oeste do Pacífico tropical Sul que pode ter favorecido o posicionamento da ZCIT-AO a sul do limiar definido para esse caso devido ao enfraquecimento dos alísios de sudeste. Os campos de ROLE (Figura 42a) e precipitação (Figura 42c) mostram um favorecimento de convecção a sul do limiar, onde também há uma anomalia positiva de precipitação. $O$ inverso ocorre a norte do limiar. O campo de ROLE (Figura 42a) ainda mostra favorecimento de convecção sobre parte das Regiões N, NE e SE até o Atlântico Sudoeste, padrão associado à fase 1 da OMJ de acordo com a literatura (JONES, 2009).

$\mathrm{Na}$ fase 2 (Figura 43), os campos em altos (Figuras 43b e 43d) e baixos níveis (Figura 43a) mostram a propagação de um trem de onda sobre o Pacífico Sul que atravessa a América do Sul e outro sobre o Pacífico Norte, chegando ao Atlântico Norte. Esses padrões intensificaram a ASAS e a ASAN, respectivamente. No HS, o padrão do trem de onda de Rossby assemelha-se ao modo PSA2 negativo (MO; HIGGINS, 1998). Os campos de ROLE (Figura 43a) e precipitação (Figura 43c) mostram favorecimento de convecção e anomalia positiva de precipitação a sul do limiar e desfavorecimento de convecção e anomalia negativa de precipitação a norte do mesmo. 
As fases 3 e 4 (Figuras 44 e 45) apresentam padrão um pouco diferente das fases anteriores, pois os campos em altos (Figuras 44b, 44d, 45b e 45d) e baixos níveis (Figuras 44a e 45a) da atmosfera mostram um favorecimento de circulação anticiclônica sobre o Atlântico Norte, intensificando a ASAN. Com isso, a ZCIT-AO poderia posicionar-se mais a sul do limiar definido para esse caso. Ambas as fases apresentam anomalias negativas de ROLE (favorecimento de convecção) (Figuras $44 a$ e 45a) e positivas de precipitação (Figuras $44 c$ e 45 c) a sul do limiar e o oposto a norte do mesmo. Os campos de ROLE (Figuras 44a e 45a) dessas fases mostram favorecimento de convecção sobre o litoral norte da Região NE.

A propagação de um trem de ondas em altos níveis sobre a América do Norte na fase 5 (Figura 46) favoreceu uma anomalia anticiclônica sobre o Atlântico norte a leste do Golfo do México, como pode ser observado através dos campos de vento meridional (Figura 46b) e função de corrente (Figura 46d). Esse padrão pode ter fortalecido os alísios de nordeste e causado o deslocamento da ZCIT-AO para sul do limiar definido. O campo de precipitação (Figura 46c) mostra anomalias positivas de precipitação a sul do limiar e negativas a norte. Os campos de ROLE (Figura 46a) e precipitação (Figura 46c) indicam supressão de convecção e anomalias negativas de precipitação sobre o Brasil Central e SE, além de favorecimento de convecção e anomalias positivas de precipitação sobre o extremo Sul do país.

As fases 6 e 7 (Figuras 47 e 48) mostram o enfraquecimento da ASAS através dos campos de função de corrente (Figuras $47 d$ e $48 d$ ) e vento meridional (Figuras 47b e 48b) em $200 \mathrm{hPa}$. Como explicado em outros casos, o enfraquecimento desse sistema pode ter contribuído para o deslocamento da ZCIT-AO para sul, ficando a sul do limiar definido. Ambas as fases apresentam favorecimento de convecção (ROLE negativo) (Figuras 47 a e $48 a$ ) e anomalias positivas de precipitação (Figuras $47 \mathrm{c}$ e 48c) a sul do limiar, chegando ao litoral norte da Região NE, e desfavorecimento de convecção e anomalias negativas de precipitação a norte do mesmo.

Na fase 8 (Figura 49), um trem de onda desloca-se a partir do Pacífico equatorial Oeste e segue até o Atlântico Sul, favorecendo um padrão de circulação anticiclônica localizado em aproximadamente $45^{\circ}$ S sobre o Atlântico Sul, padrão que 
pode ser observado através dos campos de função de corrente (Figura 49d) e vento meridional (Figura 49b) em 200 hPa e escoamento em 850 hPa (Figura 49a). Esse padrão favorece a convergência de umidade entre NE/SE (Figura 49a) e possibilita o posicionamento da ZCIT-AO a sul do limiar. O campo de ROLE (Figura 49a) mostra favorecimento de convecção por toda a Região NE e norte da Região SE do Brasil, o que é esperado para essa fase da OMJ (JONES, 2009). Há supressão de convecção (ROLE positivo) e anomalia de precipitação negativa a norte do limiar. 

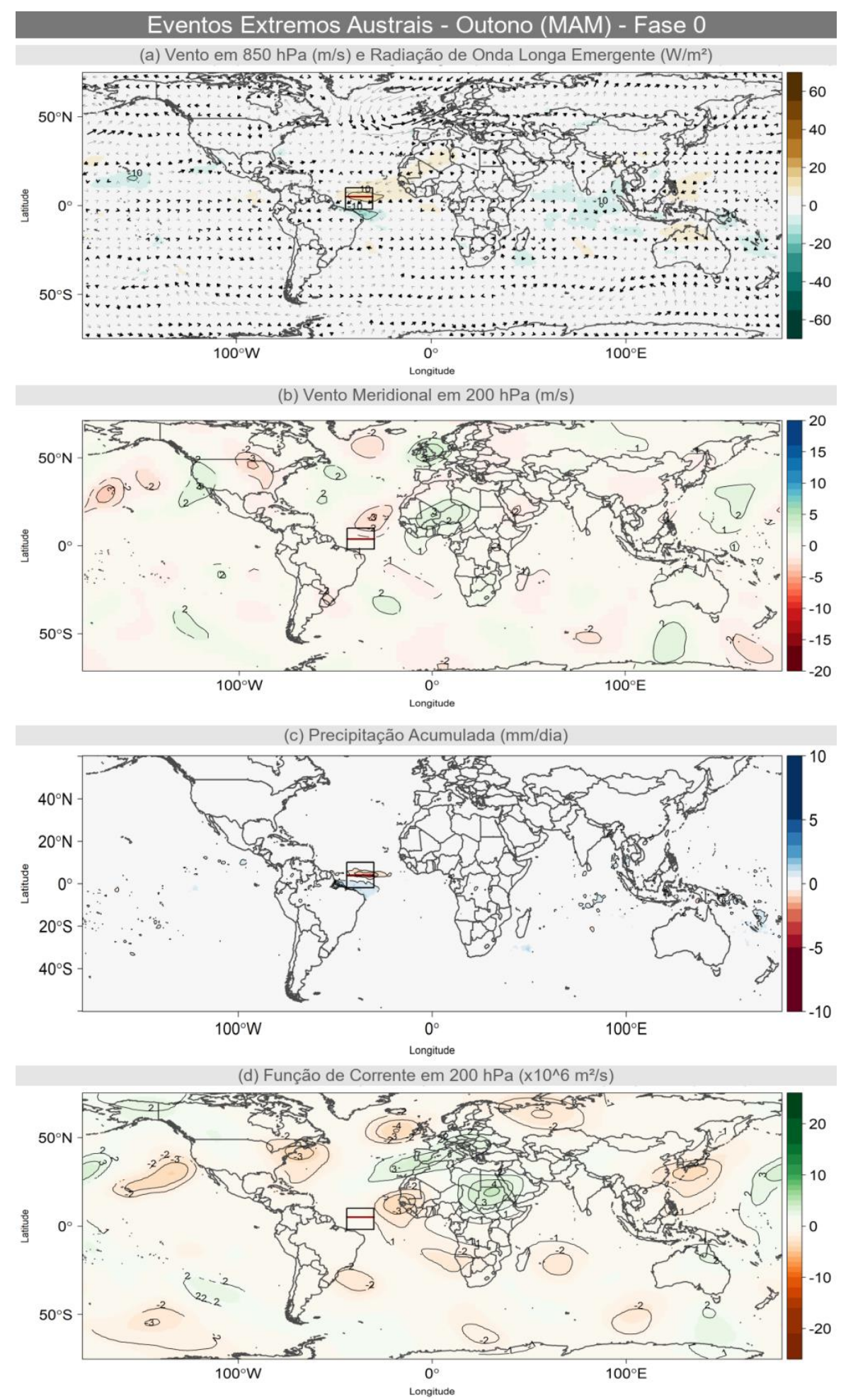

Figura 40 - Composições para os eventos extremos austrais para o Outono (MAM) e fase 0 da OMJ das anomalias de (a) vento em $850 \mathrm{hPa}\left({ }^{*} 100 \mathrm{~m} / \mathrm{s}\right)$ e ROLE $\left(\mathrm{W} / \mathrm{m}^{2}\right)$, (b) vento meridional em $200 \mathrm{hPa}$ (m/s), (c) precipitação (mm/dia) e (d) função de corrente em $200 \mathrm{hPa}$ $\left(x 10^{\wedge} 6 \mathrm{~m}^{2} / \mathrm{s}\right)$. A caixa preta representa a Região de Estudo e a linha vermelha representa 0 percentil (limiar) do IZCIT-AO para esse caso. Os vetores em negrito e as áreas contornadas representam significância estatística ao nível de 5\%. 


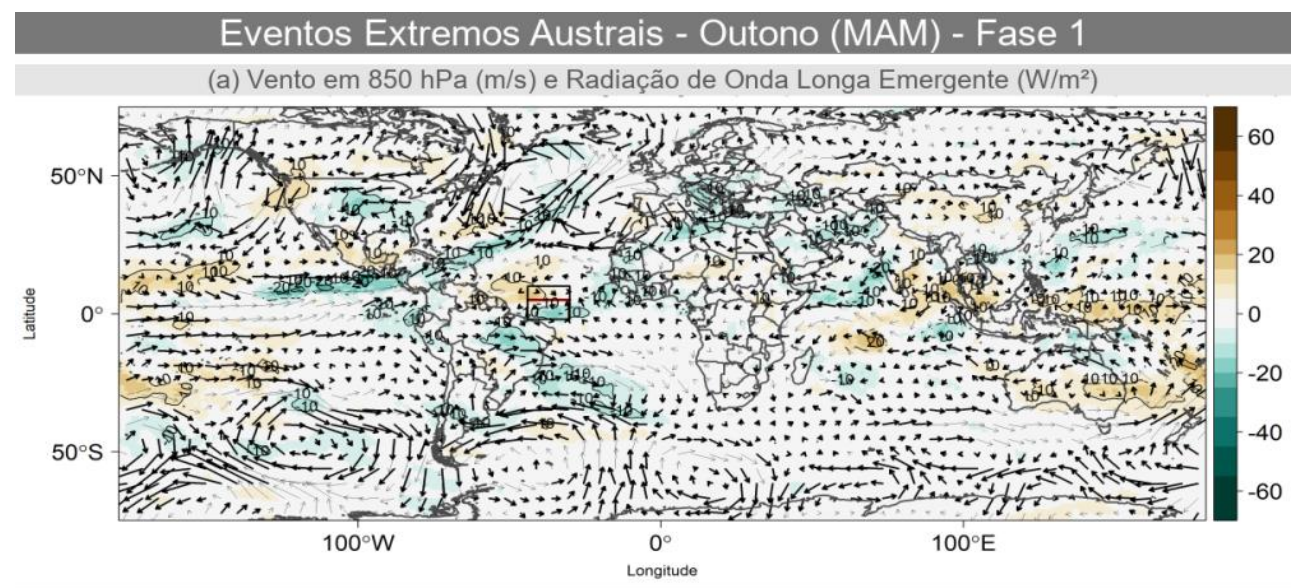

(b) Vento Meridional em $200 \mathrm{hPa}(\mathrm{m} / \mathrm{s})$

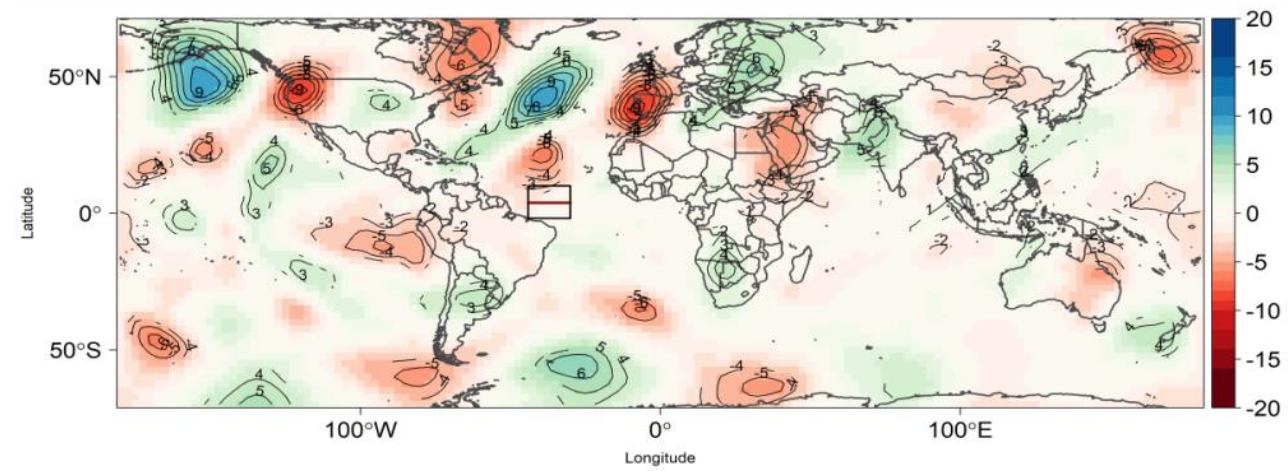

(c) Precipitação Acumulada ( $\mathrm{mm} / \mathrm{dia}$ )

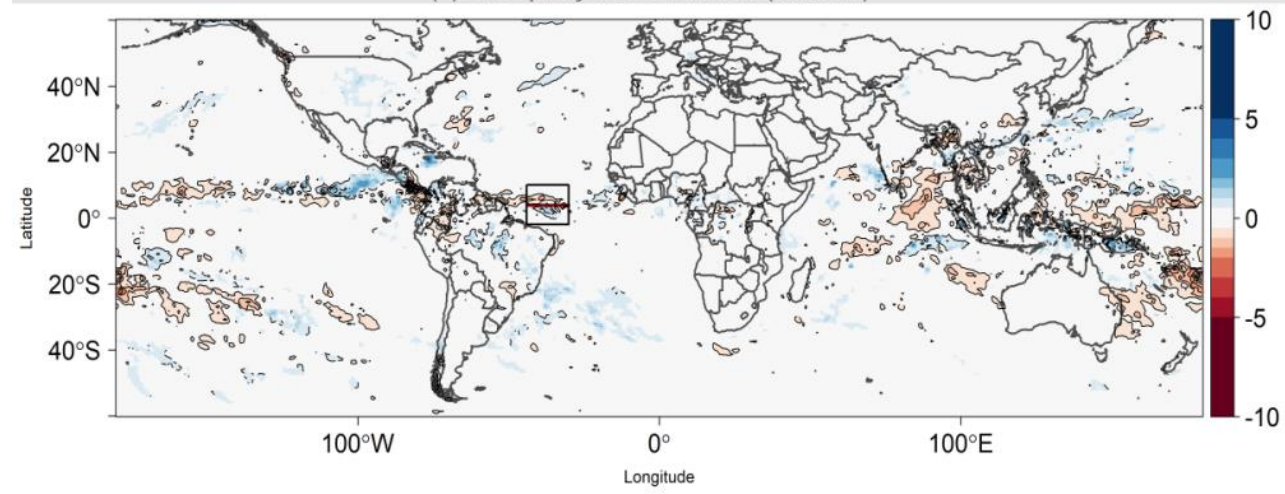

(d) Função de Corrente em $200 \mathrm{hPa}\left(\times 10^{\wedge} 6 \mathrm{~m}^{2} / \mathrm{s}\right)$

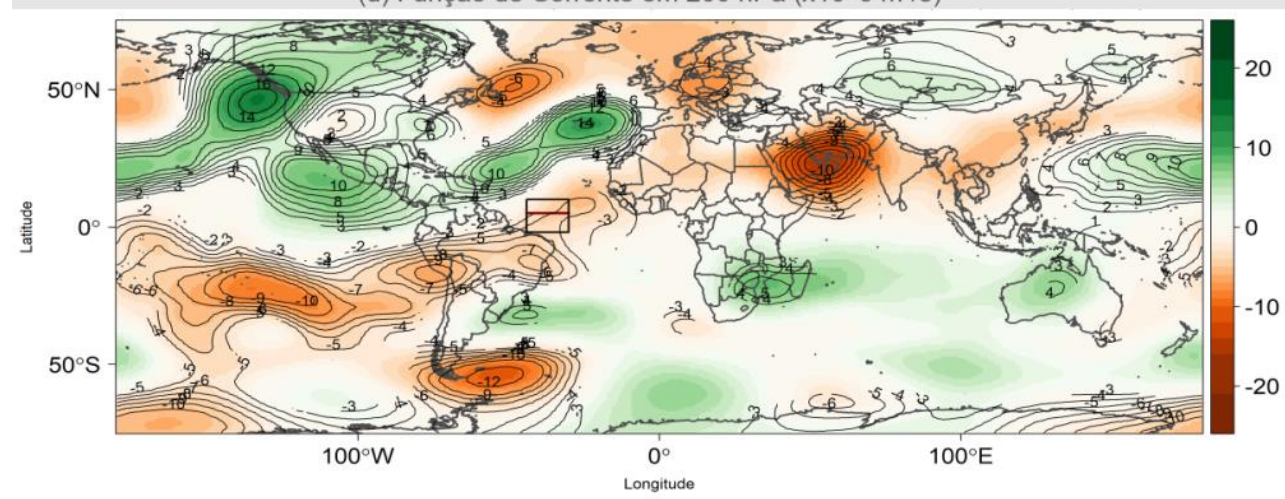

Figura 41 - Idem à Figura 41, porém para fase 1 da OMJ. 


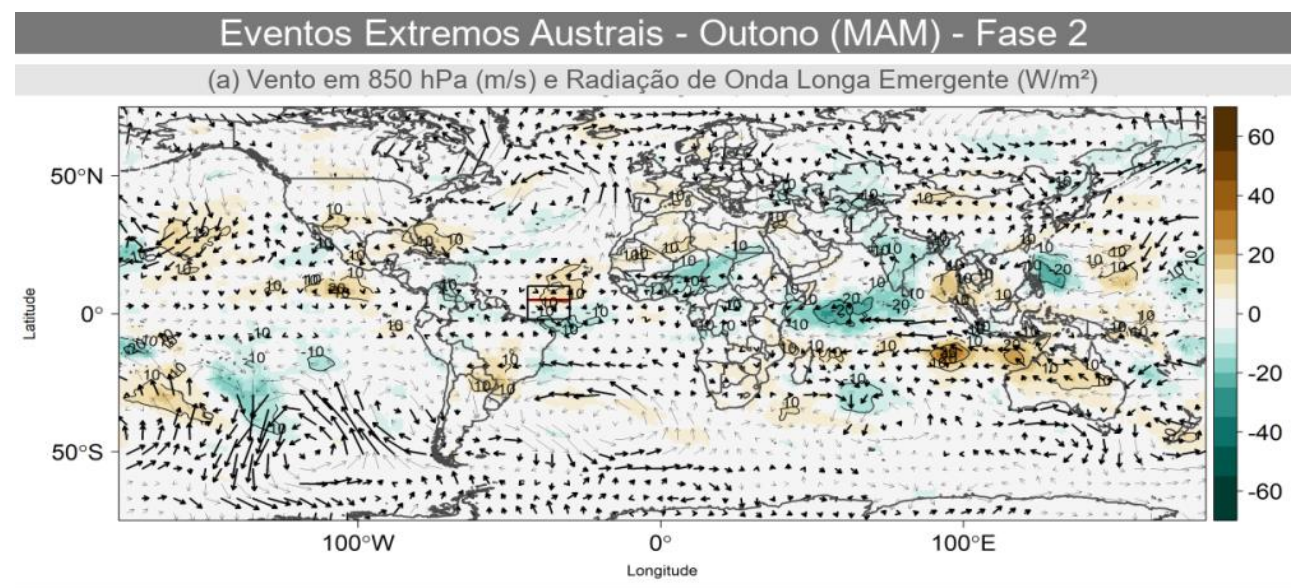

(b) Vento Meridional em $200 \mathrm{hPa}(\mathrm{m} / \mathrm{s})$

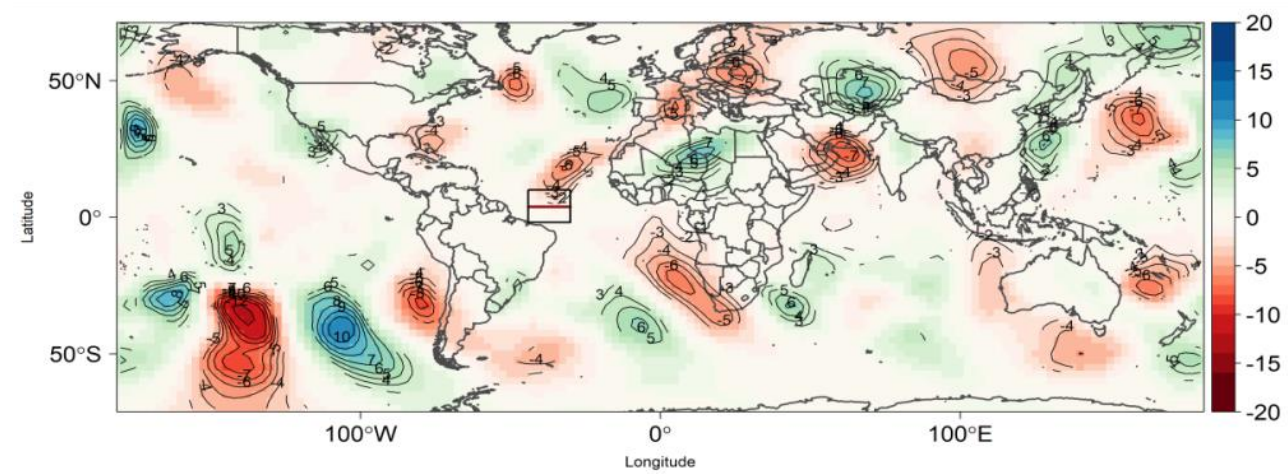

(c) Precipitação Acumulada ( $\mathrm{mm} / \mathrm{dia}$ )

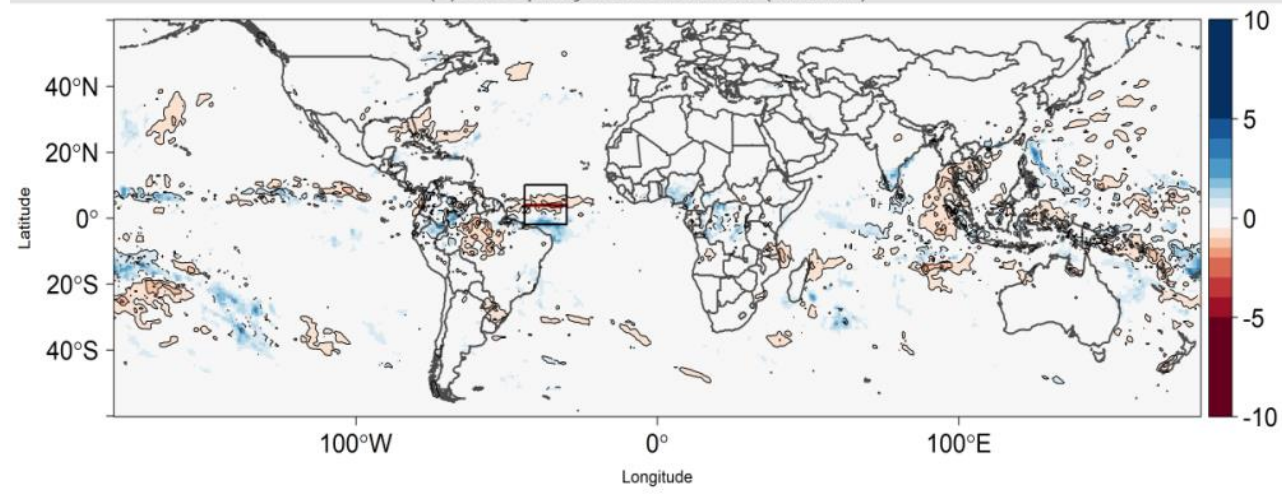

(d) Função de Corrente em $200 \mathrm{hPa}\left(\times 10^{\wedge} 6 \mathrm{~m}^{2} / \mathrm{s}\right)$

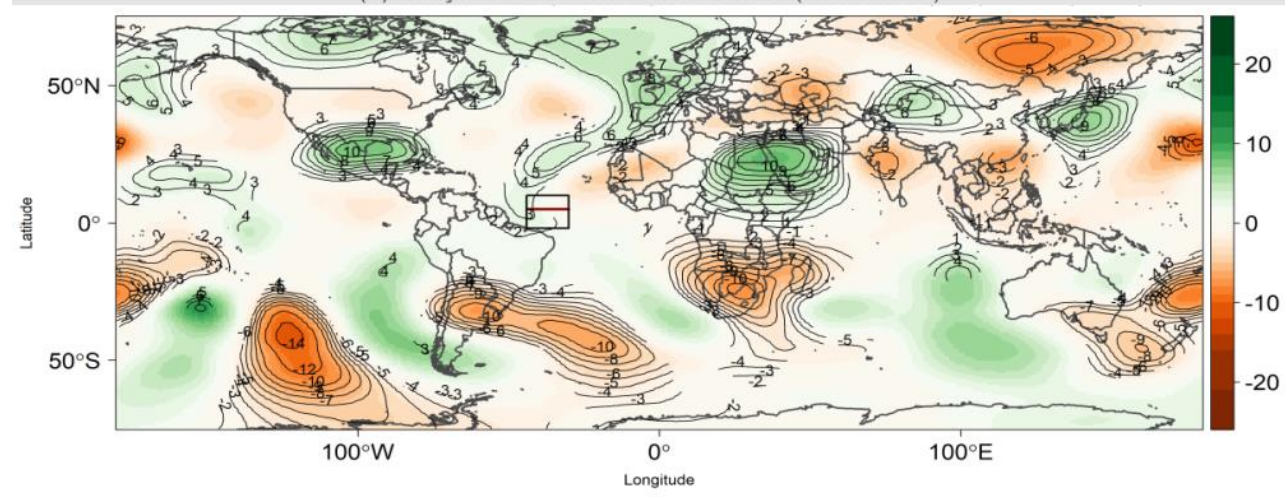

Figura 42 - Idem à Figura 41, porém para fase 2 da OMJ. 


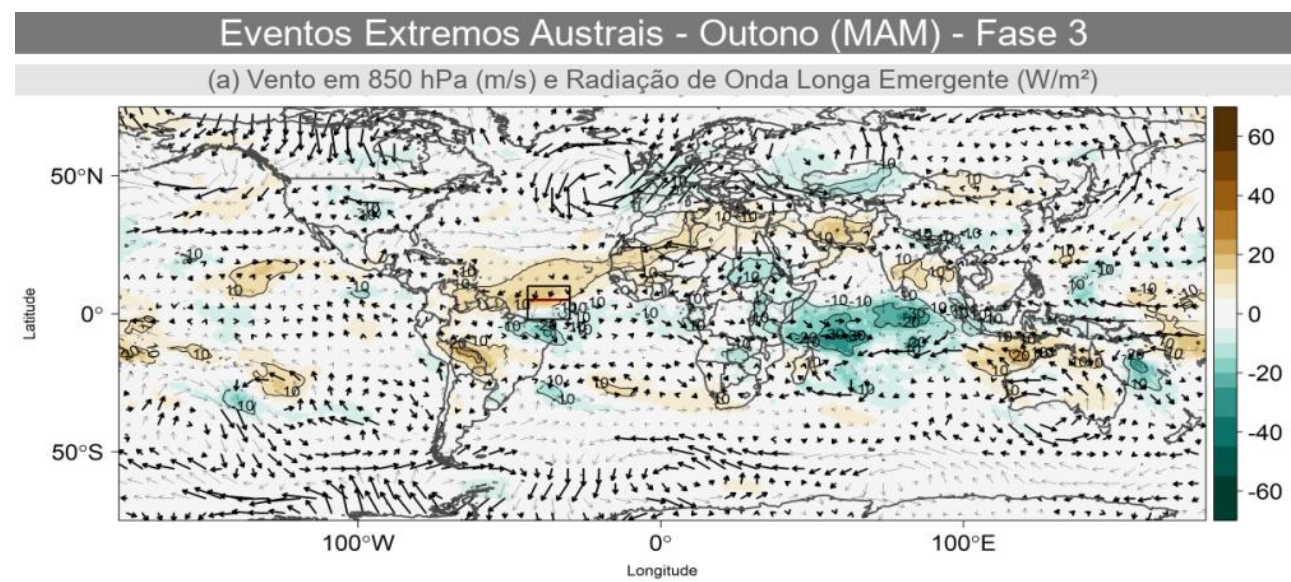

(b) Vento Meridional em $200 \mathrm{hPa}(\mathrm{m} / \mathrm{s})$

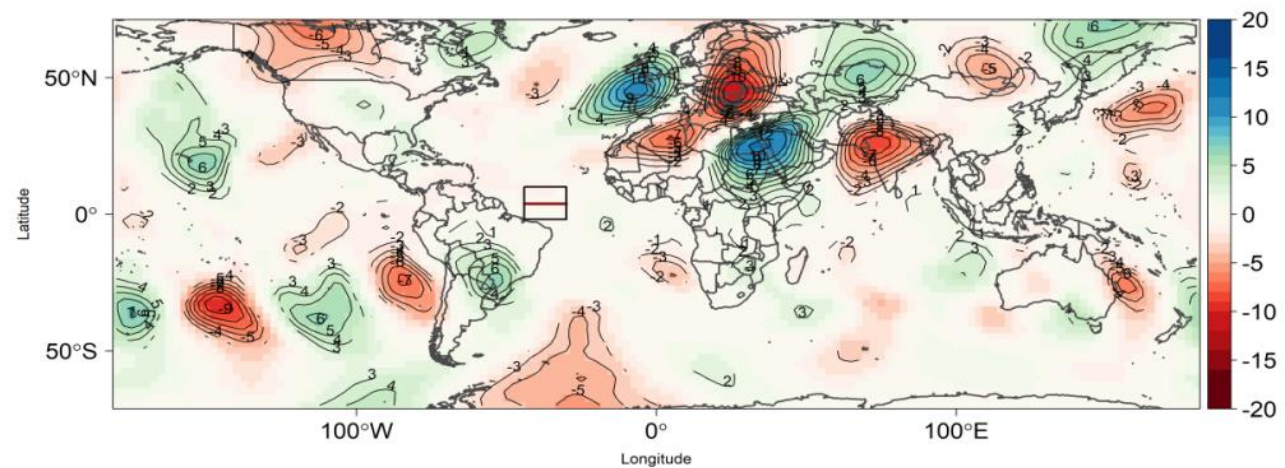

(c) Precipitação Acumulada ( $\mathrm{mm} / \mathrm{dia}$ )

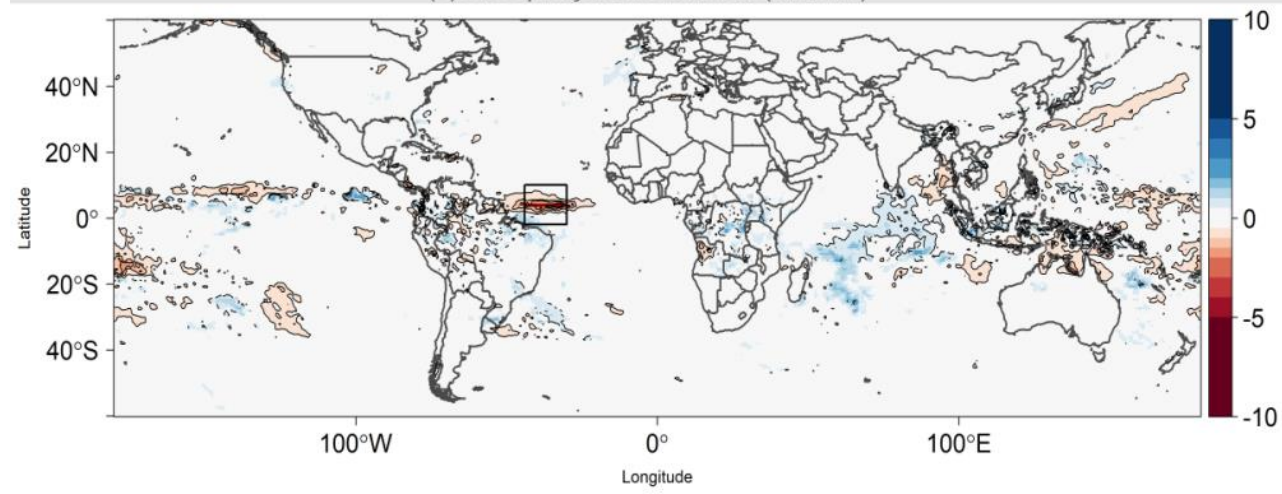

(d) Função de Corrente em $200 \mathrm{hPa}\left(\times 10^{\wedge} 6 \mathrm{~m}^{2} / \mathrm{s}\right)$

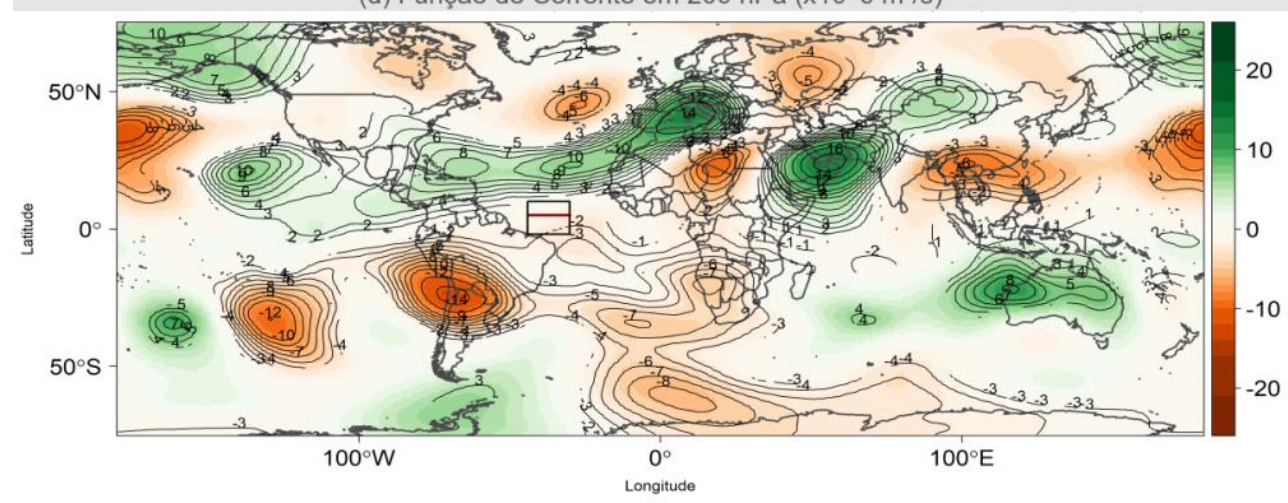

Figura 43 - Idem à Figura 41, porém para fase 3 da OMJ. 


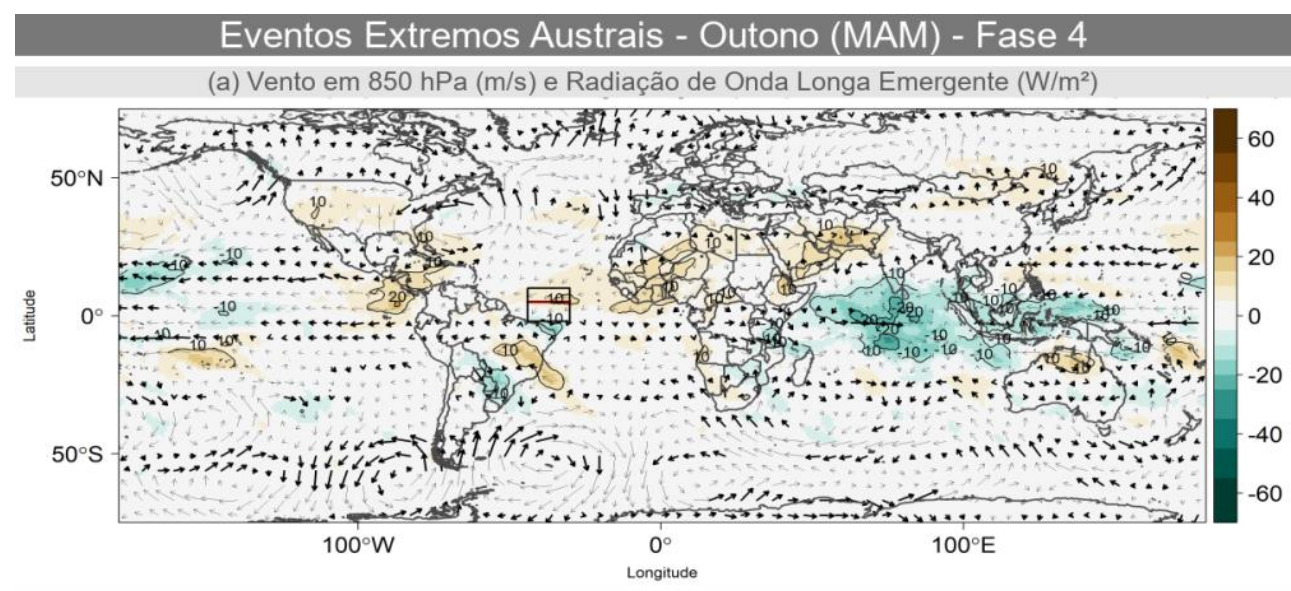

(b) Vento Meridional em $200 \mathrm{hPa}(\mathrm{m} / \mathrm{s})$

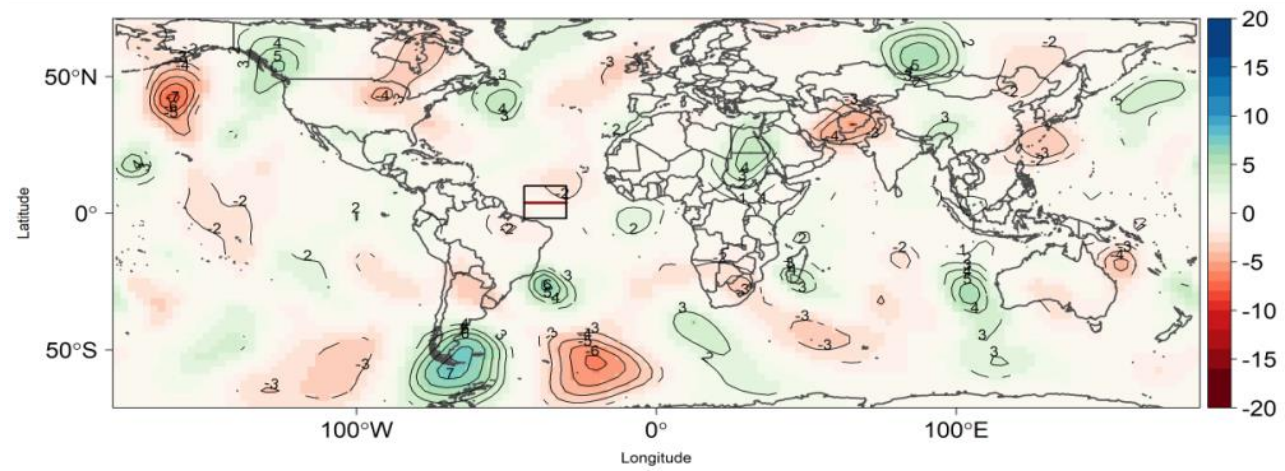

(c) Precipitação Acumulada ( $\mathrm{mm} / \mathrm{dia}$ )

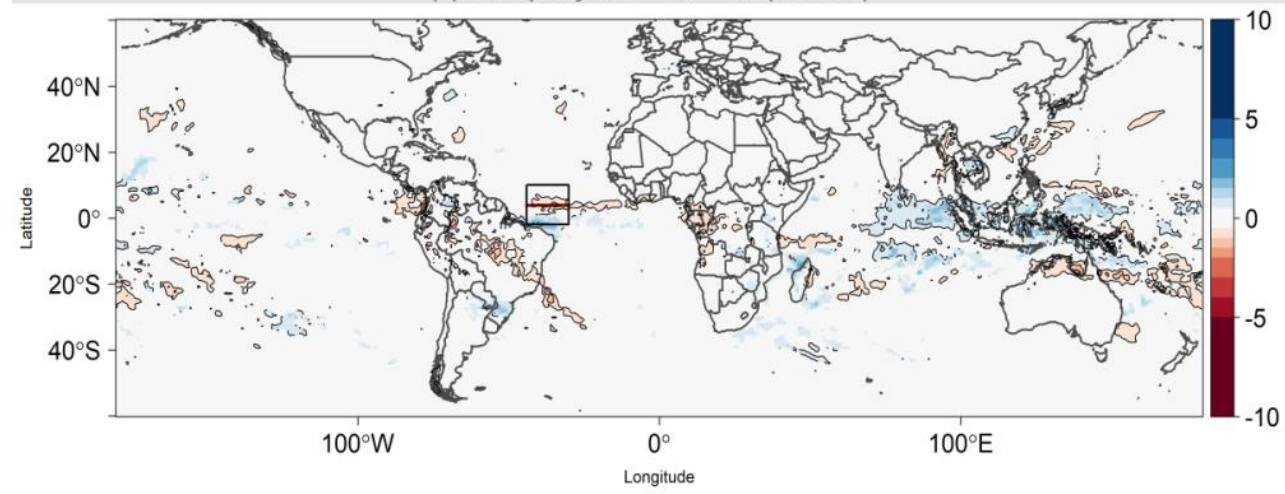

(d) Função de Corrente em $200 \mathrm{hPa}\left(\times 10^{\wedge} 6 \mathrm{~m}^{2} / \mathrm{s}\right)$

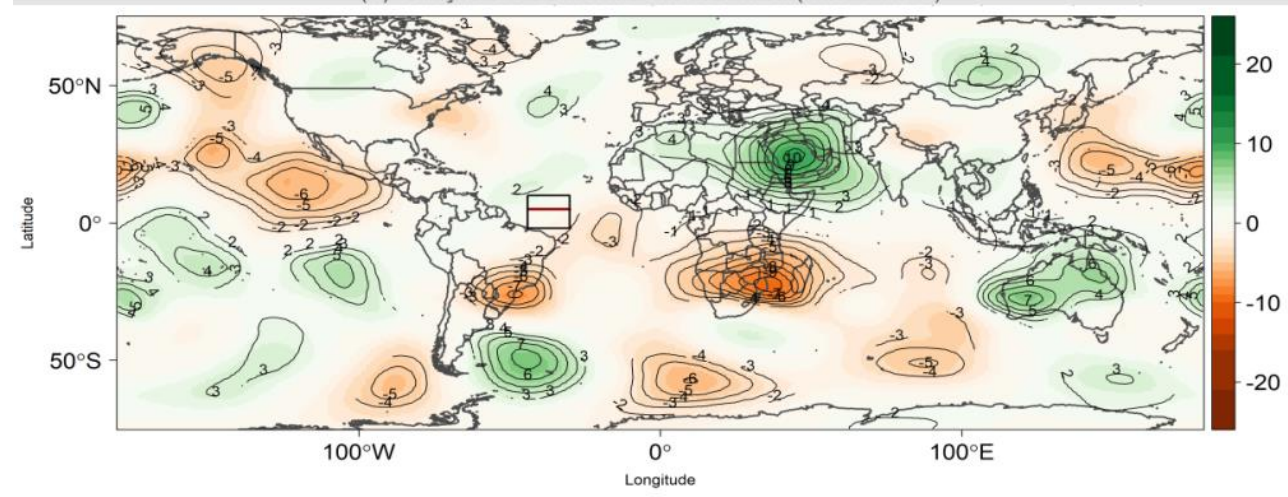

Figura 44 - Idem à Figura 41, porém para fase 4 da OMJ. 


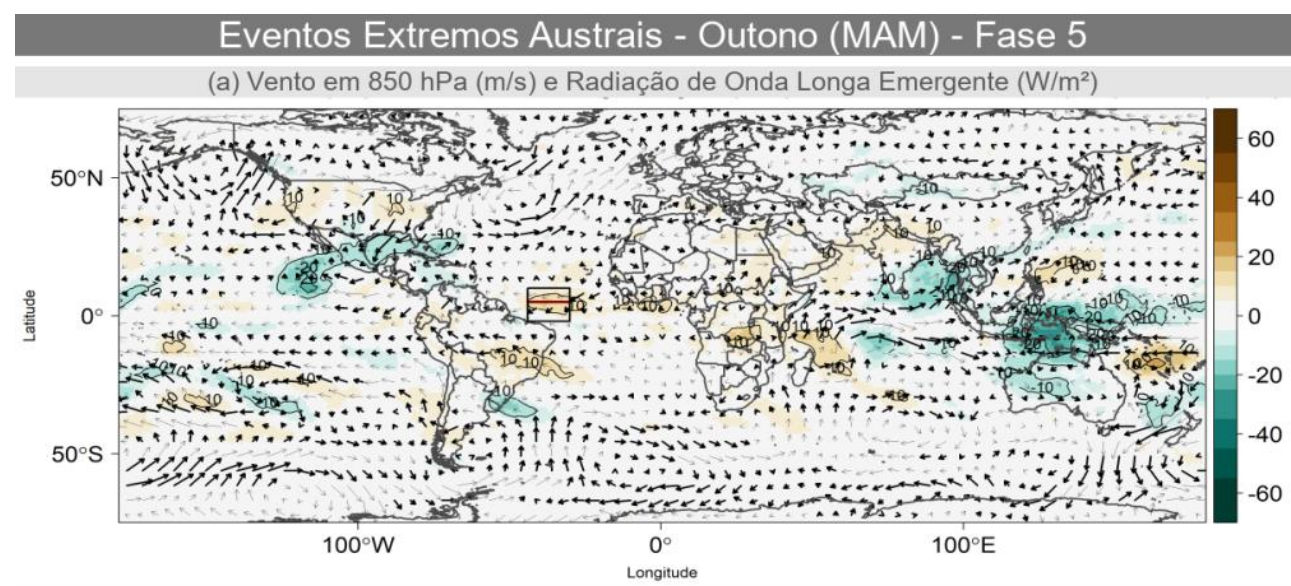

(b) Vento Meridional em $200 \mathrm{hPa}(\mathrm{m} / \mathrm{s})$

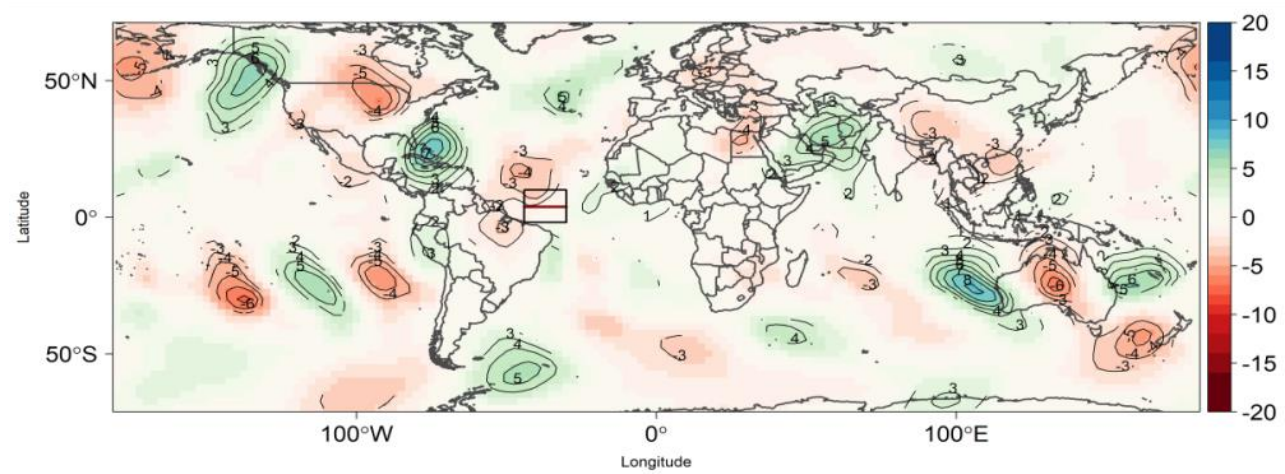

(c) Precipitação Acumulada ( $\mathrm{mm} / \mathrm{dia}$ )

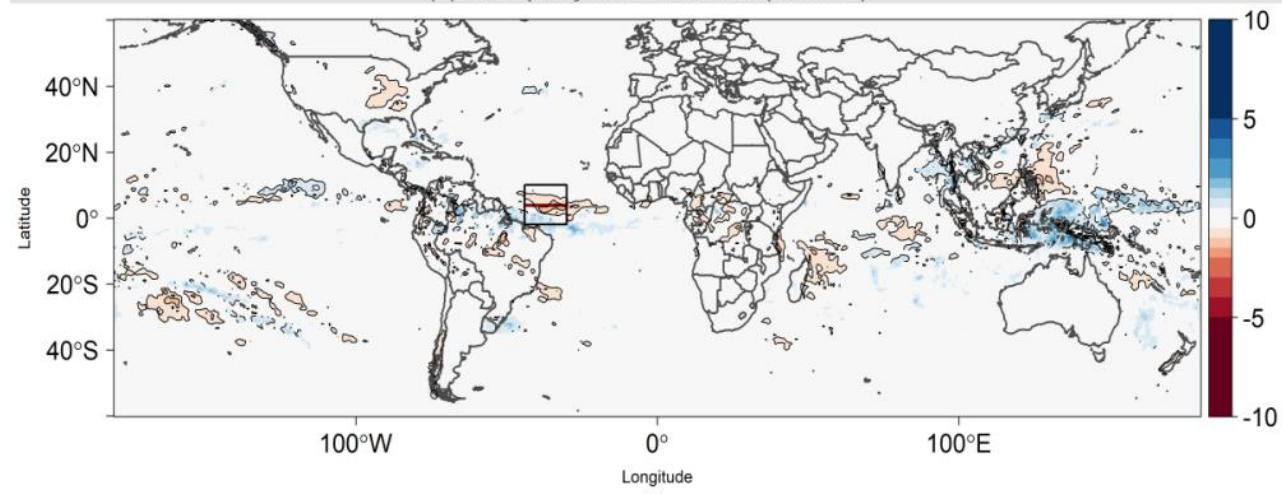

(d) Função de Corrente em $200 \mathrm{hPa}\left(\times 10^{\wedge} 6 \mathrm{~m}^{2} / \mathrm{s}\right)$

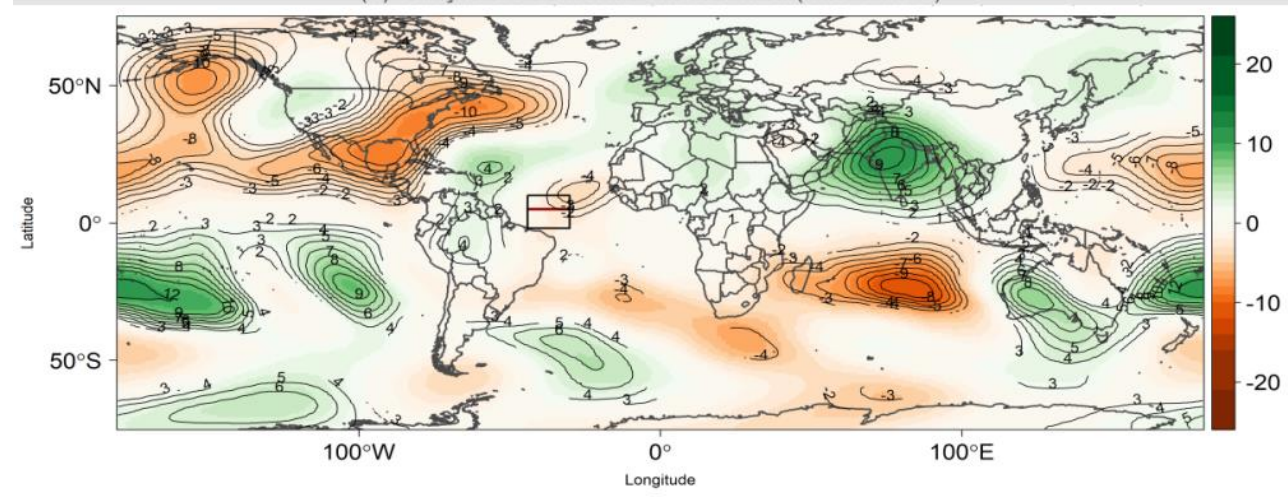

Figura 45 - Idem à Figura 41, porém para fase 5 da OMJ. 


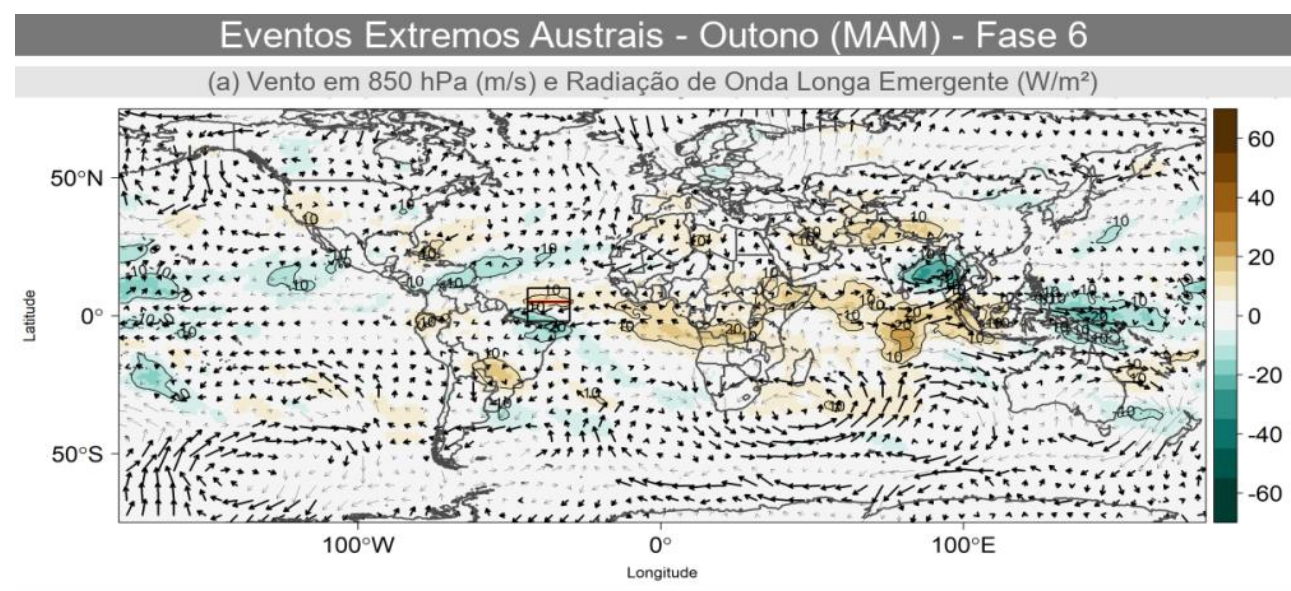

(b) Vento Meridional em $200 \mathrm{hPa}(\mathrm{m} / \mathrm{s})$

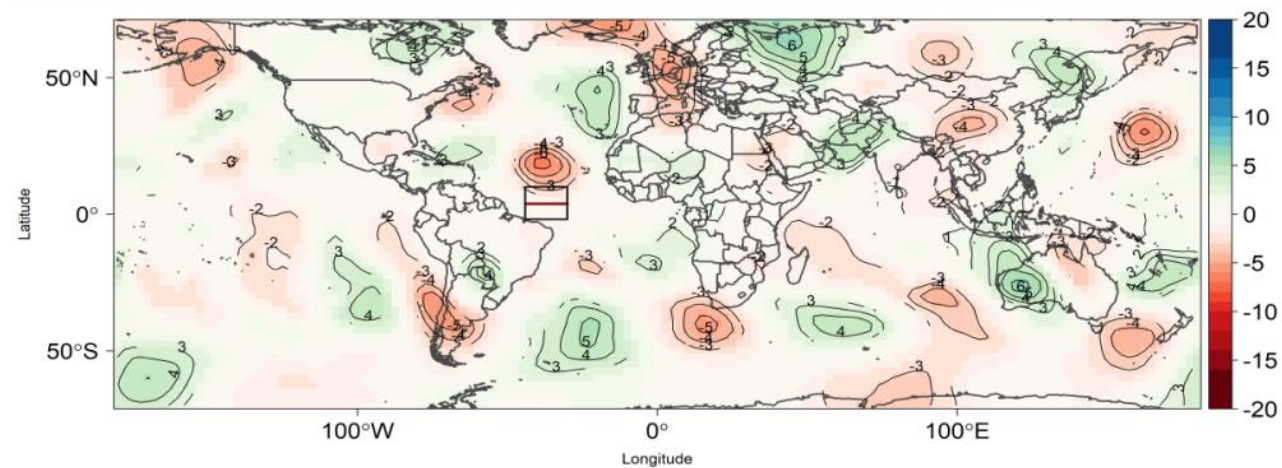

(c) Precipitação Acumulada ( $\mathrm{mm} / \mathrm{dia})$

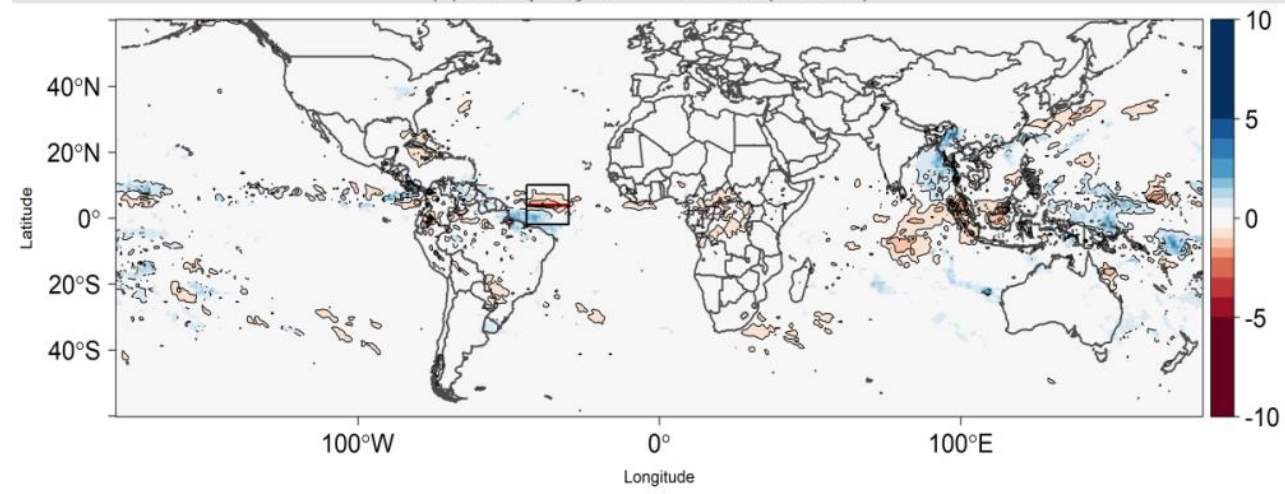

(d) Função de Corrente em $200 \mathrm{hPa}\left(\times 10^{\wedge} 6 \mathrm{~m}^{2} / \mathrm{s}\right)$

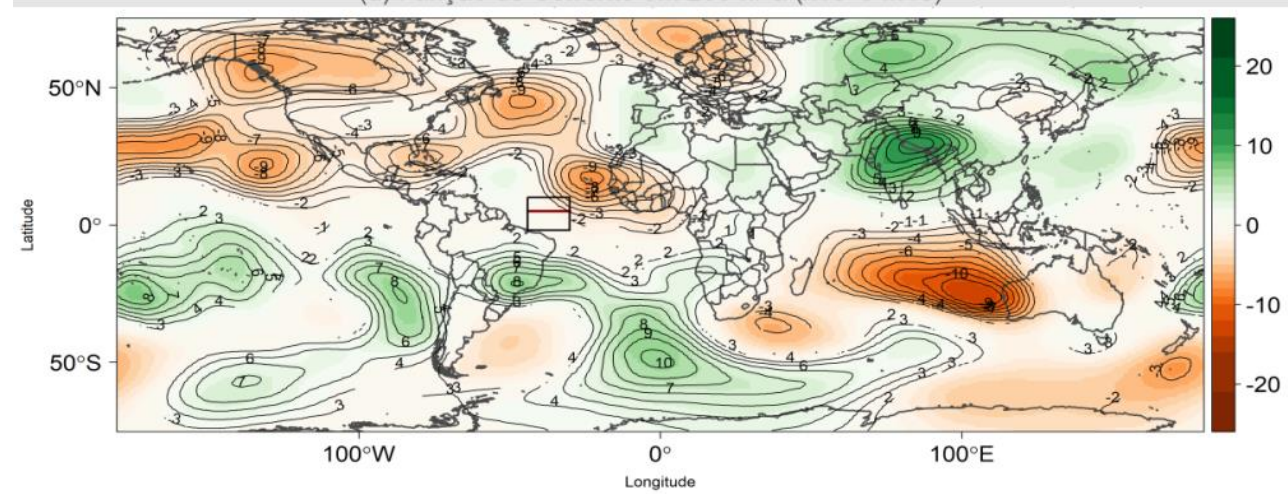

Figura 46 - Idem à Figura 41, porém para fase 6 da OMJ. 


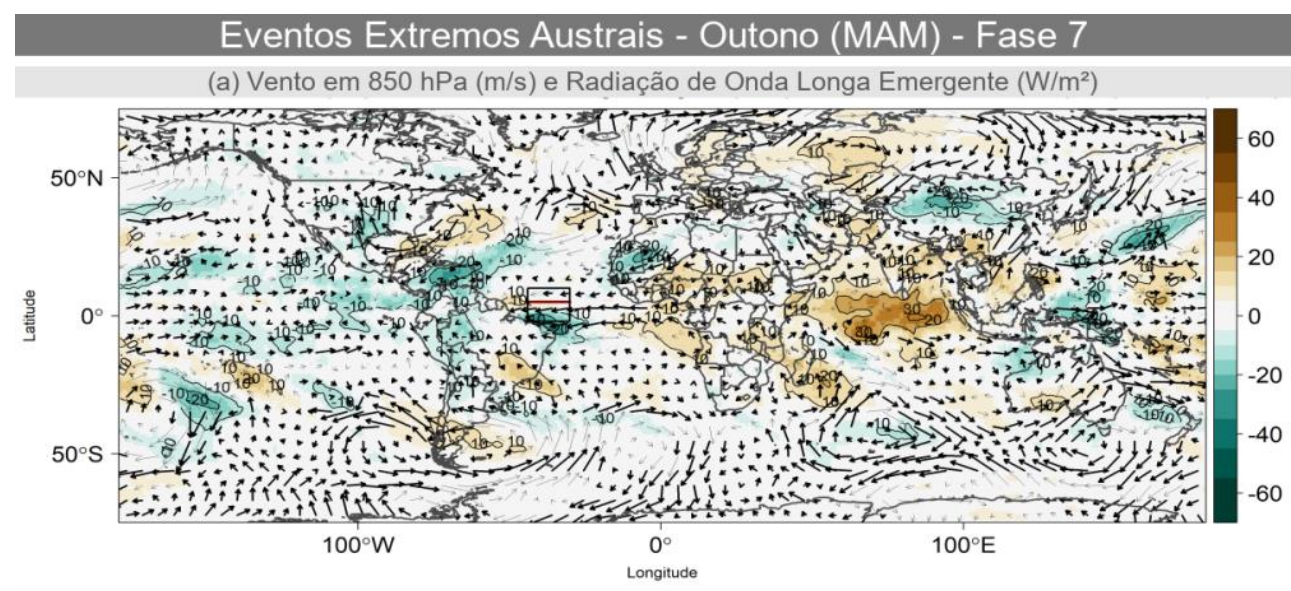

(b) Vento Meridional em $200 \mathrm{hPa}(\mathrm{m} / \mathrm{s})$

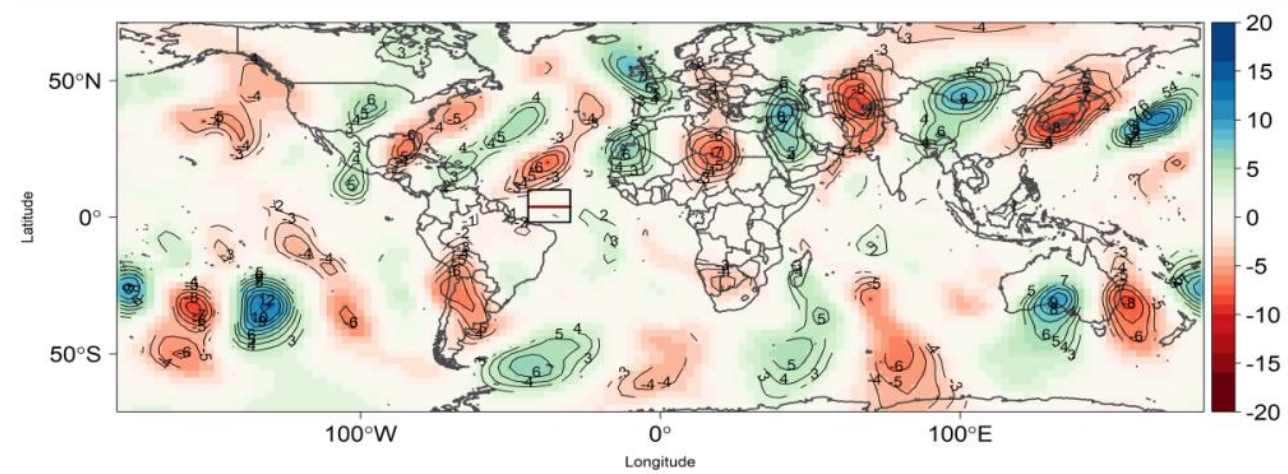

(c) Precipitação Acumulada ( $\mathrm{mm} / \mathrm{dia}$ )

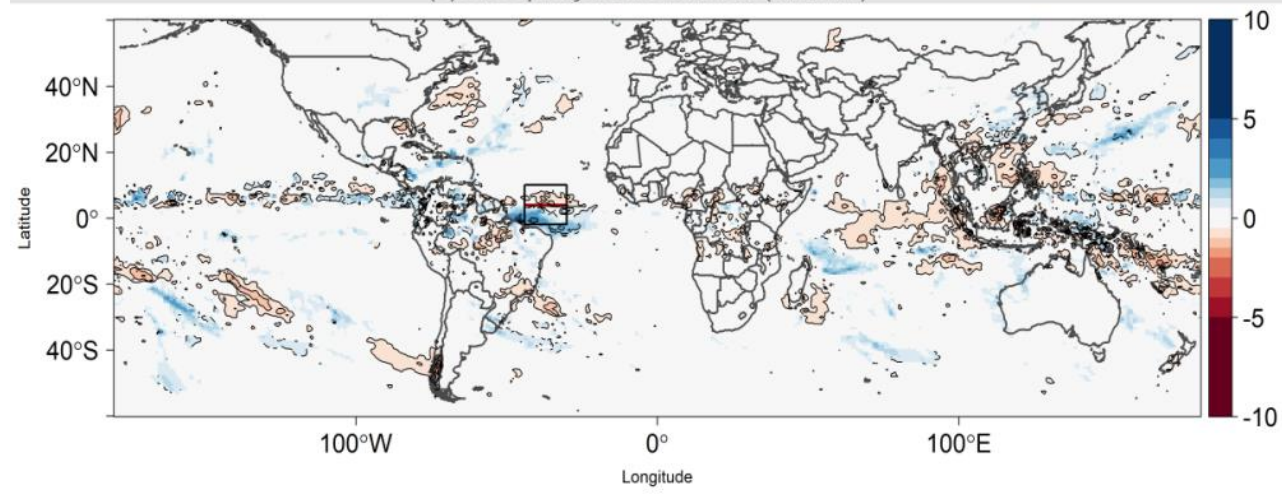

(d) Função de Corrente em $200 \mathrm{hPa}\left(\times 10^{\wedge} 6 \mathrm{~m}^{2} / \mathrm{s}\right)$

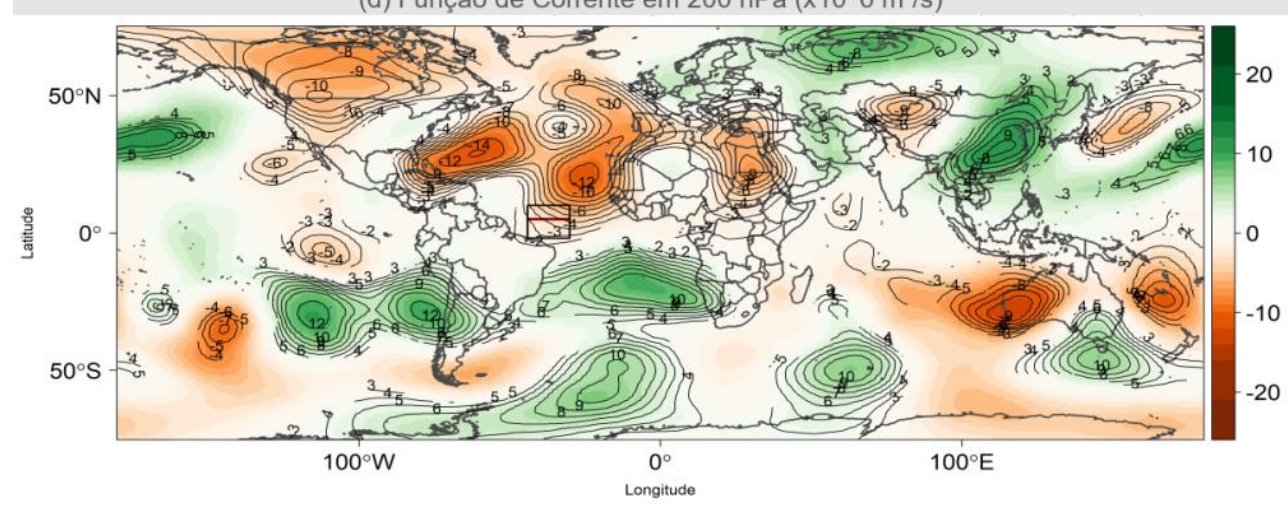

Figura 47 - Idem à Figura 41, porém para fase 7 da OMJ. 


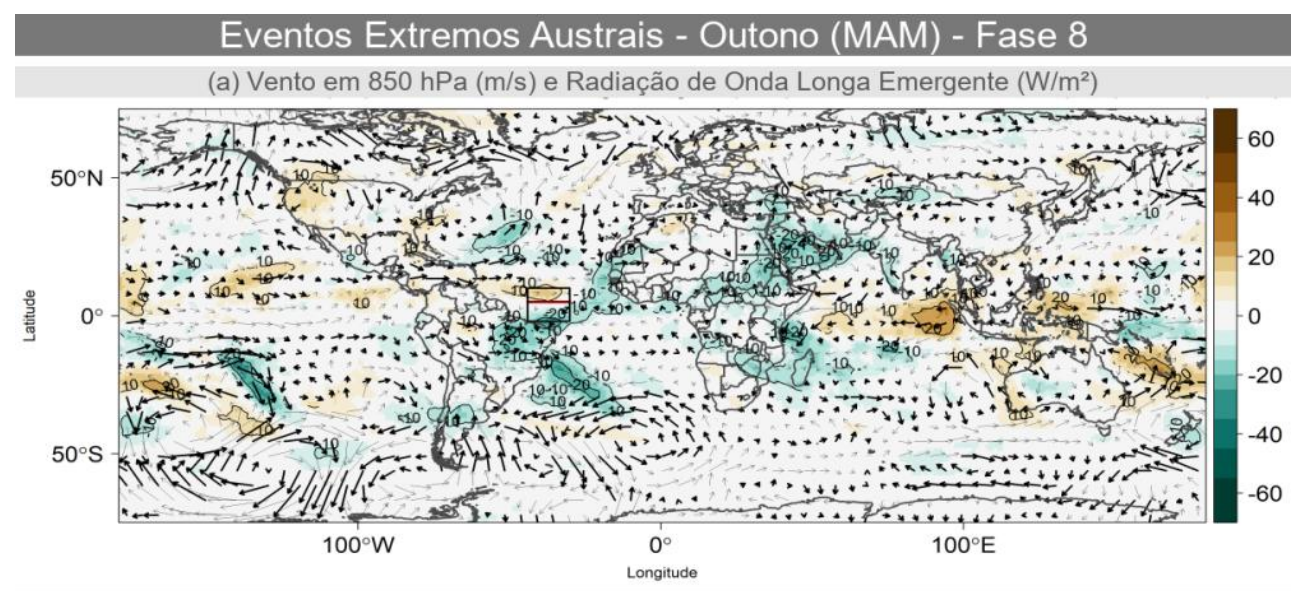

(b) Vento Meridional em $200 \mathrm{hPa}(\mathrm{m} / \mathrm{s})$

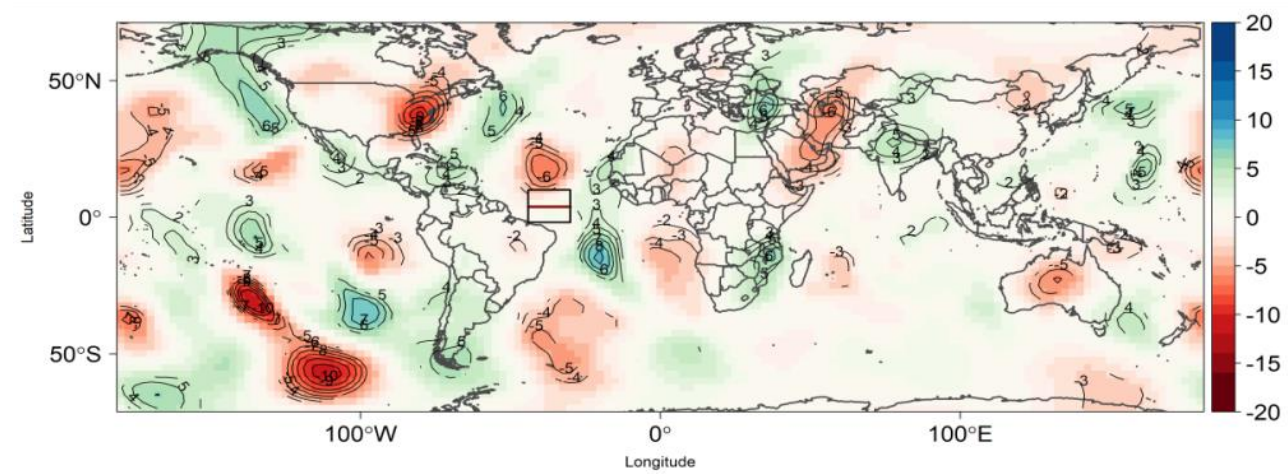

(c) Precipitação Acumulada ( $\mathrm{mm} / \mathrm{dia}$ )

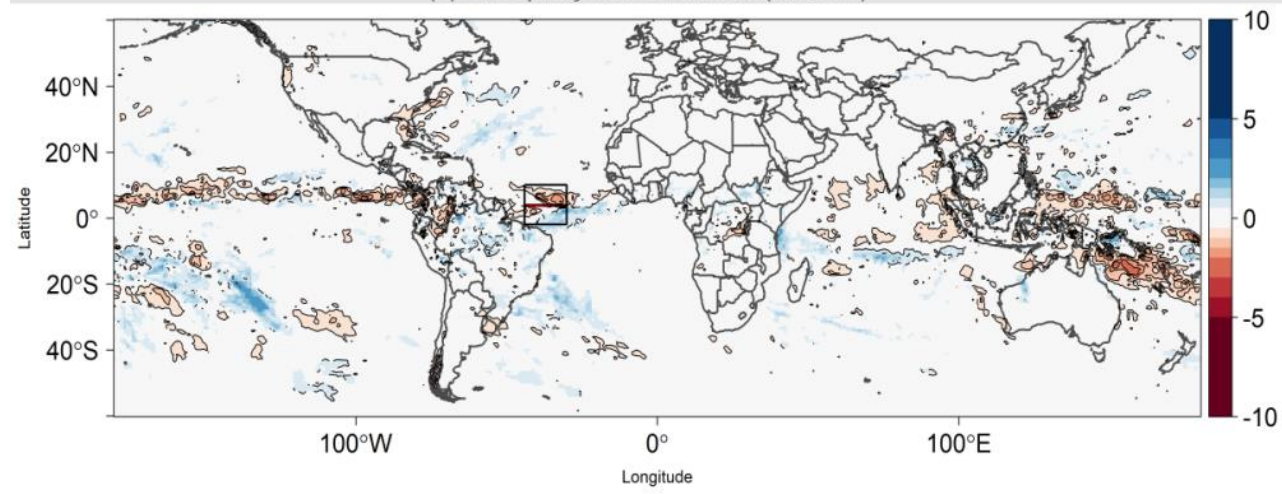

(d) Função de Corrente em $200 \mathrm{hPa}\left(\times 10^{\wedge} 6 \mathrm{~m}^{2} / \mathrm{s}\right)$

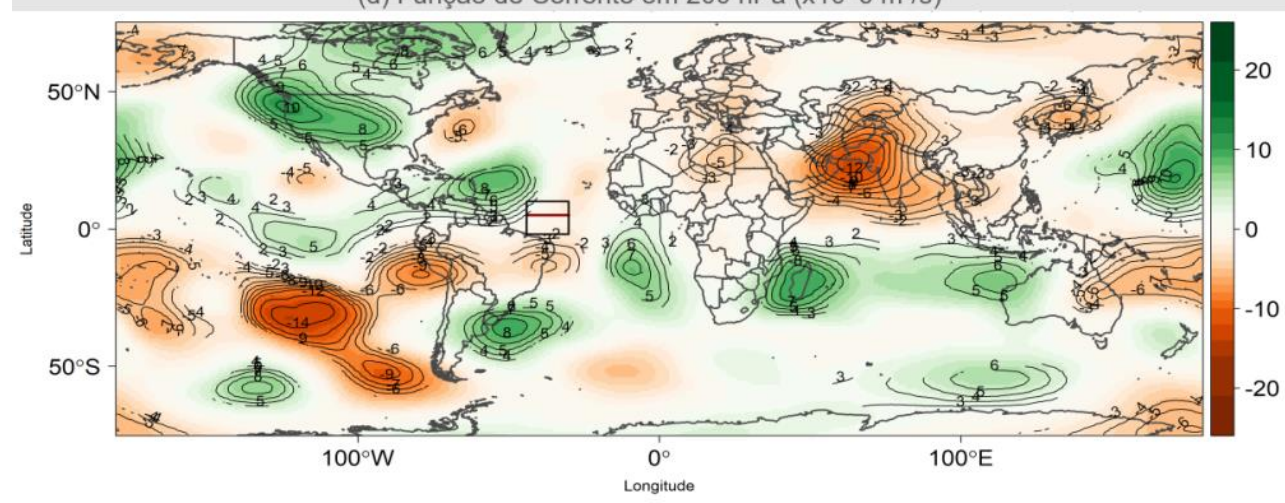

Figura 48 - Idem à Figura 41, porém para fase 8 da OMJ. 


\subsection{Estudo de Casos Extremos}

Como discutido na Subseção 3.2.5, os casos selecionados através dos critérios discutidos anteriormente estão representados a seguir:

- Caso 1: Extremo austral outono: 30/04 a 08/05/2004;

- Caso 2: Extremo austral primavera: 13 a 21/10/1997;

- Caso 3: Extremo boreal outono: 11 a 18/04/2004;

- Caso 4: Extremo boreal primavera: 18 a 28/11/2000.

As Figuras 50, 52, 54 e 56 mostram as composições de anomalias intrassazonais de ROLE e vento ( $850 \mathrm{hPa}$ ) calculadas para cada um dos casos selecionados e as Figuras 51, 53, 55 e 57 mostram as imagens de satélite correspondentes ao dia em que a ZCIT esteve em sua posição mais extrema no período.

As fases predominantes da $\mathrm{OMJ}$ e as médias das posições latitudinais obtidas através do IZCIT-AO filtrado para cada caso são mostradas na Tabela 1. Os posicionamentos médios (utilizando o IZCIT-AO filtrado) e as fases predominantes considerando todos os anos selecionados para o presente estudo (1995-2010) e no mesmo período dos casos selecionados também se encontram nessa tabela.

O Caso 1 apresenta um padrão de favorecimento de convecção sobre a faixa oeste do Brasil Central, Região Sul e sobre o extremo norte do país (Figura 50), este último devido ao posicionamento da ZCIT mais a sul do que a média do IZCITAO. Pode-se observar também que a ASAS está enfraquecida (circulação ciclônica sobre o Atlântico Sul central, em aproximadamente $20^{\circ} \mathrm{S}$ ) e os alísios de nordeste sobre o Atlântico tropical estão fortalecidos devido ao padrão de circulação sobre o Atlântico norte, o que contribuiu para o deslocamento da ZCIT-AO para sul. A banda de nebulosidade observada na imagem de satélite (Figura 51) sobre o Atlântico tropical oeste apresenta padrão coerente com o favorecimento da convecção descrito. Nesse evento, o IZCIT-AO filtrado nos mostrou que a ZCIT-AO atingiu o valor de 2,9º 
$\mathrm{N}, 1,3$ grau ao sul da posição média intrassazonal considerando todos os anos do estudo. Entretanto, a OMJ esteve inativa no período, indicando que o deslocamento extremo da ZCIT-AO esteve associado a outro fenômeno na banda intrassazonal.

Em relação ao Caso 2 observa-se um favorecimento de convecção sobre - Brasil Central e Região SE, além de desfavorecimento sobre o sul do país (Figura 52). Nesse caso não há favorecimento de convecção sobre o extremo norte do país, porém há desfavorecimento sobre o Atlântico tropical norte, próximo a $10^{\circ} \mathrm{N}$. Ainda na Figura 52, podemos observar a ASAS enfraquecida, o explica o deslocamento da ZCIT-AO para sul. Na imagem de satélite (Figura 53), observa-se que a ZCIT-AO não aparece bem configurada no período. A desconfiguração da ZCIT-AO sobre o HN nesse período pode ter influenciado na determinação do IZCIT-AO, pois alguma convecção local mais a sul pode ter aparecido e influenciado a latitude selecionada pelo método. A limitação da região de estudo, que está compreendida entre $2^{\circ} \mathrm{S}$ e $10^{\circ}$ $\mathrm{N}$, também pode ter influenciado na precisão da seleção desses eventos. $\mathrm{O}$ valor do IZCIT-AO medido nesse caso foi de 2,3ํN N 1,6 grau ao sul da posição média intrassazonal para o mesmo período. A OMJ também esteve inativa nesse caso.

Tabela 1 - Dados estatísticos para cada caso selecionado

\begin{tabular}{c|ccccc}
\multicolumn{1}{c}{} & $\begin{array}{c}\text { Fase } \\
\text { predominante } \\
\text { do evento }\end{array}$ & $\begin{array}{c}\text { Fase } \\
\text { predominante no } \\
\text { período de estudo }\end{array}$ & $\begin{array}{c}\text { Média do IZCIT- } \\
\text { AO filtrado no } \\
\text { evento }\end{array}$ & $\begin{array}{c}\text { Média do IZCIT-AO } \\
\text { filtrado no período de } \\
\text { estudo }\end{array}$ \\
\hline Caso 1 & $\begin{array}{c}\text { Extremo austral } \\
\text { outono }\end{array}$ & 0 & 0 & $2,9^{\circ} \mathrm{N}$ & $4,2^{\circ} \mathrm{N}$ \\
Caso 2 & $\begin{array}{c}\text { Extremo austral } \\
\text { primavera }\end{array}$ & 0 & 0 & $2,9^{\circ} \mathrm{N}$ & $4,5^{\circ} \mathrm{N}$ \\
Caso 3 & $\begin{array}{c}\text { Extremo boreal } \\
\text { outono }\end{array}$ & 8 & 0 & $6,4^{\circ} \mathrm{N}$ & $4,7^{\circ} \mathrm{N}$ \\
Caso 4 & $\begin{array}{c}\text { Extremo boreal } \\
\text { primavera }\end{array}$ & 4 & 0 & $5,7^{\circ} \mathrm{N}$ & $4,5^{\circ} \mathrm{N}$
\end{tabular}


Analisando as composições para cada caso fica evidente que os eventos extremos boreais, Casos 3 e 4, apresentam uma estrutura bem mais configurada da ZCIT-AO. As imagens de satélite desses casos (Figuras 55 e 57) mostram a banda de nebulosidade associada à ZCIT-AO claramente organizada sobre o Atlântico Norte, distante da costa norte do Brasil.

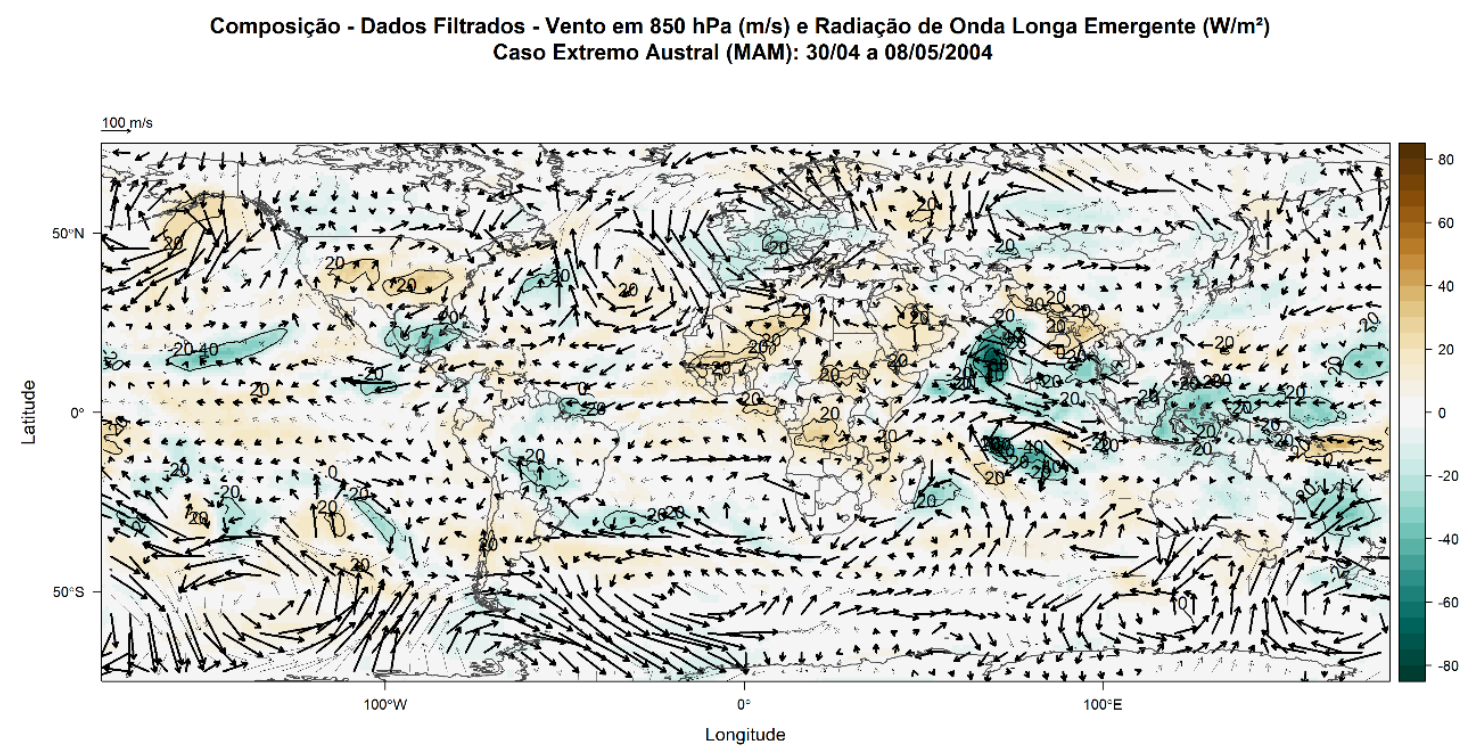

Figura 49 - Composições de médias diárias de anomalias intrassazonais de ROLE $\left(\mathrm{Wm}^{2}\right)$ e vento $(850 \mathrm{hPa})\left(\mathrm{ms}^{-1}\right)$ para o Caso 1. Regiões estatisticamente significativas estão contornadas ou em negrito (vetores).

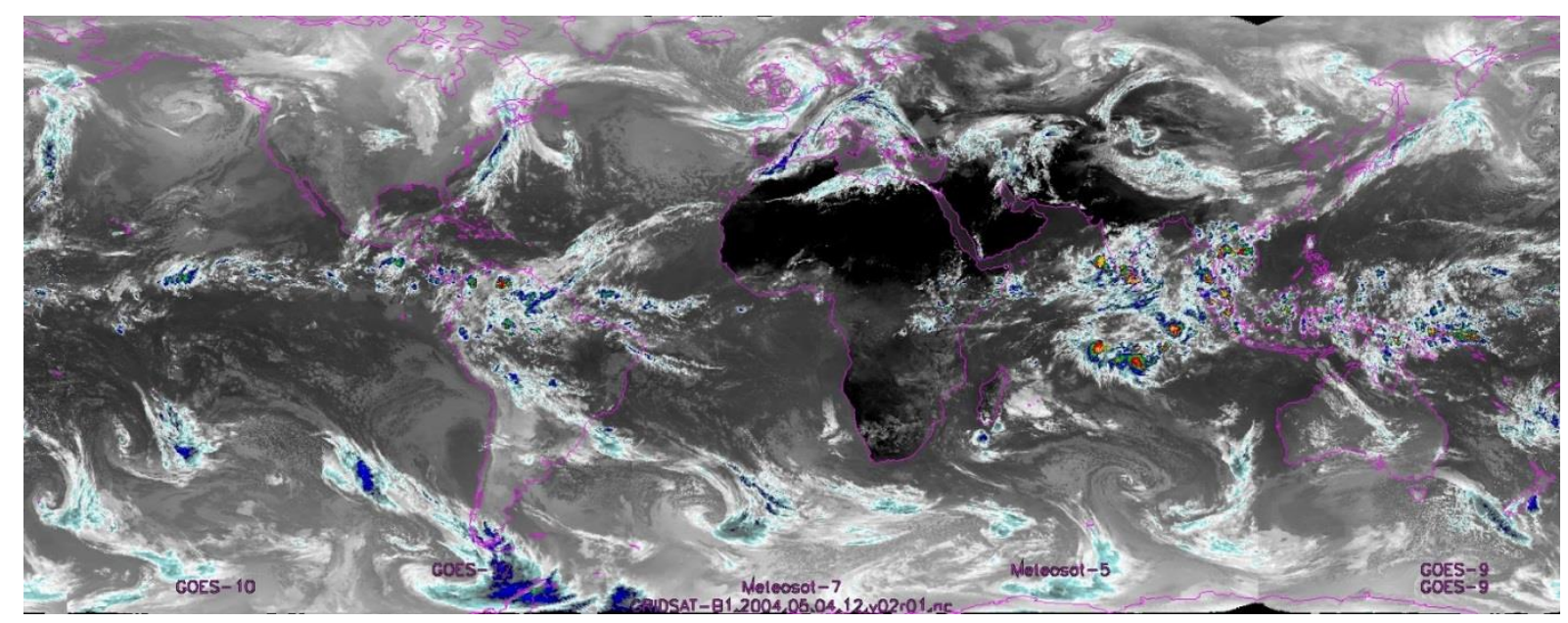

Figura 50 - Imagem de satélite global para o dia 04/05/2004 às $12 Z$ (Fonte: NCDC-NOAA) 
No Caso 3, as anomalias de ROLE (Figura 54) mostram favorecimento de convecção no centro-sul do país e supressão sobre o norte da Região Nordeste, sobre o Atlântico tropical. Esse padrão não é consistente com a fase 8 da OMJ, fase na qual estava predominantemente a OMJ neste evento, pois esta fase está associada a favorecimento de convecção sobre o Brasil Central e Nordeste. O fortalecimento da ASAS explica o deslocamento da ZCIT-AO para norte e também pode ser observado na Figura 54. O IZCIT-AO apresentou valor de 6,4ํ $\mathrm{N}$ nesse caso, ficando 1,7 grau ao norte da posição média intrassazonal para o período.

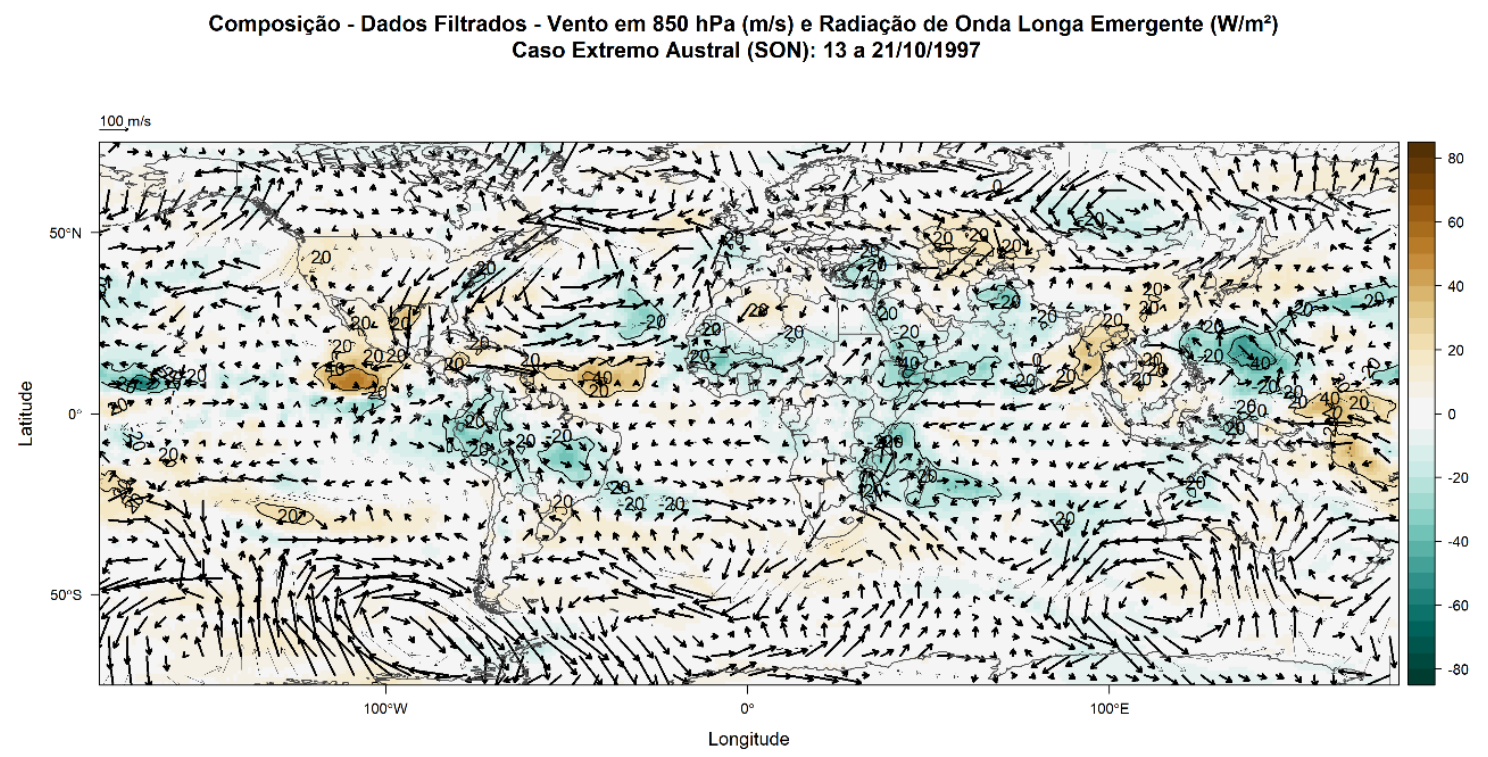

Figura 51 - Composições de médias diárias de anomalias intrassazonais de ROLE $\left(\mathrm{Wm}^{2}\right)$ e vento $(850 \mathrm{hPa})\left(\mathrm{ms}^{-1}\right)$ para o Caso 2. Regiões estatisticamente significativas estão contornadas ou em negrito (vetores).

Para o Caso 4, o campo de anomalia de ROLE (Figura 56) mostra desfavorecimento de convecção sobre o Sudeste e Nordeste do Brasil, se estendendo até o Atlântico adjacente, que pode ser verificado através das anomalias negativas de ROLE nessas regiões. O escoamento na superfície também se apresenta intenso e anomalamente de sudeste sobre a região. A fase predominante da OMJ no período foi 4 e o padrão de anomalias de ROLE observadas é consistente com aquele 
associado a essa fase, com favorecimento de convecção sobre o Índico leste e região da Indonésia e supressão sobre a faixa leste do Brasil. No mesmo campo, observase favorecimento de convecção sobre o Atlântico tropical norte, associado ao deslocamento da ZCIT-AO ao norte da média do índice. Ainda na Figura 56 podem ser observados o fortalecimento da ASAS e, consequentemente, dos alísios de sudeste, o que provavelmente contribuiu para o deslocamento da ZCIT-AO para norte. O IZCIT-AO nesse evento apresentou valor de $5,7^{\circ} \mathrm{N}$, enquanto a posição média intrassazonal do índice nesse período é $4,5^{\circ} \mathrm{N}$, indicando que a ZCIT-AO esteve localizada a norte da posição média para esse período.

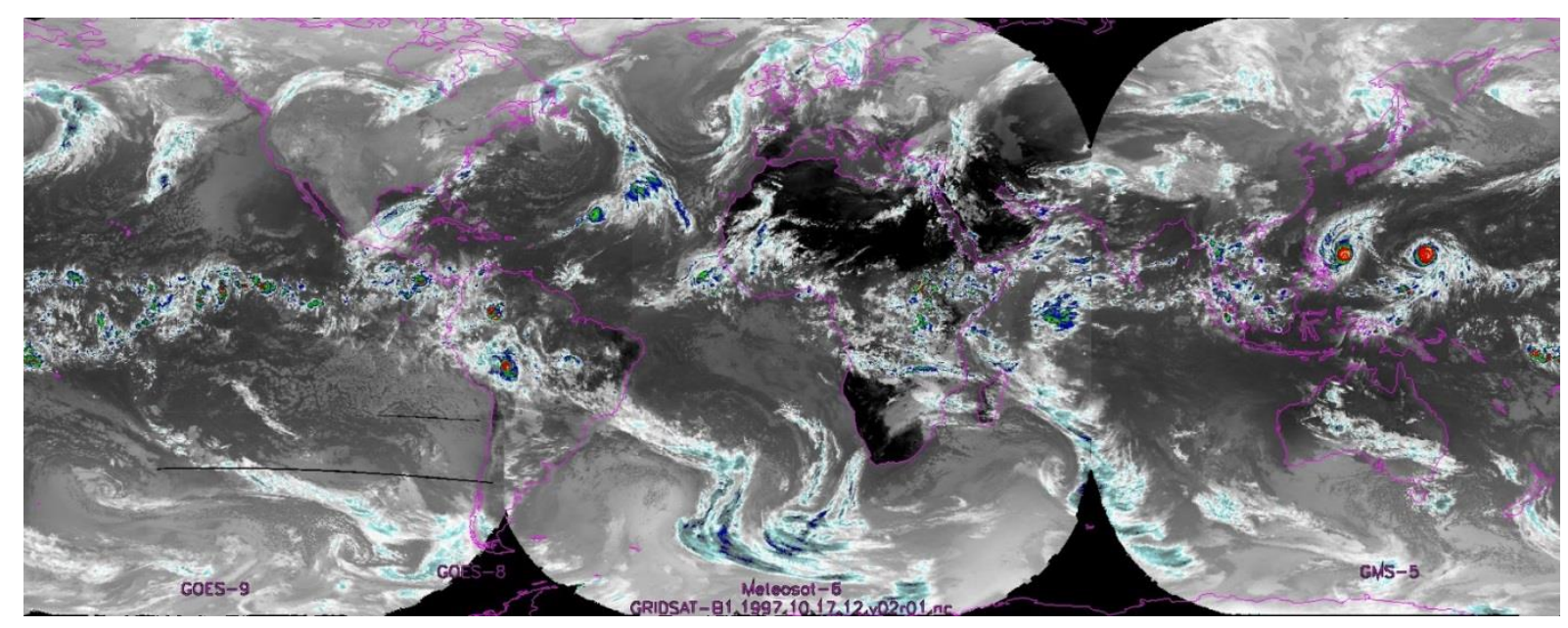

Figura 52 - Imagem de satélite global para o dia 17/10/1997 às $12 Z$ (Fonte: NCDC-NOAA).

Através dessas análises fica claro que mecanismos intrassazonais podem modular o posicionamento da ZCIT-AO mais a norte ou a sul de sua posição climatológica. Porém, esses mecanismos não estão restritos apenas à OMJ, como mencionado anteriormente. Nos casos extremos austrais (Caso 1 e 2) por exemplo, os extremos ocorreram enquanto a OMJ esteve inativa, indicando que outro modo ou evento pode ter favorecido seu deslocamento mais a sul, como já indicaram os autores Jones e Schemm (2000). 


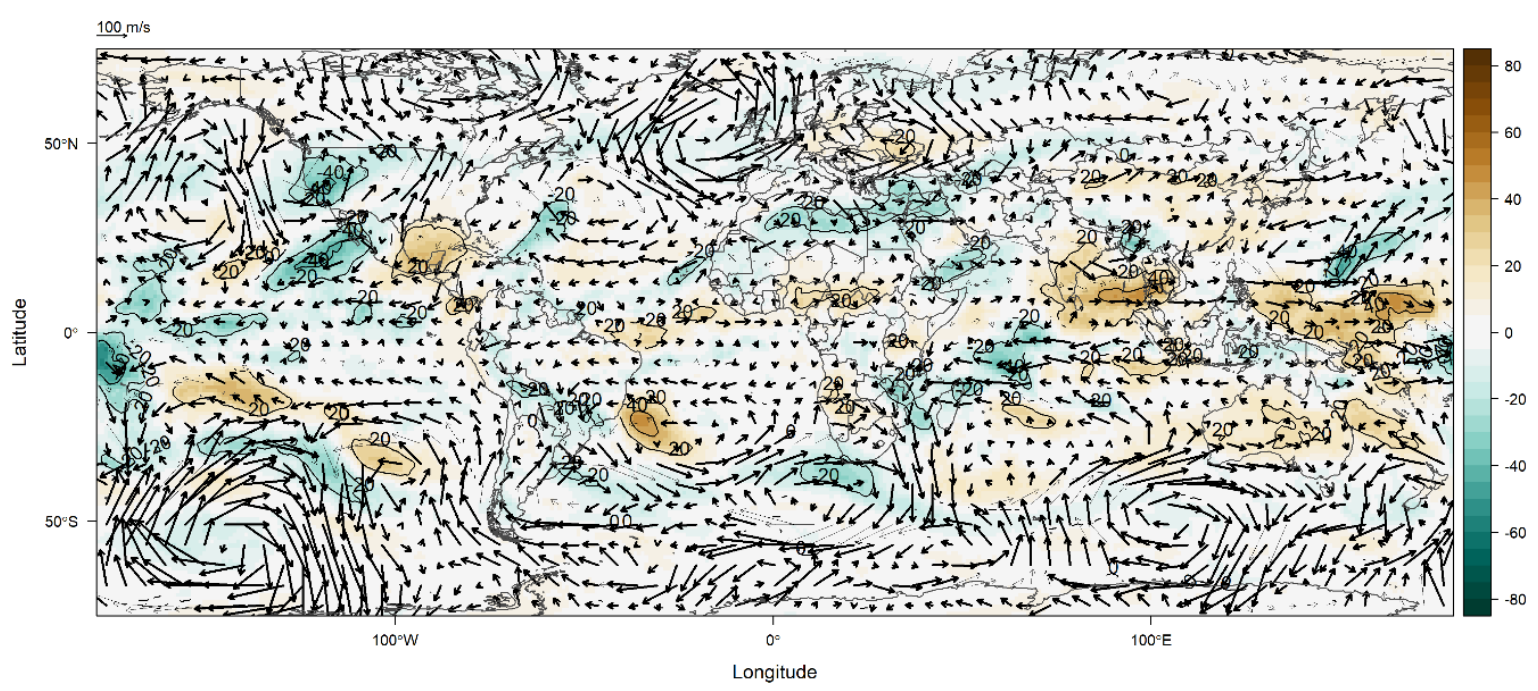

Figura 53 - Composições de médias diárias de anomalias intrassazonais de ROLE $\left(\mathrm{Wm}^{2}\right)$ e vento $(850 \mathrm{hPa})\left(\mathrm{ms}^{-1}\right)$ para o Caso 3. Regiões estatisticamente significativas estão contornadas ou em negrito (vetores).

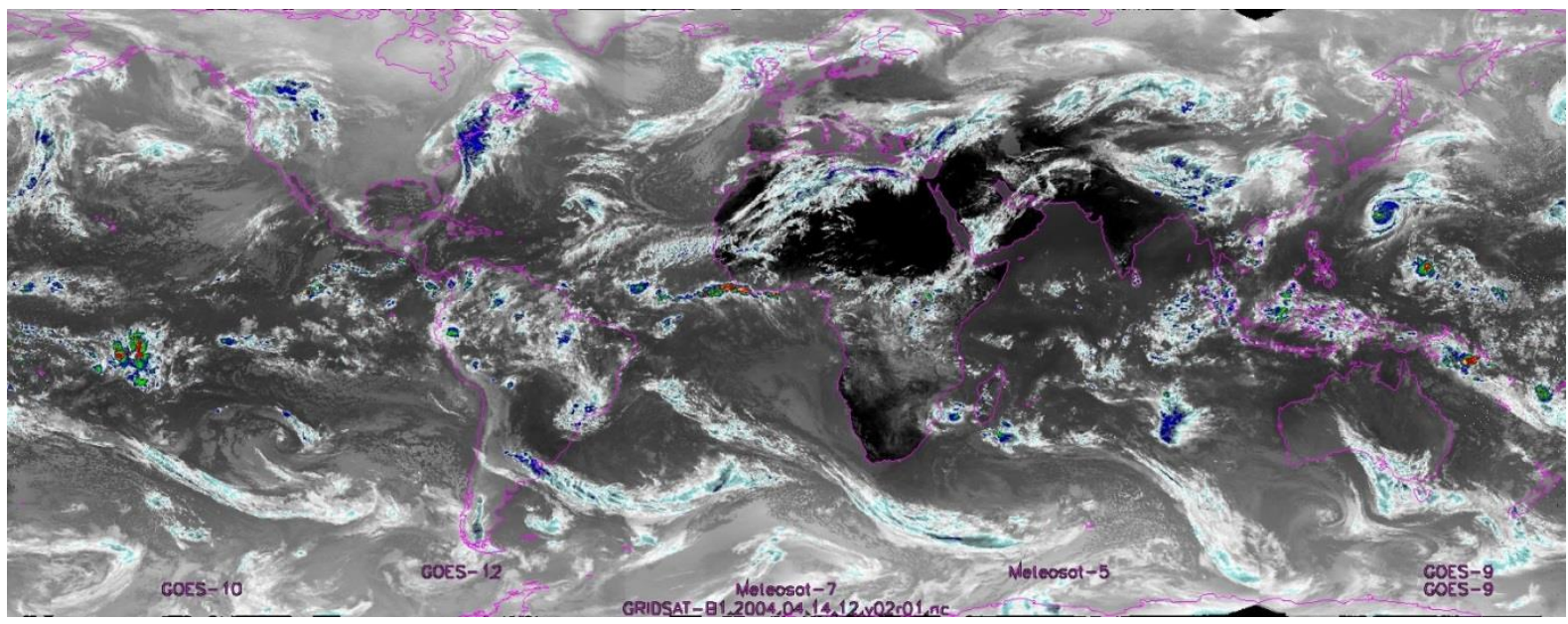

Figura 54 - Imagem de satélite global para o dia 14/04/2004 às $12 Z$ (Fonte: NCDC-NOAA). 
Composição - Dados Filtrados - Vento em $850 \mathrm{hPa}(\mathrm{m} / \mathrm{s})$ e Radiação de Onda Longa Emergente $\left(\mathrm{W} / \mathrm{m}^{2}\right)$ Caso Extremo Boreal (SON): 18 a 28/11/2000

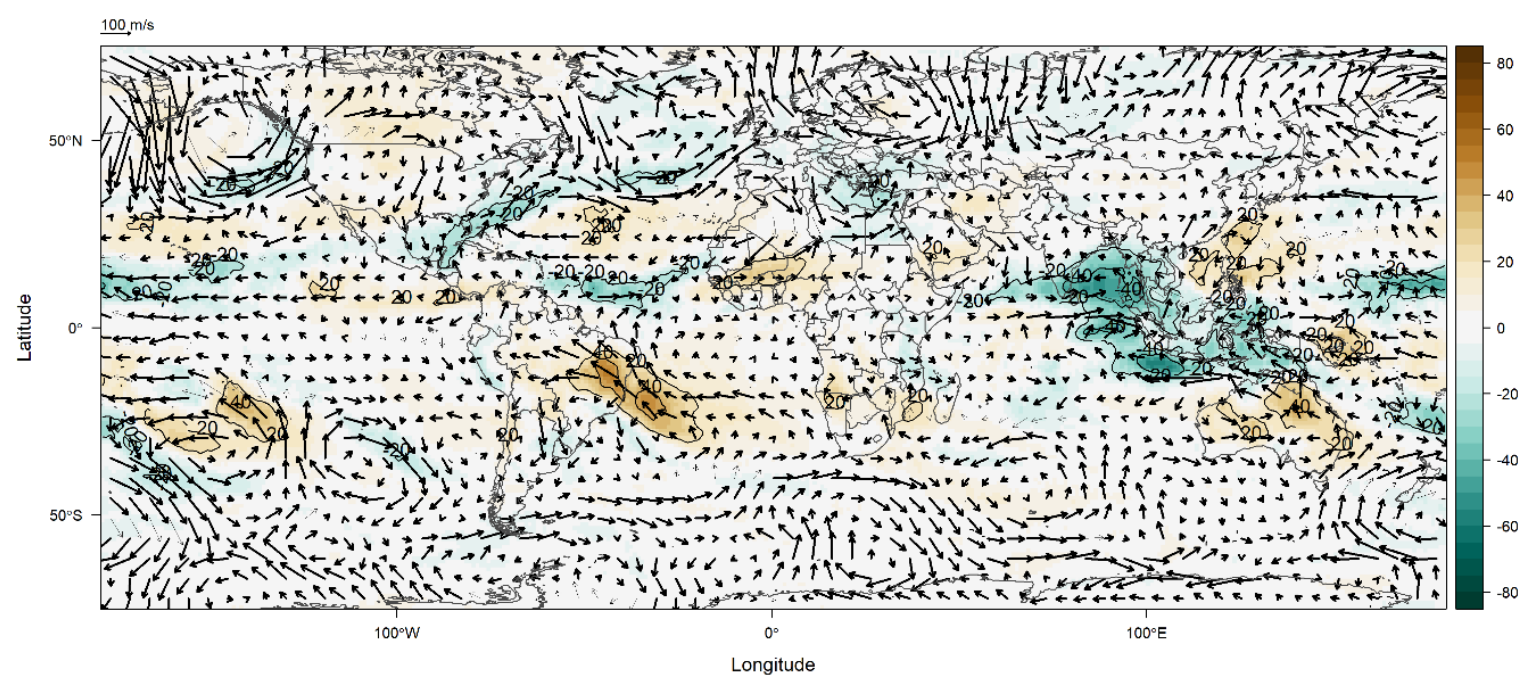

Figura 55 - Composições de médias diárias de anomalias intrassazonais de ROLE $\left(\mathrm{Wm}^{2}\right)$ e vento $(850 \mathrm{hPa})\left(\mathrm{ms}^{-1}\right)$ para o Caso 4. Regiões estatisticamente significativas estão contornadas ou em negrito (vetores).

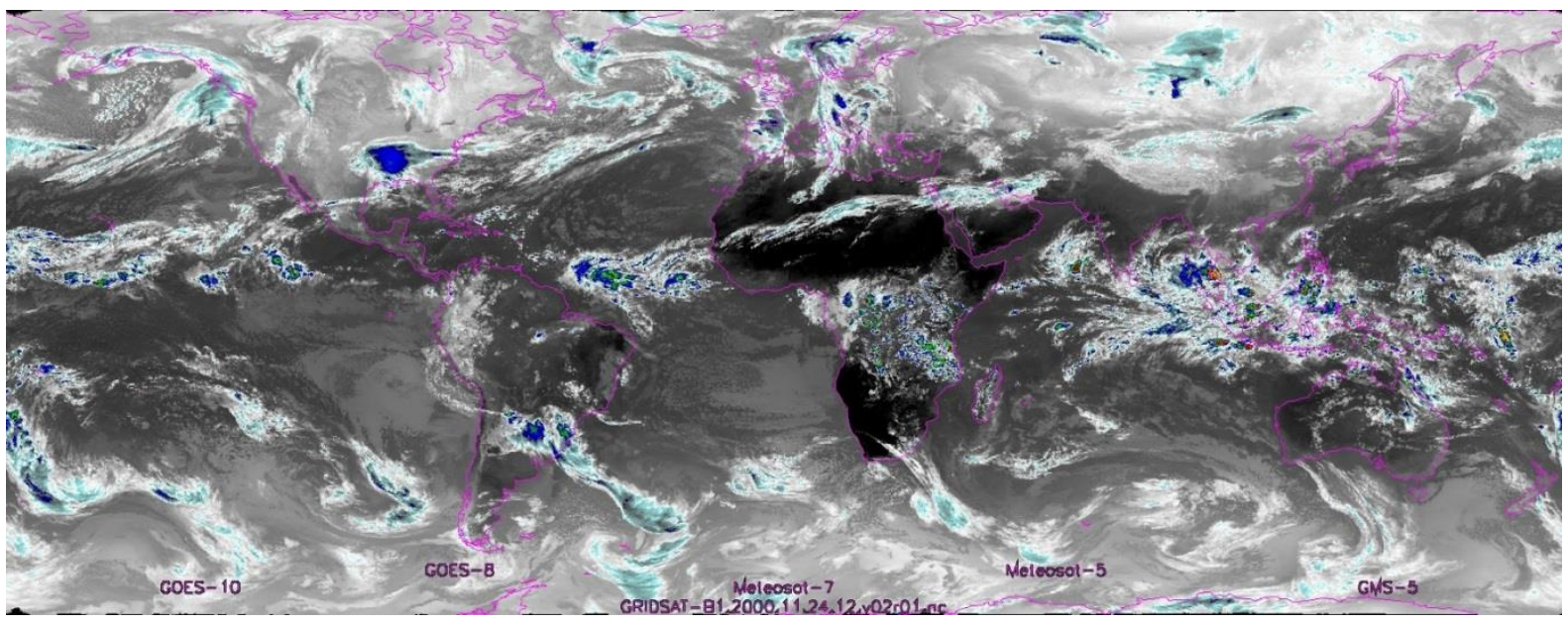

Figura 56 - Imagem de satélite global para o dia 24/11/2000 às $12 Z$ (Fonte: NCDC-NOAA). 


\section{CONCLUSÕES}

O presente trabalho teve como principal objetivo avaliar a relação entre a variabilidade do posicionamento latitudinal da ZCIT-AO na escala intrassazonal e a atividade da OMJ. Para cumprir o objetivo, foi necessário estabelecer um critério de localização latitudinal da ZCIT-AO, analisar a relação da atividade da OMJ e suas fases com os extremos austrais e boreais da posição latitudinal da ZCIT-AO e avaliar possíveis mecanismos atmosféricos locais e padrões de teleconexão atmosférica associados a essa variabilidade.

O IZCIT-AO, índice elaborado para a caracterização da posição latitudinal da ZCIT na região de estudo compreendida entre $44^{\circ} \mathrm{O}$ a $30^{\circ} \mathrm{O}$ e de $2^{\circ} \mathrm{S}$ a $10^{\circ} \mathrm{N}$ (Figura 5) e que teve como base dois aspectos meteorológicos que possibilitam a caracterização da ZCIT (máxima cobertura de nuvens convectivas e confluência dos ventos alísios em superfície), mostrou-se coerente, descrevendo bem o ciclo anual da ZCIT-AO (Figura 7) e possibilitando a análise da relação da variabilidade da posição desse sistema com as fases da OMJ.

A comparação de eventos extremos com as fases da OMJ (Figura 13) permitiu identificar um padrão na ocorrência de eventos, principalmente no outono austral (Figura 13a), estação em que a ZCIT-AO se encontra mais a sul durante seu ciclo anual. Para essa estação houve uma maior ocorrência de eventos extremos austrais durante as fases 3 a 6 , enquanto os extremos boreais foram mais frequentes nas fases 7 a 2 da OMJ. Essa relação de deslocamento da posição latitudinal da ZCIT$\mathrm{AO}$ com o deslocamento da OMJ para leste pode influenciar diretamente em regimes de precipitação das regiões adjacentes ao Atlântico tropical, bem como a Região NE do Brasil.

As análises de composições e de padrões de teleconexão (Subseção 4.2) sugerem que as perturbações atmosféricas geradas pela OMJ na região dos Oceanos Índico e Pacífico podem modular indiretamente o posicionamento latitudinal da ZCITAO. Essas perturbações são propagadas através de trens de ondas de Rossby. $O$ 
fortalecimento, enfraquecimento ou deslocamento da ASAS e da ASAN foram alguns dos mecanismos observados nesse trabalho associados ao deslocamento latitudinal da ZCIT-AO. Na maioria dos casos um trem de ondas se desloca sobre o Pacífico Norte e/ou Sul e chega à região do Atlântico Norte e/ou Sul favorecendo anomalias ciclônicas ou anticiclônicas, contribuindo diretamente para o enfraquecimento ou fortalecimento dos alísios, o que favorece o deslocamento da ZCIT-AO para norte ou sul.

Particularmente para a Região NE do Brasil, que é a região do Brasil que é a mais influenciada pelo posicionamento da ZCIT-AO e sendo um dos focos do presente estudo, a OMJ em sua fase 8 é a mais associada ao favorecimento de convecção e anomalias positivas de precipitação quando a ZCIT-AO se encontra em seus extremos austrais, tanto na primavera como no outono.

Os estudos de casos extremos mostraram que os extremos austrais representados pelos Casos 1 (Figuras 50 e 51) e 2 (Figuras 52 e 53) corroboram os resultados de Mo e Higgins (1998) e Jones e Schemm (2000), pois, mesmo com oscilação inativa, outros mecanismos intrassazonais podem modular a variabilidade da posição da ZCIT-AO tanto no outono como na primavera. Os Casos 3 e 4, que representaram os extremos boreais para outono e primavera, respectivamente, apresentam uma ZCIT-AO melhor definida do que os extremos austrais nos Casos 1 e 2. Através das imagens de satélite desses casos (Figuras 55 e 57) o padrão de nebulosidade associado à ZCIT-AO pode ser identificado mais facilmente.

$O$ presente trabalho sugere que as fases da OMJ podem influenciar o deslocamento latitudinal da ZCIT-AO e, desta forma, favorecer ou não a precipitação sobre o Brasil, principalmente nas Regiões $\mathrm{N}$ e NE, contribuindo para o avanço do conhecimento desta importante interação. 


\section{TRABALHOS FUTUROS}

As variações diárias presentes no IZCIT-AO podem atribuir erros à série temporal de posições latitudinais da ZCIT-AO, como sugerido e discutido no trabalho de Coelho (2002). Para uma análise mais precisa, e que poderia diminuir a probabilidade de erro, poderia se considerar uma escala pentadal, utilizando as médias de 5 dias das variáveis. Também se sugere uma análise considerando a filtragem das variáveis quem compõem o IZCIT-AO antes do cálculo do índice, evitando a filtragem após a obtenção do mesmo.

Outro fator importante a ser destacado é que embora a região de estudo compreendida entre $44^{\circ} \mathrm{O}$ a $30^{\circ} \mathrm{O}$ e de $2^{\circ} \mathrm{S}$ a $10^{\circ} \mathrm{N}$ (Figura 5) tenha sido escolhida para reter somente a convecção associada à ZCIT-AO, a mesma pode extrapolar as latitudes da região selecionada e sua posição pode ser mal caracterizada pelos métodos utilizados para calcular o índice neste trabalho, uma vez que a ZCIT-A pode

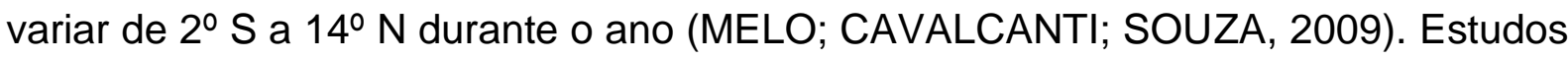
adicionais considerando uma região de estudo um pouco maior, compreendida entre as latitudes $2^{\circ} \mathrm{S}$ e $14^{\circ} \mathrm{N}$, poderia melhorar localização latitudinal da ZCIT-A.

Sugere-se também uma análise mais detalhada do comportamento da propagação de trem de ondas de Rossby em cada caso através de composições do estado da atmosfera para $n$ dias antes e depois do evento em questão (lag composites). Ainda no que tange a ondas, sugere-se investigar a propagação de ondas equatoriais e sua influência na variabilidade intrassazonal da posição latitudinal da ZCIT-AO, que não era o escopo do presente trabalho.

Além disso, a mesma análise elaborada no presente estudo pode ser feita utilizando outros índices que definem fases da OMJ, como o proposto por Wheeler e Hendon (2004), por exemplo. Esse índice, que é baseado nas duas componentes principais de EOFs, RMM1 e RMM2, não considera a fase 0 (inativa) da OMJ, o que pode apresentar resultados interessantes. 
Essas sugestões são importantes ampliar a presente pesquisa e auxiliar na compreensão de alguns pontos que com certeza trariam uma discussão mais profunda para este estudo. 


\section{REFERÊNCIAS BIBLIOGRÁFICAS}

ASNANI, G. C. Tropical Meteorology. Pune: Prof. C. G. Asnani, 1993. 202 p.

BAIN, C. L.; DE PAZ, J.; KRAMER, J.; MAGNUSDOTTIR, G.; SMYTH, P.; STERN, H.; WANG, C. Detecting the ITCZ in Instantaneous Satellite Data using Spatiotemporal Statistical Modeling: ITCZ Climatology in the East Pacific. Journal of Climate, v.24, p. 216-230, 2011.

CARVALHO, M. A. V.; OYAMA, M. D. Variabilidade da largura e intensidade da Zona de Convergência Intertropical Atlântica: aspectos observacionais. Revista Brasileira de Meteorologia, v. 28, n. 3, p. 305-316, set. 2013.

CHATFIELD, C. The Analysis of Time Series: An introduction (5. Ed). New York: Chapman \& Hall/CRC, 1996, 283 p.

CHIANG, J. C. H.; KUSHNIR, Y.; GIANNINI, A. Deconstructing Atlantic Intertropical Convergence Zone variability: Influence of the local cross-equatorial sea surface temperature gradient and remote forcing from the eastern equatorial Pacific. Journal of Geophysical Research, v. 107, n. D1, 4004, 2002.

COELHO, M. S. Estudo da estrutura vertical horizontal da precipitação e da circulação atmosférica na região da ZCIT. 2002. 158f. Dissertação (Mestrado) Instituto Nacional de Pesquisas Espaciais, São José dos Campos, 2002.

DE SOUZA, E. B.; AMBRIZZI, T. Modulation of the intraseasonal rainfall over tropical Brazil by the Madden-Julian Oscillation. International Journal of Climatology, v. 26, p. 1759-1776, 2006. 
DE SOUZA, E. B.; KAYANO, M. T.; AMBRIZZI, T. Intraseasonal and submonthly variability over the Eastern Amazon and Northeast Brazil during the autumn rainy season. Theoretical and Applied Climatology, v. 81, p. 177-191, 2005.

ENFIELD, D. B. Relationships of inter-American rainfall to tropical Atlantic and Pacific SST variability. Geophysical Research Letters, v. 23, n. 23, p. 3305-3308, nov.1996.

FERREIRA, N. S. Zona de convergência intertropical. Boletim do Climanálise Especial - Comemoração dos 10 anos, São Paulo, 1996. Disponível em: http://climanalise.cptec.inpe.br/ rclimanl/boletim/cliesp10a/zcit_1.html. Acesso em: 28 jun. 2020.

FERREIRA, N. S.; REPELLI, C. A.; ALVES, J. M. B.; DE SOUZA, E. B. LOCZCIT - Um procedimento numérico para localização do eixo central da Zona de Convergência Intertropical no Atlântico tropical. Revista Brasileira de Meteorologia, v. 20, n. 2, p. 159-164, ago. 2005.

GHIL, M.; MO, K. Intraseasonal Oscillations in the Global Atmosphere. Part I: Northern Hemisphere and Tropics. Journal of the Atmospheric Sciences, v. 48, n. 5, p. 752 779, mar. 1991.

GRODSKY, S. A.; CARTON, J. A. Coupled land/atmosphere interactions in the West African Monsoon. Geophysical Research Letters, v. 28, n. 8, p. 1503-1506, abr. 2001.

GU, G.; ADLER, R. F. Interannual variability of boreal summer rainfall in the equatorial Atlantic. International Journal of Climatology, v. 29, p. 175-184, 2009. 
HAFEZ, Y. Variability of Intertropical Convergence Zone (ITCZ) and Extreme Weather Events. Atmospheric Model Applications, p. 111-136, 2012.

HASTENRATH, S.; HELLER, L. Dynamics of climatic hazards in northeast Brazil. Quarterly Journal of the Royal Meteorological Society, v. 103, n. 435, p. 77-92, 1977.

HASTENRATH, S.; LAMB, P. Some aspects of circulation and climate over the eastern equatorial Atlantic. Monthly Weather Review, v. 105, p. 1019-1023, ago. 1977.

HASTENRATH, S. Climate Dynamics of the Tropics. Dordrecht: Kluwer Academic Publishers, 1996. $488 \mathrm{p}$.

HOSKINS, B. J.; KAROLY, D. J. The Steady Linear Response of a Spherical Atmosphere to Thermal and Orographic Forcing. Journal of the Atmospheric Sciences, v. 38, p. 1179-1196, 1981.

JONES, C.; SCHEMM, J.-K. E. The Influence of Intraseasonal Variations on Medium - to Extended - Range Weather Forecasts over South America. Monthly Weather Review, v. 128, p. 486-494, fev. 2000.

JONES, C. A Homogeneous Stochastic Model of the Madden-Julian Oscillation. Journal of Climate, v. 22, p. 3270-3288, jun. 2009.

KAROLY, D. Southern Hemisphere Circulation Features Associated with El NiñoSouthern Oscillation Events. Journal of Climate, v. 2, p. 1239-1252, nov. 1989. 
KILADIS, G. N.; WEICKMANN, K. M. Extratropical Forcing of Tropical Pacific Convection during Northern Winter. Monthly Weather Review, v. 120, p. 1924-1938, set. 1992.

LEE, H.-T.; SCHRECK, C. J.; KNAPP, K. R. Generation of the Daily OLR Climate Data Record. In: Eumetsat Meteorological Satellite Conference, 2014, Geneva, Switzerland, 22-26 September 2014.

LEE, H.-T. Climate Algorithm Theoretical Basis Document (C-ATBD): Outgoing Longwave Radiation (OLR) - Daily. NOAA's Climate Data Record (CDR) Program, CDRP-ATBD-0526, 2014, 46 p.

MADDEN, R. A.; JULIAN, P. R. Description of Global-Scale Circulation Cells in the Tropics with a 40-50 Day Period. Journal of the Atmospheric Sciences, v.29, p. 1109-1123, set. 1972.

MADDEN, R. A.; JULIAN, P. R. Detection of a 40-50-day oscillation in the zonal wind in the tropical Pacific. Journal of the Atmospheric Sciences, v. 28, p. 702-708, jul. 1971.

MADDEN, R. A.; JULIAN, P. R. Observation of the 40-50 day tropical oscillation - a review. Monthly Weather Review, v. 122, p. 814-837, maio 1994.

MALONEY, E. D.; HARTMANN, D. L. Frictional Moisture Convergence in a Composite Life Cycle of the Madden-Julian Oscillation. Journal of Climate, v. 11, p. 2387-2403, set. 1998.

MATTHEWS, A. J. Propagation mechanisms for the Madden-Julian Oscillation. Quarterly Journal Royal Of The Meteorological Society, v. 126, n. 569, p. 26372651, out. 2000. 
MELO, A. B. C.; CAVALCANTI, I. F. A.; SOUZA, P. P. Zona de Convergência Intertropical do Atlântico. In: CAVALCANTI, I. F. A.; FERREIRA, N. J.; JUSTI DA SILVA, M. G. A.; SILVA DIAS, M. A. F. (Orgs.). Tempo e Clima no Brasil. São Paulo: Oficina de Textos, 2009, cap. 2, p. 25-41.

MO, K. C. Relationships between Low-Frequency Variability in the Southern Hemisphere and Sea Surface Temperature Anomalies. Journal of Climate, v. 13, p. 3599-3610, out. 2000.

MO, K. C; GHIL, M. Statistics and dynamics of persistent anomalies. Journal of the Atmospheric Sciences, v. 44, p. 877-901, 1987.

MO, K. C.; HIGGINS, R. W. The Pacific-South American Modes and Tropical Convection during the Southern Hemisphere Winter. Monthly Weather Review, v. 126, p. 1581-1596, jun. 1998.

PHILANDER, S. G. H.; GU, D.; HALPERN, D.; LAMBERT, G.; LAU, N.-C.; LI, T.; PACANOWSKI, R. C. Why the ITCZ is Mostly North the Equator. Journal of Climate, v.9, p. 2958-2972, dez. 1996.

SAHA, S. et al. The NCEP Climate Forecast System Reanalysis. Bulletin of the American Meteorological Society, v. 91, n. 8, p. 1015-1057, ago. 2010.

SOUZA, P.; CAVALCANTI, I. F. A. Atmospheric centres of action associated with the Atlantic ITCZ position. International Journal of Climatology, v. 29, p. 2091-2195, 2009. 
SPIEGEL, M. R. Schaum's Outline of Theory and Problems of Statistics. Schaum Publishing and Co. Tradução de Pedro Consentino. São Paulo: McGraw-Hill, 1972, $518 \mathrm{p}$.

TOMAZIELLO, A. C. N. Variabilidade da Zona de Convergência Intertropical do Atlântico durante as estações seca e chuvosa da América do Sul tropical. 2014. 192f. Tese (Doutorado em Meteorologia) - Instituto de Astronomia, Geofísica e Ciências Atmosféricas, Universidade de São Paulo, São Paulo, 2014

TOMAZIELLO, A. C. N.; CARVALHO, L. M. V.; GANDU, A. W. Intraseasonal variability of the Atlantic Intertropical Convergence Zone during austral summer and winter. Climate Dynamics, v. 47, p. 1717-1733, set. 2016.

UVO, C. B. A Zona de Convergência Intertropical (ZCIT) e sua relação com a precipitação da Região Norte do Nordeste Brasileiro. 1989. 99f. Dissertação (Mestrado em Meteorologia) - Instituto Nacional de Pesquisas Espaciais, São José dos Campos, 1989.

UVO, C. B.; NOBRE, C. A. A Zona de Convergência Intertropical (ZCIT) e a precipitação no norte do Nordeste do Brasil. Parte I: a posição da ZCIT no Atlântico equatorial. Climanálise, v. 4, n. 7, p. 34-40, 1989.

VAREJÃO-SILVA, M. A. Meteorologia e climatologia: versão digital 2. Recife: Esalq, 2006, 449 p.

WALISER, D. E.; GAUTIER, C. A satellite-derived climatology of the ITCZ. Journal of Climate, v. 6, p. 2162-2174, nov. 1993. 
WALISER, D. E.; SOMERVILLE, R. C. J. Preferred Latitudes of the Intertropical Convergence Zone. Journal of the Atmospheric Sciences, v. 51, n. 12, p. 16191639, jun. 1994.

WALLACE, J. M.; GUTZLER, T. S. Teleconnections in the Geopotential Height Field during the Northern Hemisphere Winter. Monthly Weather Review, v. 109, p. 784812, abr. 1981.

WHEELER, M. C.; HENDON, H. H. An All-Season Real-Time Multivariate MJO Index: Development of an Index for Monitoring and Prediction. Monthly Weather Review, v. 132, p. 1917-1932, ago. 2004.

XAVIER, T. M. B. S.; XAVIER, A. F. S.; SILVA DIAS, P. L.; SILVA DIAS, M. A. F. A Zona de Convergência Intertropical - ZCIT e suas relações com a chuva no Ceará (1964-98). Revista Brasileira de Meteorologia, v. 15, n. 1, p. 27-43, 2000. 